\title{
Housing and consumption in New Zealand: A financial accelerator DSGE model and SVAR analysis
}

by

Andrew D. Fung

A thesis

submitted to the Victoria University of Wellington in fulfilment of the requirements for the degree of Doctor of Philosophy

Victoria University of Wellington

2012

Copyright (C)2012 Andrew D. Fung

All rights reserved. 



\section{Abstract}

This thesis examines the role of a financial accelerator mechanism for housing in the context of a small open economy. Following the seminal financial accelerator framework in a Dynamic Stochastic General Equilibrium (DSGE) model set out by Bernanke, Gertler and Gilchrist (1999) (BGG), Aoki, Proudman and Vlieghe (2002, 2002a, 2004) (APV) examine the role of the financial accelerator for the housing market. In my basic model (Chapter 2), I extend the analysis of APV from a closed economy to a small open economy in which imports are used as intermediate inputs into the production process and foreign demand for domestically produced goods is influenced by the real exchange rate. Unlike APV, I set the endowment of housing to be consistent with the nature of consumer behaviour, in that "rule of thumb" (ROT) consumers (who do not save) are renters, further differentiating them from "permanent income hypothesis" (PIH) consumers.

I find that in contrast to APV, the financial accelerator effect does not increase the responsiveness of consumption and output to various shocks. This is due in part to the endowment of housing being restricted to PIH households. I find that the presence of a financial accelerator increases the responsiveness of the housing market to nominal interest rate, technology, and foreign shocks.

Moreover, even though the financial accelerator reduces the reaction of the nonhousing variables to shocks, there is still a positive correlation between house prices and consumption, consistent with the widely observed empirical relationship between the two. Furthermore, given that PIH households have access to the capital markets, the model does not rely on a wealth effect to generate this correlation even though homeowners can engage in housing equity withdrawal.

In Chapter 3 I extend the DSGE model to include a more fully specified fiscal sector. I find that consistent with the RBC view of fiscal policy, a positive government spending shock has a negative impact on the housing market. Using the type of fiscal rule proposed by Galí, Vallés and López-Salido (2004), I find that government spending crowds out private consumption, including the purchase of housing services and has a negative impact on house prices. Despite the positive short-term impact on output, tax increases that would ultimately fund the spending shock act as a drag on consumption. 
In Chapter 4 I examine the New Zealand empirical data in order to see whether a financial accelerator effect can be detected. Using a small seven variable Structural Vector Auto-Regression model I find that shocks to house prices do not have a significant impact on the mortgage rate-benchmark interest rate spread in the manner suggested by the financial accelerator model. This may be due to other costs (such as funding mortgage lending through the international swap market by New Zealand banks) having a significant impact on the setting of mortgage rates and thus the spread. I also find that government spending does not appear to have a significant impact on house prices and the median response is mildly negative - consistent with the result from the DSGE model. Nevertheless, the SVAR does detect a significant relationship between shocks to house prices and household consumption. 


\section{Acknowledgements}

My thanks go to Viv Hall, Christoph Thoenissen and Kunhong Kim. Viv, as my primary supervisor, provided me with not only very helpful guidance on the macroeconomic aspects of this thesis over its prolonged gestation but also assisted greatly in navigating the administrative challenges. I have also benefitted greatly from Christoph's expertise in modelling. I would like to thank Kunhong, who contributed significantly to the shape of the thesis in its early stages.

I would like to thank the staff and post-graduate students of the School of Economics and Finance at Victoria University of Wellington for their help on a variety of issues and also their feedback during my presentations whilst writing this thesis. I would like to thank Tram for being an understanding roommate, putting up with my mess and providing the support that all $\mathrm{PhD}$ candidates need from time to time. A special thank you goes to various people at the Reserve Bank of New Zealand, especially Ashley Lienart for his help in obtaining several data series and Christie Smith for his input on a number of econometric issues. This paper also benefited from helpful comments and suggestions from Jeffrey Sheen, David Mayes and Martin Berka.

I would also like to thank the Inland Revenue Department for its support and especially John Nash for his encouragement and for giving time off to complete this thesis.

My thanks also go to my family for their support over the years. In particular, my thanks go to Leefun for her forebearance. 



\section{Contents}

List of figures $\quad x$

List of tables $\quad$ xii

1 Housing and consumption - an overview and introduction of the $\begin{array}{ll}\text { financial accelerator } & 1\end{array}$

2 The basic small open economy model 10

2.1 Introduction . . . . . . . . . . . . . . . . . . . . . . . . . 10

2.2 Overview . . . . . . . . . . . . . . . . . . 11

2.3 Firms . . . . . . . . . . . . . . . . . . 12

2.4 Households . . . . . . . . . . . . . . . . . . . . 15

2.5 Housing investment . . . . . . . . . . . . . . . . . . . . . . 19

2.6 Monetary authority . . . . . . . . . . . . . . . . 19

2.7 Current account . . . . . . . . . . . . . . . . . . . . 19

2.8 Shock processes . . . . . . . . . . . . . . . . . . . . . . . 20

2.9 Log-linear model equations . . . . . . . . . . . . . . . . . . . 20

2.10 Parameterisation and calibration - Consistency with NZ data . . . . . 22

2.11 Steady state . . . . . . . . . . . . . . . . . . . 25

2.12 Comparison with a closed economy model . . . . . . . . . . . . . 27

2.12.1 Response to an interest rate shock . . . . . . . . . . . . . . . 29

2.12.2 Response to a technology shock . . . . . . . . . . . . 35

2.13 Impact of the financial accelerator . . . . . . . . . . . . . . . . . 41

2.13.1 Monetary policy shock . . . . . . . . . . . . . . . . . . . 42

2.13.2 Setting the premium to zero . . . . . . . . . . . . 47

2.13.3 Setting the responsiveness of the return on housing to zero . . 47

2.13.4 Technology and other shocks - comparison of basic model with model without financial accelerator . . . . . . . . . . . . . . 49 
2.13.5 Role of ROT consumers . . . . . . . . . . . . . . . 50

2.13.6 Concluding remarks . . . . . . . . . . . . . . . . 52

3 The fiscal model $\quad 55$

3.1 Introduction . . . . . . . . . . . . . . . . . . 55

3.2 Additional fiscal equations . . . . . . . . . . . . . . . 56

3.3 Parameterisation of the fiscal model . . . . . . . . . . . . . . . . 61

3.4 Government spending shock . . . . . . . . . . . . . . . . . 62

3.5 Comparison of fiscal model with basic model . . . . . . . . . . . . . . 71

3.6 Sensitivity analysis - Changing the proportion of ROT consumers . . 77

3.7 Concluding comments . . . . . . . . . . . . . . . . . . 88

4 Examining the financial accelerator using an SVAR 90

4.1 Introduction . . . . . . . . . . . . . . . . . . . . . . . 9 90

4.2 Variable selection . . . . . . . . . . . . . . . . . . . . . . . . 91

4.3 Unit root testing . . . . . . . . . . . . . . . . . . 96

4.4 Levels data . . . . . . . . . . . . . . . . . . . . . . . . 100

4.4 .1 Unit root testing . . . . . . . . . . . . . 100

4.4 Cointegration . . . . . . . . . . . . . . 101

4.5 Lag length selection . . . . . . . . . . . . . . . . . . . . . 103

4.6 Identification . . . . . . . . . . . . . . . . . . . 103

4.7 Ordering . . . . . . . . . . . . . . . . . . . . . . . . 104

4.8 Estimation . . . . . . . . . . . . . . . . . . . 105

4.9 SVAR equations . . . . . . . . . . . . . . . . 106

4.10 Impulse response functions . . . . . . . . . . . . . . . . . . . . 107

4.11 Variance decomposition . . . . . . . . . . . . . . . . . . . 112

4.12 Concluding comments . . . . . . . . . . . . . . . . . . . 114

5 Conclusions and potential future research $\quad 116$

5.1 The DSGE models . . . . . . . . . . . . . . . . . . 116

5.2 The SVAR . . . . . . . . . . . . . . . . . . 117

5.3 Future research . . . . . . . . . . . . . . . . . . . . . 119

$\begin{array}{lr}\text { Bibliography } & 121\end{array}$

A Comparison of basic model with and without financial accelerator to other shocks 
C Derivation of log-linear equations: Basic model 145

C.1 Firms . . . . . . . . . . . . . . . . . . . . . . . 145

C.2 Input demand determination . . . . . . . . . . . . . . . 146

C.3 Marginal cost . . . . . . . . . . . . . . . . . . . . . . 147

C.4 Resource constraint . . . . . . . . . . . . . . . . . . . . 149

C.5 Export demand . . . . . . . . . . . . . . . . . . . 149

C.6 Prices . . . . . . . . . . . . . . . . . . 150

C.7 Households . . . . . . . . . . . . . . . . . . . . . . 150

C.7.1 PIH consumers' first order conditions . . . . . . . . . . . . 151

C.7.2 Wage determination . . . . . . . . . . . . . . 154

C.7.3 Rule of thumb first order conditions . . . . . . . . . . . . . . 154

C.8 Aggregate consumption definition . . . . . . . . . . . . . 156

C.9 The mortgage - risk-free interest rate relation . . . . . . . . . . 156

C.10 Ex-post gross return on housing . . . . . . . . . . . . . . . 157

C.11 Net worth accumulation . . . . . . . . . . . . . . . . . 158

C.12 Housing equity withdrawal . . . . . . . . . . . . . . . . . 159

C.13 Housing capital accumulation . . . . . . . . . . . . . . . 160

C.14 House prices and investment . . . . . . . . . . . . . . . . . . 160

C.15 Current account . . . . . . . . . . . . . . . . 161

C.16 Phillips curve . . . . . . . . . . . . . . . . . 163

C.16.1 Flexible price output . . . . . . . . . . . . . . 166

C.17 Real exchange rate identity . . . . . . . . . . . . . . . . 167

C.18 Nominal interest rate identity . . . . . . . . . . . . . . 167

D Derivation of log-linear equations: Fiscal model 168

D.1 Rule of thumb consumption . . . . . . . . . . . . . . . . . . . 168

D.2 Government . . . . . . . . . . . . . . . . . 168

D.3 Resource constraint . . . . . . . . . . . . . . . . . . . 169

D.4 Current account . . . . . . . . . . . . . . . . . . . 170

$\begin{array}{ll}\text { E Derivation of the steady state equations } & 171\end{array}$

E.1 Ex-ante return on housing . . . . . . . . . . . . . . . 171

E.2 Relative price of rental . . . . . . . . . . . . . . . . . . . . 171

E.3 Relative price of consumption goods . . . . . . . . . . . . . . . . . 172

E.4 Dividend . . . . . . . . . . . . . . . . . . . . . . . . 172 
E.5 Aggregate consumption . . . . . . . . . . . . . . . . . . 172

E.6 Household consumption of goods . . . . . . . . . . . . . . . . 173

E.7 Investment . . . . . . . . . . . . . . . . . . . . . . . 173

E.8 Resource constraint . . . . . . . . . . . . . . . . . . . . . . 173

E.9 Aggregate labour . . . . . . . . . . . . . . . . . . . . . 173

E.10 Goods producers first order conditions . . . . . . . . . . . . . . 174

E.11 Wage rate . . . . . . . . . . . . . . . . . . . . . . 174

E.12 Rule of thumb labour supply . . . . . . . . . . . . . . . . . . . . 174

E.13 Permanent income hypothesis labour supply . . . . . . . . . . . . . . 174

E.14 Rule of thumb consumption . . . . . . . . . . . . . . . . 175

E.15 Permanent income hypothesis consumption . . . . . . . . . . . . 175

F Derivation of the steady state equations: fiscal model $\quad \mathbf{1 7 6}$

F.1 Resource constraint . . . . . . . . . . . . . . 176

F.2 Rule of thumb labour supply . . . . . . . . . . . . . . 176 


\section{List of Figures}

1.1 New Zealand house prices and household consumption . . . . . . . 2

1.2 Levels data . . . . . . . . . . . . . . . . . . . . . . . . 2

1.3 HP filtered data . . . . . . . . . . . . . . . . 2

1.4 New Zealand housing equity injection (negative indicates withdrawal of funds from housing stock $\ldots \ldots \ldots \ldots$. . . . . . . . 5

1.5 New Zealand household claims to dwelling values: household indebtedness as a proportion of housing assets . . . . . . . . . . . . . 6

2.1 Response to a $-0.25 \%$ nominal interest rate shock, closed economy model and basic model . . . . . . . . . . . . . . . . . . . 31

2.2 Response to a $1 \%$ technology shock, basic model and closed economy 37

2.3 Response to a $-0.25 \%$ nominal interest rate shock, basic model with and without the financial accelerator . . . . . . . . . . . . . . 42

3.1 Response to a $1 \%$ government spending shock . . . . . . . . . . . 65

3.2 Fiscal model comparison - Response to a $0.25 \%$ nominal interest rate shock . . . . . . . . . . . . . . . . . . . 72

3.3 Sensitivity to $n$ - Response to a -25 basis point nominal interest rate shock . . . . . . . . . . . . . . . . . 78

3.4 Sensitivity to $n$ - Response to a $1 \%$ government spending shock . . 83

4.1 Real house prices and net worth . . . . . . . . . . . . . . . . . 92

4.2 Variables in $\log$ levels . . . . . . . . . . . . . . . . . . . . . . . 94

4.3 Variables detrended . . . . . . . . . . . . . . . . . . . 95

4.4 Enders (2004), p. 213, modified unit root testing procedure . . . . . . 97

4.5 Impulse response functions . . . . . . . . . . . . . . . . . . . . 109

A.1 Response to a 1\% technology shock, basic model with and without the financial accelerator . . . . . . . . . . . . . . . . . 128 
A.2 Response to a 25 basis point foreign real interest rate shock, basic model with and without the financial accelerator . . . . . . . . . . 133

A.3 Response to a $1 \%$ foreign demand shock, basic model with and without the financial accelerator . . . . . . . . . . . . . . . 138 


\section{List of Tables}

2.1 Basic model parameter values . . . . . . . . . . . . . . . 25

2.2 Open economy model steady state values . . . . . . . . . . . . . . 28

2.3 Basic model response relative to closed model, technology and interest rate shocks . . . . . . . . . . . . . . . . . 4 4 41

2.4 Comparison of shock period response, financial accelerator on and off with differing values of $n,-25$ basis point nominal interest rate shock 52

3.1 Fiscal model steady state values . . . . . . . . . . . . . . . . . 60

3.2 Innovation variances $\ldots \ldots \ldots$. . . . . . . . . . . . 60

3.3 Fiscal model moment matching . . . . . . . . . . . . . . . . . 62

3.4 Parameters from NZ-calibrated DSGE models . . . . . . . . . . . . . 63

4.1 Unit root test results - Detrended data . . . . . . . . . . . . . . . 98

4.2 Unit root test results - Levels data . . . . . . . . . . . . . . . . 100

4.3 Lag length selection criteria and LR test . . . . . . . . . . . . . . 103

4.4 Variance decomposition . . . . . . . . . . . . . . . . . 113 


\section{Chapter 1}

\section{Housing and consumption - an overview and introduction of the financial accelerator}

The purpose of this thesis is to examine the role of the financial accelerator with regard to the housing market, in the context of a small open economy. Given that the financial accelerator forms part of the wider housing-consumption relationship, it is useful to provide some context and sketch out the housing and consumption literature as a background. In this chapter, I set out an overview of this research before discussing the specific role of the financial accelerator.

Housing has been an increasingly important element of New Zealand household balance sheets and wealth. As a proportion of total assets, housing accounted for $65 \%$ in 1990, growing to around $74 \%$ in 2010. Although less consistent in terms of an upward trend, net housing worth (value of housing stock less household debt) as a proportion of net wealth rose from $60 \%$ to $68 \%$ over the same time frame. ${ }^{1}$ Clearly then, despite the financial deregulation since the 1980's and the relatively light regulation of the finance sector, housing's dominance of non-human wealth has grown.

Given this heavy weighting of housing in household wealth, it is natural to look at the extent to which it affects consumption spending by households. Although there has been a rapid growth in studies of the role of housing in the macroecon-

\footnotetext{
${ }^{1}$ RBNZ Household Assets and Liabilities data, 2010
} 
omy, there is still debate over the the theoretical underpinning. Empirically, there appears to be a strong correlation between real house prices and consumption (see Figure 1.3) but the econometric studies to date have provided mixed results as to the fundamental nature of the relationship.

Figure 1.1: New Zealand house prices and household consumption

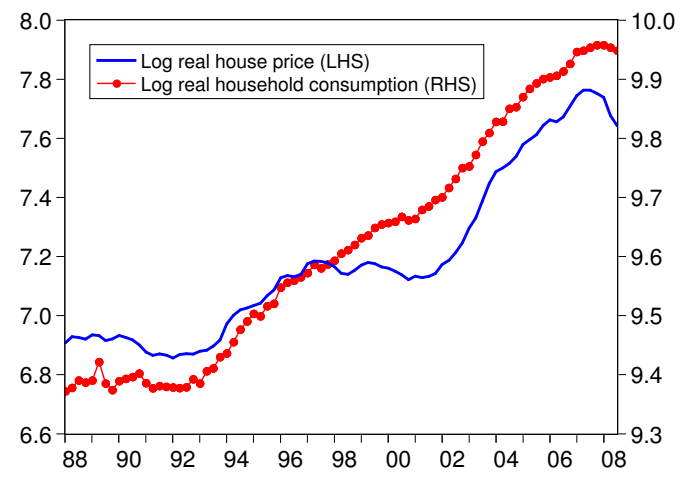

Figure 1.2: Levels data

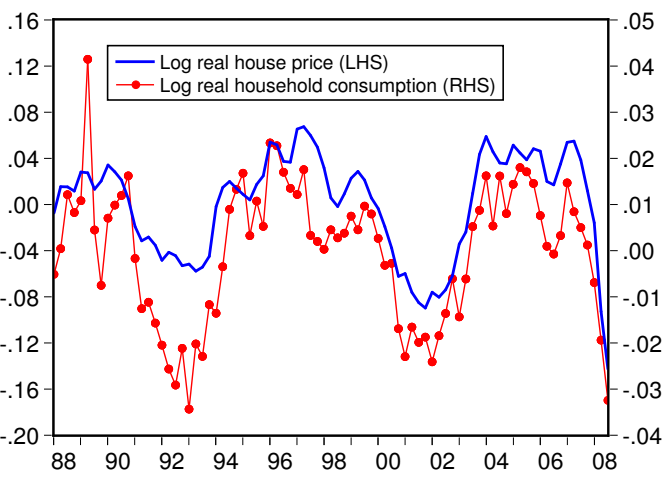

Figure 1.3: HP filtered data

Indeed, early studies of housing wealth did not set out a clear theoretical underpinning. Typical of this approach is Case, Quigley and Shiller (2005) in which consumption is regressed against both stock market and housing wealth and a marginal propensity to consume out of housing wealth estimated. Implicit in this approach is the assumption that homeowners view changes in housing wealth as permanent and as a result spend more, either by running down non-housing savings or by reducing the equity they hold in their homes (mortgage or housing equity withdrawal). This approach to estimating the effect of housing wealth is still common (see, for example, Fisher, Otto and Voss, 2010). In New Zealand, De Veirman and Dunstan (2008) follow a similar approach and find a signficant relationship between housing wealth and consumption. Smith (2010) also adopts this approach but examines in more detail other factors such as demographics and ownership status and finds a significant relationship between house prices and expenditure.

However, the simple assertion that a change to the value of houses is a change in wealth ignores the stream of housing services that stem from home ownership. A rise in house prices necessarily implies an increase in the imputed value of rental to be consumed over time by homeowners. Buiter (2010) sets out the argument 
that house price changes result in a wealth re-distribution from those "short" housing (such as tenants and potential first-home buyers) to those "long" housing (e.g. homeowners looking to downsize to smaller houses or to rent). Homeowners in the middle who own a house and do not intend changing their housing status are left unaffected. Over the course of the last three census, New Zealanders have become more mobile with the median number of years at their current address falling from 5.2 years in 1996 to 3.7 years in 2006. Admittedly these figures include renters but given that over half of New Zealand households do own their own house, this reduction likely reflects an increase in turnover in the owner-occupier part of the housing stock. While this might suggest that households do look to realise the gains made in house values, for every seller there is a buyer who must pay a higher price.

Of course, factors such as demographics and the regulatory environment may impact on the housing market. ${ }^{2}$ For example, economies where the birth rate is above or below 2 will experience a changing demand for housing services and would thus likely see changes to house prices over time. Buiter (2010) also points to the potential for bubbles to affect house prices and expenditure behaviour. This, however, requires a degree of myopia on the part of house buyers (or arguably a degree of irrationality) in that bubbles by definition are not justified by exogenous factors (such as changing demographics or regulation) and thus should not be seen as permanent.

One possible explanation for why a "pure" wealth effect exists in aggregate is that a significiant proportion of houseowners do not value the imputed rental in the same way as expected by Buiter. Shafer and Thaler (2006) note that where consumption purchases have an investment element, there is a tendency for consumers to discount the eventual consumption by too much. Given that housing can be characterised as an investment that yields housing services over time, it thus may be that houseowners undervalue the stream of housing services as they are being consumed and thus do not equate estimates of the current market value with the present value of the services they receive. If homeowners heavily discount the value of housing services, the result is an excess of the current house value over the present value of the imputed rental and a perception that their wealth has increased. ${ }^{3}$

\footnotetext{
${ }^{2}$ See Grimes and Aitken (2006) for an example of how regulatory differences may impact on house prices in New Zealand and Stillman and Maré (2008) for an examination of the effect of migration on New Zealand house prices.

${ }^{3}$ Behavioural economics may also help explain this through the impact of anchoring. Although interest rates on mortgages vary, the principal on which mortgage payments are set is determined
} 
Proponents of a wealth effect have more recently turned from explaining the correlation by a pure wealth effect to one of credit constraints. There is a similarity between borrowing to fund margin trading of financial assets and the use of a downpayment and mortgage to purchase a house as any subsequent change to the value of the property accrues to the homeowner and not the mortgagor. Homeowners that refinance their mortgage in a rising property market are able to increase the amount borrowed against their house due to the effective increase in the equity stake.

Liu, Wang and Zha (2010) set out a closed economy DSGE model where credit constraints amplify macroeconomic fluctuations via house prices. Aron, Duca, Muelbauer, Murata and Murphy (2010) point to research that suggests credit liberalisation has had a significant impact on homeowners' ability to access housing wealth and explicitly incorporate a credit conditions index into their regressions of consumption on various forms of wealth. There are two issues with relying on such a mechanism as the explanation for the housing wealth-consumption relationship. First, the nature of the typical mortgage contract is one-sided in that while the homeowner may be able to increase borrowing as values rise, banks are not able to decrease the amount of debt during periods of market decline. ${ }^{4}$ Thus loosening credit constraints may occur during periods of positive house price growth but would be less obvious during price declines. Second, such an explanation does not sit well with the observation that New Zealand homeowners tended to pay down their mortgage debt. Figure 1.4 shows that New Zealand housing equity injection, as measured by the RBNZ, was broadly positive up until 2003 at which point it turned negative but then went sharply positive in the wake of the Global Financial Crisis. In addition to the inconsistency of rising injections up until 2002 with a housing market that underwent a major upswing over the 1993-1998 period, the relatively flat period of house prices and consumption between 2004 and 2006 coincides with a period of significant equity withdrawal. Thus the idea that rising housing wealth relaxes credit constraints and thence facilitates higher consumption does not appear

by the initial purchase price, regardless of what happens to the current market value. This may reinforce in the minds of houseowners with mortgages that the price they pay on a monthly basis (their mortgage payment) is equal to the imputed rent and is unrelated to the current value of the house.

${ }^{4}$ Although it may take several years before repricing of mortgages occurs, the underlying extension of credit may have a term of decades. While banks may add a premium if the loan to value ratio increases, it would be difficult for them to require accelerated repayment of part of the principle. 
to be borne out by the agggregate data.

Figure 1.4: New Zealand housing equity injection (negative indicates withdrawal of funds from housing stock)

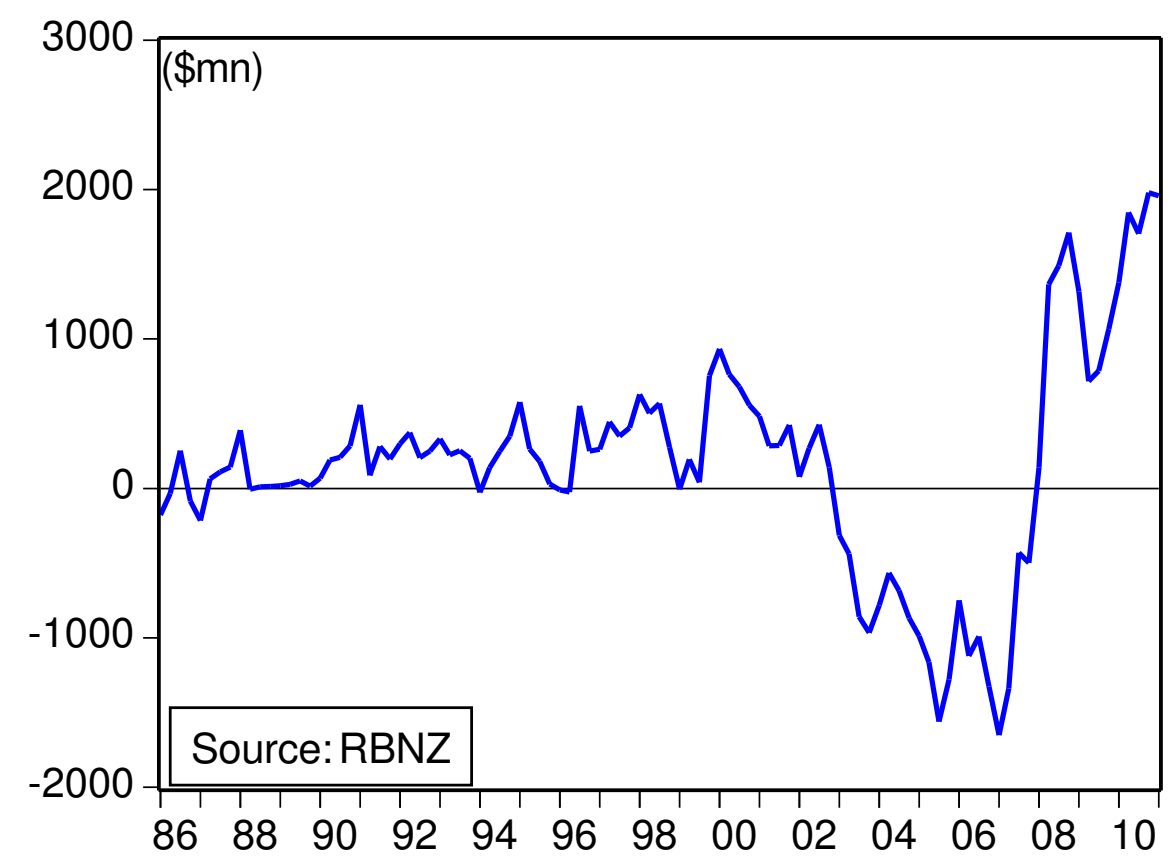

Household financial liabilities (which in New Zealand are largely driven by residential mortgage debt) rose over the period 1990-2000 (see Figure 1.5). However, I note that there were two bouts of real house price deflation that overlapped with this rise in household liabilities (1990-1992 and 1998-2001, see Figure 1.2). If there is a causal relationship running from house price movements to credit constraints (in terms of the extent to which they are binding), one would expect to see a flattening of the household claims to housing value ratio during the periods of house price retracement.

This does not completely rule out relaxed credit criteria. It is quite possible that competition between mortgage providers (be they banks or non-bank lending institutions such as building societies or finance companies) led to an erosion of credit criteria over time. While an increased demand for mortgages may have drawn lenders into the mortgage market, this is not the same as a credit collateral effect. Another way to look at this is to note that relaxed credit criteria may have allowed for greater borrowing even if house prices had remained unchanged. 
Figure 1.5: New Zealand household claims to dwelling values: household indebtedness as a proportion of housing assets

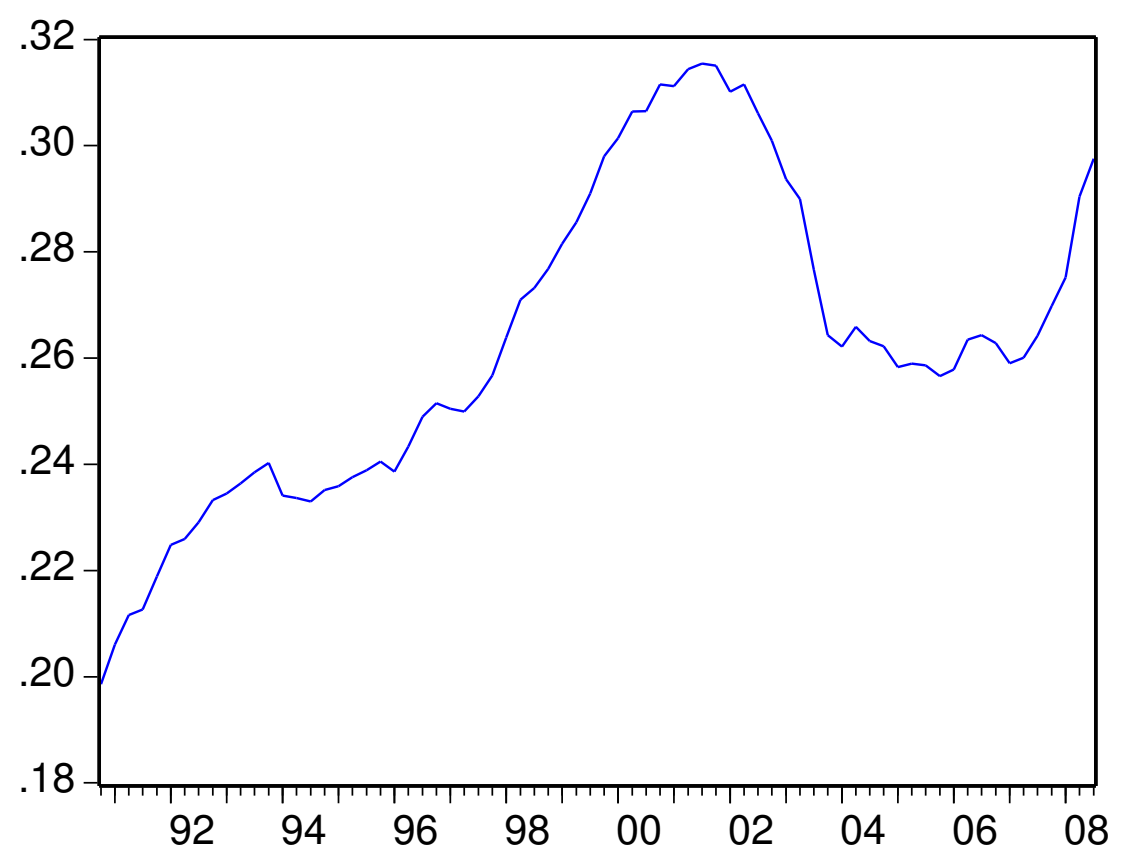

Furthermore, Attanasio, Leicester and Wakefield (2010) provide a lifecycle model incorporating credit constraints that suggests a pure wealth effect would be more apparent among older households. This is consistent with Buiter's view that older households would benefit from a redistribution. Attanasio et al. use UK data to show that consumption booms (concurrent with housing booms) tend to be driven by younger consumers which they suggest is consistent with an income shock rather than a wealth effect. This explanation, where a third factor is driving both the rise in housing wealth and expenditure but separately, is termed the "common causality" model in the literature.

Smith's (2010) examination of New Zealand data, however, points to a stronger impact on older households although there is still an aggregate impact. In other words, while there is some distributional effect, there is also a significant relationship between house prices and expenditure at the aggregate level.

Related to the "credit/collateral channel" is a potential role for a financial accelerator. Interest rates reflect, inter alia, credit risk and serve as a means to ration 
credit. When house prices rise, the increase in the value accrues to the homeowner and thus provides additional equity. This additional equity may either be used to reduce the loan to value ratio of the next house pruchase or is available to fund consumption via housing equity withdrawal. Standard financial theory suggests that a lower credit risk requires a lower interest rate and thus where risk is mitigated (by increased collateral value, say), a lower mortgage interest rate should entail. For a given benchmark risk-free interest rate, the spread between the mortgage rate and the benchmark should thus narrow. At the other extreme, if the homeowner extracts sufficient equity such that the loan to value ratio is unchanged, the spread may remain constant but consumption would rise. Of course, some combination of these two effects is possible with a modest decline in the spread and additional consumption expenditure.

Bernanke, Gertler and Gilchrist (1999) (hereafter referred to as BGG) lay out the framework for a financial accelerator mechanism in the context of business capital and how it may exacerbate economic cycles in a closed economy model. Key to BGG is the incorporation of credit market frictions. Whereas economic models typically use the risk-free interest rate as the key interest variable, in reality borrowers often have to pay significantly higher interest rates. It would be obvious to any experienced lender that extending loans involves a risk that the money may not be repaid (or that in the event of the borrower defaulting, the quantum of funds recoverable would be less than the principal and any accrued interest). As a result, lenders will typically charge a premium over the risk free rate. BGG embody this as a risk premium paid by borrowers (firms). While in practice the size of the risk premium will depend on a myriad of factors (that influence the ability to service and ultimately repay or affect the cost of providing the funds) BGG simplify this relationship to one of dependence on net assets. As a borrower's net assets increase in value, the likelihood that the lender will recover monies owed also increases, allowing for a reduction in the risk premium. Conversely events that cause a reduction in the borrower's net assets serve to drive up the interest rate faced by the borrower. Thus to the extent that net assets are co-cyclical with other economic shocks, the financial accelerator mechanism serves to amplify the effect of the original shock.

In a similar vein, Aoki, Proudman and Vlieghe (2002, 2002a, 2004) (hereafter APV) apply the concept of a financial accelerator to the housing market and (household) consumption, also in a closed economy model. Abstracting from explicit holdings of 
financial assets, APV set up a model in which household's net assets are driven by the value of the housing stock and the debt required to purchase the housing stock. As the net value of the housing stock increases, the interest premium charged by lenders on mortgages declines. Houseowners thus face both an increase in the equity in their homes and a lower mortgage cost (for a given risk-free interest rate). Thus they have the ability and incentive to withdraw some of the change in equity and use it to fund consumption. A key element in the APV model is the heterogenous households of which a portion is able to freely access the debt market while the remainder are constrained by current income although both types are endowed with housing assets. APV find that the financial accelerator amplifies the effect of shocks.

Iacoviello and Neri (2010) set out a closed economy DSGE model that also includes land as an explicit factor of production for housing. Their version of the financial accelerator is embodied in the budget constraint of homeowners by setting a debt limit for "impatient" households that is tied to the nominal value of the housing stock. Thus a rise in the value of the housing stock allows impatient households access to a greater amount of debt and thence fund consumption. As with APV, both patient and impatient households have housing assets. To foreshadow discussion in Chapter 2, I note that this treatment skips over the rationale for assuming that households which do not accumulate wealth have a housing asset.

Chapters 2 and 3 set out a dynamic stochastic general equilibrium (DSGE) model incorporating the financial accelerator. These build on the framework set up by APV and use a small open economy setting with an expansion in Chapter 3 to include an explicit fiscal sector. These models are calibrated to match New Zealand data. I find that the financial accelerator serves to amplify the effect of shocks on the housing market but may dampen the effects on non-housing variables including consumption. Chapter 4 examines the New Zealand data using a structural vector autoregression (SVAR). While the house price-consumption relationship is confirmed, the financial accelerator mechanism appears to be absent. Chapter 5 concludes with a summary of the results from the theoretical and empirical models along with identification of areas for further research. 


\section{Chapter 2}

\section{The basic small open economy model}

\section{$2.1 \quad$ Introduction}

The original APV model was constructed in a closed economy setting. In this chapter, I set out a modified version incorporating an open economy extension and calibrated for the New Zealand economy. The inclusion of a foreign sector makes the model more applicable to a small open economy such as New Zealand. In particular, the key open economy elements are as follows: the production function includes an imported intermediate good, the goods producing sector sells to foreign consumers in addition to home consumers, and a proportion of consumers are able to access foreign capital markets. It should be noted that this model focuses on certain key features of the New Zealand economy in order to avoid overly complicating the analysis. In particular, I follow APV in abstracting from productive capital. Similarly I abstract from international trade in services, consumer imports and cross-border investment. Thus the model does not seek to provide a basis for forecasting the behaviour of the New Zealand economy and especially the housing market but rather attempts to highlight the mechanism by which the housing market may influence aggregate economic activity (and vice versa).

This chapter is set out in the following manner. The components of the basic DSGE model are set out in their standard form, followed by a summary of their log-linear counterparts (the derivation of which is contained in Appendix C). The calibration of the model parameters (including steady state values) using New Zealand data is 
then discussed. The basic model is then compared with the closed economy approach adopted by APV. The effect of the financial accelerator is then explored, comparing the basic model response with the response when the accelerator is switched off. The sensitivity of the model to the presence of rule of thumb consumers is then examined.

\subsection{Overview}

In the basic model there are three explicit agents in the economy: households, firms and a monetary authority. All agents are assumed to be infinitely lived.

Following the framework used by APV, there are two types of households. The first type of consumers is freely able to access the capital markets and is thus able to smooth consumption across time by buying or selling financial assets. These households follow the permanent income hypothesis and are thus denoted by the term PIH. The other type of household exhibits rule of thumb consumption, spending all their income on consumption and are thus referred to hereinafter as ROT consumers. ROT consumers are effectively completely credit constrained as they have no access to the credit markets. This dimorphic characterisation of consumers stems from Campbell and Mankiw's (1989) seminal work on consumption.

Unlike the model used by APV, in this thesis ROT households are further characterised by the fact that they do not own any housing assets. This preserves consistency so that households which cannot access the credit markets to smooth consumption are also unable to access the credit markets to purchase a house i.e. they would not be granted a mortgage. Given that residential mortgage lending institutions (primarily banks in New Zealand) would be unwilling to extend credit to potential borrowers who have no assets, not to mention insufficient funds for a deposit on a house, this is not only reasonable but also arguably more realistic than positing credit-constrained consumers repeatedly accessing the mortgage market. Both types of consumers purchase goods from firms each period, receive wage income from labour supplied to firms and pay rental to the homeowners.

PIH households are further divided into two complementary components: a home- 
owner and a consumer. The homeowner transacts in the housing market each period, selling the housing stock and purchasing the stock anew. Against the net worth of housing stock, the homeowner borrows to meet any shortfall between the price of the housing stock bought at the end of the period and the price realised on sale of the existing housing stock. Net worth is defined as the value of the housing stock less outstanding debt and less any dividends paid to consumers. This dividend is the mechanism by which housing equity withdrawal is captured. Homeowners also charge a rental fee to consumers. Thus the housing stock is completely owned by the PIH households and the ROT consumers pay rental to their PIH landlords.

Firms produce a continuum of consumer goods and are monopolistically competitive. Each period they hire labour from households and also purchase an intermediate input from overseas. These imports are used up each period and capital is effectively assumed to be constant. The output of firms is consumed (by either households or government), exported or used to produce additional housing stock. The conversion of consumer goods to housing stock is assumed to follow a q-type investment theory.

The monetary authority has a Taylor rule reaction function (with lagged inflation and the output gap as indicators of inflationary pressure) and uses the nominal interest rate as its lever subject to a smoothing parameter. In the basic model, there is no role for fiscal policy and I exclude government spending as a demand shock (especially as such a treatment would still require a funding source).

The model is specified in log-linear terms. The law of recursive motion is solved for in MATLAB using Uhlig's (1995) toolkit (code available on request).

\section{$2.3 \quad$ Firms}

Goods production is undertaken by firms. These goods are differentiated so that there is monopolistic competition giving producers a degree of market power (including the ability to set their prices) over the short run. Firms are assumed to be domestically owned. While this is arguably a strong assumption given the high degree of foreign ownership of New Zealand resident businesses, the assumption ab- 
stracts from the need to consider equity investment flows. While no firm dividend is explicitly modelled in order to keep the model as simple as possible. Logically, ownership of firms should reside with the PIH households as ROT households are unable to build up savings in order to purchase an equity stake. However, if PIH households do not view changes to firm dividends as permanent income changes, then they will not alter their consumption behaviour in response.

Firms use a combination of labour and imported intermediate goods as inputs (in combination with an exogenously given level of technology) by way of a CES production function to produce consumption goods. The output of firm $z$ is given by:

$$
y_{t}(z)=\left[\alpha I M_{t}(z)^{\gamma}+(1-\alpha)\left(A_{t} L_{t}(z)\right)^{\gamma}\right]^{\frac{1}{\gamma}}
$$

where $I M_{t}(z)$ is the quantity of intermediate imports used by firm $z, L_{t}(z)$ is similarly labour demand, $A_{t}$ is economywide labour-augmenting technology, $\alpha$ is the weight given to imports (and thus $1-\alpha$ is the weight on labour) and $\frac{1}{1-\gamma}$ is the elasticity of substitution between labour and imports.

Price stickiness is incorporated into the model through limiting the ability of firms to reset their prices every period. Rather, each firm has a 25 percent chance to set the price for its good, $p_{t}(z)$, each period, giving an average duration for its price of four quarters. Firms maximise their profits by choosing $p_{t}(z)$ (when able) and thereby indirectly labour and import quantities (minimising their cost given the price level chosen). Their marginal cost condition aggregating across firms (with respect to labour) is thus:

$$
\lambda_{t}=\frac{W_{t}}{(1-\alpha) A_{t}^{\gamma}\left\{\frac{Y_{t}}{L_{t}}\right\}^{1-\gamma}}
$$

Equating marginal costs across labour and intermediate imports yields:

$$
\left(\frac{I M_{t}}{L_{t}}\right)^{1-\gamma} A_{t}^{\gamma}=\frac{\alpha}{1-\alpha} \frac{w_{t}}{R S_{t}}
$$

where $w_{t}=W_{t} / P_{t}$ is the real wage rate and $R S_{t}$ is the real exchange rate.

Standard monopolistic competitition assumptions are made with firms setting the price for their own goods but taking the aggregate consumption good price level and overall aggregate price levels, $P_{c, t}$ and $P_{t}$ respectively, as given. Similarly firms view 
the nominal exchange rate, $S_{t}$ (measured in domestic currency units per foreign currency unit), and the foreign price of imports, $P_{t}^{*}$, as given, reflecting the small size of domestic firms relative to the world market for the intermediate inputs. ${ }^{1}$ Firms' output is such that the demand for their goods (from either domestic use or foreign demand) is just met. Thus the disposal of aggregate goods output may be written as:

$$
Y_{t}=c_{t}+I_{t}+E X_{t}
$$

where $c_{t}$ is the consumption by households of consumer goods, $I_{t}$ is the use of consumer goods by house producers and $E X_{t}$ is foreign purchases.

Following Obstfeld and Rogoff(1996), consumer goods have an aggregate price level given by:

$$
P_{c, t}=\left[\int_{0}^{1} p_{t}(z)^{1-\epsilon} d z\right]^{\frac{1}{1-\epsilon}}
$$

where $\epsilon$ is the price elasticity of demand faced by each firm.

It then follows that household demand for consumer goods is dependent on the relative price in the following manner:

$$
c_{t}^{j}(z)=\left(\frac{p_{t}(z)}{P_{c, t}}\right)^{-\epsilon} c_{t}^{j}
$$

where $c_{t}^{j}(z)$ is the demand from consumer $j$ of firm $z$ 's good, $p_{t}(z)$ is the price of good $z, P_{c, t}$ is the aggregate price for all consumer goods and $c_{t}^{j}$ is consumer $j$ 's demand across all goods.

Foreign demand is also assumed to follow a similar derivation but with an additional term from the nominal exchange rate:

$$
\begin{aligned}
E X_{t}(z) & =\left(\frac{S_{t}^{-1} p_{t}(z)}{S_{t}^{-1} P_{c, t}}\right)^{-\epsilon} E X_{t} \\
& =\left(\frac{p_{t}(z)}{P_{c, t}}\right)^{-\epsilon} E X_{t}
\end{aligned}
$$

\footnotetext{
${ }^{1}$ The definition of the nominal exchange rate as units of domestic currency per one foreign currency unit means that an appreciation in the exchange rate is equivalent to decline in $S_{t}$. Similarly, for the real exchange rate, a decline in $R S_{t}$ represents an appreciation. Thus, in the following figures, a vertical drop represents an appreciation of the exchange rate.
} 
As per McCallum and Nelson (1999), I assume that aggregate export demand is given by

$$
E X_{t}=\left(R S_{t}\right)^{\vartheta}\left(Y_{t}^{f}\right)^{\zeta}
$$

where $R S_{t}=\frac{S_{t} P_{t}^{f}}{P_{t}}$ is the real exchange rate, $Y_{t}^{f}$ is foreign output, and $\vartheta>0, \zeta>0$.

\subsection{Households}

Depending upon their consumption behaviour, there may be an additional homeownership component to the household. Rule of thumb (ROT) consumers do not accumulate financial assets or liabilities and thus cannot logically accumulate sufficient wealth so as to afford a deposit on a house (let alone purchase one outright). In contrast, permanent income hypothesis (PIH) consumers are able to access the capital markets and thus either save or borrow. PIH households thus own the stock of housing. The homeowner component of the household rents the housing stock to both ROT consumers and PIH consumers. PIH households sell and repurchase the entire housing stock each period and depending upon their net worth relative to the value of the housing stock, will pay a dividend to the PIH consumers.

Standard Dixit-Stiglitz assumptions on utility and demand lead to consumer j's demand for aggregated consumption goods (Equation 2.3.6). Consumers divide their spending on consumer goods and housing rental according to the following equations:

$$
C_{t}=\left[v^{\frac{1}{\eta}}\left(c_{t}\right)^{\frac{\eta-1}{\eta}}+(1-v)^{\frac{1}{\eta}}\left(h_{t}\right)^{\frac{\eta-1}{\eta}}\right]^{\frac{\eta}{\eta-1}}
$$

where $v$ is the share of expenditure on consumer goods and $\eta$ is the elasticity of substitution between consumption goods and housing.

$$
\begin{aligned}
c_{t} & =v\left(\frac{P_{c, t}}{P_{t}}\right)^{-\eta} C_{t} \\
& =v X_{c, t}^{-\eta} C_{t}
\end{aligned}
$$


where $X_{c, t}=\frac{P_{c, t}}{P_{t}}$ is the relative price of the representative consumption good.

$$
\begin{aligned}
h_{t} & =(1-v)\left(\frac{P_{h, t}}{P_{t}}\right)^{-\eta} C_{t} \\
& =(1-v) X_{h, t}^{-\eta} C_{t}
\end{aligned}
$$

where $X_{h, t}=\frac{P_{h, t}}{P_{t}}$ is the relative price of rental services.

Consumers' intra-period utility is given by

$$
\log C_{t}+\xi \log \left(1-L_{t}\right)
$$

where $\xi$ is the disutility of labour coefficient.

Both types of consumers seek to maximise this but are subject to different time horizons and budget constraints. ROT consumers allocate each period's income to either goods consumption or rental. Hence ROT consumer utility maximisation is subject to the following single-period constraint:

$$
C_{t}^{r}=w_{t} L_{t}^{r}
$$

where $C_{t}^{r}$ is aggregate consumption by ROT consumers and $L_{t}^{r}$ is the labour supplied by ROT consumers. In other words, ROT consumption is not affected by changing expectations and is simply dependent on current period income. As a result, as shown in Appendix C, labour supply by ROT households is constant so that

$$
L_{t}^{r}=\frac{1}{1+\xi}
$$

In contrast, PIH consumers borrow or lend in order to smooth their consumption across time. In keeping with the small open economy concept, there are no restrictions on the flow of capital. However, this is not the same as complete markets and does not automatically result in an equalisation of the domestic and foreign interest rates. ${ }^{2}$ The De Paoli (2009) treatment of foreign currency borrowing adopted here is to make the domestic interest rate equal to the foreign interest rate plus a premium $(\psi)$, the size of which is positively related to aggregate real foreign debt

\footnotetext{
${ }^{2}$ Indeed, New Zealand is well known for having a significant interest rate premium despite relatively open capital markets.
} 
levels $\left(\psi^{\prime}()>0.\right)$.

$$
R_{t+1}=\left(R_{t+1}^{f}\right) \psi\left(R S_{t} B_{F, t}\right)
$$

where $B_{F, t}$ is the issuance (positive) or purchase (negative) of real foreign currency debt by consumers and $R_{t+1}$ the real domestic interest rate from period $t$ to $t+1$. Thus PIH consumers face the following budget constraint (expressed in real terms):

$$
C_{t}^{P}+B_{H, t-1}+R S_{t} B_{F, t-1}=\frac{B_{H, t}}{\left(R_{t+1}\right)}+\frac{R S_{t} B_{F, t}}{\left(R_{t+1}^{f}\right) \psi\left(R S_{t} B_{F, t}\right)}+\frac{W_{t}}{P_{t}} L_{t}^{p}+D_{t}
$$

where $C_{t}^{p}$ is consumption by PIH consumers, $L_{t}^{p}$ is the labour supplied by PIH consumers, $B_{H, t}$ is the face value of real domestic currency bonds issued (or sold) at time $t$ with maturity $t+1, R_{t+1}^{f}$ is the foreign interest rate and $D_{t}$ is the dividend paid by homeowners to consumers.

Maximising intra-period utility with respect to consumption and domestic bond holdings yields:

$$
\frac{1}{C_{t}^{P}}=R_{t+1}^{f} \psi\left(R S_{t} B_{F, t}\right) \beta E_{t}\left(\frac{1}{C_{t+1}^{P}} \frac{R S_{t+1}}{R S_{t}}\right)
$$

Substituting this into the first order condition with respect to foreign bond holdings results in:

$$
R_{t+1}=R_{t+1}^{f} \psi\left(R S_{t} B_{F, t}\right) E_{t}\left(\frac{R S_{t+1}}{R S_{t}}\right)
$$

Foreign consumers are assumed to trade only in foreign currency bonds. As noted by De Paoli (2009), the assumption that idiosyncratic risk is pooled domestically allows for only foreign currency denominated bonds to be traded in equilibrium and the net foreign asset position to be identified.

In keeping with BGG, the cost of borrowing for the purchase of housing capital is at a premium to the risk-free interest rate, this premium varying inversely with the extent that the borrower has net positive wealth. Because of the agency problem mortgage lenders will only lend to homeowners at a premium to the risk-free rate. Homeowners will stand to make a gain (or loss) on their capital in addition to the rental from consumers. They will borrow up to the point that the cost of borrowing is just equal to their expected return from the housing asset. Thus,

$$
E_{t} R_{h, t+1}=f\left(\frac{N_{t+1}}{q_{t} h_{t+1}}\right) R_{t+1}
$$


where $E_{t} R_{h, t+1}$ is the expected rate of return on owning housing from period $t$ to $t+1, N_{t+1}$ is the net worth of the household determined at the end of period $t$ and thus carried over into period $t+1, q_{t}$ is the real price of housing in period $t, f^{\prime}<0$ and $h_{t+1}$ is the stock of housing determined at the end of period $t$ and carried over into period $t+1$.

Housing stock bought in period $t$ is rented to consumers in period $t+1$. In addition, the price of the housing stock may change thus providing a capital gain or loss. Finally, depreciation $(\delta)$ is assumed to erode some of the value of the existing housing stock. Thus, the return to homeowners may be expressed as:

$$
E_{t} R_{h, t+1}=E_{t}\left(\frac{X_{h, t+1}+(1-\delta) q_{t+1}}{q_{t}}\right)
$$

The key element of the financial accelerator mechanism is the net worth of homeowners. At the start of each period, the value of homeowners is given by the return on housing multiplied by the housing stock (determined in period $t-1$ ) less the debt and interest incurred:

$$
V_{t}=R_{h, t} q_{t-1} h_{t}-f\left(\frac{N_{t}}{q_{t-1} h_{t}}\right) R_{t} b_{t}
$$

where $b_{t}$, the borrowing undertaken to finance the purchase of the housing stock, is equal to $q_{t} h_{t+1}-N_{t+1}$.

In order to capture the possibility of housing equity withdrawal (or even injection), a dividend from homeowners to consumers is included. The size of the dividend is determined by the homeowner's net worth:

$$
D_{t}=\chi\left(\frac{N_{t+1}}{q_{t} h_{t+1}}\right)
$$

where $\chi^{\prime}>0$.

After paying the dividend $\left(D_{t}\right)$ to PIH consumers, the net worth of homeowners is given by

$$
N_{t+1}=V_{t}-D_{t}
$$




\subsection{Housing investment}

In keeping with APV, investment and house prices are linked by a Tobin's q relationship, in that house producers' investment relative to the exisiting housing stock is driven by the price of housing compared to the cost of its replacement. House producers purchase $I_{t}$ of the consumption goods and use this to produce $h_{t+1}$ units of housing:

$$
h_{t+1}=\Phi\left(\frac{I_{t}}{h_{t}}\right) h_{t}
$$

where $\Phi($.$) is concave, giving rise to the equilibrium condition of$

$$
\frac{q_{t}}{X_{c, t}}=\Phi^{\prime}\left(\frac{I_{t}}{h_{t}}\right)
$$

\subsection{Monetary authority}

The monetary authority uses a Taylor rule comprising the nominal interest rate for current period (interest to be paid in the following period), the last period's goods price inflation and an output gap measure.

$$
\hat{R}_{t+1}^{n}=\rho_{i} \hat{R}_{t}^{n}+\left(1-\rho_{i}\right) \gamma_{\pi} \hat{\pi}_{t-1}+\left(1-\rho_{i}\right) \gamma_{y} \mathrm{ygap}_{t}
$$

where $\rho_{i}$ is the smoothing coefficient, $\gamma_{\pi}$ is the weight on lagged inflation and $\gamma_{y}$ is the weight on the output gap. The gap is defined as the difference between actual output and the output level achievable under fully flexible prices. Thus the flexible price output response in the following figures is graphically the difference between the output and output gap responses.

\subsection{Current account}

The current account is the sum of the resource constraints for all agents in the economy. For the combined consumer, homeowner and houseproducer there are net expenditures of $c_{t}+I_{t}+R S_{t} B_{F, t-1}+B_{H, t-1}$ with revenues of $\frac{R S_{t} B_{F, t}}{R_{t+1}^{f} \psi(.)}+\frac{B_{H, t}}{R_{t+1}}+\frac{W_{t}}{P_{t}} L_{t}$. For goods producing firms, expenditures are $\frac{W_{t}}{P_{t}} L_{t}-R S_{t} I M_{t}$ while revenues are $Y_{t}$. Assuming that domestic currency debt is in net zero supply, then the current 
account reduces to

$$
R S_{t} B_{F, t-1}=\frac{R S_{t} B_{F, t}}{R_{t+1}^{f} \psi(.)}+E X_{t}-R S_{t} I M_{t}
$$

\subsection{Shock processes}

The model is subject to four different shocks, namely a technology shock, a domestic nominal interest rate shock, a foreign real interest rate shock and a foreign demand shock. The shock processes are stationary and have similar forms, such that for each shock, $k$, its log difference is given by

$$
\hat{k}_{t}=\rho_{k} \hat{k}_{t-1}+\epsilon_{k, t} .
$$

where $0<\rho_{k}<1$, ensuring that the processes are stationary. ${ }^{3}$

While there is some appeal to modelling permanent shocks, this can be problemmatic for economies that are subject to multiple shock types. A permanent shock effectively imparts a trend to the model and as noted by Beneš et al. (2009), estimation of a DSGE model with trends may not be possible due to insufficient observations given the need to pin down multiple trends.

\section{$2.9 \quad$ Log-linear model equations}

The derivation of the log-linear equations is set out in Appendix C. Variables with a hat are the percentage change from their steady state value and variables without a subscript are the steady state values. The key equations as they appear in the Matlab code are as follows:

$$
\begin{gathered}
\hat{Y}_{t}=\varphi I \hat{M}_{t}+(1-\varphi)\left(\hat{A}_{t}+\hat{L}_{t}\right) \\
I \hat{M}_{t}=\hat{L}_{t}+\frac{1}{1-\gamma} \hat{w}_{t}-\frac{\gamma}{1-\gamma} \hat{A}_{t}-\frac{1}{1-\gamma} \hat{R S_{t}} \\
\hat{m} c_{t}=\hat{w}_{t}-(1-\gamma) \varphi I \hat{M}_{t}+(1-\gamma) \varphi \hat{L}_{t}-[(1-\gamma)(1-\varphi)+\gamma] \hat{A}_{t}
\end{gathered}
$$

\footnotetext{
${ }^{3}$ Stationarity of the technology shock is a particularly strong assumption. However, this also means that it is not necessary to deflate real variables by the technology process $A_{t}$.
} 


$$
\begin{aligned}
& \hat{Y}_{t}=\left(\frac{c}{Y}\right) \hat{c}_{t}+\left(\frac{I}{Y}\right) \hat{I}_{t}+\left(\frac{E X}{Y}\right) \hat{E X_{t}} \\
& \hat{E X_{t}}=\vartheta \hat{R S_{t}}+\zeta \hat{Y}_{t}^{f} \\
& \hat{X}_{c, t}=-\frac{1-\nu}{\nu}\left(\frac{X_{h}}{X_{c}}\right)^{1-\eta} \hat{X}_{h, t} \\
& \hat{c}_{t}=\hat{C}_{t}-\eta \hat{X}_{c, t} \\
& \hat{X}_{h, t}=\frac{1}{\eta} \hat{C}_{t}-\frac{1}{\eta} \hat{h}_{t} \\
& \hat{C}_{t}^{r}=\frac{w L^{r}}{C^{r}} \hat{w}_{t} \\
& \hat{C}_{t}^{p}=E_{t} \hat{C}_{t+1}^{p}-\hat{R}_{t+1} \\
& \hat{C}_{t}^{p}=\hat{w}_{t}+\frac{L^{p}}{1-L^{p}} \hat{L}_{t}^{p} \\
& \hat{C}_{t}=n_{C} \hat{C}_{t}^{p}+\left(1-n_{C}\right) \hat{C}_{t}^{r} \\
& \hat{L}_{t}=n_{l} \hat{L}_{t}^{p} \\
& \hat{R}_{t+1}=\hat{R}_{t+1}^{f}+\delta_{b} \hat{b}_{t}+E_{t} \hat{R S} S_{t+1}-\hat{R S_{t}} \\
& E_{t} \hat{R}_{h, t+1}=\hat{R}_{t+1}+\Omega\left(\hat{N}_{t+1}-\hat{q}_{t}-\hat{h}_{t+1}\right) \\
& \hat{R}_{h, t}=(1-\mu) \hat{X}_{h, t}+\mu \hat{q}_{t}-\hat{q}_{t-1} \\
& \hat{D}_{t}=\frac{\chi^{\prime}(\phi)}{\chi(\phi)} \phi\left(\hat{N}_{t+1}-\hat{q}_{t}-\hat{h}_{t+1}\right) \\
& \hat{h}_{t+1}=\delta \hat{I}_{t}+(1-\delta) \hat{h}_{t} \\
& \hat{q}_{t}=\Gamma_{d}\left(\hat{I}_{t}-\hat{h}_{t}\right)+\hat{X}_{c, t} \\
& \hat{R}_{t+1}^{n}=\hat{R}_{t+1}+E_{t} \hat{\pi}_{t+1} \\
& \hat{R}_{t+1}^{n}=\rho_{i} \hat{R}_{t}^{n}+\left(1-\rho_{i}\right) \gamma_{\pi} \hat{\pi}_{t-1}+\left(1-\rho_{i}\right) \gamma_{y} g \hat{a} p_{t} \\
& \beta C\left[b_{t}\left(1+a \delta_{b}\right)-a \hat{R}_{t+1}^{f}\right]=b_{t-1} C+b\left[\Delta \hat{S}_{t}+\hat{\pi}_{t}^{f}-\hat{\pi}_{t}\right] \\
& -E X\left[\zeta \hat{Y}_{t}^{f}+\vartheta \hat{R S_{t}}\right]+\frac{S P^{f}}{P} I M\left[I \hat{M}_{t}+\hat{R S_{t}}\right]
\end{aligned}
$$




$$
\begin{gathered}
\hat{\pi}_{t}=\hat{\pi}_{c, t}-\hat{X}_{c, t}+\hat{X}_{c, t-1} \\
\hat{\pi}_{c, t}=\kappa \hat{m} c_{t}+\beta E_{t} \hat{\pi}_{c, t+1} \\
E_{t} \hat{R S_{t+1}-\hat{R S} S_{t}}=E_{t} \hat{S}_{t+1}-\hat{S}_{t}+E_{t} \hat{\pi}_{t+1}^{f}-E_{t} \hat{\pi}_{t+1}
\end{gathered}
$$

where

$$
\begin{aligned}
\phi & =\frac{N}{q h} \\
\varphi & =\frac{\alpha I M^{\gamma}}{\alpha I M^{\gamma}+(1-\alpha)(A L)^{\gamma}} \\
\mu & =\frac{(1-\delta) q}{X_{h}+(1-\delta) q} \\
\Gamma_{d} & =\frac{\Phi^{\prime \prime}(I / h)}{\Phi^{\prime}(I / h)}\left(\frac{I}{h}\right) \\
n_{C} & =n \frac{C^{p}}{C} \\
n_{L} & =n \frac{L^{p}}{L} \\
b n & =\frac{1}{\phi}-1 \\
\Omega & =\frac{f^{\prime}(\phi)}{f(\phi)} \phi \\
\kappa & =\frac{(1-\theta)(1-\theta \beta)}{\theta} \\
\delta_{b} & =-\psi^{\prime}\left(R S B_{F}\right) C
\end{aligned}
$$

\subsection{Parameterisation and calibration - Consis- tency with NZ data}

In determining the steady state, I have attempted to use parameter and variable values that are broadly consistent with New Zealand data. The introduction of the open economy requires a judgment as to which data should be used to calibrate the import and export related parameters. Given that the model abstracts from services and also consumer goods imports, two possible treatments suggest themselves in order to establish steady state imports: using only data on capital and intermediate imports or disregarding the nature of the components and using aggregate data on exports and imports. Either approach has its own drawbacks. Focusing only on intermediate (including capital) imports is implicitly equivalent 
to saying that imported consumption goods play no role in the economy. In reality, New Zealand relies heavily on imports for a variety of consumption goods with consumption goods accounting for a quarter of all merchandise imports. Similarly, services imports comprised around a quarter of all imports over the last two decades. Against these factors, including consumption goods as part of imports would overstate the extent to which producers rely on imported goods. Similarly, while imports of business services may well be used by firms producing in New Zealand, personal services (for example overseas travel expenses) are clearly not.

An additional important consideration is the relationship with the current account. New Zealand has historically run a current account deficit and this is part of the reason why its interest rates have also historically been subject to a significant country-risk premium. Rather than focus on the components of the current account that most closely match the model definitions, I use the debits and credits data from Statistics New Zealand current account data. Given that this thesis explicitly models a premium based on the level of foreign debt, it is appropriate to set the steady state trade parameters so that there is a steady state current account deficit and thus a steady state premium in the domestic interest rate. ${ }^{4}$

The CES share parameter for imports $(\alpha)$ is set at 0.2 , lower than import weights for other New Zealand-calibrated DSGE models (see Table 3.4). Although empirically the dollar value of capital and intermediate imports is large in comparison to gross labour earnings, I attribute the share parameter that would accrue to capital to labour instead, in line with the implied household ownership of firms.

In keeping with the general approach to using DSGE models, the coefficient for leisure utility $(\xi)$ is set so that the steady state supply of labour is equal to 0.33 .

The elasticity of substitution between imports and labour is set such that $\gamma=-0.2$, reflecting a relatively modest degree of complementarity between labour and imports. This is considerably smaller in absolute value than the value estimated by Szeto (2002) for the substitution between imported and domestically produced goods for a New Zealand CES production function. However, given that Szeto's model is

\footnotetext{
${ }^{4}$ The steady state ratios are calculated using (GNE + current account credits) as the denominator, where GNE includes government spending. While this is inconsistent with the underlying basic model structure, the inclusion of government spending is done to allow for comparison with the fiscal model of Chapter 3.
} 
a nested CES with labour and imports at different levels, it is not directly comparable. More importantly, the choice of $\gamma$ is constrained by the need to ensure that the flexible price output reacts sensibly to a technology shock (see Equation C.16.8).

The proportion of PIH consumers is set to 0.7, in line with the RBNZ FPS model assumption (Black et al., 1997). The RBNZ's DSGE model, KITT, (Beneš et al, 2009) does not distinguish between different consumer types.

The weight on goods consumption $(\nu)$ of 0.81 is set to be consistent with the expenditure weights obtained from Statistics New Zealand's Household Expenditure Surveys. The net worth to housing value ratio $\left(\phi=\frac{N}{q h}\right)$ is set to 0.7 , which is also the value used in RBNZ's KITT. Over the past twenty years, net worth in New Zealand (as measured by the the value of the housing stock less claims on households) as a proportion of the value of the housing stock has averaged around 70-75\%. However, it should be noted that this includes a period of sustained decline until the early 2000s. In addition, the RBNZ's measure of household equity injection was approximately zero at times when the net worth ratio was around $70-73 \%$.

The steady state interest rate premium (2.6\% on an annual basis) is obtained from the historical average of the RBNZ's Variable First Home Mortgage series over the risk-free 90-day Treasury Bill interest rate.

The coefficients $\left(\rho_{i}, \gamma_{\pi}\right.$ and $\left.\gamma_{y}\right)$ in the monetary policy rule are estimated from a simple regression of the risk-free rate on its own one period lag, lagged inflation and the output gap. ${ }^{5}$

The cost of intermediation in the foreign currency bond market, $\delta_{b}$ is set to -0.001 , following Thoenissen (2004).

A number of the deep structural parameters cannot be identified (at least easily) from empirical data and the values used are set broadly in line with other studies and adjusted so that the moments generated by the extended model in Chapter 3 approximate the empirical data. The specifics are set out in more detail in Chapter

\footnotetext{
${ }^{5}$ Specifically, the estimates for $\rho_{i}, \gamma_{\pi}$ and $\gamma_{y}$ are $0.89,1.01$, and 0.18 , respectively. The inflation and output gap coefficients are somewhat smaller than the standard assumed values of 1.5 and 0.5 , respectively.
} 


\begin{tabular}{|l|l|l|}
\hline Parameter & Description & Basic model \\
\hline \hline$\phi$ & Steady state net worth to housing stock value $(N / q h)$ & 0.7 \\
$\mathrm{EX} / \mathrm{Y}$ & Steady state export/output ratio & 0.245 \\
$\mathrm{IM} / \mathrm{Y}$ & Steady state import/output ratio & 0.282 \\
$\nu$ & Steady state goods consumption as a proportion of overall consumption & 0.81 \\
$f(\phi)$ & Steady state interest rate premium factor & 1.0064 \\
\hline $\mathrm{n}$ & Proportion of consumers that are PIH & 0.7 \\
$\frac{\chi^{\prime}(\phi)}{\chi(\phi)} \phi$ & Sensitivity of dividend to net worth ratio & 3 \\
$\Gamma_{d}$ & q-theory sensitivity & 0.52 \\
$\Omega$ & Sensitivity of interest rate premium to $\phi_{t}$ & -0.1 \\
$\xi$ & Leisure coefficient in utility function & 1.1097 \\
$\beta$ & Discount rate & 0.99 \\
$\delta$ & Housing depreciation rate & 0.005 \\
$\vartheta$ & Export sensitivity to real exchange rate & 1 \\
$\zeta$ & Export sensitivity to foreign demand & 1 \\
$\alpha$ & Import weight in production function & 0.2 \\
$\gamma$ & Labour-imports substitution coefficient in production function & -0.2 \\
$\eta$ & Consumer substitution between housing and goods coefficient & 1 \\
$\rho_{i}$ & Interest rate smoothing coefficient & 0.89 \\
$\rho_{a}$ & Autocorrelation for technology shock & 0.18 \\
$\rho_{R^{f}}$ & Autocorrelation of foreign interest rate shock & 0.89 \\
$\rho_{Y f}$ & Autocorrelation of foreign demand shock & 0.85 \\
$\rho_{X i i}$ & Autocorrelation of interest rate shock & 0.40 \\
$\gamma_{\pi}$ & Coefficient on inflation in monetary policy rule & 1.01 \\
$\gamma_{y}$ & Coefficient on output gap in monetary policy rule & 0.18 \\
$1-\theta$ & Probability of firm resetting its price & 0.25 \\
\hline \hline
\end{tabular}

Table 2.1: Basic model parameter values

3.3. In order for the basic model and the fiscal model to be comparable, I use the same parameter values across model types. As a result the moments for the basic model are further from the observed values. Matching moments for the basic model would require different parameter values and it would thus be difficult to establish whether the differences in model responses are due to assumed parameter values or the different model structure.

\subsection{Steady state}

In order to calculate the recursive laws of motion for the the log-linear model (which essentially works off deviations from an assumption of being initially in the steady state), a number of steady state values are required (e.g. $I M, L)$. Thus in order to make the model consistent, these parameters should be based on a computed steady 
state which is in turn consistent with empirical data. This latter aspect, of course, relies on further assumptions as to whether the data is reflective of a steady state.

The steady state relationships implied by the model equations mean that it is possible to derive the steady state by using only a small subset of the model variables. This thesis uses the real price of housing and the stock of housing as the key variables upon which the rest of the steady state may be calculated. In addition, the disutility of labour coefficient, $\xi$, is set so that the steady state provision of labour is equal to 0.33 . The steady state relationships are set out below with the derivations from the equilibrium equations in Appendix E. Using these relationships, in combination with the assumed parameter values (detailed in Table 2.1) allow for the key steady state values to be computed (see Table 2.2).

The process of computing the steady state begins as follows. The real house price $(q)$ and housing stock $(h)$ are set. The net worth to housing stock ratio parameter $\left(\phi=\frac{N}{q h}\right.$, calibrated at 0.7$)$ then determines the net worth $(N)$ via Equation 2.11.1. The discount rate is set to 0.99 (consistent with other DSGE model values), implying a steady state real interest rate $(R)$ of $4.1 \%$ per annum. The mortgage interest rate - risk-free benchmark premium is estimated at $2.6 \%$ per annum and this determines the steady state return on housing $\left(R_{h}\right)$ via Equation 2.11.2. The return on housing and net worth then determine the dividend from the homeowner to the consumer $(D)$. The real house price and return on housing $\left(R_{h}\right)$ determine the relative price of rental $\left(X_{h}\right)$, which then determines the relative price of the consumption good $\left(X_{c}\right)$. The housing stock and $X_{h}$ determine aggregate consumption $(C)$ from which goods consumption $(c)$ is determined. This process sequentially calculates the steady state values, ultimately determining the steady state consumption of goods and housing rental values for both the ROT and PIH consumers.

There are five exogenous steady state variables (real house price, housing stock, aggregate labour, the real exchange rate and technology) which are used to calculate the additional sixteen steady state variables (endogenously). Both the real exchange rate and technology are normalised to 1 in the steady state to simplify the equations, leaving the first three as the basis on which the steady state is calculated.

The steady state equations used to derive the steady state variable values are as follows: 


$$
\begin{aligned}
& \frac{N}{q h}=0.7 \\
& R_{h}=f\left(\frac{N}{q h}\right) R \\
& X_{h}=\left[R_{h}-(1-\delta)\right] q \\
& 1=\left[v X_{c}^{1-\eta}+(1-v) X_{h}^{1-\eta}\right]^{\frac{1}{1-\eta}} \\
& D=N\left(R_{h}-1\right) \\
& C=\frac{h}{(1-v) X_{h}^{-\eta}} \\
& c=v X_{c}^{-\eta} C \\
& I=\delta h \\
& Y=\frac{c+I}{1-\frac{E X}{Y}} \\
& L=\left(\frac{Y^{\gamma}-I M^{\gamma}}{1-\alpha}\right)^{\frac{1}{\gamma}} \\
& \left(\frac{I M}{L}\right)^{1-\gamma}=\frac{\alpha}{1-\alpha} \frac{w}{R S} \\
& w=\frac{C \xi}{(1-L)} \\
& E X=\frac{E X}{Y} Y \\
& I M=\frac{I M}{Y} Y \\
& E X=R E R^{\vartheta}\left(Y^{f}\right)^{\zeta}
\end{aligned}
$$

\subsection{Comparison with a closed economy model}

Identifying the specific differences that result from including an open economy requires a comparable closed economy model. The closed economy model follows the structure of the APV model but specifically drops the dividend from the ROT budget constraint and eliminates the unfunded government demand for goods. It should 


\begin{tabular}{|l|l|c|c|}
\hline Variable & Description & Basic model & No accelerator \\
\hline \hline & Exogenous values & 5.9382 & 8.4942 \\
$h$ & Real house price & 0.5 & 0.5 \\
$L$ & Housing stock & 0.33 & 0.33 \\
$R S$ & Aggregate labour & 1 & 1 \\
$A$ & Real exchange rate & 1 & 1 \\
\hline & Technology & & \\
$R_{h}$ & Endogenous values & 1.0166 & 1.0101 \\
$X_{c}$ & Return on housing & 1.6187 & 1.6187 \\
$X_{h}$ & Relative price of consumption good & 0.1283 & 0.1283 \\
$I$ & Relative price of renting & 0.0025 & 0.0025 \\
$N$ & Housing investment & 2.0784 & 2.9730 \\
$D$ & Net worth & 0.0345 & 0.0300 \\
$C$ & Housing dividend & 0.3376 & 0.3376 \\
$Y$ & Aggregate consumption & 0.2271 & 0.2271 \\
$w$ & Real output & 0.5592 & 0.5592 \\
$I M$ & Real wage & 0.0640 & 0.0640 \\
$E X$ & Imports & 0.0556 & 0.0556 \\
$E X-R S I M$ & Exports & -0.0084 & -0.0084 \\
$c$ & Current account & 0.1690 & 0.1690 \\
\hline$L^{r}$ & Goods consumption & 0.4740 & 0.4740 \\
$L^{p}$ & ROT labour supply & 0.2683 & 0.2683 \\
$C^{r}$ & PIH labour supply & 0.2651 & 0.2651 \\
$C^{p}$ & ROT consumption & 0.3687 & 0.3687 \\
\hline
\end{tabular}

Table 2.2: Open economy model steady state values 
be noted that a single factor of production closed economy model is not entirely comparable with a two-factor open economy model as there are a number of structural issues that are likely contribute to the difference in responses. The flexible price output plays a key role here. In particular, the real exchange rate has a significant influence on the open economy model responses across both types of shocks (i.e. an unexpected shock reduction in the nominal interest rate by 25 basis points and a $1 \%$ shock increase in technology) discussed below. That said, the manner in which the real exchange rate influences the responses does vary across the shock types and thus they warrant discussion individually. Overall, the non-housing market variables display a stronger reaction to the shocks in the basic open economy model than the closed economy model but the reaction of the housing market variables may be shock specific.

\subsubsection{Response to an interest rate shock}

The responses of the closed and basic (open) models to a 25 basis point shock reduction in the nominal interest rate are shown in Figure 2.1. The open economy displays a somewhat more muted response to the interest rate shock than the closed economy model across all variables with the sole exception of the output gap.

The reduction in the nominal interest rate in the shock period leads to a reduction in the real interest rate. Expected inflation is above the steady state (see below) and thus there is an unambiguous reduction in the real interest rate in the shock period. PIH consumption increases in both the closed and basic models as a result of the lower real interest rate. In the basic model there is an additional effect as the real interest rate reduction leads to a depreciation in the real exchange rate. Although this increases export demand, it also reduces the flexible price output level as import prices increase. This results in the basic model output gap increasing more than the closed economy and as a consequence the monetary policy response in the basic model is also stronger, offsetting some of the initial shock and also increasing the real interest rate. Thus the basic model PIH consumption response is moderated relative to the closed model and consequently a smaller output of goods is required and thus the wage rate response in the basic model is more moderate compared to the closed economy increase, which further reduces demand as ROT consumers reduce spending. The overall reduction in goods consumption outweighs the effect 
of increased export demand due to the higher weighting of consumption in the allocation of output $\left(\frac{c}{Y}\right.$ is 0.744 versus $\frac{E X}{Y}$ of 0.245$)$, resulting in an unambiguous decline in output relative to the closed model. Given that the responses of output and investment are weaker in the basic model, it logically follows that the real house price should be lower than the closed economy model.

Overall, the basic model shows that in response to an expansionary nominal interest rate shock it will display less variability in consumption, output, wages and prices due to the presence of the exchange rate effect on exports and imports. In effect, the real exchange rate provides a mechanism which absorbs part of the impact of the interest rate shock and decreases volatility relative to the closed economy. 
Figure 2.1: Response to a $-0.25 \%$ nominal interest rate shock, closed economy model and basic model
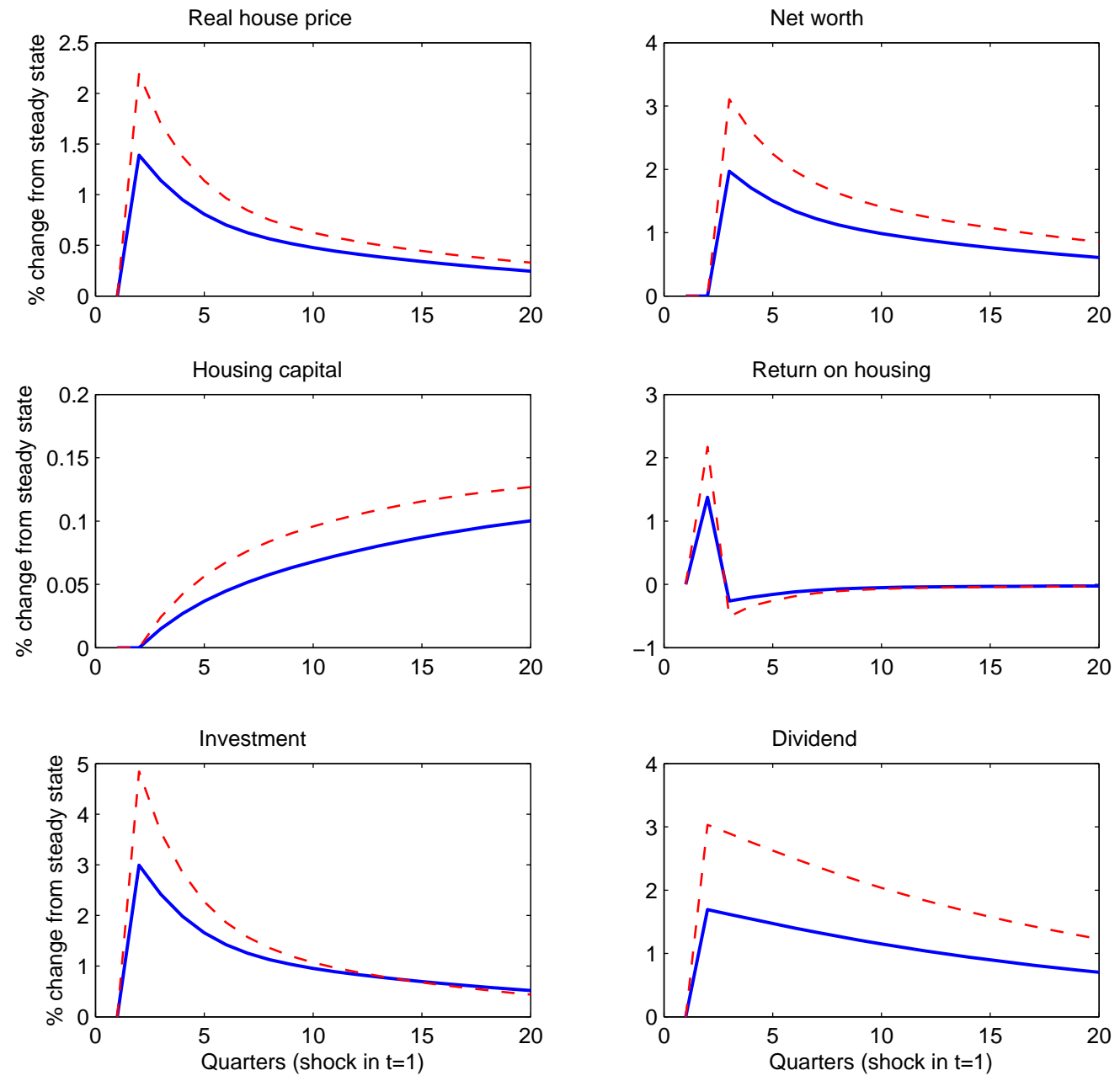

Basic model - - - Closed model 
Figure 2.1: Response to a $-0.25 \%$ nominal interest rate shock, closed economy model and basic model (continued)
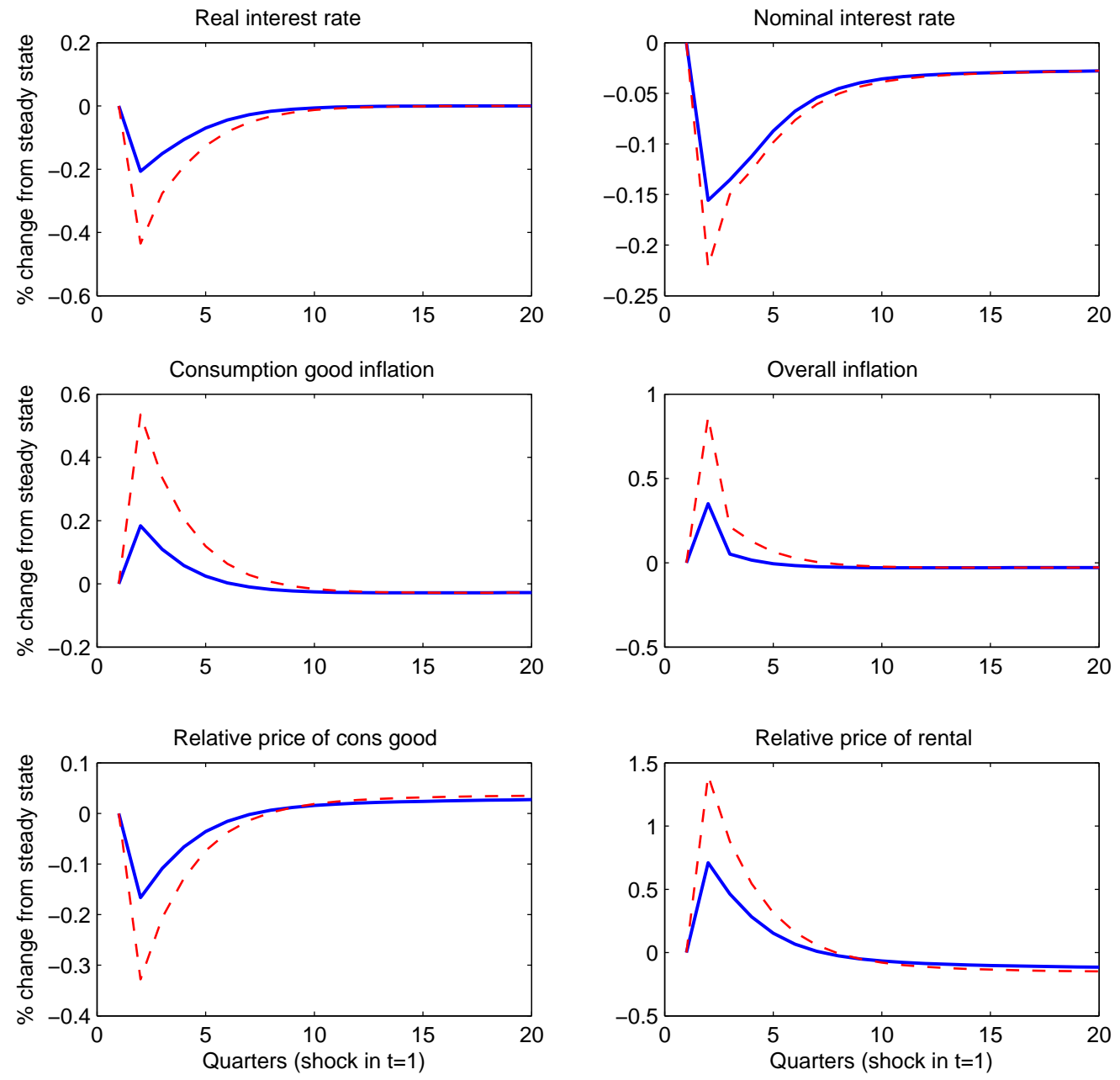

Basic model --- Closed model 
Figure 2.1: Response to a $-0.25 \%$ nominal interest rate shock, closed economy model and basic model (continued)
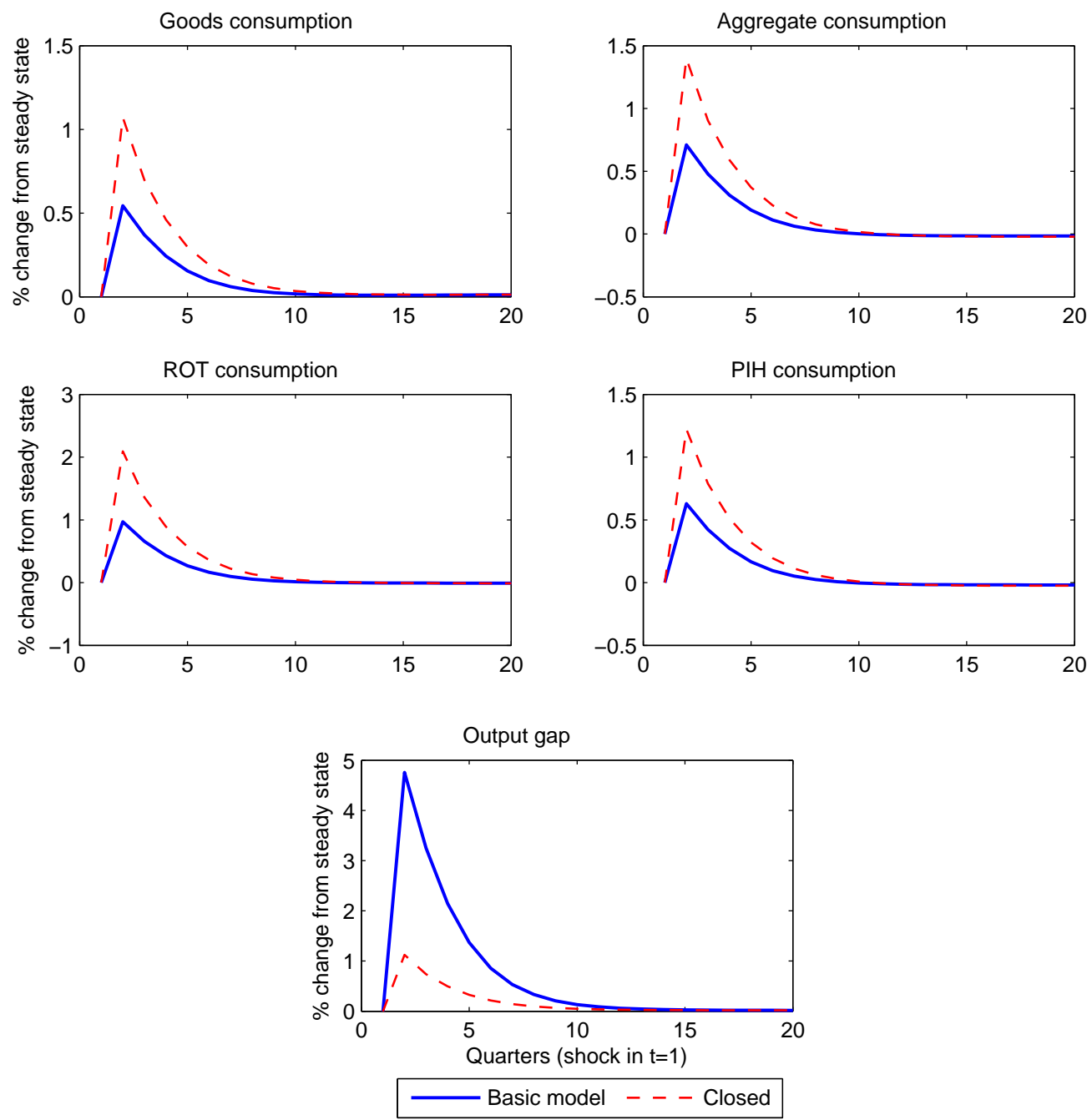
Figure 2.1: Response to a $-0.25 \%$ nominal interest rate shock, closed economy model and basic model (continued)
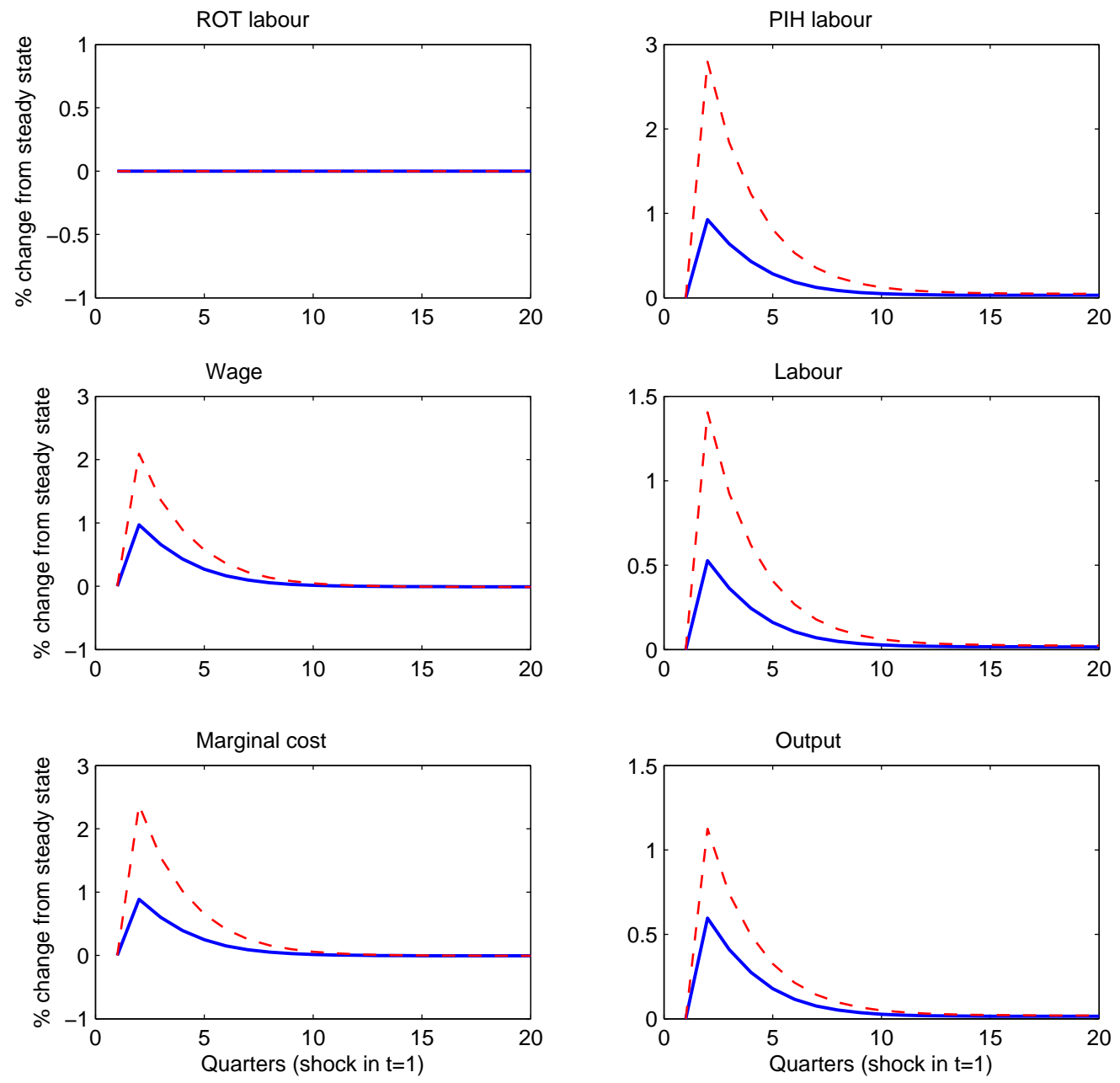

Basic model --- Closed model 


\subsubsection{Response to a technology shock}

The responses of the models to a 1\% increase in technology are shown in Figure 2.2. Immediately, it can be seen that the housing market response in the basic model response is stronger than the closed model.However, the responses need to be interpreted with care as the different production functions have a significant impact on the flexible price output.

Technology enters the model through the production function. Given that the only variables in the production function in the closed economy are technology (which is not a choice variable) and labour, technology assumes a more significant role in the production function compared to the basic open economy model. This is particularly clear in the flexible price output equations for the closed model (which is ultimately only a function of technology) and the basic model (which is also a function of the real exchange rate):

$$
\text { Closed economy } \quad \hat{Y}_{t}^{\text {flex }}=\frac{1}{1-(1-\alpha)(1-L)} \hat{A}_{t}
$$

Basic model $\quad \hat{Y}_{t}^{f l e x}=\frac{(1-\alpha)\left(\frac{A L}{Y}\right)^{\gamma} \frac{1+\tau}{1-\gamma+\tau}}{(1-\alpha)\left(\frac{A L}{Y}\right)^{\gamma}-\frac{(1-\gamma)}{1-\gamma+\tau}} \hat{A}_{t}-\frac{\alpha(I M / Y)^{\gamma}}{(1-\gamma)\left[(1-\alpha)\left(\frac{A L}{Y}\right)^{\gamma}-\frac{(1-\gamma)}{1-\gamma+\tau}\right]} \hat{R S_{t}}$

where $\tau=\frac{L}{1-L}$.

Whereas in the basic model the real exchange rate affects the cost of imports and thus also the maximising behaviour of producers, there is no such effect in the closed economy model. The difference in the underlying production function means direct comparisons should be made with care. In addition, Equations (2.12.1) and (2.12.2) highlight the the real exchange rate channel through which a technology shock affects the basic model but not the closed version.

Although in the basic model the reduction in the real interest rate results in a depreciation of the real exchange rate in the shock period, this is not sufficient to overcome the effect of the technology shock on flexible price output. As a result the technology shock generates an even larger negative output gap in the basic model and via the monetary policy reaction rule, elicits a decline in the nominal and real interest rates relative to the closed economy model. 
Consumption by PIH consumers thus rises more in the basic model, requiring a higher wage response and thus driving ROT consumption higher as well. The unambiguously higher consumption in turn drives up the relative price of rental (given the initially fixed stock of housing) and drives down the relative price consumption goods. The ratio of the house price to the consumption good price is thus driven higher. Investment rises in response. Given the rise in the return on housing and stronger investment, a positive house price response would also follow. ${ }^{6}$

Whereas an interest rate shock response is more easily compared across model types, the responses to a technology shock are highly dependent on the differences in their respective production functions. That aside, the comparison with the closed economy shows that the response of an open economy may be significantly different from those suggested by a closed economy model.

${ }^{6} \mathrm{~A}$ decline in the house price would move away from the equilibrium condition of (2.9.16), requiring an even higher relative price of rental and thus leading to a non-feasible explosive outcome. 
Figure 2.2: Response to a $1 \%$ technology shock, basic model and closed economy
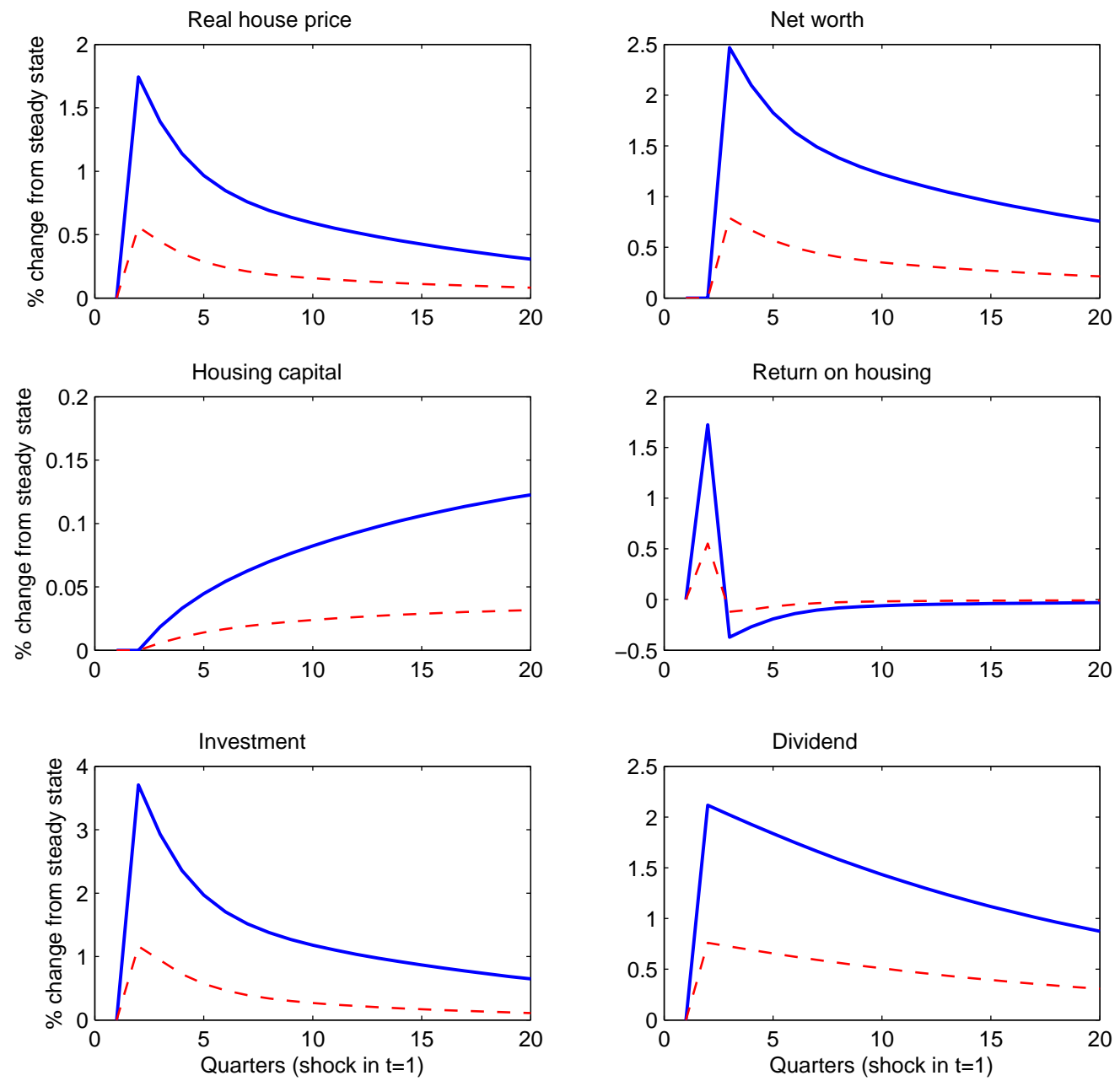

Basic model - - - Closed model 
Figure 2.2: Response to a $1 \%$ technology shock, basic model and closed economy (continued)
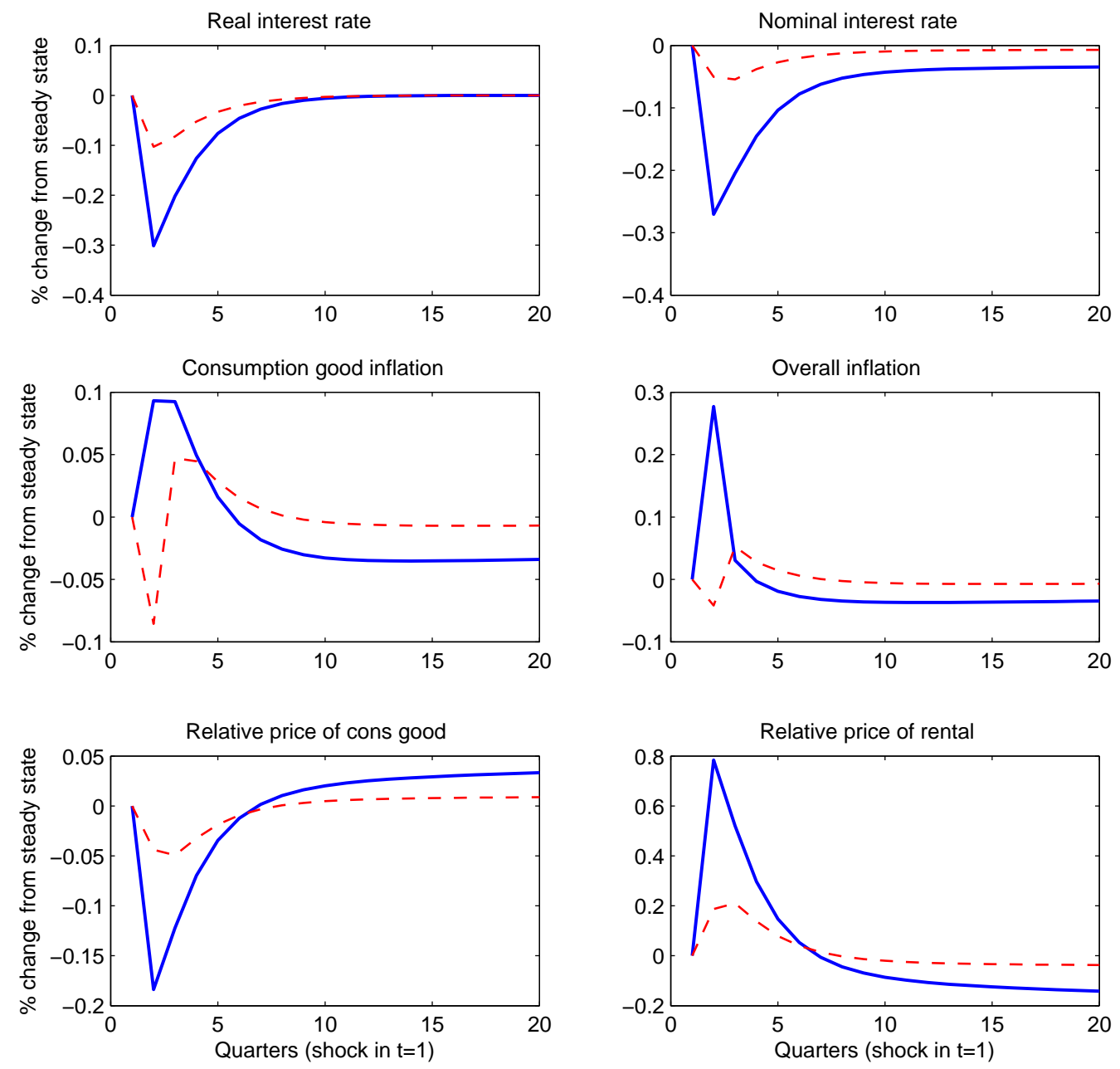

Basic model --- Closed model 
Figure 2.2: Response to a $1 \%$ technology shock, basic model and closed economy (continued)
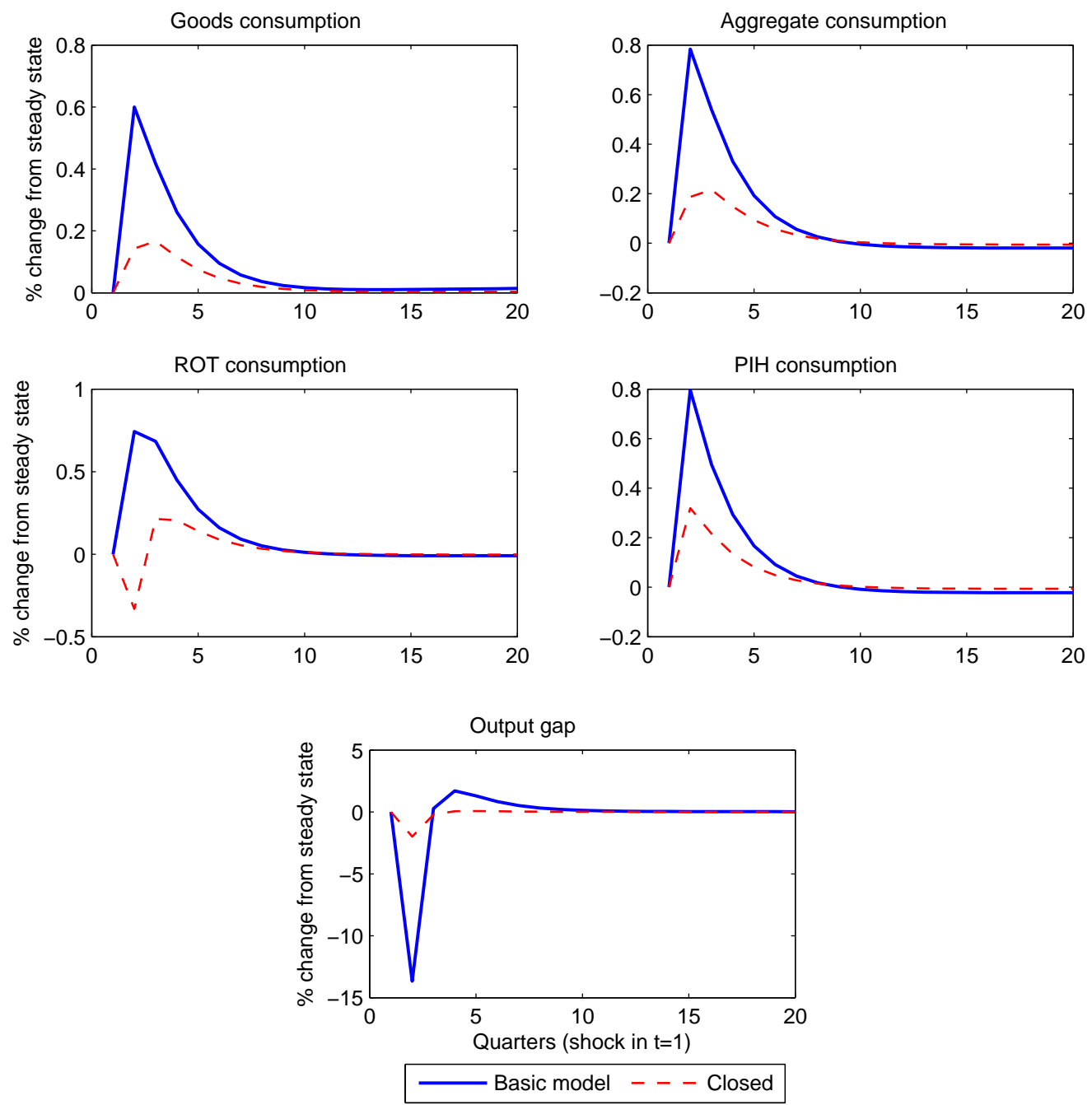
Figure 2.2: Response to a $1 \%$ technology shock, basic model and closed economy (continued)
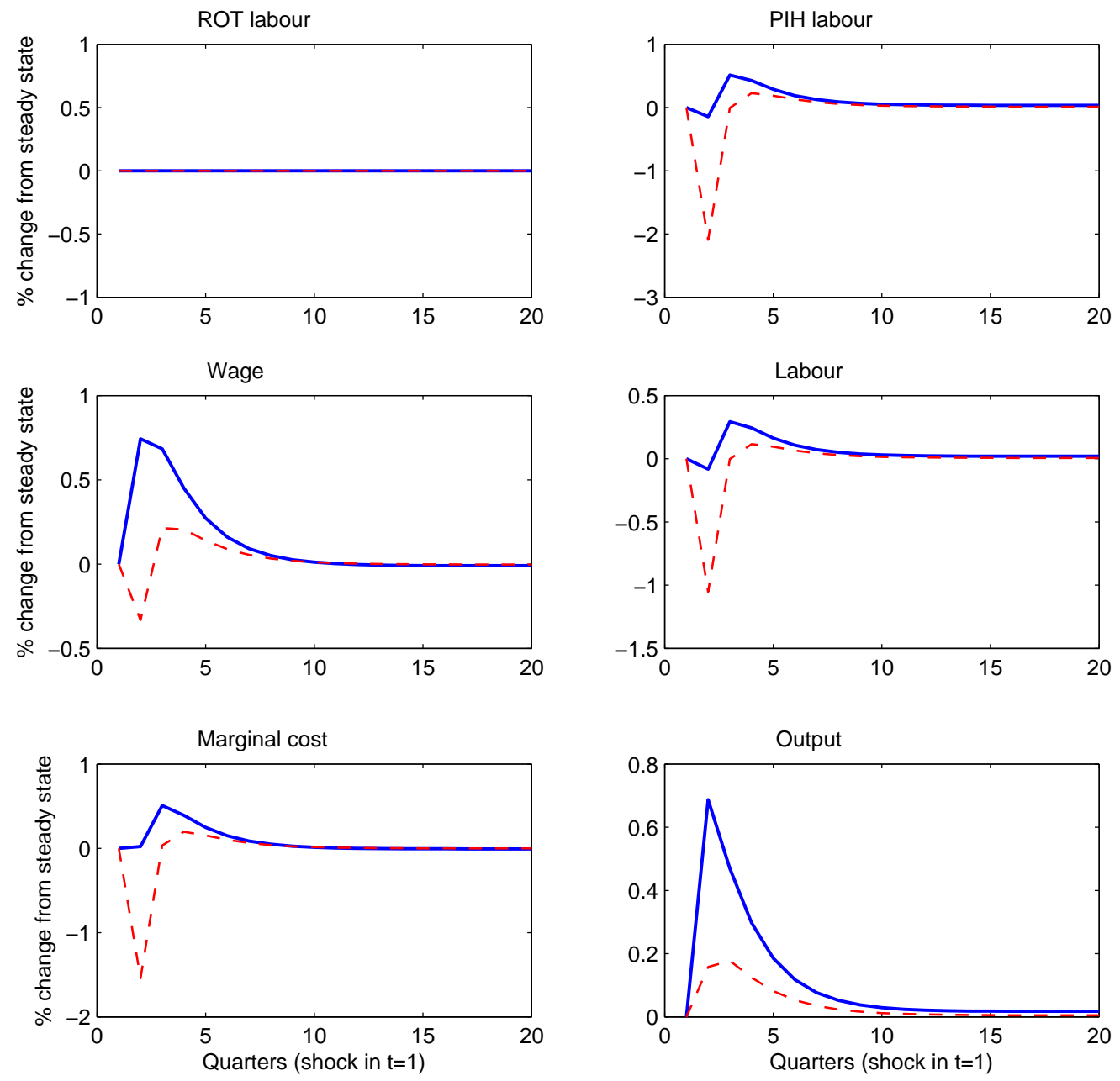

Basic model --- Closed model 
Relative to the closed economy model, the responses of the basic economy to the two shocks are summarised in Table 2.3.

\begin{tabular}{|l|cc|}
\hline Sector & Interest rate shock & Technology shock \\
\hline Housing & Smaller & Larger \\
Consumption \& Output & Smaller & Larger \\
\hline
\end{tabular}

Table 2.3: Basic model response relative to closed model, technology and interest rate shocks

\subsection{Impact of the financial accelerator}

The effect of incorporating a financial accelerator is examined by comparing the impulse response functions derived from two models. In the model with no financial accelerator the steady state mortgage interest rate faced by homeowners (and thence the return on housing) is delinked from their net worth ratio. This is done by way of two adjustments to the basic open economy model. First, the steady state premium is set to zero (i.e. in terms of Equation 2.11.2, $f\left(\frac{N}{q h}\right)=1$ ), as discussed in subsection 2.13.2. This in itself has relatively little impact as the model is specified in dynamic terms. The second, and arguably more important modification, is to set the responsiveness of the mortgage debt interest rate (which is equal to the return on housing) to the net worth ratio to zero $(\Omega=0$ in Equations 2.9.15 and 2.9.17) and is discussed in subsection 2.13.3.

The steady state for the model with the financial accelerator switched off varies slightly from the basic model (see Table 2.2). In particular, a higher real house price is necessary to ensure the net worth-housing value ratio is 0.7. As a result, net worth is higher. The dividend is lower as this is determined by both net worth and the return on housing, the latter of which is equal to the real interest rate when $f(\phi)=1$. In fact, the higher real house price is offset by the lower return on housing and as a result the relative price of rental is the same whether or not the financial accelerator is switched off. This, combined with the holding of the housing stock constant means that aggregate consumption is unchanged. It then follows that goods consumption, investment, output, the wage rate and the dissaggregation of consumption and labour across consumer types are all the same. 


\subsubsection{Monetary policy shock}

Figure 2.3 compares the impulse responses of the basic model model with the responses of the model with the financial accelerator switched off to an interest rate shock in the form of a 25 basis point cut to the nominal interest rate. Unsurprisingly, the most significant differences relate to the housing market. In general, the presence of the financial accelerator gives rise to a larger housing market reaction to the interest rate shock.

Figure 2.3: Response to a $-0.25 \%$ nominal interest rate shock, basic model with and without the financial accelerator
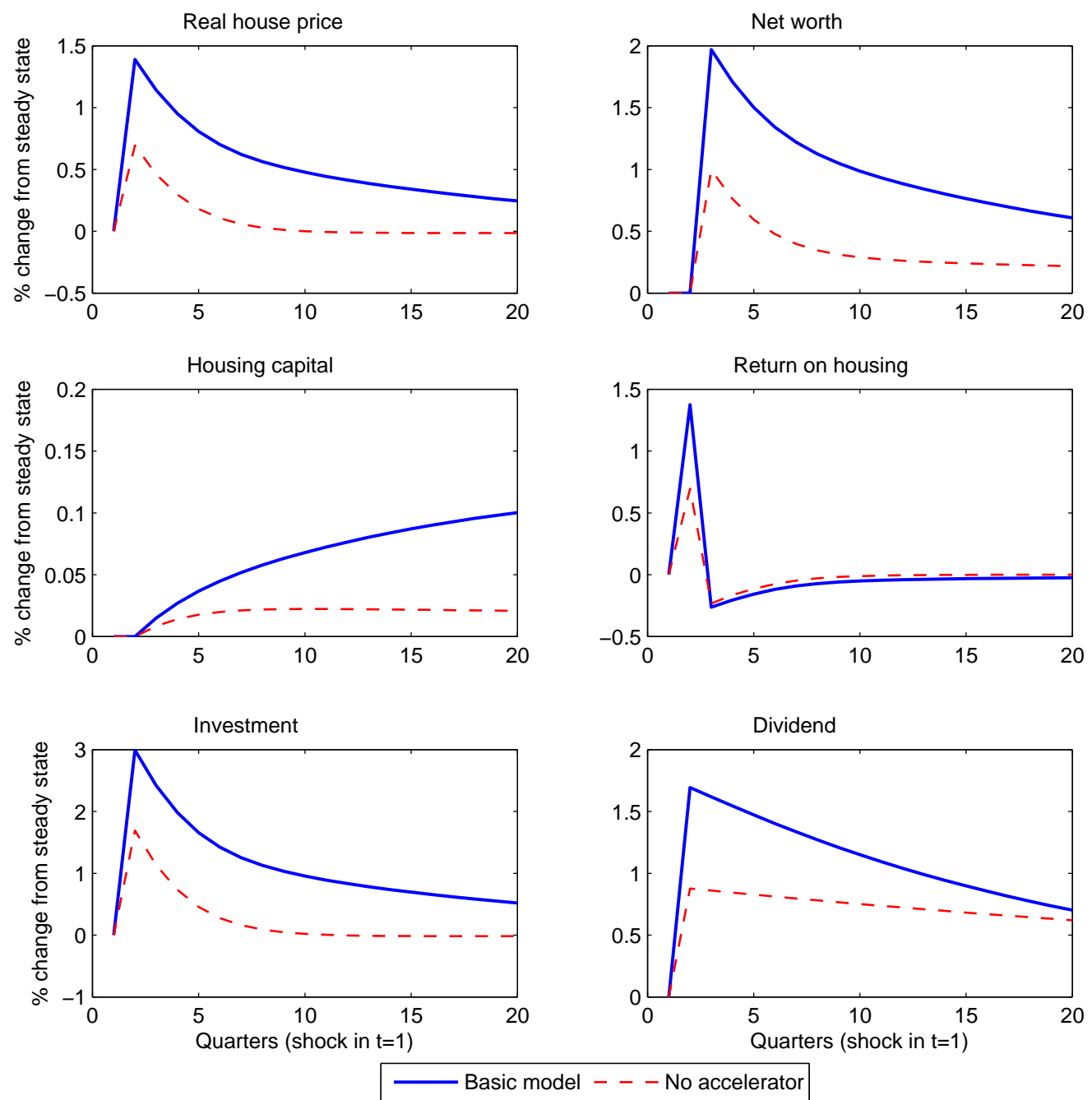
Figure 2.3: Response to a $-0.25 \%$ nominal interest rate shock, basic model with and without the financial accelerator (continued)
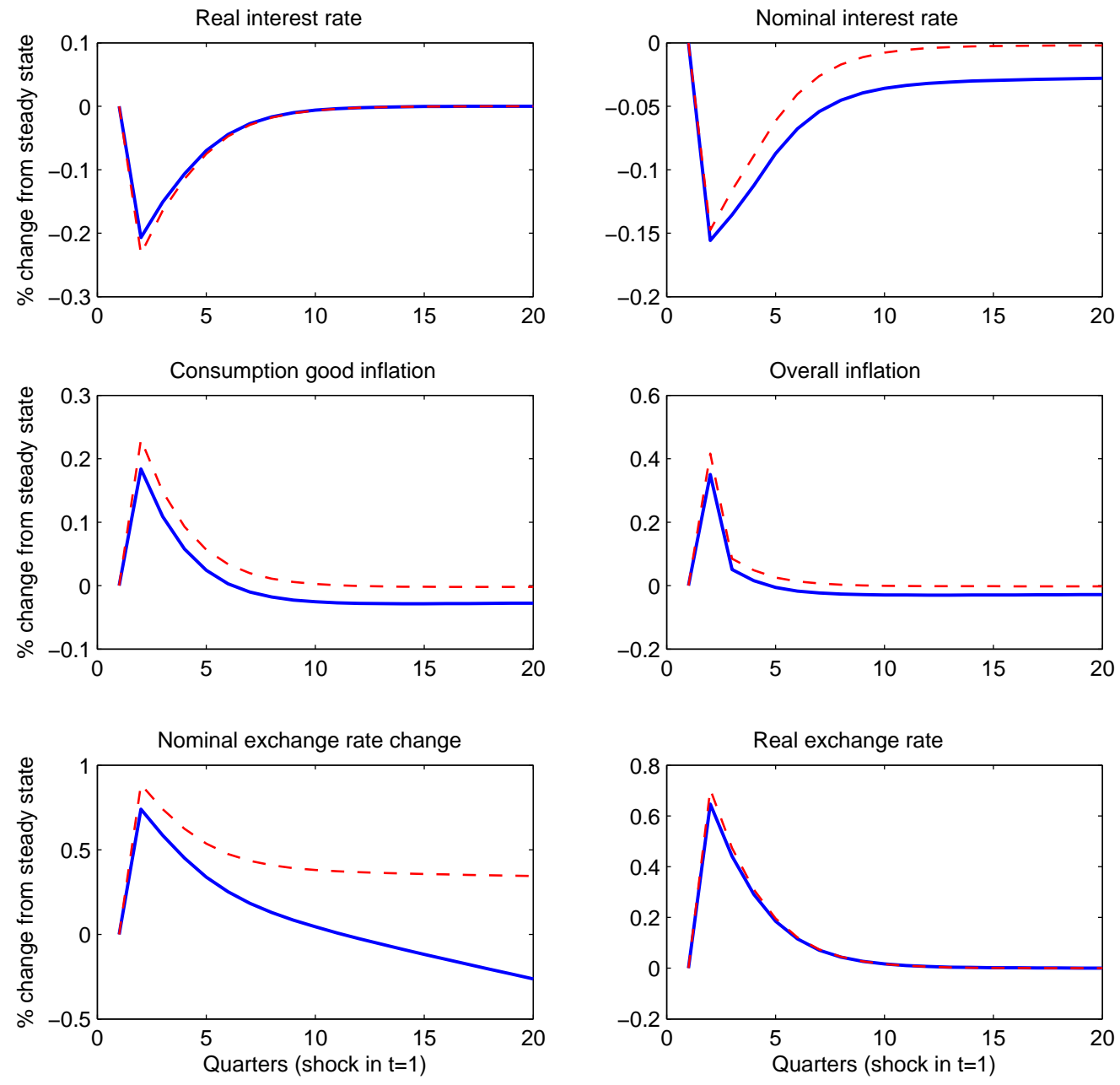

Basic model --- No accelerator 
Figure 2.3: Response to a $-0.25 \%$ nominal interest rate shock, basic model with and without the financial accelerator (continued)
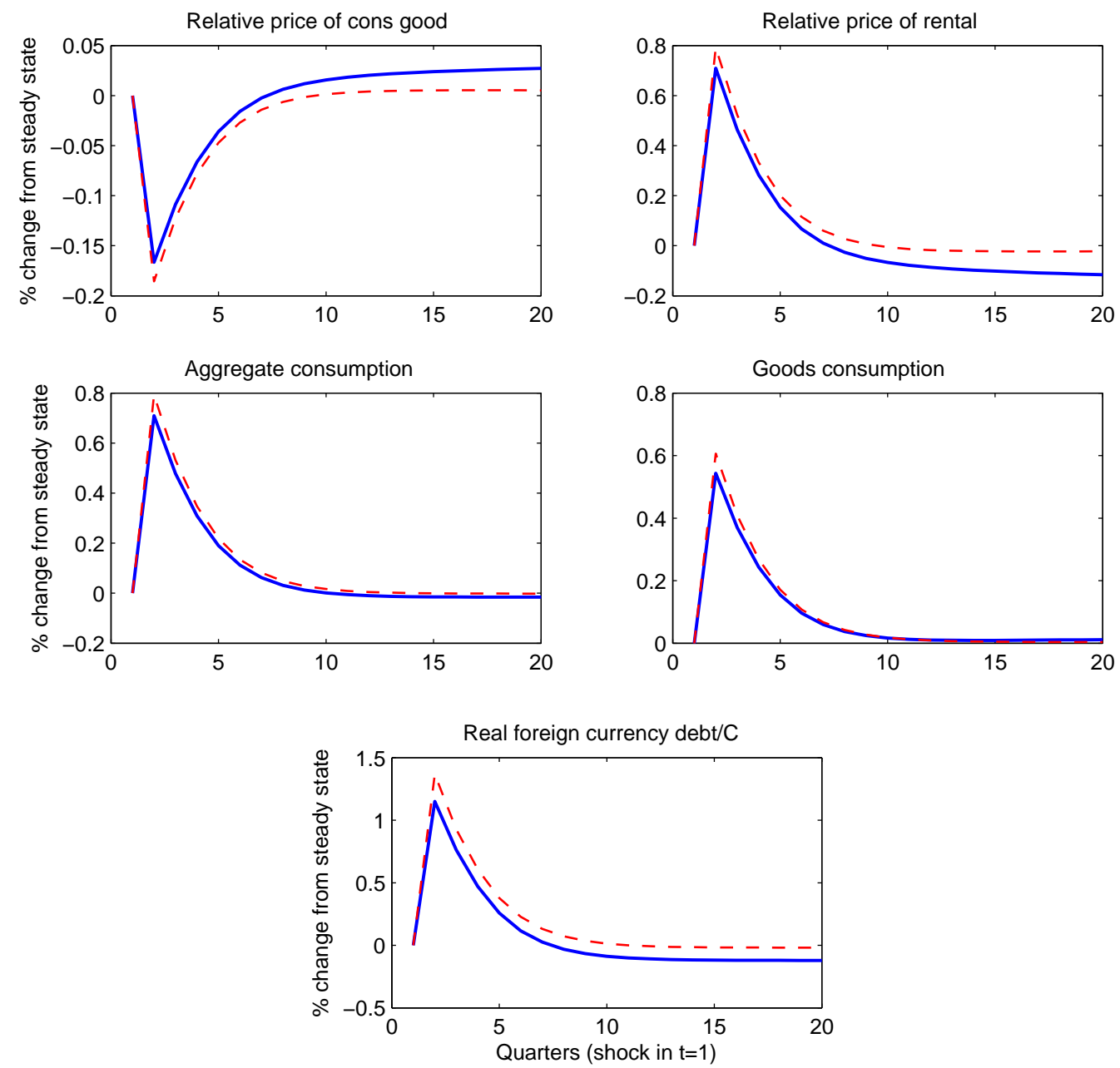

- Basic model - - - No accelerator 
Figure 2.3: Response to a $-0.25 \%$ nominal interest rate shock, basic model with and without the financial accelerator (continued)
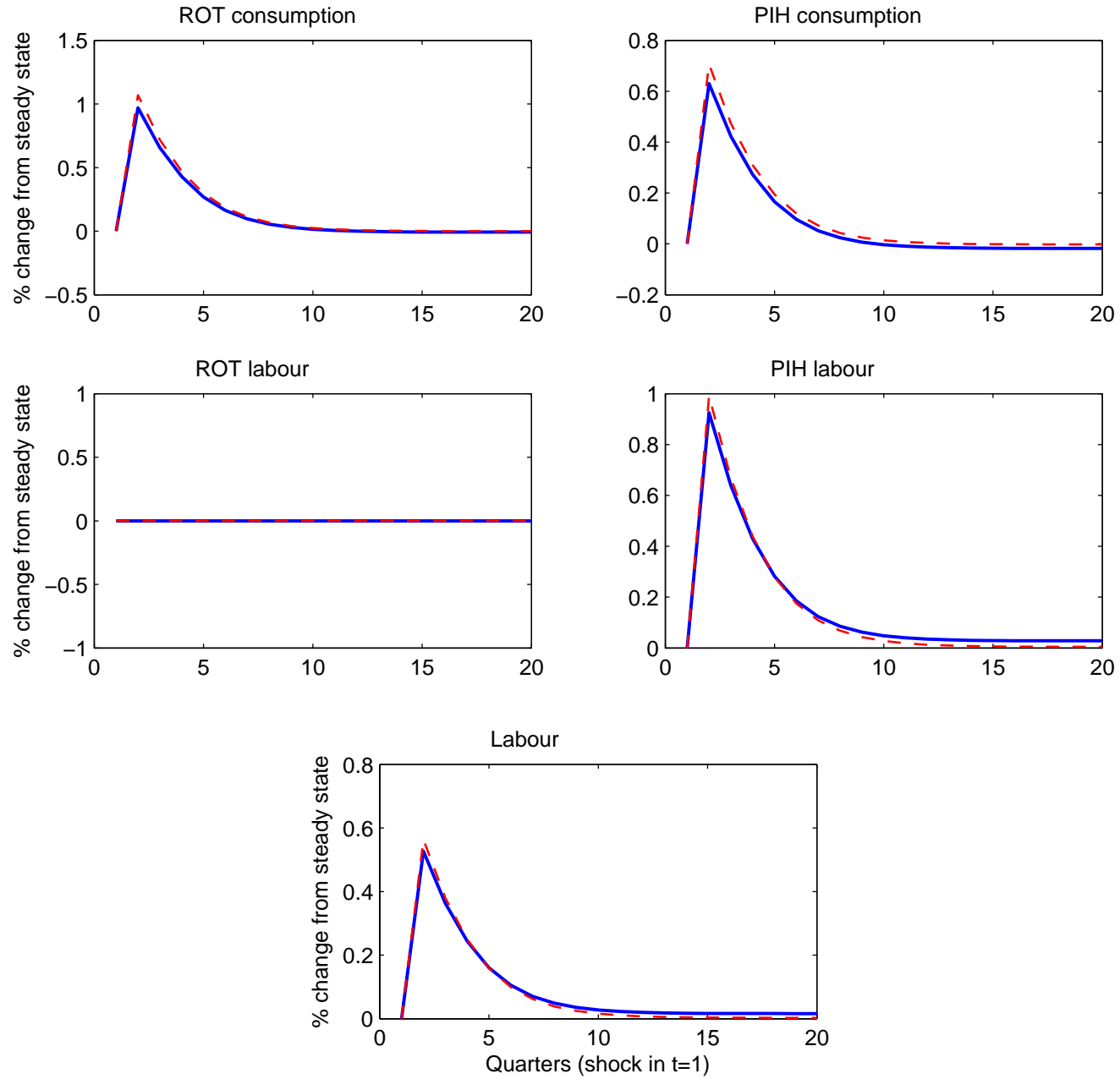

- Basic model - - - No accelerator 
Figure 2.3: Response to a $-0.25 \%$ nominal interest rate shock, basic model with and without the financial accelerator (continued)
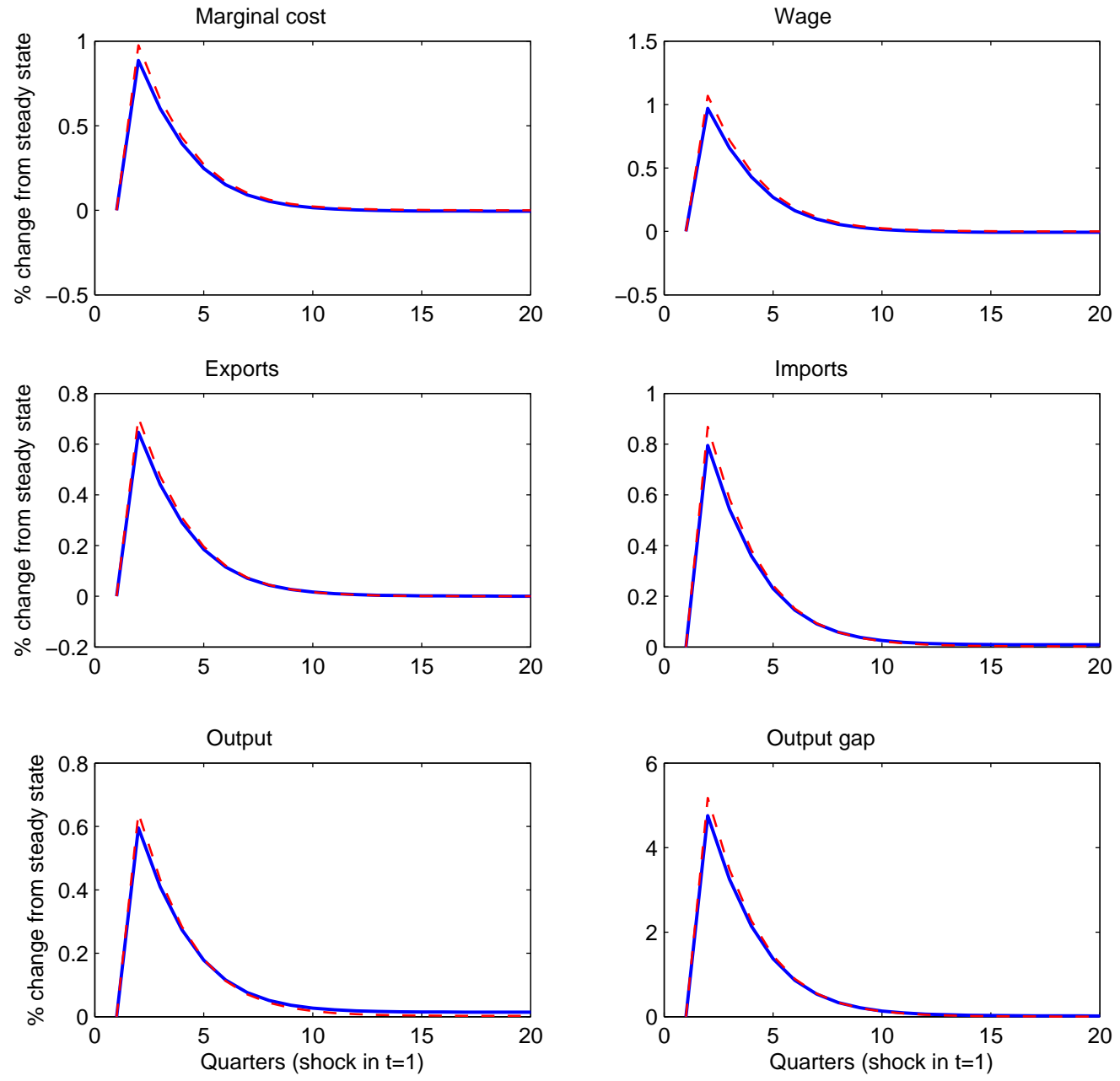

Basic model --- No accelerator 


\subsubsection{Setting the premium to zero}

The steady state premium for the interest rate faced by homeowners in the basic open economy model is set to 260 basis points on a per annum basis. In order to remove this impact of this, I set the premium to zero (i.e. setting $f\left(\frac{N_{t+1}}{q_{t} h_{t+1}}\right)=1$ in Equation 2.4.10) in the model with no financial accelerator. ${ }^{7}$ This reduces the steady state return required by homeowners. As a result, the steady state quantum of housing (and thus both rental supply and rental demand) must be higher in the model with no premium. This highlights the frictional nature of the financial accelerator in that while it may reinforce the impact of various shocks, it also acts as an imperfection in the housing market.

For completeness sake, I note that the reduction in the steady state return on housing also impacts on the evolution of net worth. However, it is also worth noting that although this serves to dampen the response of net worth to its various determinants, this is not the dominant effect in comparing the behaviour of net worth across models.

\subsubsection{Setting the responsiveness of the return on housing to zero}

Equation (2.4.10) sets out the relationship between the expected return on housing (equivalent in equilibrium to the interest rate charged on mortgages), net worth and the real interest rate. This represents the key financial accelerator mechanism, explicitly linking the mortgage interest rate to the homeowner's net worth ratio. By setting $\Omega=\frac{f^{\prime}(\phi)}{f(\phi)} \phi$ to zero in the log-linear model, this mechanism is removed.

The impact of the financial accelerator is most evident in the housing market variables. Using an expansionary monetary policy shock (i.e. an unexpected reduction in the nominal interest rate), the basic model displays significantly greater response in terms of the reactions of the real house price, investment, housing capital and net worth compared to the model with no financial accelerator. The return on housing (equivalent to the mortgage rate) does react more strongly initially but unlike the other housing market variables the responses with and without the financial accel-

\footnotetext{
${ }^{7}$ Although a model with no financial accelerator may still incorporate a constant premium for mortgage interest rates above the interest rate, this raises the question of how the existence of a (fixed) premium can be justified while at the same time it is invariant to the borrower's net worth.
} 
rator converge quickly.

Following the stronger house price and net worth reaction, the initial dividend response will also be stronger in the presence of the financial accelerator. It is worth noting that when the financial accelerator is switched off, the dividend declines in a relatively linear fashion after its initial jump in the shock period. In contrast under the basic model the dividend declines more rapidly as the net worth ratio moderates and thus unwinds the additional stimulus provided by the compressed finance premium.

The increase in the return on housing in the shock period is the result of both an increase in real house prices as well as the current relative price of rental services. Given that the corollary to the latter is a lower relative consumption goods price, Equation (2.5.1) requires that the impact on investment is an unambiguous increase. In effect, real house prices rise faster than goods inflation resulting in an increase in investment.

Contrary to APV, however, I find that consumption becomes more sensitive to an interest rate shock in the absence of a financial accelerator. While it is true that the presence of $\Omega$ jointly with a positive steady state premium is the result of informational imperfections (i.e. the inability of lenders to costlessly monitor borrowers), their setting to zero should not be automatically read as if this inefficiency were removed. Indeed, as an alternative version of the model (responses available upon request), I allow the steady state premium to remain at $2.6 \%$ but set $\Omega$ to zero. Thus the informational asymmetry persists but does not change with shifting perceptions of risk. The impulse responses are practically identical to those given when both the premium and $\Omega$ are set to zero, suggesting that the main driver here is $\Omega$, not the steady state premium. The somewhat counter-intuitive result (i.e. increasing the premium sensitivity to net worth reduces the consumption response) stems from the separation of the net worth position from the consumer aspect of the household. Whereas APV had allowed ROT consumers to benefit from increasing net worth, I remove this effect.

The presence of a financial accelerator allows for a greater impact on the housing sector. With a larger impact on house prices, this effectively draws more resources into the housing sector (investment is higher in the basic model). Given the larger re- 
sultant housing stock under the model with a financial accelerator, there is tendency for the relative price of rental to decline for longer (the corollary to which is that the relative price of the consumption good will tend to rise for longer). The net impact of this is to lower the inflation path and increase the real interest rate path relative to the model without the financial accelerator. In turn, the higher real interest rate response reduces consumption on the part of the PIH consumers. This in turn reduces the need for labour services on the part of firms and thus wage reductions are experienced by both PIH and ROT households, reinforcing the consumption decline.

This phenomenon may also be explained in a more mechanical way. When an expansionary monetary policy shock occurs it boosts the housing market (initially through increased demand for housing services which only adjust with a lag). The improvement in the net worth ratio leads to a reduction in the premium. Given that homeowners equate returns on housing to the cost, the reduced premium means that homeowners come to expect a further reduction in the return on housing. This requires that either (relative) rental or house prices are expected to be lower than otherwise. Given that the housing market has been boosted by the shock, the effect is more likely to come in the form of reduced rental as investment in housing adds to the stock. If relative rentals are lower than previously anticipated, the relative price of consumption goods must be higher (by definition). The net effect is a reduction in expected inflation compared to when there is no accelerator and this in turn implies a higher real interest rate and less consumption.

\subsubsection{Technology and other shocks - comparison of basic model with model without financial accelerator}

The responses of the model without the financial accelerator and the basic model to shocks to technology, the foreign real interest rate and foreign demand are shown in Appendix A.

Following a technology shock, as with the monetary policy shock, most of the real economy variables display similar behaviour whether or not the financial accelerator is switched on or not. Where there are noticeable differences in the impulse response functions (IRF) between the basic model and the model with the financial accelerator switched off, a similar explanation to that in the context of the monetary policy 
shock effect is possible. In particular, the higher net worth response under the basic model allows for higher real house prices and a greater deviation away from the steady state housing capital (both in terms of the shock period and in subsequent periods).

Both the foreign interest rate and foreign demand shocks show a high degree of similarity between the impulse responses with and without the finanical accelerator when considering the non-housing market variables. As with the interest rate and technology shocks, housing market variables exhibit a noticeable divergence between the two model variants. In particular, real house prices, net worth (at least initially) and the stock of housing show greater sensitivity to the shocks when the financial accelerator is switched on.

\subsubsection{Role of ROT consumers}

ROT consumers are often included in models in order capture consumer behaviour that is generally apparent in empirical data but cannot be explained by models based on Ricardian only behaviour. In effect, the ROT consumers allow for an increased consumption response to current income that would not be present with PIH-only consumers. In the model used by APV the ROT consumer budget constraint includes a dividend from homeowners to consumers, allowing consumption and labour supply of ROT consumers to respond to the housing market. As noted by Galí et al. (2004), ROT consumers provide a fixed supply of labour when their income is based solely on wages. There is a strong theoretical objection to allowing ROT consumers to deviate from the behaviour posited by Galí et al. (2004). Not only does this raise the issue of effectively giving ROT consumers an endowment of housing which they would have never been able to obtain, it also affects the dynamics of the model by making ROT consumer behaviour sensitive to the dividend-wage ratio.

Under the APV approach where ROT consumers receive dividends from homeowners, combining ROT consumers' first order conditions with regard to leisure and the 
fixed expenditure rule yields

$$
\begin{aligned}
\frac{w_{t}}{\xi}\left(1-L_{t}^{r}\right) & =w_{t} L_{t}^{r}+D_{t} \\
\Rightarrow L_{t}^{r}\left[w_{t}\left(\frac{1}{\xi}+1\right)\right] & =\frac{w_{t}}{\xi}+D_{t} \\
L_{t}^{r}\left(\frac{1+\xi}{\xi}\right) & =\frac{1}{\xi}-\frac{D_{t}}{w_{t}} \\
L_{t}^{r} & =\frac{1}{1+\xi}-\frac{\xi}{1+\xi} \frac{D_{t}}{w_{t}}
\end{aligned}
$$

The second term here is the dividend wedge. The dividend represents income that is not earnt through labour and thus enables the ROT consumers to reduce the amount of labour provided but still enjoy the same level of consumption. Thus the APV result with regard to $L_{t}^{r}$ depends on the behaviour of the dividend which is in turn driven by the net worth ratio. This generates an inconsistency in the logic behind ROT consumers. Even though they do not save, nor can they access the debt market to fund borrowing to smooth consumption, they are somehow able to access the mortgage market. Although this produces a richer dynamic response, the theoretical foundations are questionable. In order to avoid this inconsistency, this thesis makes ROT consumption dependent only on current income (and taxes in the fiscal model, see Chapter 3). Thus ROT consumers do not benefit from a higher dividend. In contrast, PIH consumers, while they receive the higher dividend, do not change their consumption behaviour on the basis that the shock is seen as temporary.

In order to explore whether the proportion of ROT consumers affect the model responses, I compare three alternate versions of the model with each version having a different value for $n$ of $0.31,0.70$ and 0.99 , respectively. The possible range of values that may be taken by $n$ does not encompass the full $[0,1]$ range. This is due to the assumption that consumers will, in aggregate, provide one-third of their time as labour to firms in the steady state. Once $n$ drops below approximately 0.31 , PIH consumer labour supply hits a corner solution and the aggregate steady state labour assumption cannot hold (as this requires a negative supply of labour by PIH households, $n<0.31$ is deemed unfeasible).

Table (2.4) compares selected initial responses of the model under different values for the proportion of consumers that are PIH with the basic model with the financial accelerator either switched on or off. 
The pattern of initial responses to an expansionary interest rate shock are similar across different values of $n$. The difference columns shows the extent to which the variable response differs depending upon whether the financial accelerator is swiched on or not. These differences change little when the the value of $n$ is set to a minumum of $0.31,0.7$ and 0.99 . This indicates that the initial dynamics of the model are robust to the assumed proportion of ROT consumers.

\begin{tabular}{|c|c|c|c|c|c|c|c|c|c|}
\hline & \multicolumn{3}{|c|}{$n=0.31$} & \multicolumn{3}{|c|}{$n=0.7$} & \multicolumn{3}{|c|}{$n=0.99$} \\
\hline Variable & $\begin{array}{l}\text { Basic } \\
\text { model }\end{array}$ & No FA & Diff. & $\begin{array}{l}\text { Basic } \\
\text { model }\end{array}$ & No FA & Diff. & $\begin{array}{l}\text { Basic } \\
\text { model }\end{array}$ & No FA & Diff. \\
\hline Real house price & 1.425 & 0.677 & 0.748 & 1.390 & 0.694 & 0.695 & 1.377 & 0.699 & 0.679 \\
\hline Net worth* & 2.026 & 0.977 & 1.050 & 1.969 & 0.995 & 0.974 & 1.950 & 1.000 & 0.950 \\
\hline Housing capital ${ }^{*}$ & 0.016 & 0.009 & 0.007 & 0.015 & 0.008 & 0.007 & 0.015 & 0.008 & 0.006 \\
\hline Investment & 3.176 & 1.777 & 1.398 & 2.993 & 1.692 & 1.300 & 2.936 & 1.666 & 1.269 \\
\hline Real interest rate & -0.215 & -0.236 & 0.021 & -0.207 & -0.233 & 0.026 & -0.204 & -0.231 & 0.027 \\
\hline Aggregate consumption & 0.964 & 1.053 & -0.090 & 0.710 & 0.792 & -0.082 & 0.636 & 0.715 & -0.079 \\
\hline Output & 0.740 & 0.786 & -0.047 & 0.596 & 0.642 & -0.047 & 0.554 & 0.600 & -0.046 \\
\hline Goods consumption & 0.738 & 0.806 & -0.069 & 0.543 & 0.606 & -0.063 & 0.487 & 0.547 & -0.060 \\
\hline
\end{tabular}

Table 2.4: Comparison of shock period response, financial accelerator on and off with differing values of $n,-25$ basis point nominal interest rate shock

\subsubsection{Concluding remarks}

The basic model displays more muted responses to a nominal interest rate shock, the result of a depreciation in the real exchange rate prompting an offsetting reaction by the monetary authority. A similar effect is present following a technology shock but the difference in the production functions between the closed economy model and the basic open economy model means drawing conclusions must be done with a degree of caution.

The significant difference between the closed economy model and the basic (open) economy model illustrates the importance of the open economy variables given the impact they have on the impulse response functions. In particular, the real exchange rate has a significant effect on the output gap.

The introduction of the financial accelerator has a different effect on the model depending on the the shock type. While the model responses are more muted following a nominal interest rate shock, the responses are stronger for shocks to technology, 
the foreign real interest rate and foreign demand. The interest rate shock response is in contrast to the results obtained by APV in which consumption was initially higher when the financial accelerator is switched on. While in part this result may be due to the introduction of open economy variables, the key difference is that an internally consistent allocation of the housing endowment (to PIH households only) results in a negative financial accelerator effect.

The results from varying the proportion of PIH consumers suggest that the influence of the financial accelerator is not significantly affected by the extent to which consumers are credit constrained. Under the baseline scenario where $70 \%$ of consumers are assumed to behave in a Ricardian manner, the impact of the financial accelerator on the response of non-housing variables is relatively unchanged compared to when $31 \%$ or $99 \%$ of consumers are Ricardian.

The basic model set out out in this chapter is extended further in Chapter 3 to include an explicit fiscal sector to examine how consumer behaviour and the housing market are affected by fiscal expenditure and (lump-sum) taxes. 



\section{Chapter 3}

\section{The fiscal model}

\subsection{Introduction}

I now extend the basic model by including a specific fiscal authority, hereinafter referred to as "government". Intuitively, one would expect that the stimulatory effect of government spending on the economy would naturally increase the level of economic activity, at least in the immediate period of the shock. However, this ignores the need to fund the spending and the role of taxes (whether current or future) in determining consumer spending. Mankiw's (2000) seminal discussion of fiscal policy in the context of different types of consumers ("savers and spenders") is particularly relevant. As noted by Galí, Vallés and López-Salido (2007), discerning the impact of fiscal policy on consumption is dependent on the (implicit or explicit) nature of the model used to analyse the economy. Indeed, using the RBC - IS-LM contrast of Galí et al. (2007), the RBC model would suggest a negative effect of government spending on the housing market (given that the rise in expected taxes reduces the present value of after-tax income and thus reduces consumption on goods and housing) while the IS-LM model would suggest a positive impact on consumption and house prices. ${ }^{1}$ As in the basic model, the fiscal model includes a proportion of consumers who are credit constrained (in terms of being able to borrow to fund current consumption). This combination allows for an element of non-Ricardian behaviour to influence both consumption and house prices.

\footnotetext{
${ }^{1}$ While the standard IS-LM result is for an ambiguous effect on physical capital (output rises and the income flow from the capital also rises, offset by an increase in the interest rate), the nature of the housing market is fundamentally different to productive capital stock. While a higher (real) interest rate would tend to reduce consumption (and thence demand for housing services) it is the present value of expected future income (net of taxes) that drives consumption and hence demand for housing.
} 
The introduction of the fiscal sector has a negligible effect on the behaviour of the model when responding to non-fiscal shocks. This is because the inclusion of the fiscal variables requires only changes to a small number of steady state values but will otherwise not influence the dynamics for non-fiscal shocks given the simple manner in which both government spending and taxes are modelled. I compare various settings for $n$ and find little difference in the impulse responses across shock types.

I examine the impact of fiscal policy on the housing sector by implementing a $1 \%$ shock to government expenditure. The impact on the housing market is unambiguously negative, in line with the $\mathrm{RBC}$ responses noted above, but the magnitude is relatively small. I then examine the extent to which this result is sensitive to the proportion of consumers who are credit-constrained. A larger proportion of ROT consumers results in a more pronounced negative impact on the housing market.

\subsection{Additional fiscal equations}

The government collects lump sum taxes from consumers and purchases consumer goods. The difference between these two is either funded through the sale of government bonds or, where taxes exceed expenditure, is used to retire debt. For simplicity government expenditure does not impact households directly (typically done in the literature in the form of a transfer) but rather is a source of final demand for consumer goods (and thence labour demand and imports). Following Galí et al. (2007), fiscal policy is modelled as the combination of exogenous government spending $\left(G_{t}\right)$, government debt $\left(B_{t}^{G}\right)$ and lump-sum taxes $\left(T_{t}\right)$ (all in real terms).

The model uses a lump-sum form of taxation. An alternative approach used in DSGE models is for taxes to be levied on income, e.g. Claus (2005), and would likely provide different dynamics given that ROT consumers' labour supply would be less sensitive to the wage rate (see equation 3.2.6) and fiscal shocks that affect after-tax income (for example, where taxation is in the form of an income tax) also affect demand for housing. Although not applicable to the current New Zealand tax regime, taxation of property may also impact on the behaviour of homeowners 
(i.e. PIH consumers). Neither taxes nor government spending contain automatic stabiliser elements and are thus unaffected by output.

$R_{t+1}^{-1} B_{t+1}^{G}$ represents the quantum of funds borrowed in period $t$ with $B_{t+1}^{G}$ repaid in period $t+1$. Hence the government budget constraint may be written:

$$
T_{t}+R_{t+1}^{-1} B_{t+1}^{G}=B_{t}^{G}+G_{t}
$$

A fiscal rule is also assumed that determines how government purchases are funded, either via debt or taxation.

$$
\frac{T_{t}-T}{T} \frac{T}{Y}=\phi_{B} \frac{B_{t}^{G}}{Y}+\phi_{G} \frac{G_{t}-G}{G} \frac{G}{Y}
$$

where $\phi_{B}$ and $\phi_{G}$ determine how fiscal imbalances are funded or distributed, and $B^{G}$, the steady state government debt level, is assumed to be zero. The fiscal rule embodies a stability condition so that debt financing does not explode.

In addition to the fiscal equations the inclusion of a fiscal component to the model alters a number of other equations. In particular, ROT consumer utility maximisation is subject to the following constraint:

$$
C_{t}^{r}=w_{t} L_{t}^{r}-(1-n) T_{t}
$$

Thus compared to the basic model counterpart of (2.4.4), there is an additional term $-(1-n) T_{t}$ that represents the ROT consumers' share of the lump sum tax to be paid.

The introduction of taxes creates a wedge between the fixed supply of labour that would normally entail with ROT consumers and the supply of labour in the fiscal model. This wedge stems directly from the fact that ROT consumers supply labour over and above the level that would be supplied in the absence of a tax.

As Galí et al. (2007) note, aggregate consumption in the absence of a tax can be derived in a fashion similar to that used for the basic model first order conditions, so that:

$$
C_{t}=\frac{w_{t}}{\xi}\left(1-L_{t}\right)
$$

As shown in Appendix D, ROT consumers labour supply in the fiscal model contrasts 
with the basic model equivalent of Equation (2.4.5) in that

$$
L_{t}^{r}=\frac{1}{1+\xi}+\frac{\xi}{w_{t}}(1-n) T_{t}
$$

Comparing this with Equation (2.4.5), the fiscal model tax wedge with regard to labour supply represents the need to work additional hours in order to pay the lumpsum tax obligations.

Combining (3.2.3) and (3.2.4) with the first order condition for PIH consumers in the identity for aggregate consumption gives

$$
C_{t}=(1-n)\left(w_{t} L_{t}^{r}-(1-n) T_{t}\right)+n \frac{w_{t}}{\xi}\left(1-L_{t}^{p}\right)
$$

Adopting Galí et al.'s (2007) terminology, I define $\lambda=(1-n)=$ the proportion consumers who are ROT.

$$
\begin{aligned}
C_{t} & =\lambda\left(w_{t} L_{t}^{r}-\lambda T_{t}\right)+(1-\lambda) \frac{w_{t}}{\xi}\left(1-L_{t}^{p}\right) \\
& =\frac{\lambda w_{t}}{1+\xi}+\lambda \xi \lambda T_{t}-\lambda^{2} T_{t}+\frac{w_{t}}{\xi}(1-\lambda)-\frac{w_{t}}{\xi}(1-\lambda) L_{t}^{p} \\
& =\frac{w_{t}}{\xi}\left\{\frac{\lambda \xi}{1+\xi}+\frac{\xi}{w_{t}} \xi \lambda^{2} T_{t}-\lambda \frac{\xi}{w_{t}} \lambda T_{t}+1-\lambda-(1-\lambda) L_{t}^{p}\right\} \\
& =\xi \lambda^{2} T_{t}+\frac{w_{t}}{\xi}\left\{1+\frac{\lambda \xi}{1+\xi}-\frac{\lambda(1+\xi)}{1+\xi}-\lambda \frac{\xi}{w_{t}} \lambda T_{t}-(1-\lambda) L_{t}^{p}\right\} \\
& =\xi \lambda^{2} T_{t}+\frac{w_{t}}{\xi}\left\{1-\left(\lambda L_{t}^{r}+(1-\lambda) L_{t}^{p}\right)\right\} \\
& =\xi \lambda^{2} T_{t}+\frac{w_{t}}{\xi}\left(1-L_{t}\right)
\end{aligned}
$$

It can be seen that the first term $\left(\xi \lambda^{2} T_{t}\right)$ is directly a result of the need to work extra time to pay for the tax. Hence, the lump sum tax drives a wedge $\left(\xi(1-n)^{2} T_{t}\right)$ between the usual consumption expression, the second term in Equation (3.2.6), and aggregate consumption.

The PIH consumer budget constraint (Equation 2.4.7) requires the inclusion of the lump sum tax term:

$$
C_{t}^{P}+B_{H, t-1}+R S_{t} B_{F, t-1}+n T_{t}=\frac{B_{H, t}}{\left(R_{t+1}\right)}+\frac{R S_{t} B_{F, t}}{\left(R_{t+1}^{f}\right) \psi\left(R S_{t} B_{F, t}\right)}+\frac{W_{t}}{P_{t}} L_{t}^{p}+D_{t}
$$


However, as the first order conditions with regard to consumption or bond issuance do not involve $T_{t}$, the log-linearised equations derived from the bdget constraint are the same as the basic model (as outlined in Section 2.4).

The resource constraint is also extended from the basic model to include government spending so that the fiscal model includes an additional term compared to Equation (2.3.4) in that

$$
Y_{t}=c_{t}+I_{t}+G_{t}+E X_{t}
$$

where, $G_{t}$ is aggregate government consumption of all goods and similar to the consumer demand for good $z$, government consumption of consumer good $z$ is given by

$$
G_{t}(z)=\left(\frac{p_{t}(z)}{P_{c, t}}\right)^{-\epsilon} G_{t}
$$

The fiscal model steady state (for which values for the key variables are shown in Table 3.1) is derived in the same way as the basic model with two main differences. The resource constraint now includes a term for government demand for goods (see Equation F.1.1) and ROT consumption is derived from (3.2.3) by simply dropping the time subscripts. The difference in the steady state values between the fiscal and basic models can be traced back to the presence of government spending in the steady state. From Equation (F.1.1) it can be seen that $\frac{G}{Y}$ would increase the steady state output. However, via the production function, the steady state output is also a function of technology, imports as a proportion of output and aggregate labour supply - none of which change between the two models. Thus the steady state output must be the same. Given that government spending increases $Y$ in Equation (F.1.1), another variable must serve to keep $Y$ constant. This is effectively done by a decrease in $q$.

The basic model log-linear equations are modified with equations (3.2.10) and (3.2.11) replacing (2.9.9) and (2.9.4), respectively, augmented by equations (3.2.12), (3.2.13) and (3.2.14). The derivation of the log-linear equations that change from the basic to the fiscal model is given in Appendix D.

$$
\hat{C}_{t}^{r}=\frac{w L^{r}}{C^{r}}\left(\hat{w}_{t}+\hat{L}_{t}^{r}\right)-\frac{(1-n) T}{C^{r}} \hat{T}_{t}
$$




$$
\begin{gathered}
\hat{Y}_{t}=\frac{c}{Y} \hat{c}_{t}+\frac{I}{Y} \hat{I}_{t}+\frac{G}{Y} \hat{G}_{t}+\frac{E X}{Y} \hat{E X} \hat{X}_{t} \\
\hat{L}_{t}^{r}=\frac{\xi(1-n) T}{w L^{r}}\left(\hat{T}_{t}-\hat{w}_{t}\right) \\
\frac{d B_{t+1}^{G}}{Y}=R\left[\frac{d B_{t}^{G}}{Y}+\frac{G}{Y}\left(\hat{G}_{t}-\hat{T}_{t}\right)\right] \\
\hat{T}_{t}=\left(\frac{G}{Y}\right)^{-1} \phi_{B} \frac{B_{t}^{G}}{Y}+\phi_{G} \hat{G}_{t}
\end{gathered}
$$

\begin{tabular}{|l|l|c|c|}
\hline Variable & Description & Fiscal model & Basic model \\
\hline \hline$q$ & Real house price & 5.0356 & 5.9382 \\
$h$ & Housing stock & 0.5 & 0.5 \\
\hline$R_{h}$ & Return on housing & 1.0166 & 1.0166 \\
$X c$ & Relative price of consumption good & 1.6826 & 1.6187 \\
$X h$ & 0.1088 & 0.1283 \\
$I$ & Relative price of renting & 0.0025 & 0.0025 \\
$N$ & Housing investment & 1.7625 & 2.0784 \\
$D$ & Net worth & 0.0293 & 0.0345 \\
$C$ & Housing dividend & 0.2863 & 0.3376 \\
$Y$ & Aggregate consumption & 0.2271 & 0.2271 \\
$w$ & Real output & 0.5592 & 0.5592 \\
$I M$ & Real wage & 0.0640 & 0.0640 \\
$E X$ & Imports & 0.0556 & 0.0556 \\
$E X-R S I M$ & Exports & -0.0084 & -0.0084 \\
$c$ & Current account & 0.1378 & 0.1690 \\
\hline$L^{r}$ & Goods consumption & 0.4521 & 0.4740 \\
$L^{p}$ & ROT labour supply & 0.2777 & 0.2683 \\
$C^{r}$ & PIH labour supply & 0.2435 & 0.2651 \\
$C^{p}$ & ROT consumption & 0.3047 & 0.3687 \\
\hline
\end{tabular}

Table 3.1: Fiscal model steady state values

\begin{tabular}{|l|l|l|}
\hline Parameter & Description & Value \\
\hline \hline$\sigma_{A}$ & Innovation variance of technology shock & $(0.18 \%)^{2}$ \\
$\sigma_{i}$ & Innovation variance of nominal interest rate shock & $(0.14 \%)^{2}$ \\
$\sigma_{r f}$ & Innovation variance of foreign real interest rate shock & $(0.20 \%)^{2}$ \\
$\sigma_{y f}$ & Innovation variance of foreign demand shock & $(0.67 \%)^{2}$ \\
$\sigma_{g}$ & Innovation variance of fiscal spending shock & $(1.3 \%)^{2}$ \\
\hline
\end{tabular}

Table 3.2: Innovation variances 


\subsection{Parameterisation of the fiscal model}

In order to assist comparison between the variants of the model, the paramterization is kept as similar as possible. Thus the deep structural parameters, such as $\eta, \alpha$ and $\gamma$ have the same value in the basic model as the fiscal model. The variances of the model variables depend in part on the nature of the assumed shock processes. Estimates of the actual volatility in the empirical counterparts of the shock variables are set out in Table 3.2.

Calibration of the fiscal model was carried out with the objective of minimising the difference between empirically estimated variances of a number of variables and the variances generated by the model. The model moments and the empirically observed counterparts are set out in Table 3.3. In particular, real house prices, residential investment and output were the key variables used to gauge the closeness of the moments. As noted in Chapter 2, the moments were adjusted by way of changing the values of a number of deep structural parameters, namely the sensitivity of the premium to the net worth ratio $(\Omega)$, the sensitivity of the housing dividend to the net worth ratio $\left(\frac{\chi^{\prime}(\phi)}{\chi(\phi)} \phi\right)$, the inverse of the sensitivity of the investment-housing stock ratio to the replacement cost ratio for housing $\left(\Gamma_{d}\right)$ and export sensitivity to both the real exchange rate $(\vartheta)$ and foreign demand $(\zeta)$. The data used to estimate the empirical values are described in Appendix B.

Adjustment of the structural parameters used to alter the model's moments often resulted in divergent effects. Thus it was necessary to prioritise which moments should be matched first. Given that the primary focus is on the housing market, these were used as the primary moments to match with adjustment to change other moments only done if it did not adversely effect the housing market moments. Thus while the fiscal DSGE model provides a close match in terms of the housing market moments (real house prices, net worth and residential investment), its ability to match the real exchange rate, export and import data is less close. DSGE models with sticky prices are well known to underestimate the degree of volatility in real exchange rates (see Ahmad, Lo and Mykhaylova, 2011). This would naturally tend to result in an underprediction of exports and imports given their relationship with the real exchange rate. In addition, this thesis has abstracted from shocks to foreign price levels which would clearly have implications for the volatility of the real exchange rate. 


\begin{tabular}{|l|l|c|c|}
\hline Variable & Description & Data & Fiscal model \\
\hline \hline$q$ & Real house prices & $4.54 \%$ & $4.62 \%$ \\
$N$ & Net worth & $6.65 \%$ & $6.63 \%$ \\
$R^{n}$ & Nominal interest rate & $0.31 \%$ & $0.21 \%$ \\
$\pi$ & Overall inflation & $0.57 \%$ & $1.01 \%$ \\
$S$ & Nominal exchange rate & $5.51 \%$ & $2.61 \%$ \\
$R S$ & Real exchange rate & $6.26 \%$ & $0.61 \%$ \\
$C$ & Aggregate consumption & $1.48 \%$ & $2.09 \%$ \\
$I$ & Residential investment & $9.83 \%$ & $9.79 \%$ \\
$Y$ & Output & $2.08 \%$ & $1.09 \%$ \\
$E X$ & Exports* & $5.89 \%$ & $1.03 \%$ \\
$I M$ & Imports* & $6.81 \%$ & $2.67 \%$ \\
\hline \multicolumn{2}{|c|}{$*$ Proxied by debits and credits in the current account }
\end{tabular}

Table 3.3: Fiscal model moment matching

As the fiscal model is more comprehensive than the basic model and thus should be a better representation of the New Zealand economy, it is useful to compare the parameterisation of the fiscal model with other New Zealand calibrated DSGE models. Table 3.4 includes parameters taken from other New Zealand calibrated DSGE models, being the KITT model employed by the RBNZ (Beneš et al., 2009), Claus (2005) and Liu (2006). Each model differs from the one used in this thesis in a variety of aspects and so that means the comparison must be made with a degree of caution. Arguably, KITT is the closest to this thesis' model in that it explicitly includes a housing sector and a financial accelerator but is significantly more detailed with inter alia an explicit role for capital and industry subcomponents. Neither Claus (2005) nor Liu (2006) include an explicit housing sector. Imports enter into Liu's model as competing consumption goods, whereas they are intermediate imports in Claus.

\subsection{Government spending shock}

The impulse responses to a positive $1 \%$ shock to government spending are shown in Figure 3.1. 


\begin{tabular}{|c|c|c|c|c|c|c|}
\hline Variable & Description & Fiscal model & KITT & Claus & Liu & Comment \\
\hline $\bar{\phi}$ & Net worth ratio & 0.70 & 0.70 & $\mathrm{n} / \mathrm{a}$ & $\mathrm{n} / \mathrm{a}$ & \\
\hline$\beta$ & Discount rate & 0.99 & 0.9975 & 0.9902 & 0.99 & \\
\hline$f(\phi)$ & $\begin{array}{l}\text { Steady state premium fac- } \\
\text { tor }\end{array}$ & 1.0064 & 0 & $\mathrm{n} / \mathrm{a}$ & $\mathrm{n} / \mathrm{a}$ & Quarterly premium \\
\hline$\alpha$ & $\begin{array}{l}\text { Weight on imports in pro- } \\
\text { duction function }\end{array}$ & 0.2 & 0.34 & 0.36 & $\mathrm{n} / \mathrm{a}$ & $\begin{array}{l}\text { KITT uses Cobb-Douglas } \\
\text { production function. }\end{array}$ \\
\hline$\gamma$ & $\begin{array}{l}\text { Substitutability parame- } \\
\text { ter in production function }\end{array}$ & -0.2 & $\mathrm{n} / \mathrm{a}$ & -0.1 & $\mathrm{n} / \mathrm{a}$ & \\
\hline$\delta$ & Depreciation rate & 0.005 & 0.01 & 0.0213 & $\mathrm{n} / \mathrm{a}$ & $\begin{array}{l}\text { Claus depreciation applies } \\
\text { to capital. }\end{array}$ \\
\hline$E X / Y$ & Exports/Output ratio & 0.245 & 0.3032 & 0.31 & $\mathrm{n} / \mathrm{a}$ & KITT uses $\mathrm{Y}=\mathrm{GDP}$ \\
\hline$I M / Y$ & Imports/Output ratio & 0.282 & 0.2796 & 0.33 & $\mathrm{n} / \mathrm{a}$ & \\
\hline$G / Y$ & $\begin{array}{ll}\text { Government } & \text { spend- } \\
\text { ing/Output ratio } & \end{array}$ & 0.137 & 0.2453 & 0.12 & $\mathrm{n} / \mathrm{a}$ & \\
\hline$\theta$ & Price resetting parameter & 0.75 & $\mathrm{n} / \mathrm{a}$ & 0.66 & 0.75 & $\begin{array}{l}1-\theta=\text { Probability of firm } \\
\text { resetting price }\end{array}$ \\
\hline$\Omega$ & $\begin{array}{l}\text { Sensitivity of spread to } \\
\text { net worth }\end{array}$ & -0.1 & -0.049 & $\mathrm{n} / \mathrm{a}$ & $\mathrm{n} / \mathrm{a}$ & \\
\hline$\vartheta$ & $\begin{array}{l}\text { Elasticity of exports to } \\
\text { real exchange rate }\end{array}$ & 1 & 0.1065 & 1 & 0.85 & $\begin{array}{l}\text { KITT value }=1 /(\text { adj. } \\
\text { cost for manufacted ex- } \\
\text { ports) }\end{array}$ \\
\hline$\zeta$ & $\begin{array}{l}\text { Elasticity of exports to } \\
\text { foreign demand }\end{array}$ & 1 & 0.1065 & 1 & 1 & \\
\hline
\end{tabular}

Table 3.4: Parameters from NZ-calibrated DSGE models

The increase in demand from higher government expenditure necessitates a positive output response and thus a higher wage in order to induce greater labour supply from households. The increase in output results in an increase in the output gap, eliciting a tightening response from the monetary authority, lifting both the nominal and real interest rates. It should be noted that the increase in the output gap is significantly smaller than the increase in output. The reason for this is that the increase in the real interest rate causes an appreciation of the real exchange rate (depicted by a decline in the real exchange rate chart) which in turn reduces the cost of the intermediate imports. Thus for a given cost amount, firms are able to produce more and the flexible price output level increases. At the same time the appreciation in the real exchange rate dampens export demand for domestically produced goods, offsetting some of the original increase in demand from the government spending shock. Consequently the increase in the output gap is less than the increase in output but is still positive.

The higher real interest rate dampens PIH consumption but by less than the pickup 
in ROT consumption. Aggregate consumption rises in the shock period above the steady state, resulting in an increase in the relative price of rental and a decrease in the relative price of consumption goods. With the reduction in the replacement cost of housing, house prices fall, acting as a disincentive to invest in housing. The drop in the real house price leads to a reduction in the net worth of households carried through into the following period and thus a reduction in the dividend as well.

The impact of a positive government spending shock on the housing market is clearly negative. This contrasts with the effect of an expansionary nominal interest rate shock. Thus, stimulatory shocks have different impacts on the housing market depending on their origin. I note also that the effect of a government spending shock has opposing impacts on the housing market and consumption, unlike the typically observed house price-consumption empirical correlation. Given that the magnitude of the impulse response functions is also relatively muted compared to the responses to the technology, nominal interest rate and foreign interest rate shocks, the implication is that government spending shocks do not dominate other shocks. ${ }^{2}$

\footnotetext{
${ }^{2}$ Results of the fiscal model response to technology, real foreign interest rate and foreign demand shocks are available on request.
} 
Figure 3.1: Response to a $1 \%$ government spending shock
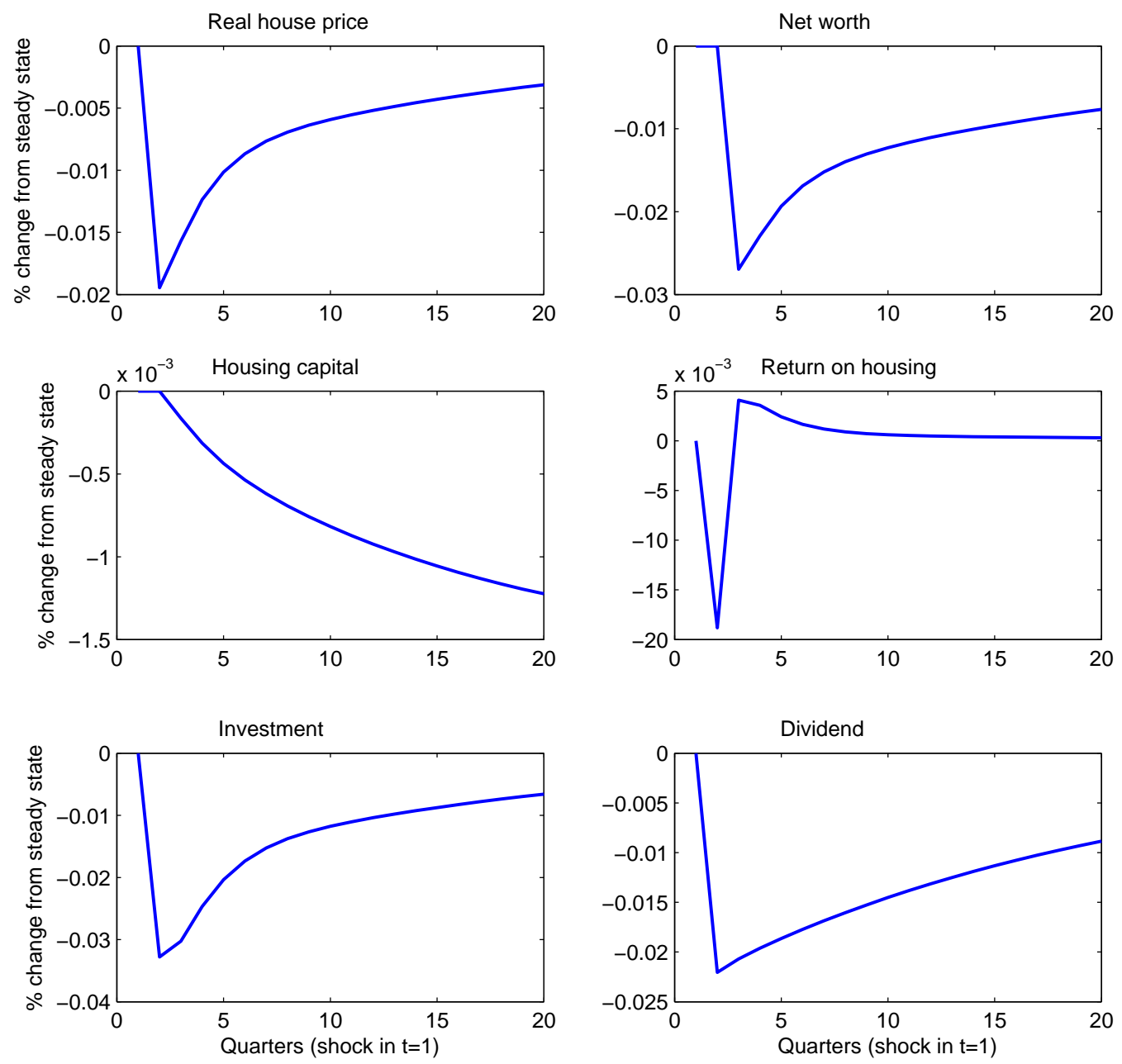
Figure 3.1: Response to a 1\% government spending shock (continued)
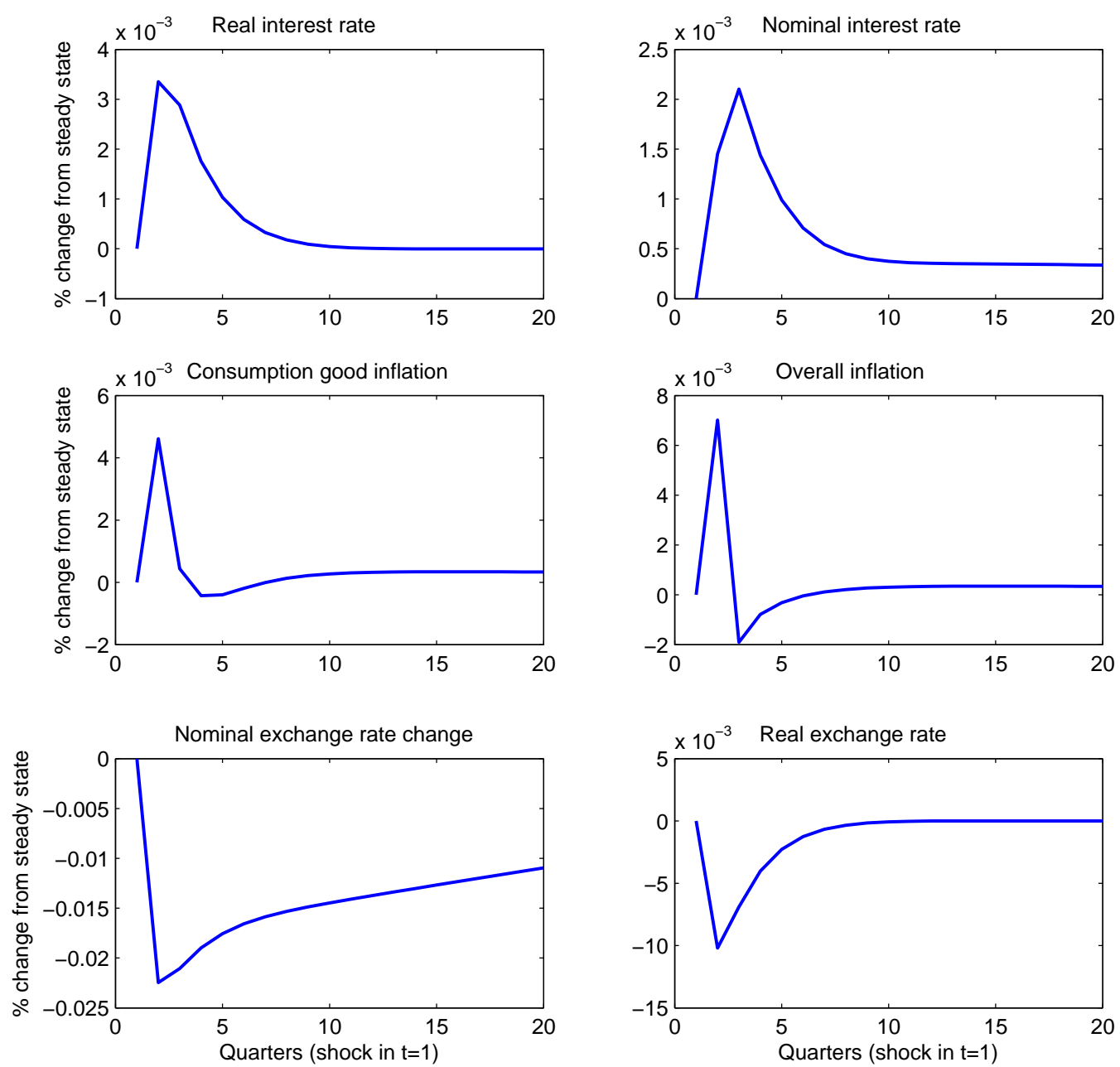
Figure 3.1: Response to a 1\% government spending shock (continued)
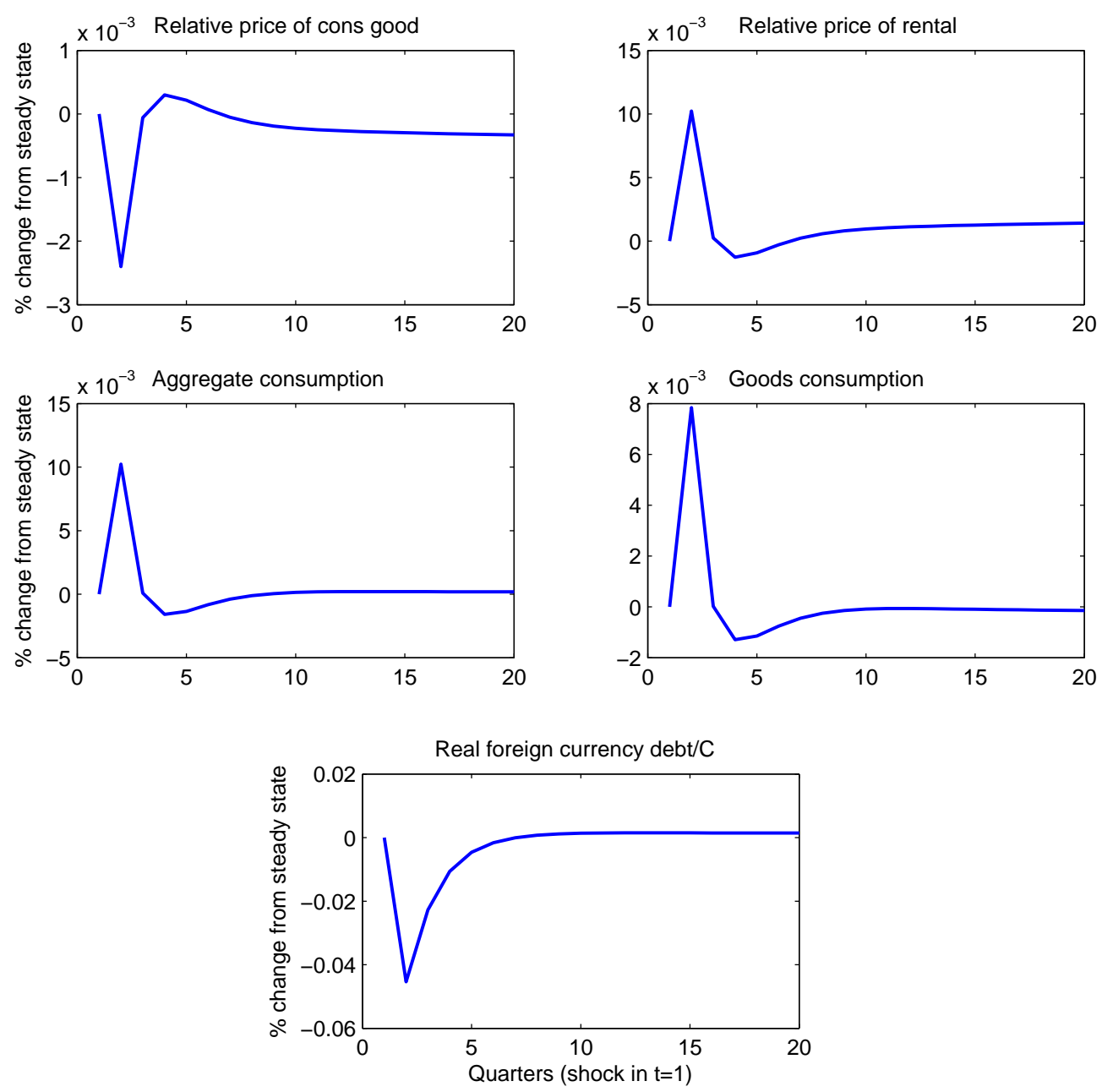
Figure 3.1: Response to a $1 \%$ government spending shock (continued)
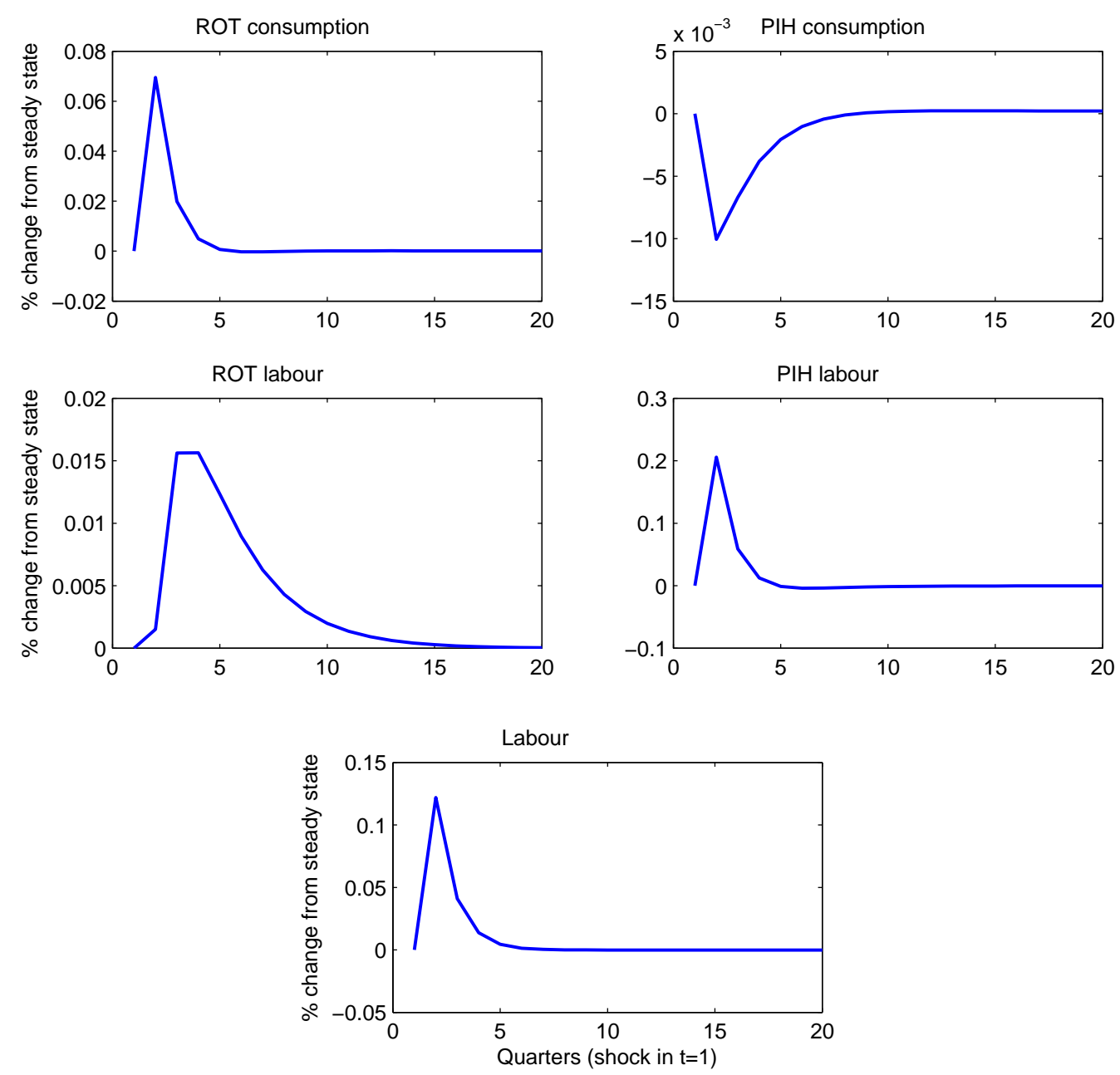
Figure 3.1: Response to a 1\% government spending shock (continued)
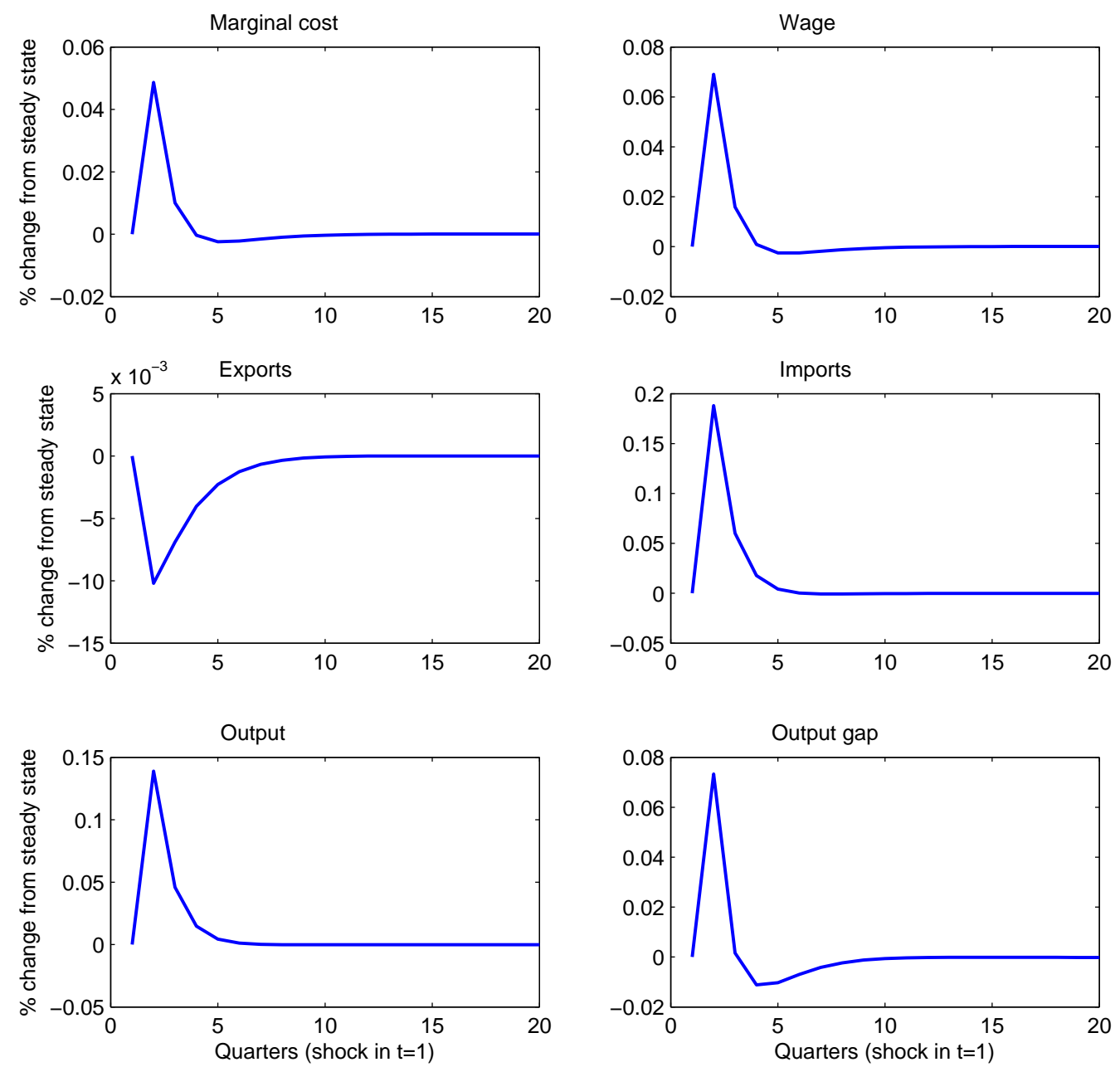
Figure 3.1: Response to a $1 \%$ government spending shock (continued)
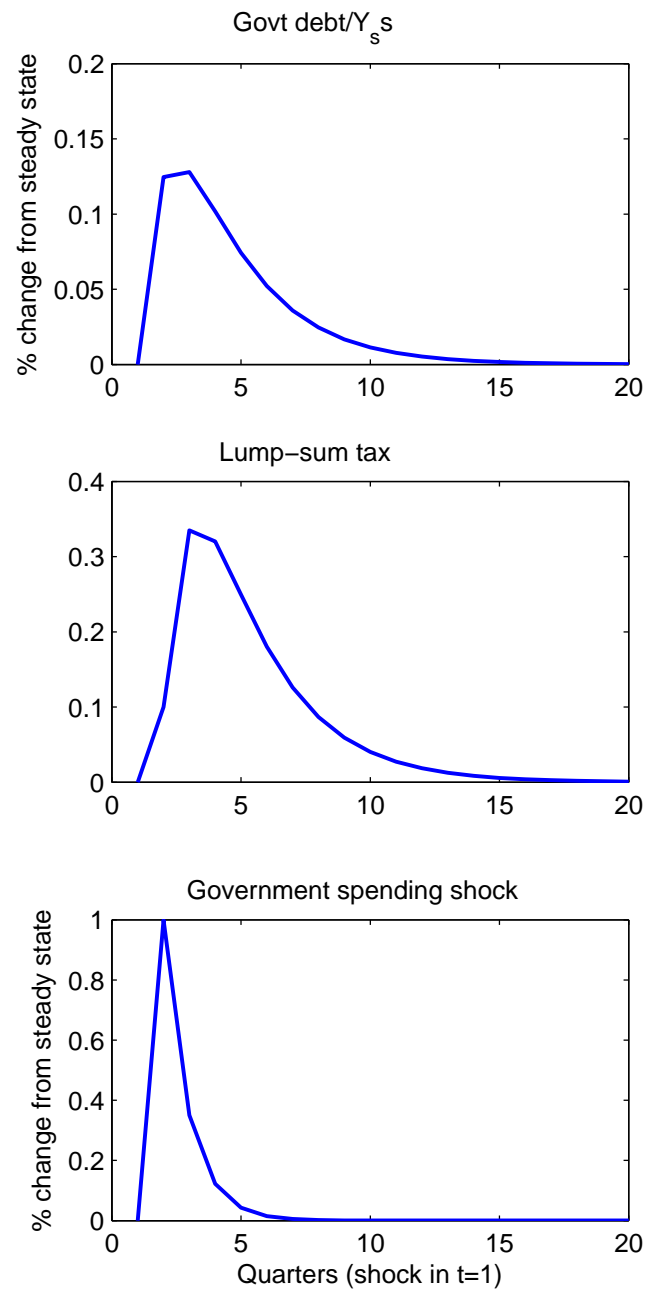


\subsection{Comparison of fiscal model with basic model}

The fiscal model impulse responses to a monetary policy shock are shown in Figure 3.2. The responses are very similar to the basic model. Given that for an interest rate shock (or any other non-fiscal shock), the fiscal variables (government spending, lump-sum taxation and government debt issuance) will not shift significantly from their steady state values, the impulse response functions of the fiscal model should be similar to those in the basic model. Recall that the steady state has been calculated in order to obtain an aggregate labour utilisation rate of 0.33 . Because of this, most aggregate level steady state values are similar across the two model types. Hence the high degree of similarity between the fiscal and basic model impulse response functions.

Unsurprisingly, the major differences in model response relate to the presence of the tax wedge. This is most obvious when looking at the ROT labour response. In the basic model ROT labour supply is constant as shown in section 3.2. The tax wedge term in Equation (3.2.6) shows that there is an inverse relationship between ROT labour supply and the real wage. As the wage rises, ROT consumers need supply less labour to meet their tax obligation and thus work fewer hours. Hence, for as long as the wage is above its steady state, ROT consumers will supply labour below their steady state level. This reduction in ROT labour outweighs the PIH labour response and as a result the aggregate labour response in the fiscal model is smaller than that of the basic model. This also results in smaller magnitude output and import responses in the fiscal model relative to the basic model. 
Figure 3.2: Fiscal model comparison - Response to a $0.25 \%$ nominal interest rate shock
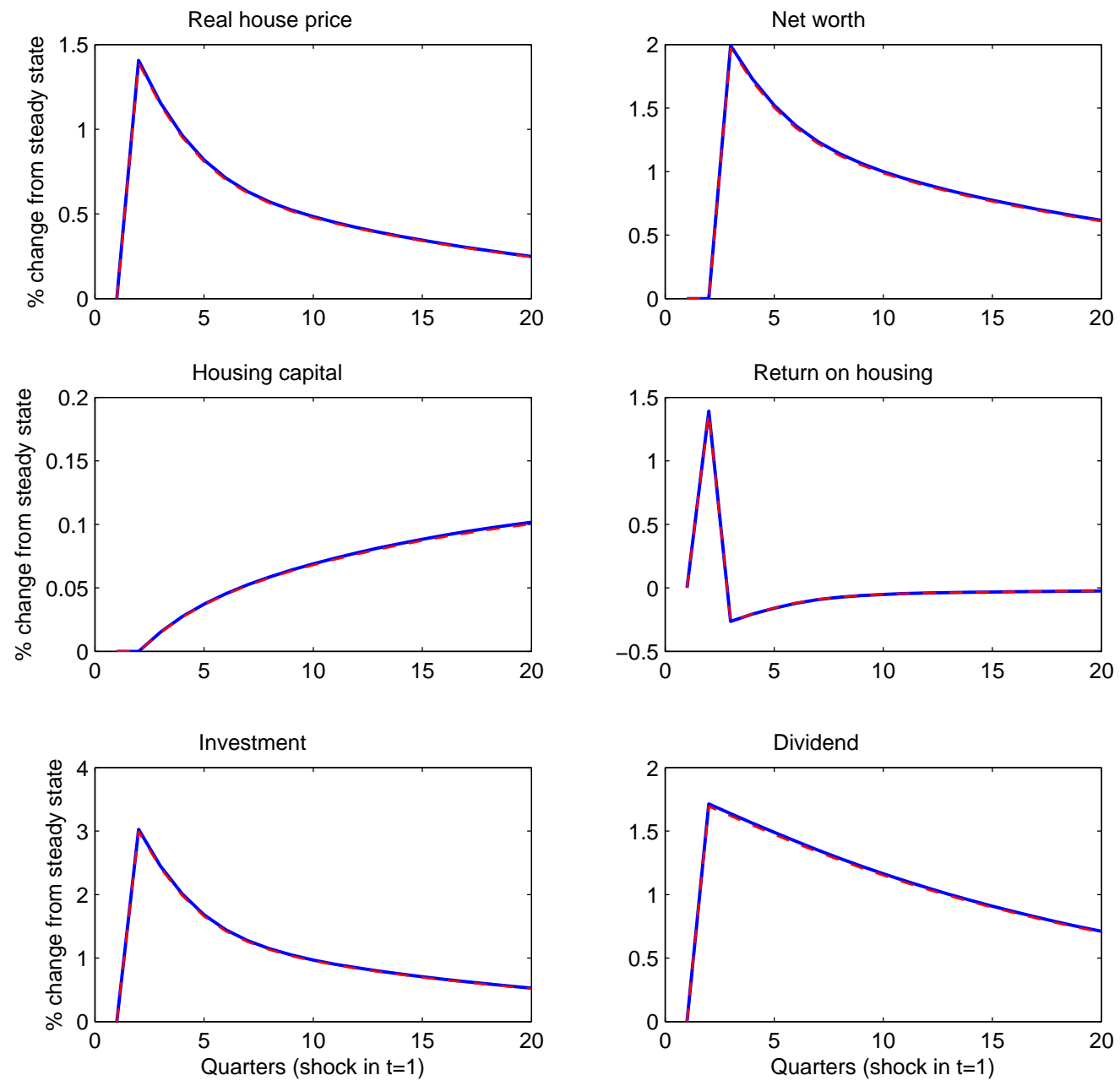

- Fiscal model - - - Basic model 
Figure 3.2: Fiscal model comparison - Response to a $-0.25 \%$ nominal interest rate shock (continued)
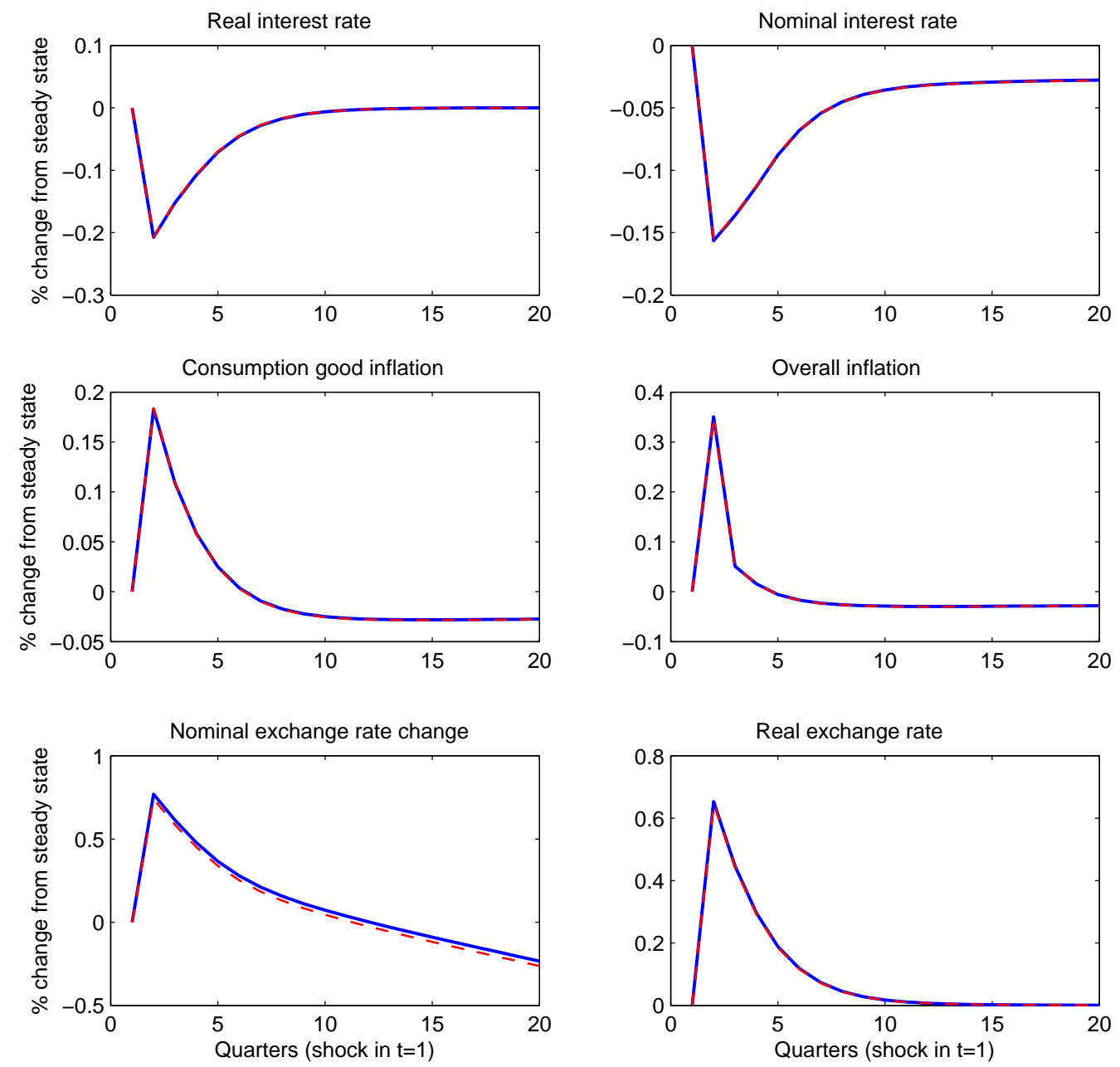

- Fiscal model --- Basic model 
Figure 3.2: Fiscal model comparison - Response to a $-0.25 \%$ nominal interest rate shock (continued)
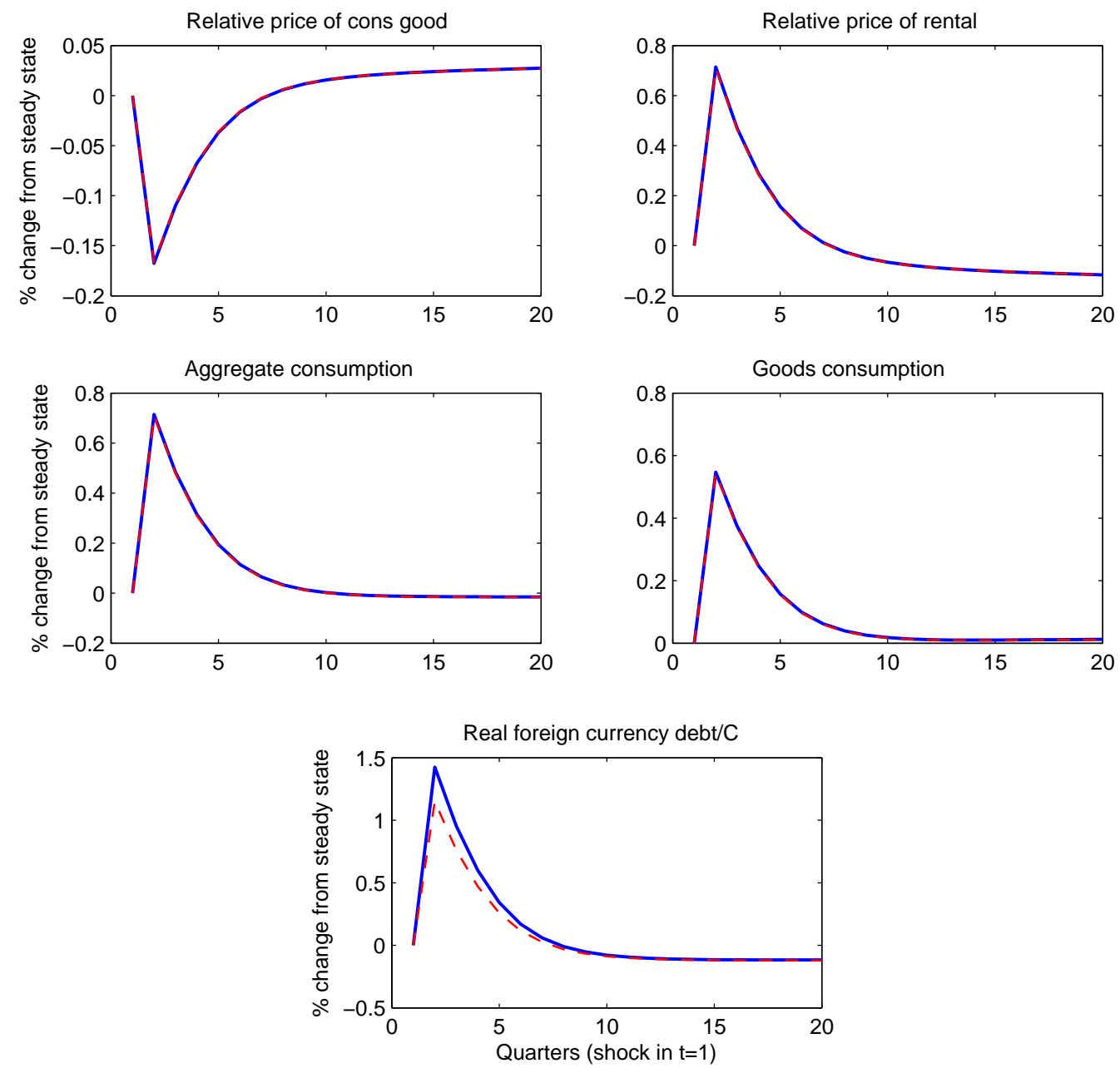

_ Fiscal model - - - Basic model 
Figure 3.2: Fiscal model comparison - Response to a $-0.25 \%$ nominal interest rate shock (continued)
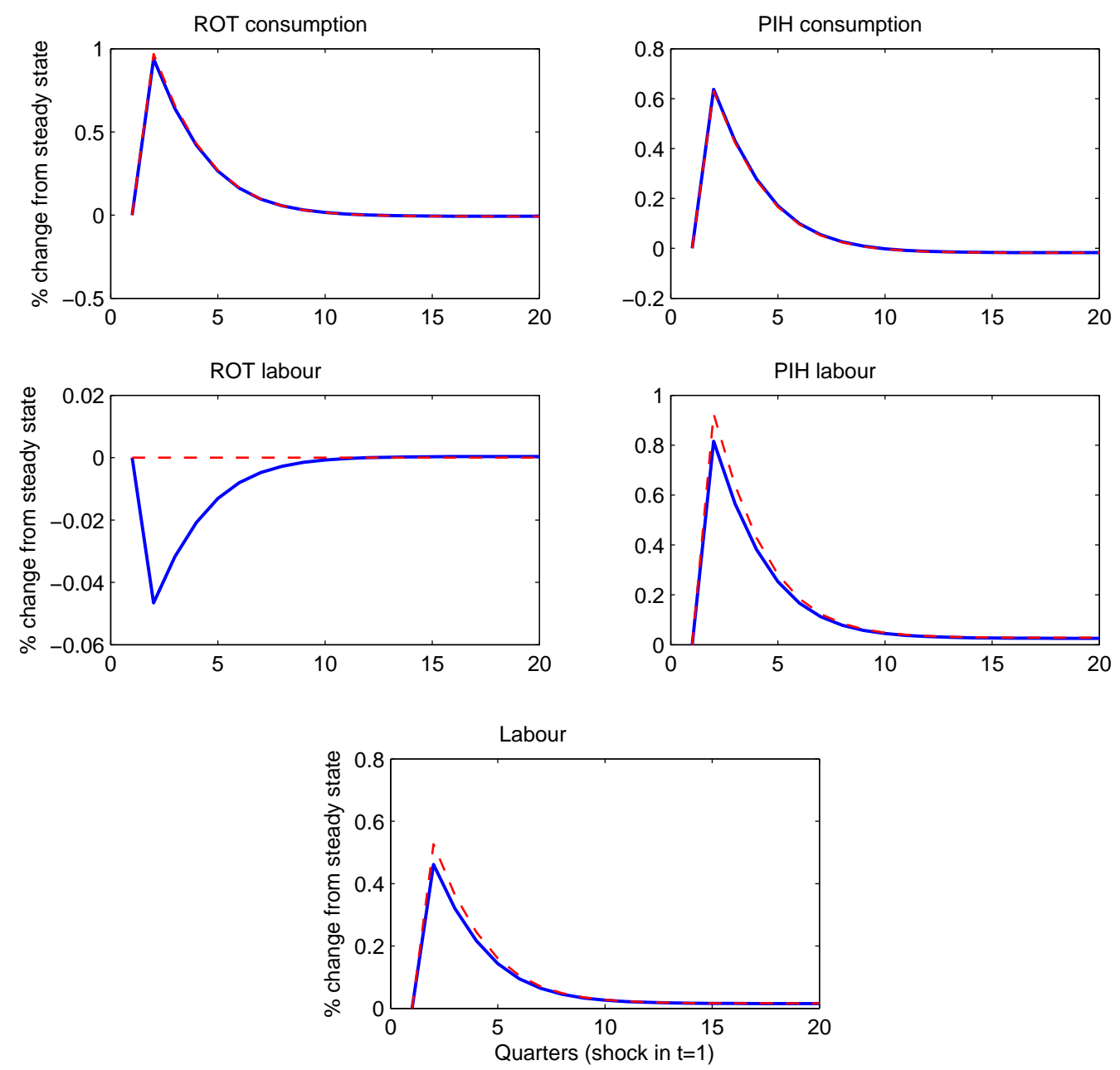

- Fiscal model - - - Basic model 
Figure 3.2: Fiscal model comparison - Response to a $-0.25 \%$ nominal interest rate shock (continued)
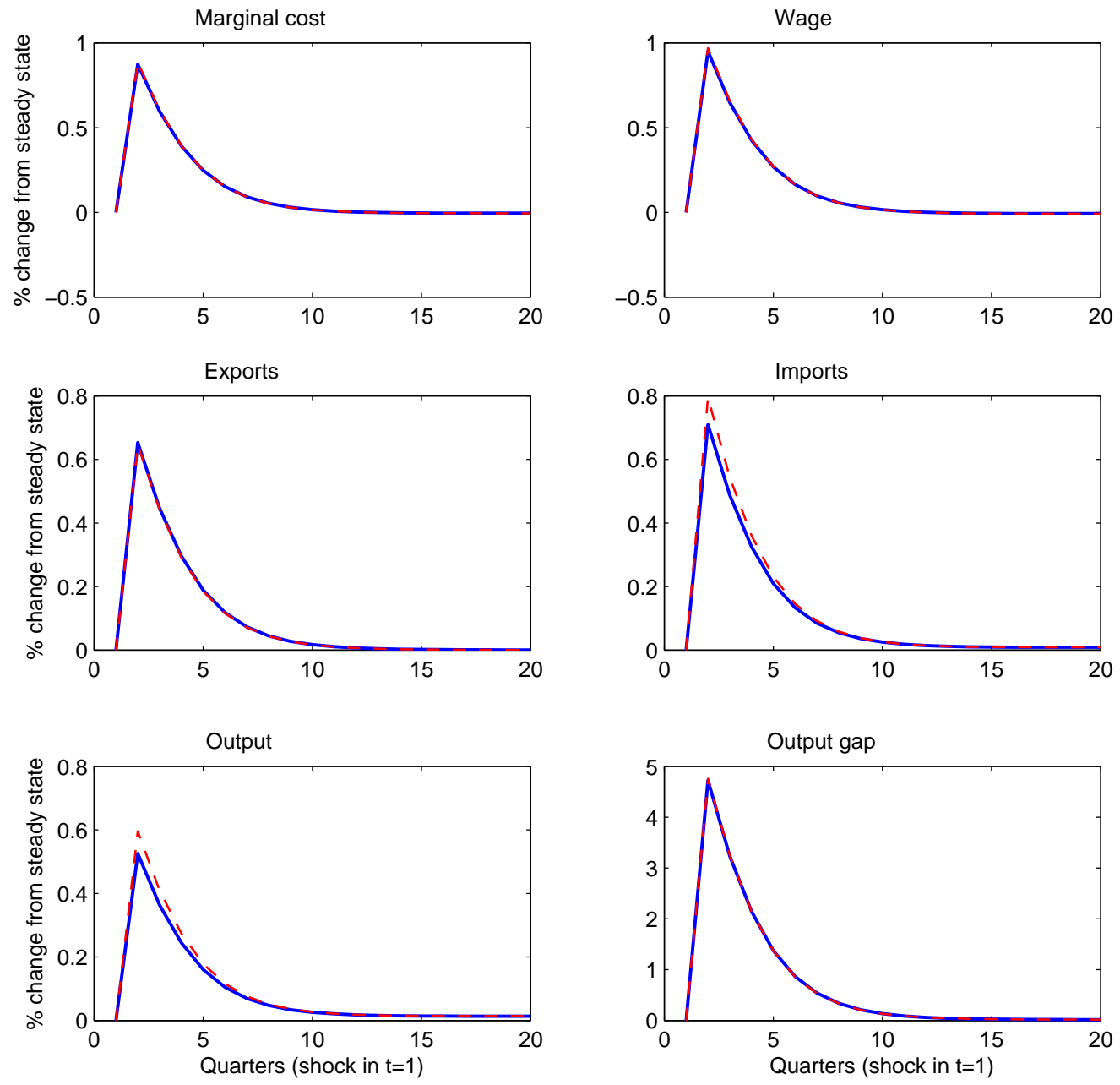

Fiscal model - - Basic model 


\subsection{Sensitivity analysis - Changing the propor- tion of ROT consumers}

In this section, I examine how changes to the assumed proportion of the ROT consumers, $1-n$, affect the model dynamics.

Given that the steady state is largely determined by the aggregate consumption behaviour (rather than the PIH and ROT consumer behaviours individually), the steady states are similar across the range of values for $n$ used, the only difference being the allocation of consumption and labour supply between the two consumer types.

As $n$ increases (i.e. the proportion of consumers who are ROT declines), the variables of the fiscal model become less sensitive to interest rate shocks (Figure 3.3). A smaller proportion of the the lump sum tax is borne by ROT consumers and thus for a given wage increase there is a smaller response in ROT labour supply.

However, as the proportion of consumers that are PIH increases, the representative PIH consumer need supply less labour. Similarly, as $n$ increases, the income of PIH consumers rises (for a given wage increase) and although they increase consumption, their smoothing behaviour means that rather than increasing consumption signific antly they reduce their borrowing.

A similar effect is noticable when examining the IRF's to a government spending shock for various values of $n$, as depicted in Figure 3.4. Again, the model shows generally greater sensitivity to the fiscal spending shock when $n$ is low, reflecting the greater sensitivity of aggregate consumption to income as $n$ declines. As with the interest rate shock, a lower value for $n$ gives rise to a bigger reaction (in the case of a positive government spending shock, a negative reaction) in the housing market.

However, I note that the impact of the government spending shock is relatively small in comparison to the interest rate shock. A $0.25 \%$ nominal interest rate shock gives rise to significantly larger impulse responses than a $1 \%$ government spending shock. The implication is that if the model were subject to a variety of different shocks, the response to a fiscal shock would quickly become lost in the presence of nominal interest rate shocks. 
Figure 3.3: Sensitivity to $n$ - Response to a -25 basis point nominal interest rate shock
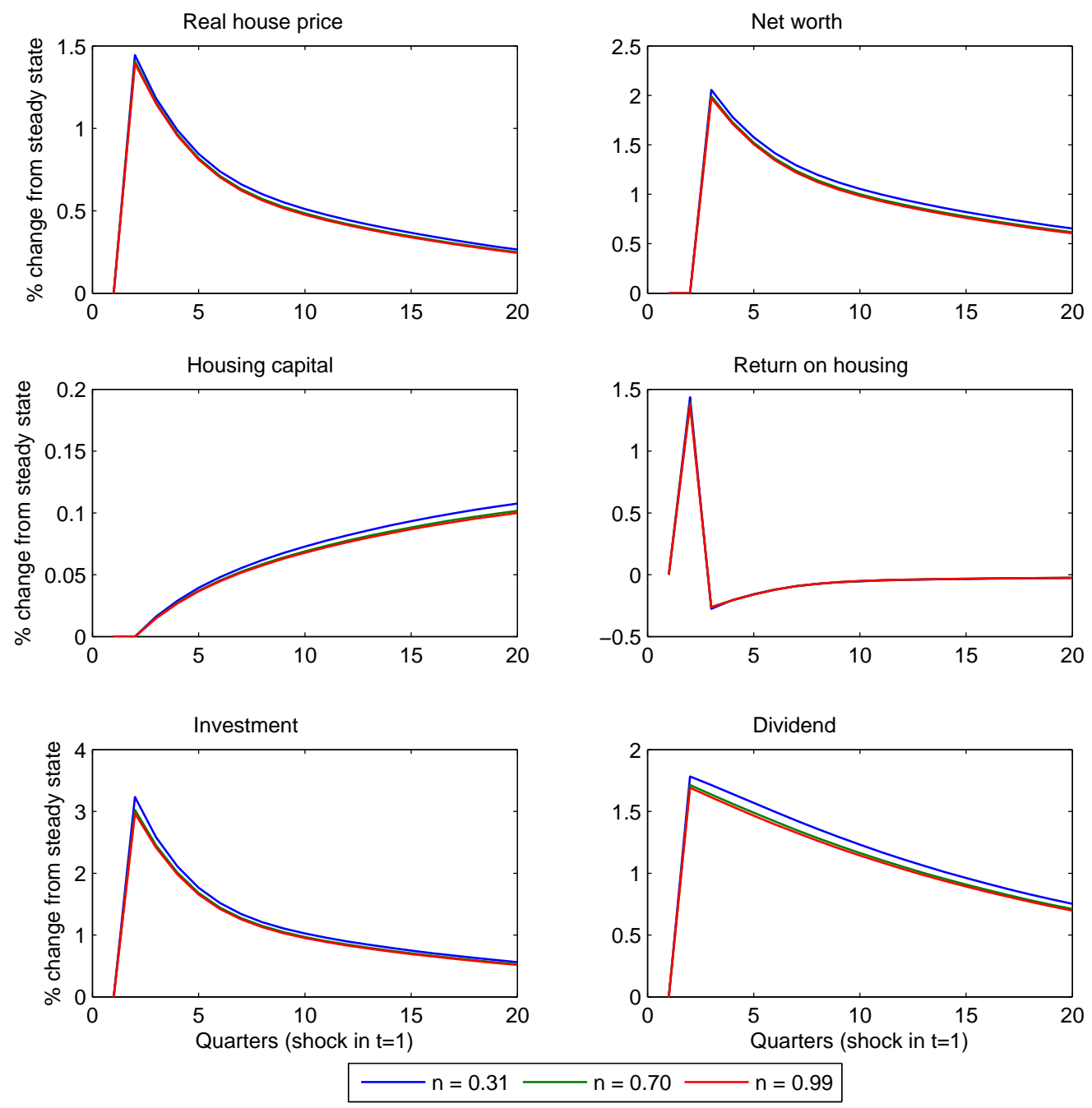
Figure 3.3: Sensitivity to $n$ - Response to a -25 basis point nominal interest rate shock (continued)
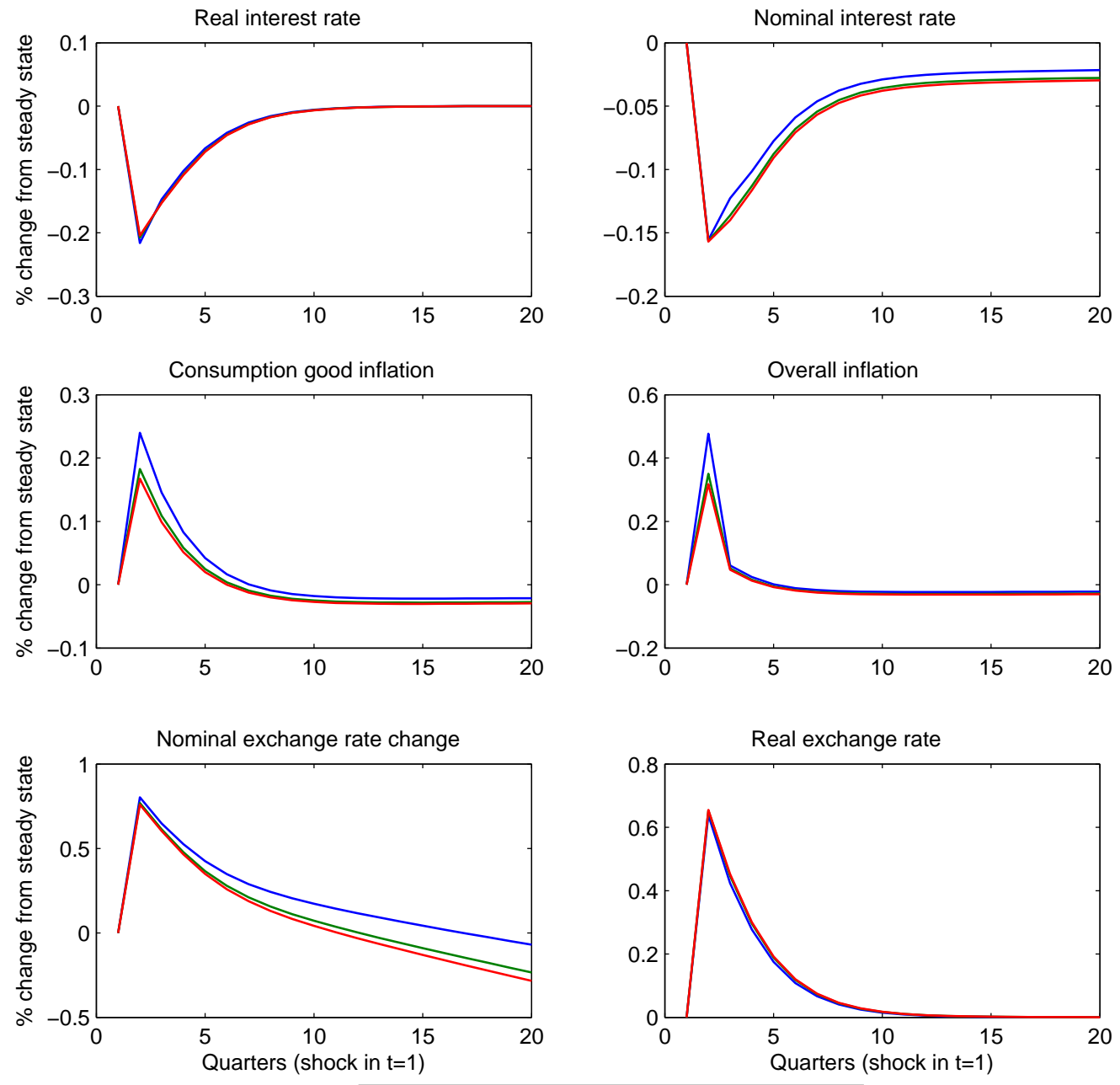

$-\mathrm{n}=0.31-\mathrm{n}=0.70-\mathrm{n}=0.99$ 
Figure 3.3: Sensitivity to $n$ - Response to a -25 basis point nominal interest rate shock (continued)
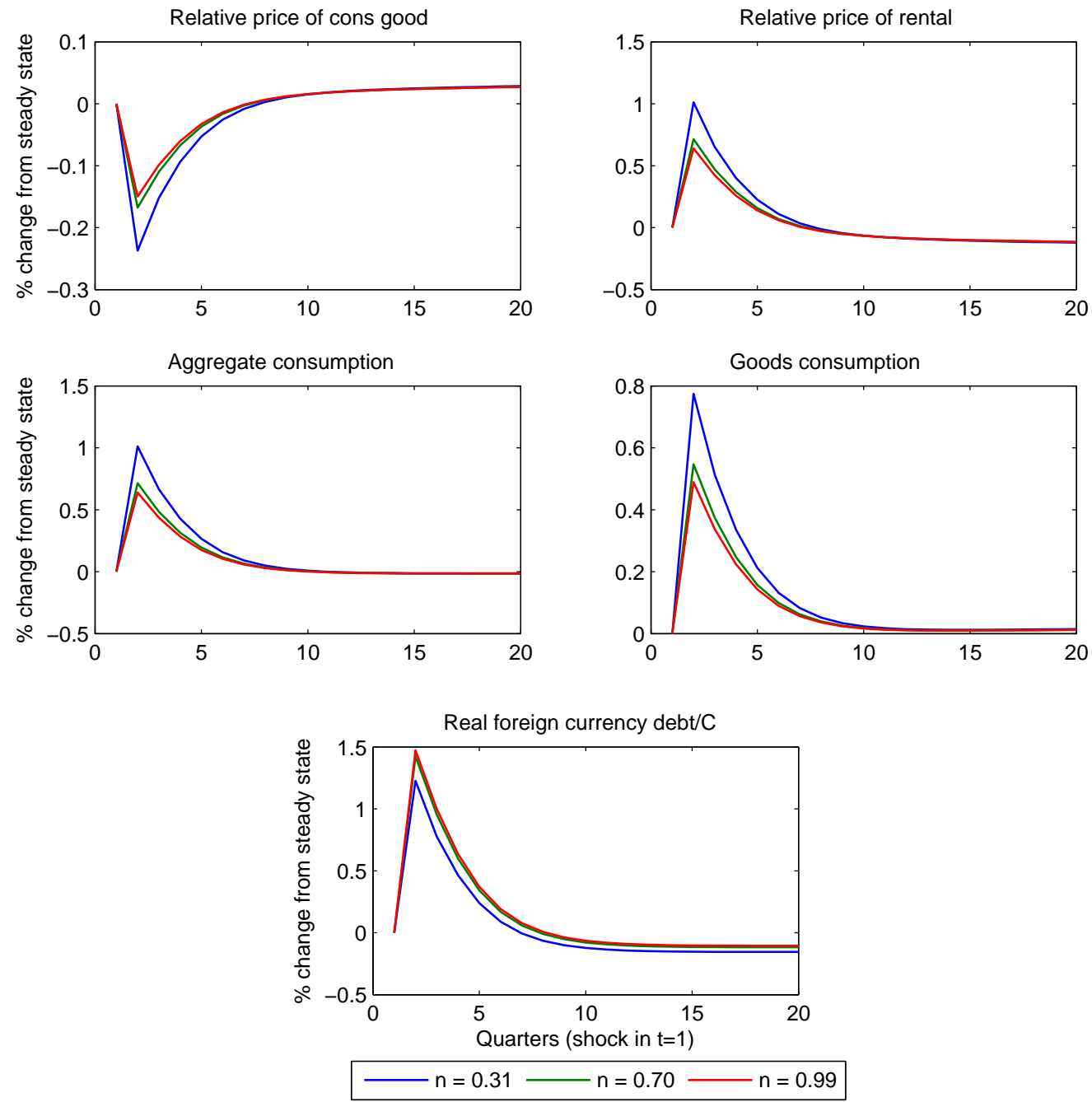
Figure 3.3: Sensitivity to $n$ - Response to a -25 basis point nominal interest rate shock (continued)
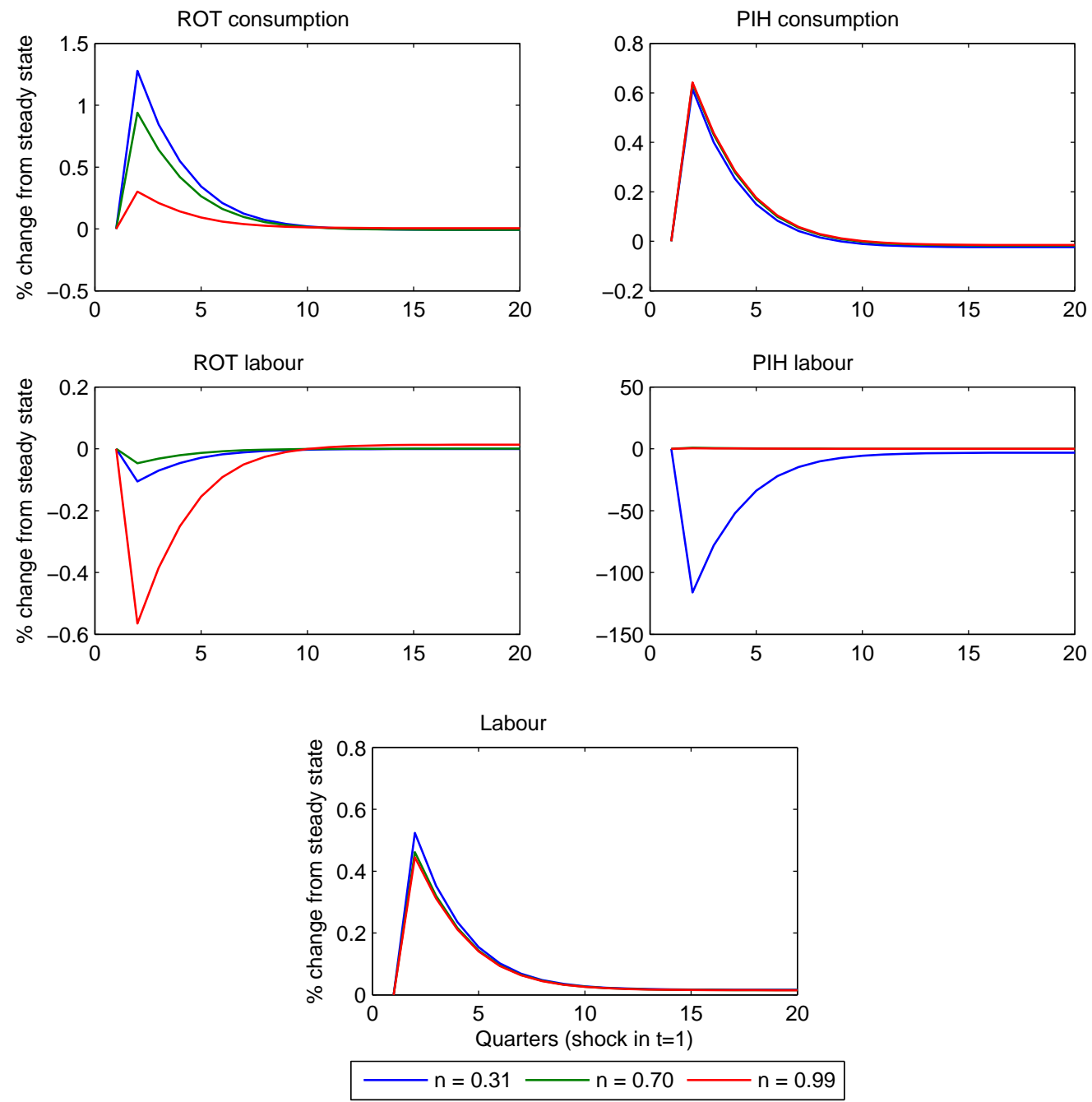
Figure 3.3: Sensitivity to $n$ - Response to a -25 basis point nominal interest rate shock (continued)
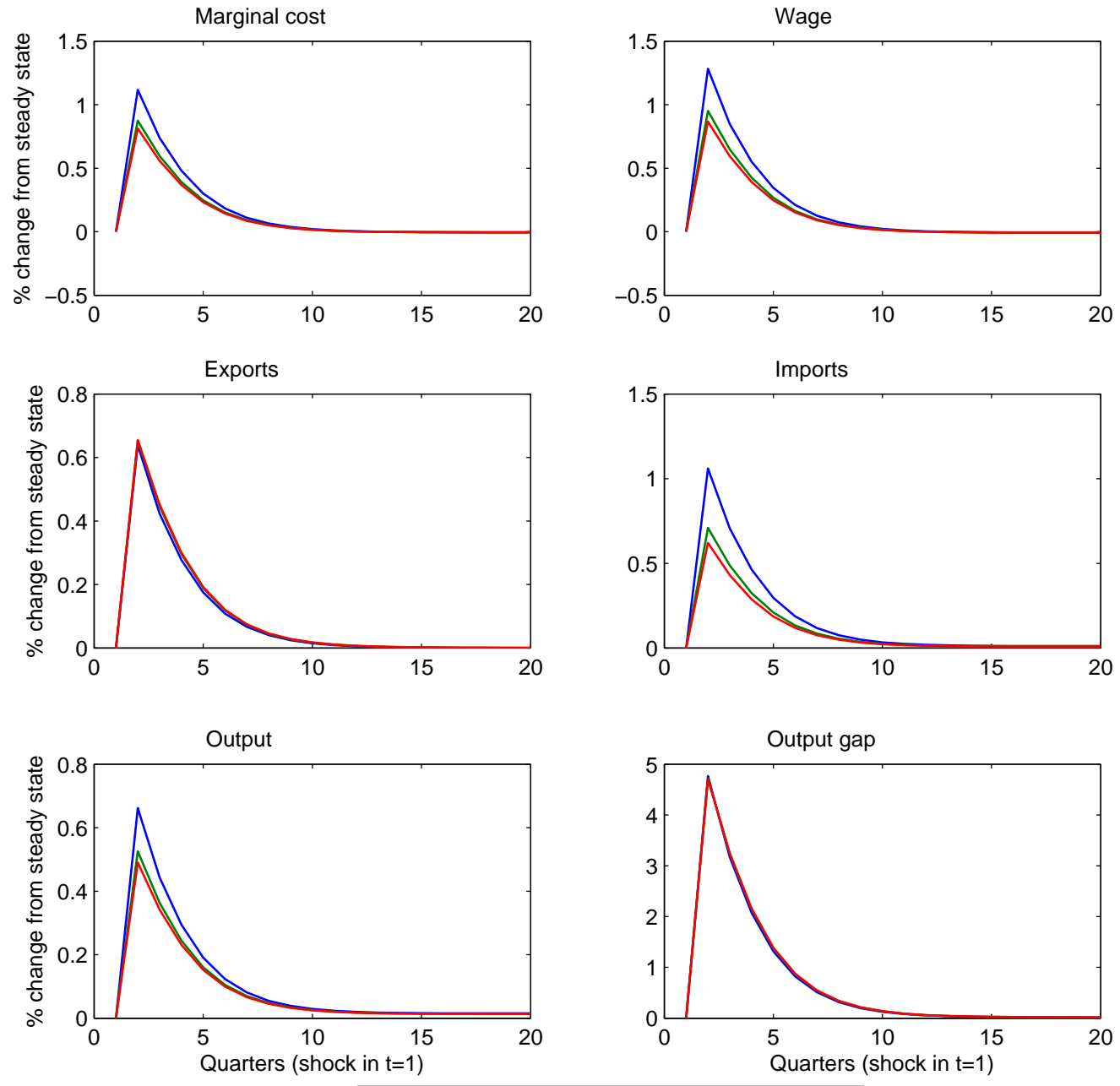

$-\mathrm{n}=0.31 \longrightarrow \mathrm{n}=0.70 \longrightarrow 0.99$ 
Figure 3.4: Sensitivity to $n$ - Response to a $1 \%$ government spending shock
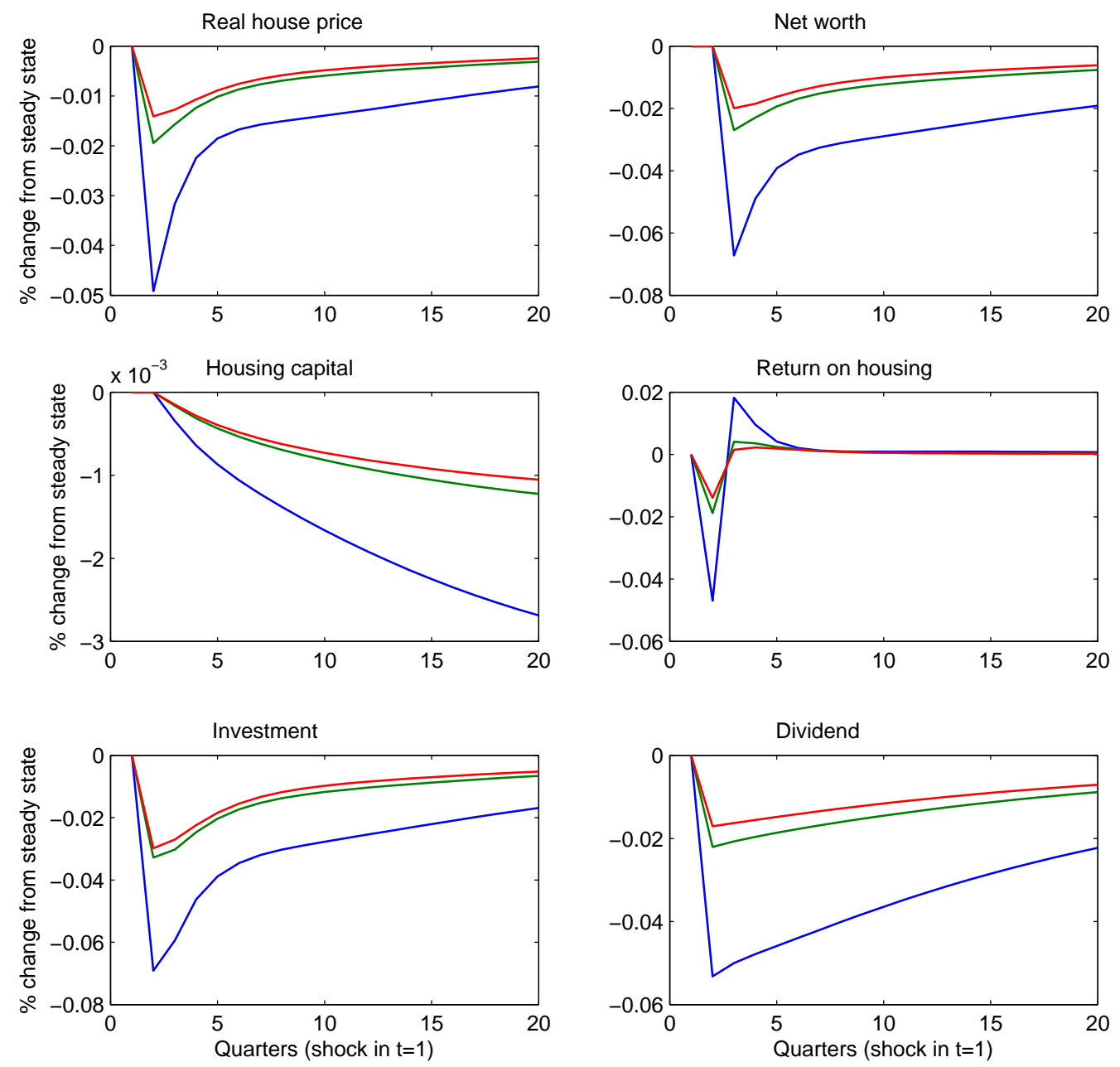

$\longrightarrow \mathrm{n}=0.31 \longrightarrow \mathrm{n}=0.70 \longrightarrow 0.99$ 
Figure 3.4: Sensitivity to $n$ - Response to a $1 \%$ government spending shock (continued)
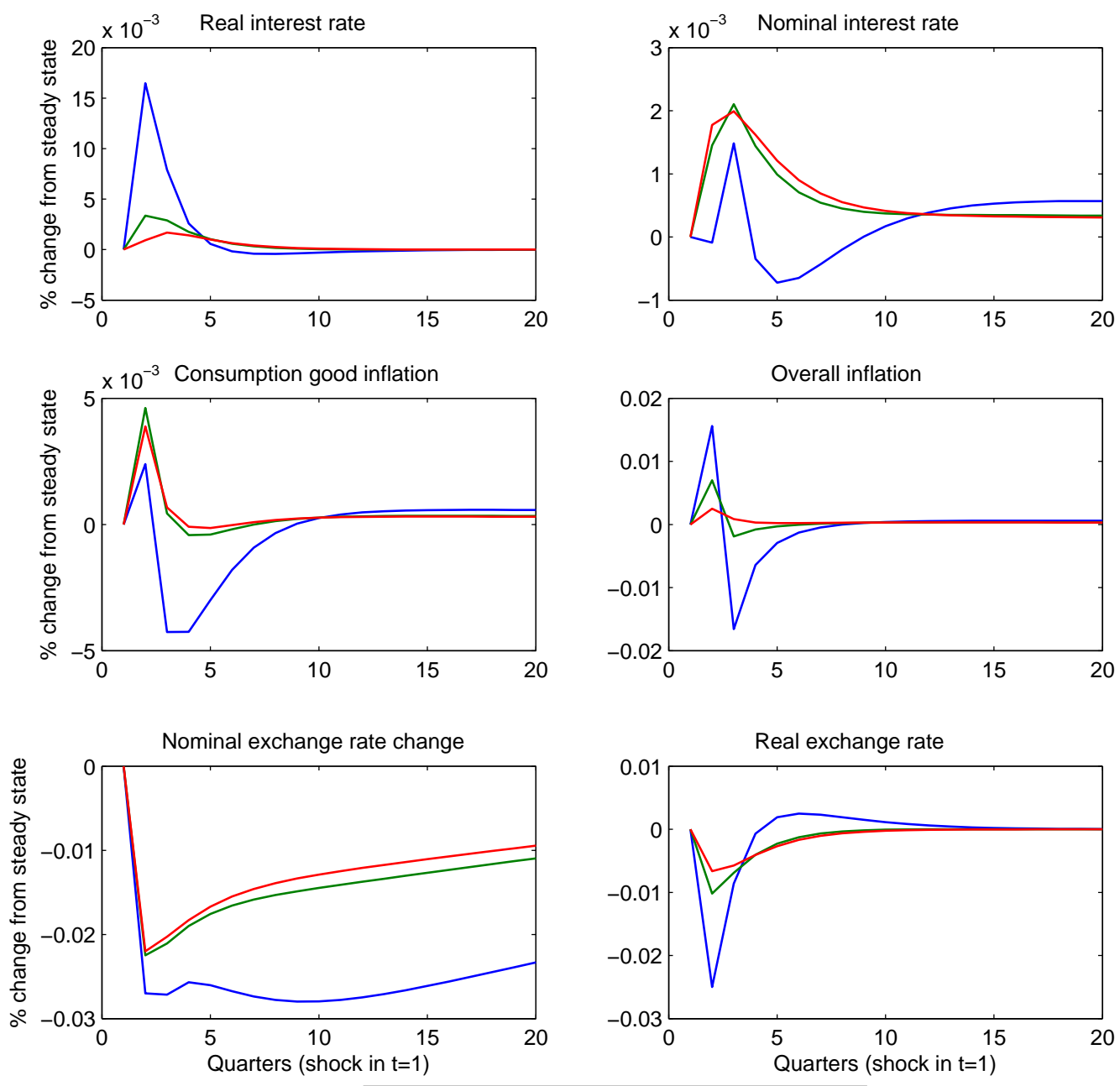

$\mathrm{n}=0.31-\mathrm{n}=0.70-\mathrm{n}=0.99$ 
Figure 3.4: Sensitivity to $n$ - Response to a $1 \%$ government spending shock (continued)
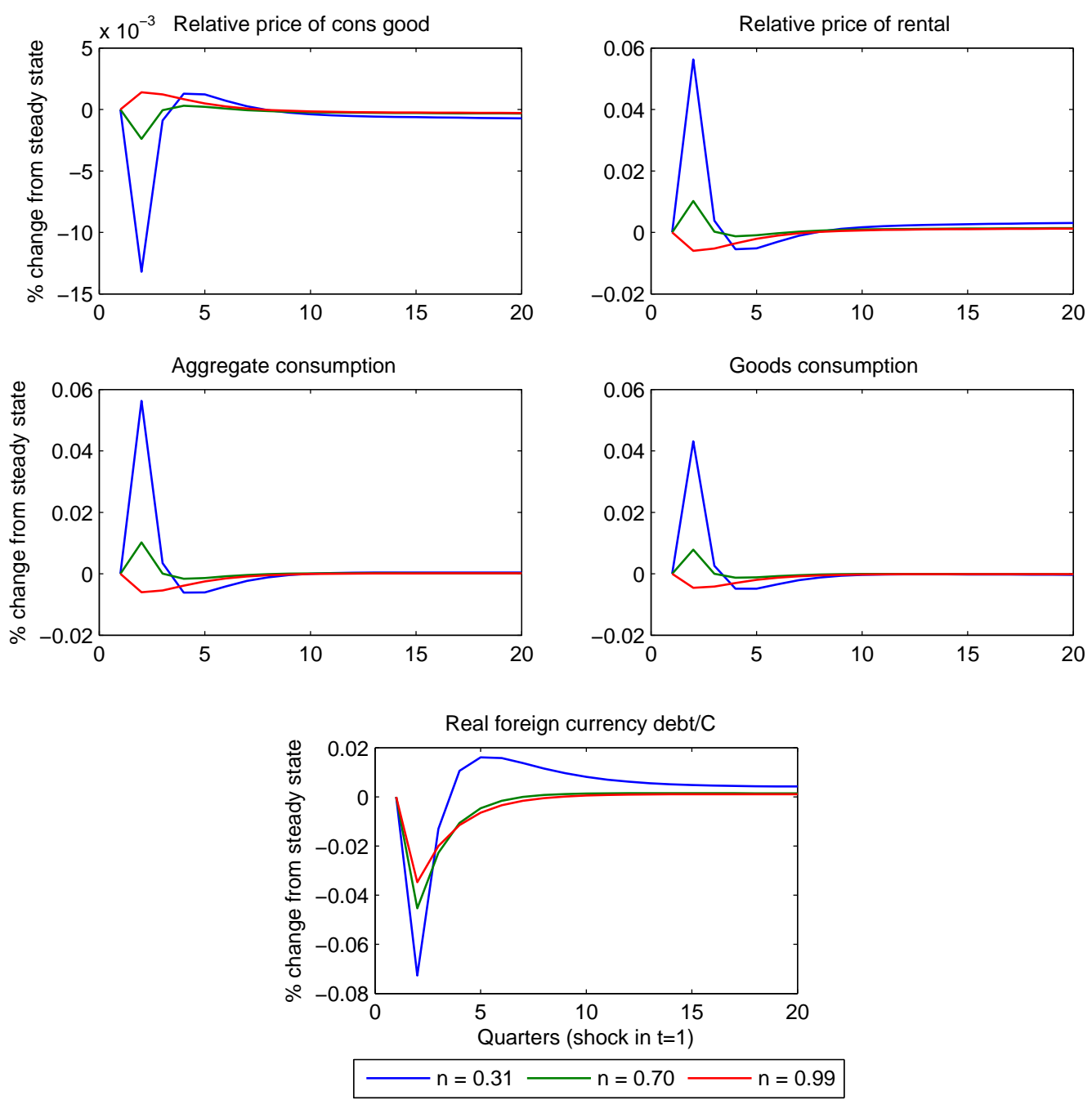
Figure 3.4: Sensitivity to $n$ - Response to a $1 \%$ government spending shock (continued)
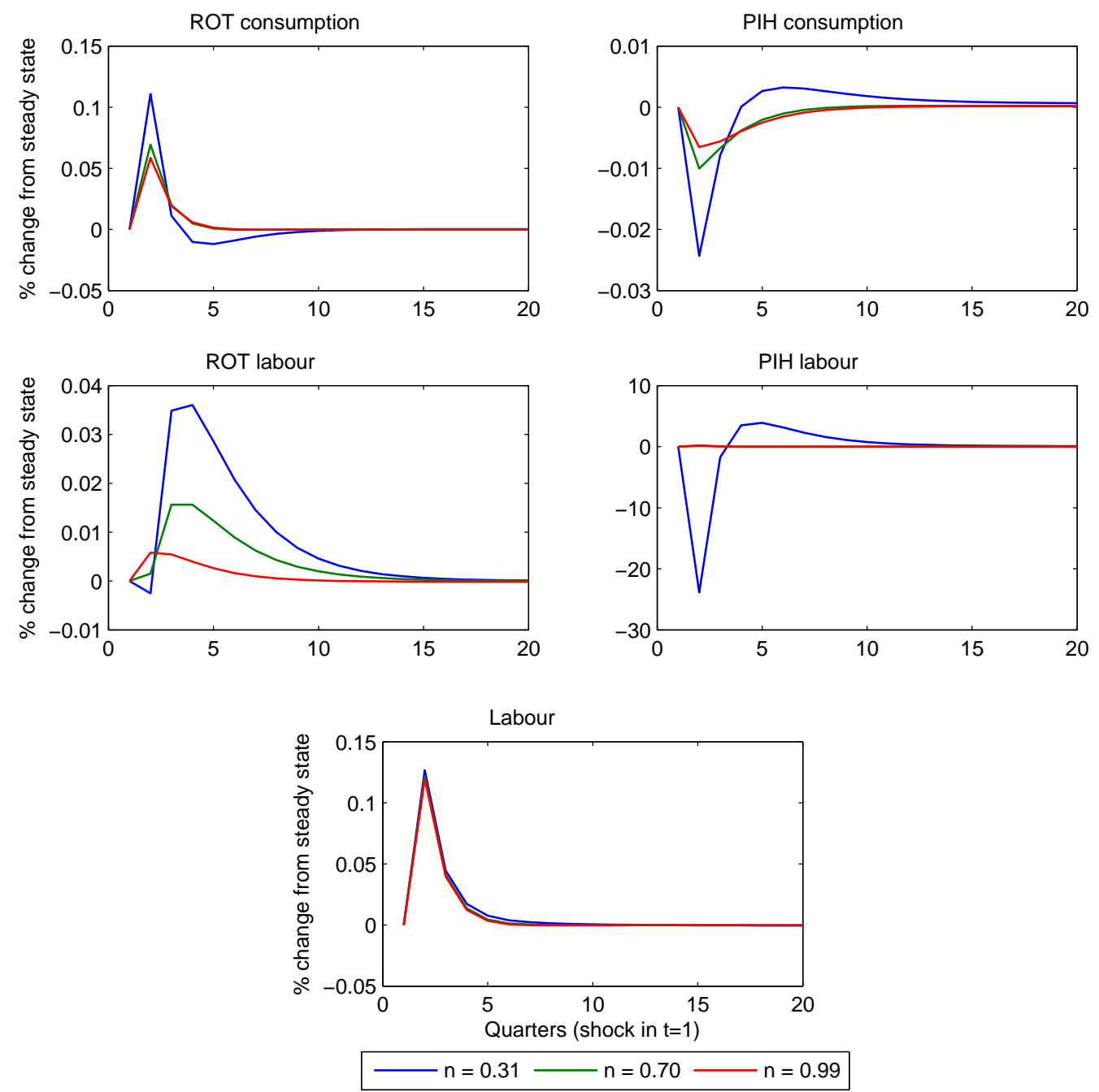
Figure 3.4: Sensitivity to $n$ - Response to a $1 \%$ government spending shock (continued)
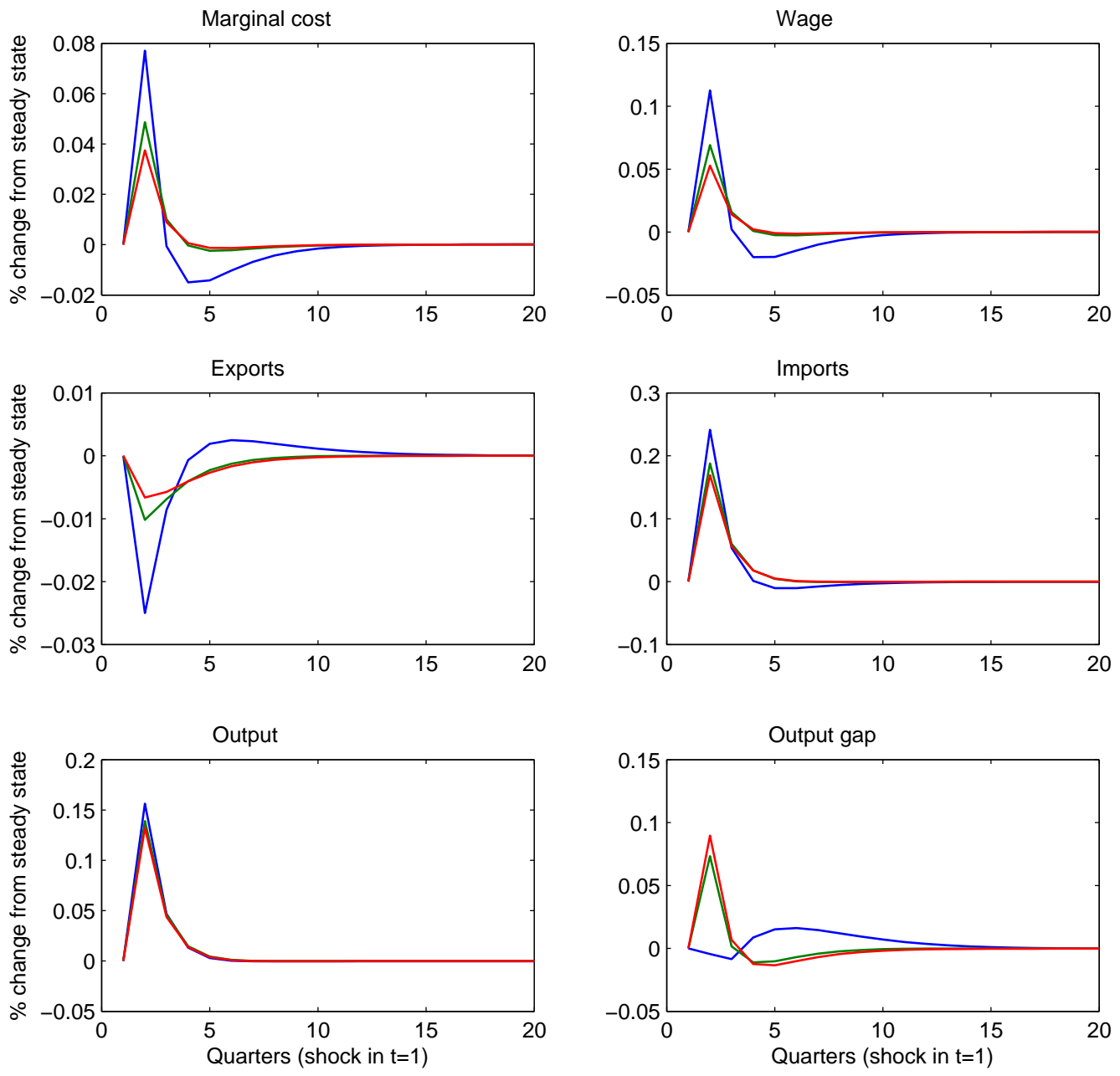

$\longrightarrow \mathrm{n}=0.31-\mathrm{n}=0.70-\mathrm{n}=0.99$ 


\subsection{Concluding comments}

Given the relatively muted response of the model to fiscal shocks, the housing market is more likely to reflect other shocks. Most other shock types have significantly larger responses than the fiscal shock. This result is still applicable when the proportion of ROT consumers is increased (to a maximum of $69 \%$ ). Thus fiscal policy is not supportive of the housing market. In turn, this suggests that although the housing market underwent a boom during most of the 2000s, this was despite rather than because of an expansionary fiscal policy.

In addition, the model behaviour suggests that the nominal interest rate is likely to be the most influential shock of the five shock types considered, particularly for the housing market. However, given that the financial accelerator effect is relatively muted (as demonstrated in Chapter 2), the need for the central bank to take into account the potential impact of the housing market on other economic variables would be similarly fairly low. 


\section{Chapter 4}

\section{Examining the financial accelerator using an SVAR}

\subsection{Introduction}

Given the theoretical basis for a financial accelerator effect on the housing market set out in Chapters 2 and 3, the natural question that arises is whether this effect is empirically visible. This chapter sets out a structural vector autoregression (SVAR) model which includes both the spread (between the mortgage interest rate and the risk-free interest rate) and household consumption. The financial accelerator concept embodies the view that an improvement in the net worth of households (relative to the value of the housing stock) reduces the riskiness of the mortgagee and thus enables a lower mortgage interest rate relative to the benchmark (risk-free) interest rate. In turn, this change in spread would influence the cost of debt servicing and thence disposable income. Thus in the presence of a financial accelerator an increase in the net worth of households should reduce the spread and in turn enable an increase in household consumption. This should result in a negative correlation between the spread and consumption expenditure.

Most econometric studies of housing markets have not focused on the financial accelerator. Iacoviello and Minetti (2008) use the spread and real house prices in a VECM aimed at examining the credit channel of monetary policy but do not look at consumption per se. Sutton (2002) looks at the determinants of house prices in the context of a VAR rather than the effect of house price shocks. Bjørnland and Jacobsen $(2008,2010)$ use house prices in a VAR that examines the role for housing 
in the transmission of monetary policy but do not focus on the specific transmission channels such as interest-sensitive expenditure. Elbourne (2007) provides a summary of several studies that include house prices and consumption but of these only Iacoviello and Minetti include a spread variable.

\subsection{Variable selection}

The choice of variables included in the VAR is driven by the need to recognise the small open economy nature of New Zealand and incorporation of various aspects of the housing market. In particular, the demand for New Zealand's exports is captured by a world growth variable relevant to New Zealand. The relative price at which New Zealand trades in goods and services, the terms of trade, is also included. More specifically, the terms of trade is measured as the quantity of imported goods that can be funded through a given quantity of exports both on a NZ dollar basis. A rising terms of trade could be indicative of either a higher return for exporters (potentially coupled with a rising demand) or decreasing cost for New Zealand to import, especially its intermediate imports, or a combination of both. Given that economic activity is a key consideration for the state of the housing market, New Zealand's gross domestic product (GDP) is a key variable to include. Moreover, this allows for the "common cause" interpretation of consumption growth.

Given the primary focus on the financial accelerator, the obvious variable to include is the spread between the mortgage rate and the benchmark government interest rate. As the theoretical underpinning of the financial accelerator is the value of the stock of housing, house prices are also included. Finally, household consumption is included as the ultimate variable of interest.

I also include a government spending variable. A secondary issue in this thesis is whether government spending influences the housing market. As noted in Chapter 3 , when government expenditure is modelled with explicit financing (debt or taxes) and a no-ponzi condition, shocks to government spending negatively impact the housing market. Moreover, if government spending has a direct impact on household consumption, including this may assist in estimation of the effect of the spread.

Clearly, this set of variables is not exhaustive and there are numerous other variables that could be included. Econometric limitations aside (see below), the initial 
analysis considered using in addition to or replacing some of the above variables with net worth, a short-term interest rate and the real exchange rate.

Net worth did not appear to provide any significant improvement in model results over and above house prices. Indeed, looking at the graphs of both net worth and house prices (Figure 4.1), there is an apparent correlation with major changes in growth occurring at similar times and with apparent similar magnitudes. This suggests that the debt component of net worth is relatively constant, given that net worth is defined as the value of the housing stock less indebtedness.

Figure 4.1: Real house prices and net worth

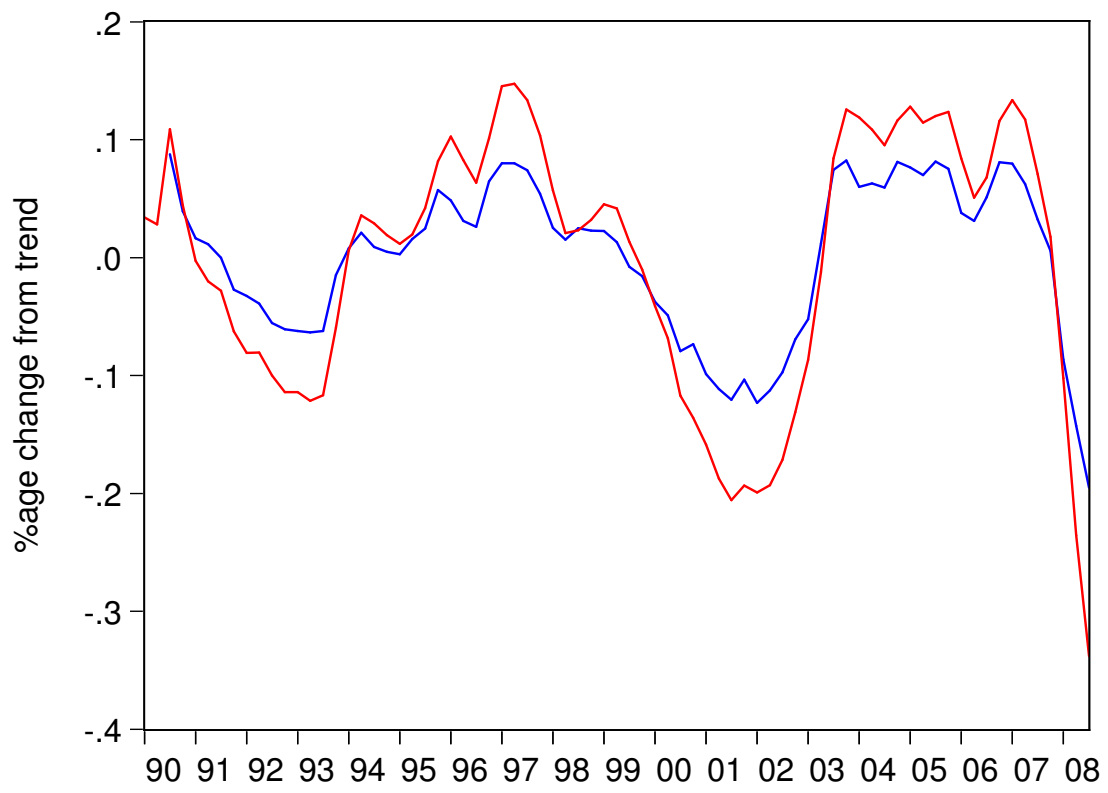

- Real net worth — Real house price

While short-term interest rates are typically included (especially with RBC-based approaches), I exclude it on the basis that it a) reduced the degrees of freedom in a relatively short sample period and b) it appeared to add little over and above the spread. Finally, the initial analysis was done using an exchange rate variable but this was dropped in favour of the terms of trade. The reason behind this was because the real exchange rate is arguably one-step further removed from the domestic economy. In the model set out in Chapters 2 and 3 the real exchange rate 
variables determine the price of intermediate imports which is more in-line with the definition of the terms of trade, making the terms of trade the more appropriate empirical counterpart to be used in the SVAR. The terms of trade is based on New Zealand dollar prices and could thus be viewed as the combination of global tradable prices in foreign currency and the exchange rate.

The seven variables of interest are: world GDP (WGDP), the terms of trade (TOT), government spending (GOV), household consumption (HH), New Zealand gross domestic product (GDP), house prices (RHPI) and the spread between the mortage interest rate and the risk-free interest rate (SPREAD). WGDP is a weighted average of GDP for economies that are relevant to New Zealand. TOT is the terms of trade as calculated by Statistics New Zealand. HH, GOV, and GDP are the household consumption, government consumption and gross domestic product components of expenditure-based GDP as calculated by Statistics New Zealand. SPREAD is the difference between the 90-day Treasury bill rate and the RBNZ's Variable First Home Mortgage rate. The variables are shown in their log level forms in Figure 4.2. The next step is to examine the series with a view to determining whether any transformation of the data is needed. In VAR models, this typically begin with an investigation into the possible presence of unit roots. Following Buckle, Kim, Kirkham, McLellan and Sharma (2007), I use a Hodrick-Prescott filter to detrend the data. The detrended data is presented in Figure (4.3). The use of an HP filter, like any filter, is not without possible drawbacks. Where data should not be filtered but has a filter applied, spurious cycles may be introduced (discussed in Cogley and Nason, 1995). Thus in order to check that spurious cycles have not influenced the subsequent results, the following SVAR model was also estimated using the raw data with no material difference in results observed.

The sample period runs from 1988Q2 to 2008Q3. Data before 1988 was not available on a consistent basis due to changes in statistical series or simply an absence of data. 2008 was used as cut off as later data was likely to be significantly affected by the global financial crisis and thus reflect changes in a number of deep institutional parameters. 
Figure 4.2: Variables in log levels
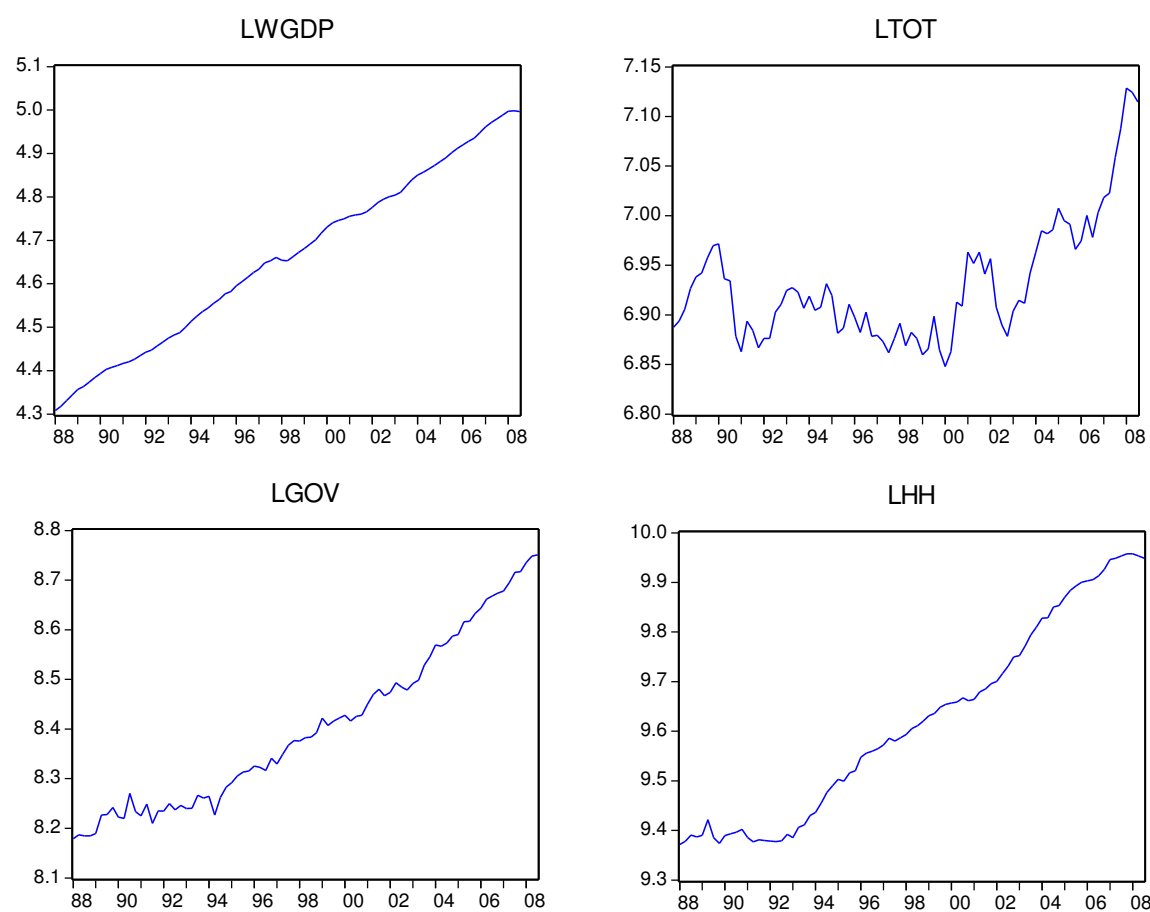

$\mathrm{LHH}$
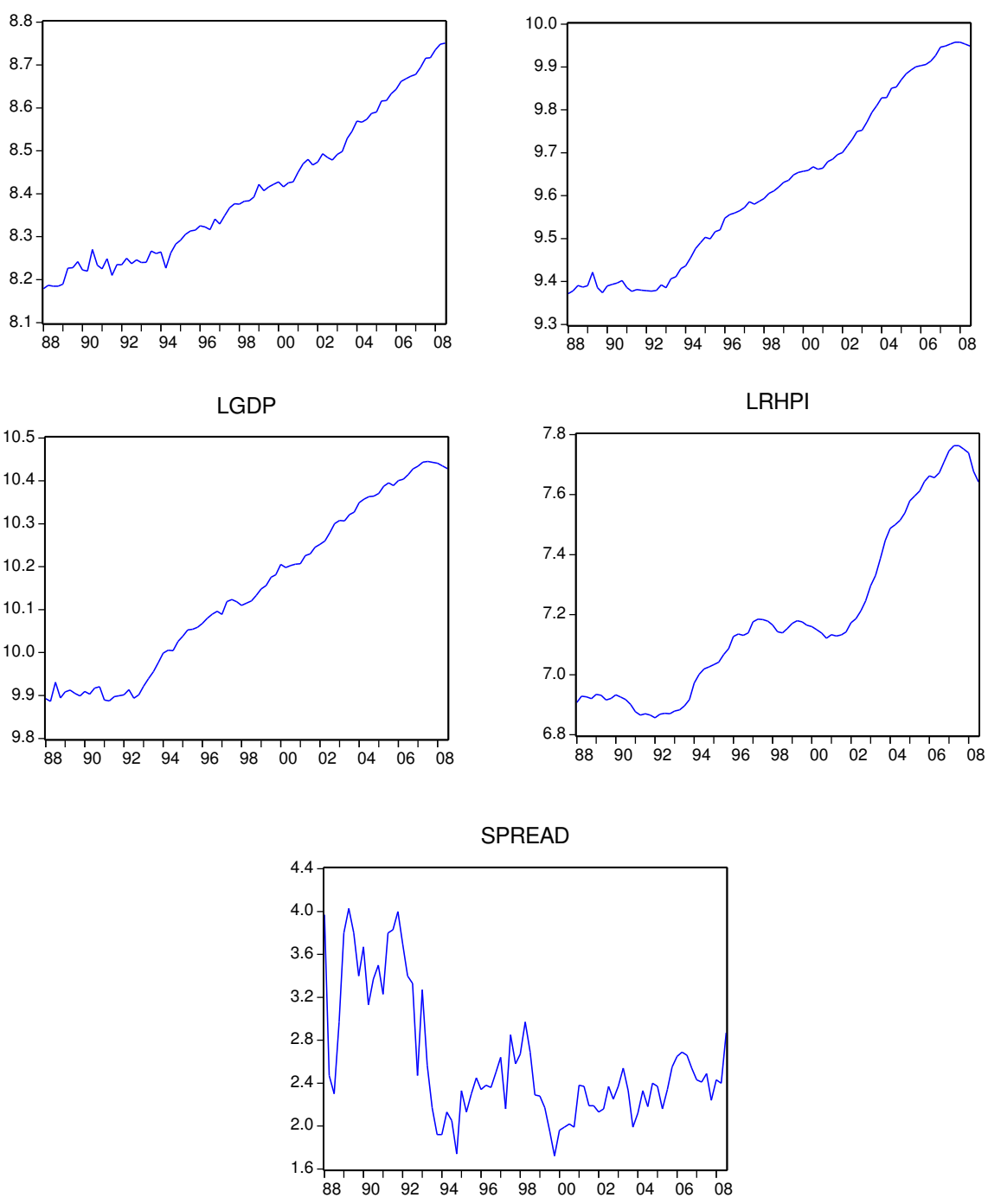
Figure 4.3: Variables detrended
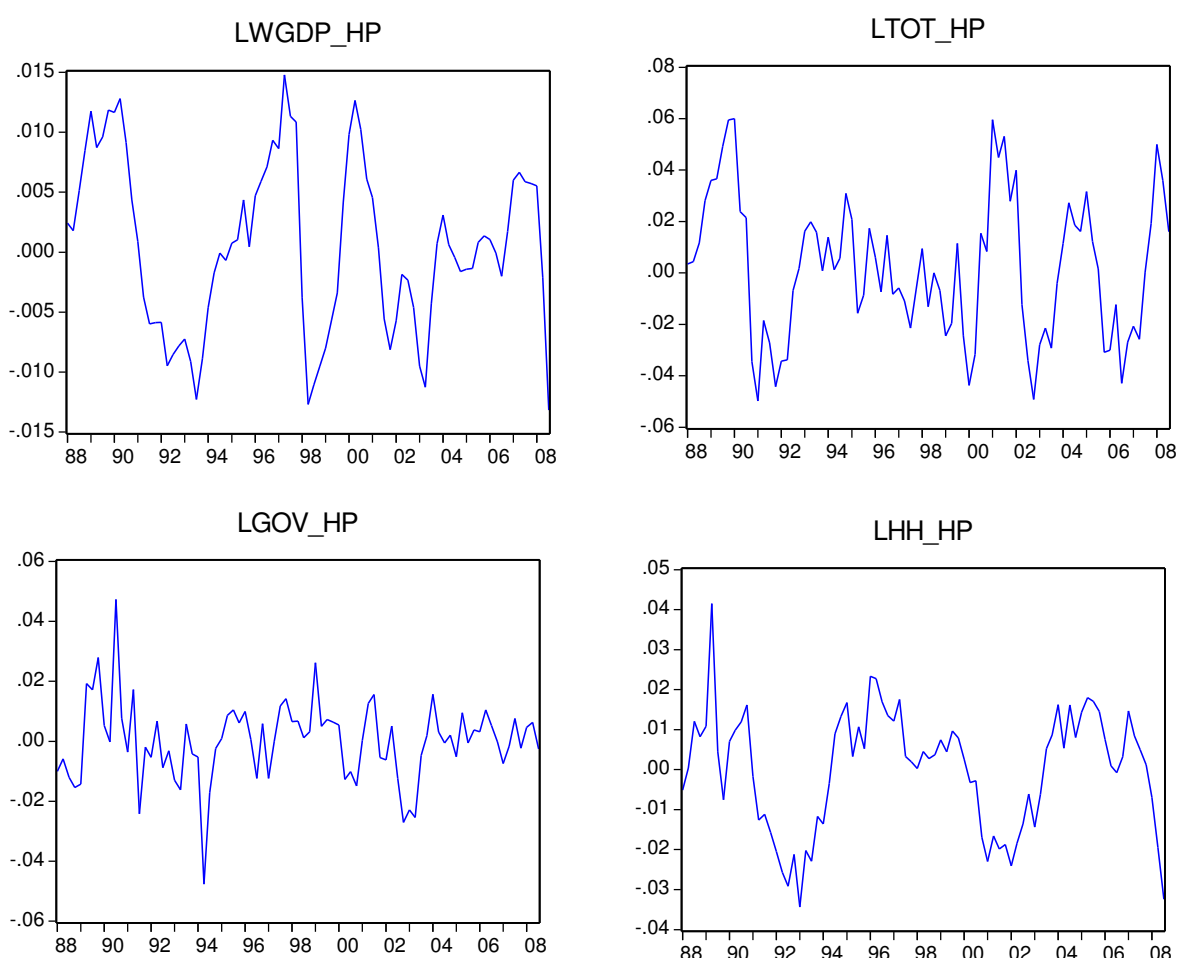

LHH_HP
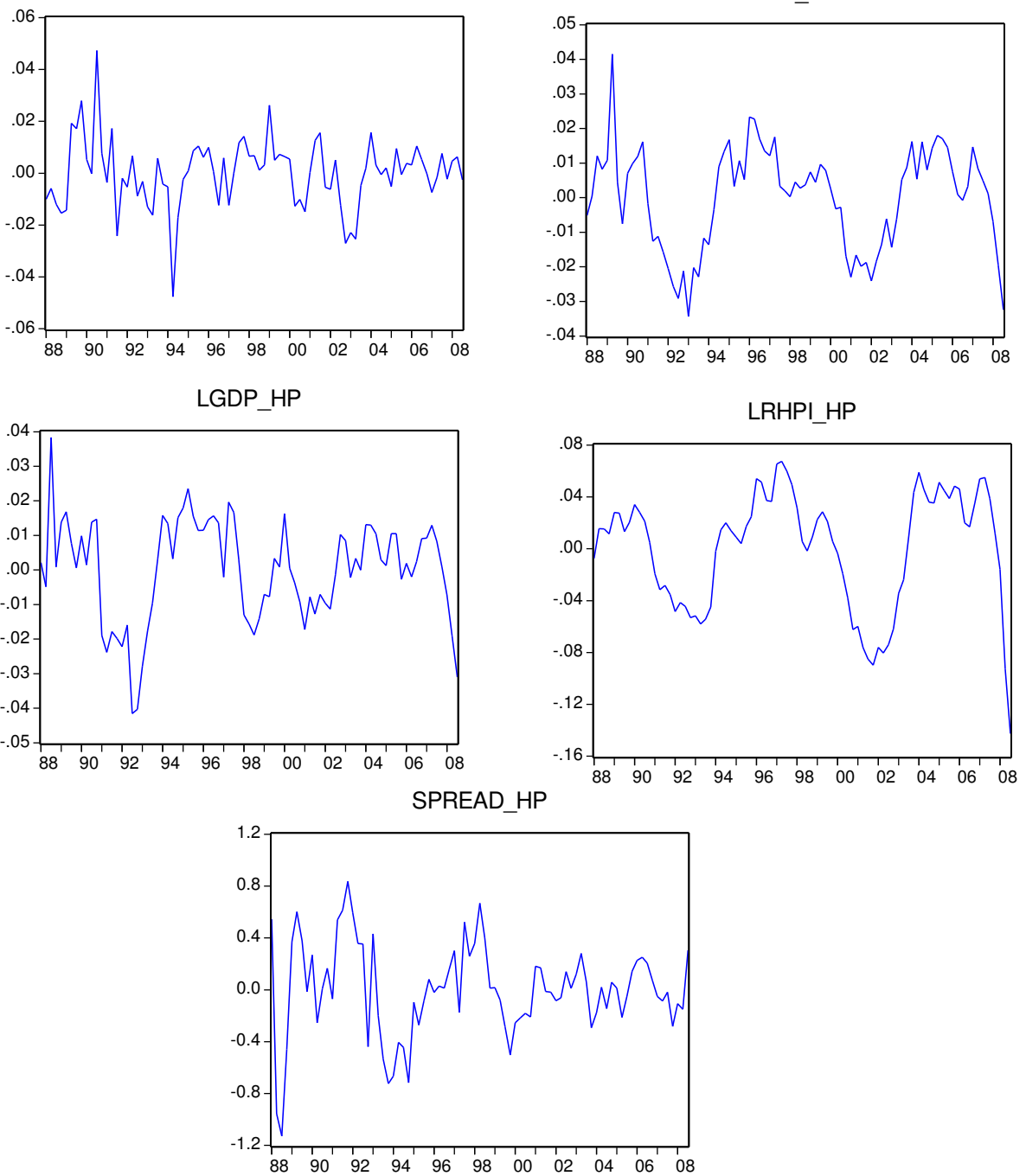


\subsection{Unit root testing}

The typical approach to VAR modelling, once variable selection has been done, is to examine each series for a possible unit root. As outlined in Enders (2004), where variables are stationary (i.e. no unit root is present) classical regression models may be applied without further manipulation of the data. However, when unit roots are present, the residuals obtained from each equation estimated using classical regression are not stationary and thus it is not possible to draw inferences or test hypotheses. The task then becomes one of identifying which variables contain unit roots and the appropriate treatment.

I use the method set out in Enders (2004), modified from Dolado, Jenkinson and Sosvilla-Rivero (1990), in which each series is modelled according to the following structure:

$$
\Delta y_{t}=a_{0}+a_{2} t+\gamma y_{t-1}+\sum_{i=1}^{p} \beta_{i} \Delta y_{t-i}+e_{t}
$$

The process tests the various components in order, modifying the test equation accordingly until a conclusion regarding the presence of a unit root is reached. Starting from the general equation, the process initially tests for whether gamma is zero. If this cannot be rejected, the next couple of steps check whether this result is due to the presence of a trend or a constant. Once the presence of a unit root is accepted, the order of integration is determined by the number of times the data must be differenced in order to reject the presence of a unit root. Enders summarises the process as reproduced in Figure 4.4.

The key test statistics for each variable are summarised in Table 4.1. The augmented Dickey Fuller test (ADF) is predicated on the number of lags (p) assumed in the process. There are a number of ways identifying the appropriate number of lags. Methods such as the Akaike (AIC) and Schwarz Information Criteria (SIC) are commonly used. I supplement this with a sequence of pare-down tests in which the regression equation is estimated with a declining number of lags, starting with 11 lags. This naturally has a tendency to select a high number of lags. The t-statistic for the coefficient on the longest is examined for significance and if none is found the number of lags is reduced and the regression re-estimated. The appropriateness of the selected value for $\mathrm{p}$ is also tested by examining the residual from the ADF 


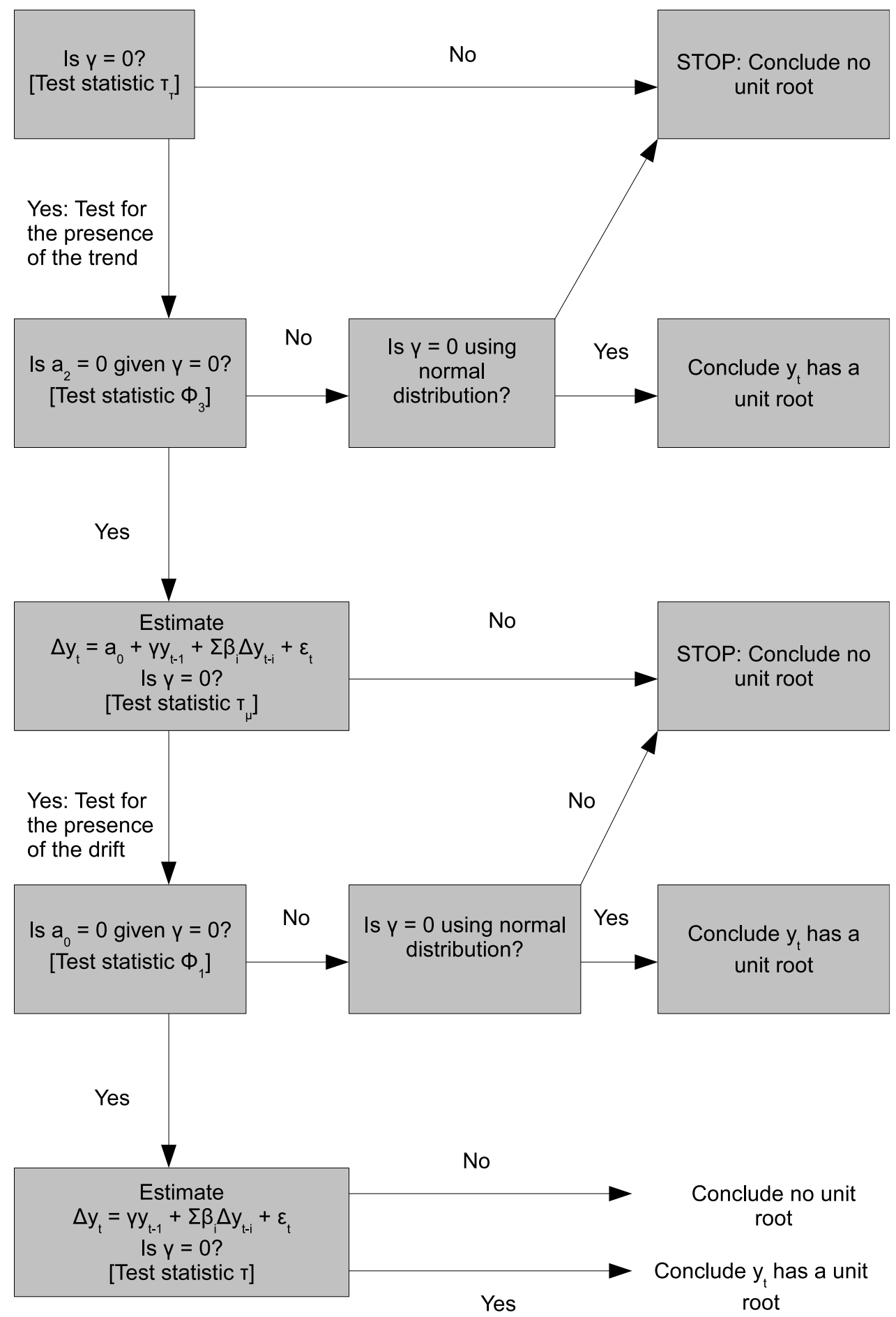

Figure 4.4: Enders (2004), p. 213, modified unit root testing procedure 
regression using the Ljung-Box Q-statistic.

Augmented Dickey-Fuller

\begin{tabular}{rrrrrrrrrrrr}
\hline & $\tau_{\tau}$ & & $\tau_{\mu}$ & & $\tau$ & $\Phi_{3}$ & $\Phi_{1}$ & & Order \\
\hline LWGDP & -4.053 & $* *$ & -4.052 & $* * *$ & -4.086 & $* * *$ & 8.708 & $* *$ & 8.251 & $* * *$ & 0 \\
LTOT & -5.298 & $* * *$ & -5.197 & $* * *$ & -5.229 & $* * *$ & 14.039 & $* * *$ & 13.503 & $* * *$ & 0 \\
LGDP & -2.667 & & -2.723 & $*$ & -2.750 & $* * *$ & 3.817 & & 3.761 & & 0 \\
LGOV & -6.186 & $* * *$ & -6.225 & $* * *$ & -6.263 & $* * *$ & 19.152 & $* * *$ & 34.501 & $* * *$ & 0 \\
LRHPI & -3.338 & $*$ & -3.441 & $*$ & -3.447 & $* * *$ & 5.925 & $*$ & 6.229 & $* *$ & 0 \\
SPREAD & -4.972 & $* * *$ & -5.006 & $* * *$ & -5.036 & $* * *$ & 12.508 & $* * *$ & 12.536 & $* * *$ & 0 \\
LHH & -3.326 & $*$ & -3.403 & $* *$ & -3.408 & $* * *$ & 5.704 & $*$ & 6.033 & $* *$ & 0 \\
\hline
\end{tabular}

Phillips-Perron

\begin{tabular}{|c|c|c|c|c|c|c|c|c|c|c|c|}
\hline & $\tau_{\tau}$ & & $\tau_{\mu}$ & & $\tau$ & & $\Phi_{3}$ & & $\Phi_{1}$ & & Order \\
\hline LWGDP & -3.609 & ** & -3.664 & $* * *$ & -3.676 & $* * *$ & 6.128 & * & 4.722 & $*$ & 0 \\
\hline LTOT & -4.273 & $* * *$ & -4.291 & $* * *$ & -4.319 & $* * *$ & 8.305 & $* *$ & 8.337 & $* * *$ & 0 \\
\hline LGDP & -3.397 & * & -3.436 & $* *$ & -3.467 & $* * *$ & 5.862 & * & 5.920 & $* *$ & 0 \\
\hline LGOV & -6.188 & $* * *$ & -6.227 & $* * *$ & -6.266 & $* * *$ & 19.152 & $* * *$ & 34.501 & $* * *$ & 0 \\
\hline LRHPI & -1.697 & & -1.779 & & -1.811 & * & 1.351 & & 0.427 & & 1 \\
\hline SPREAD & -5.204 & $* * *$ & -5.227 & $* * *$ & -5.253 & $* * *$ & 12.508 & $* * *$ & 12.536 & $* * *$ & 0 \\
\hline LHH & -2.563 & & -2.614 & $*$ & -2.641 & $* * *$ & 1.217 & & 3.385 & & 0 \\
\hline
\end{tabular}

* Significant at 10\% level ** Significant at 5\% level *** Signficant at $1 \%$ level

Italics indicate test unnecessary to reach conclusion

Table 4.1: Unit root test results - Detrended data

Given that ADF tests have a bias toward rejecting the null hypothesis of a unit root in the presence of structural breaks, I also use the Phillips-Perron (PP) test statistic. This abstracts from the assumed lag structure. The same process of testing is used with the PP test statistic.

The Enders unit root testing process resulted in rejection of the null of unit root for all variables regardless of whether the ADF or PP test was used with the one exception of real house prices. The ADF tests rejected a unit root but the PP failed to reject the null for LRHPI _HP. Given that this is the only series to indicate the presence of a unit root, there are two possible treatments. The first is to difference the HP-filtered series and then include this transformed series in the VAR. The second is to rely on the ADF tests and treat LRHPI _HP as stationary. Both versions were used as alternates in the SVAR and little difference to the results was found. Thus in order preserve consistency, the following analysis is based on the use of 


\section{LRHPI HP.}

Given the presence of a cointegrating vector for the data in level form (see below), this raises the question of the appropriate treatment of the data. One possible approach is to difference the data so as to make them stationary. However, as Lutkepohl (2005) notes:

“... a VAR process with cointegrated variables does not admit a pure

VAR representation in first differences."

Given that the log-deviations from trend are a close approximation to the percentage change for small changes, it is likely that detrending may well be subject to the same criticism.

Because most of the data would be I(1), it would then be necessary to test for cointegration. Typically data that is suspected of being cointegrated would be subject to further tests such as the Engle-Granger or Johansen tests. However, standard econometrics software assume that the variables are all endogenous or if exogenous only appear as current levels as opposed to lagged values (such as dummy variables). Because LWGDP is not endogenous, the standard application of a Johansen test is not appropriate. Boswijk and Doornik (2005) present an alternative method to estimate the distribution for the likelihood ratio used in the cointegration tests. Unfortunately, this is not accommodated in EViews.

The exogeneity of LWGDP not only causes problems for the cointegration test but also for the specification of the VAR itself. If some of the variables were cointegrated (and it would be reasonable to believe that at least some of the above selected variables would be), the appropriate framework to utilise is that of a Vector Error Correction Model (VECM). While based on the VAR formulation, the lagged variables are in difference form, in addition to one period lagged levels. However, as with the standard VAR formulation, the introduction of an exogenous series, such as LWGDP, means that conventional estimation software cannot be used to estimate the VECM.

Given the above issues, the detrending of the data provides a more tractable basis for estimating the VAR. Although detrending may well cause a loss of information, the primary focus here is on the impulse responses and thus the long-run relation- 
ships (embodied in the levels matrix contained in a VECM) are less relevant.

\subsection{Levels data}

\subsubsection{Unit root testing}

As is typically found with economic data, most of the series are I(1). World GDP is the only variable that clearly rejects the presence of a unit root. The terms of trade, government spending and the spread are all unambiguously I(1).

Augmented Dickey-Fuller

\begin{tabular}{|c|c|c|c|c|c|c|c|c|c|}
\hline & $\tau_{\tau}$ & & $\tau_{\mu}$ & $\tau$ & $\Phi_{3}$ & & $\Phi_{1}$ & & Order \\
\hline LWGDP & -3.7251 & $* *$ & -0.8354 & 4.0979 & 7.1617 & $* *$ & 9.1371 & $* * *$ & 0 \\
\hline LTOT & -1.4600 & & -0.8337 & 1.6083 & -31.8913 & & 4.6243 & & 1 \\
\hline LGDP & -2.5987 & & 0.2101 & 4.9789 & 3.5687 & & 0.0070 & & 1 \\
\hline LGOV & -1.0653 & & 1.9026 & 5.1023 & 2.9773 & & 14.9967 & $* * *$ & 1 \\
\hline LRHPI & -3.3838 & & -1.6253 & 0.7502 & 5.8201 & & 1.5367 & & 1 \\
\hline SPREAD & -2.5419 & & -2.1953 & -0.3789 & 3.2565 & & 2.4122 & & 1 \\
\hline LHH & -2.8874 & & 0.8837 & 3.5721 & 5.2887 & & 6.3064 & $* *$ & 1 \\
\hline
\end{tabular}

Phillips-Perron test results

\begin{tabular}{|c|c|c|c|c|c|c|c|c|c|c|}
\hline & $\tau_{\tau}$ & & $\tau_{\mu}$ & & $\tau$ & $\Phi_{3}$ & & $\Phi_{1}$ & & Order \\
\hline LWGDP & -3.7254 & ** & $\begin{array}{r}\mu \\
-1.6532\end{array}$ & & 13.0439 & 8.2849 & ** & 4.6243 & $* * *$ & 0 \\
\hline LTOT & -1.8652 & & -1.1536 & & 1.5186 & -31.8913 & & 0.3422 & & 1 \\
\hline LGDP & 3.5687 & & 0.0070 & & 5.1265 & 3.5687 & & 0.0070 & & 1 \\
\hline LGOV & -1.3958 & & 2.8086 & & 5.9978 & 2.6697 & & 0.5187 & & 1 \\
\hline LRHPI & -1.9164 & & 0.0704 & & 2.1953 & 2.4342 & & 0.2125 & & 1 \\
\hline SPREAD & -3.5191 & $* *$ & -2.8981 & ** & -1.0609 & 6.3379 & $* * *$ & -3.8826 & & 0 \\
\hline LHH & -2.3944 & & 0.9044 & & 5.3874 & 4.1369 & & 0.4689 & & 1 \\
\hline
\end{tabular}

* Significant at $10 \%$ level

$* *$ Significant at $5 \%$ level

*** Signficant at $1 \%$ level

Italics indicate test unnecessary to reach conclusion

Table 4.2: Unit root test results - Levels data

The Akaike and Schwarz criteria give conflicting results for the appropriate number of lags to be used in testing house prices. Regardless of the number of lags used, the Enders process results in the conclusion that there is a unit root in house prices. Although the Ljung-Box statistics show greater statistical significance for the resid- 
uals when $\mathrm{p}=1$, they remain below the $5 \%$ threshold. In order to facilitate the later analysis, I treat house prices as I(1).

Two other variables display behaviour that is dependant on the number of lags used in the ADF testing. I have identified New Zealand GDP as I(1) based on a combination of PP testing of the differenced series, a selection of 0 lags using SIC and the relatively low significance values for the lagged coefficients when estimated with six lags. The alternative, suggested by the AIC and pare-down procedure, is for 6 lags - which seems excessive and not in keeping with other VAR models. Although household consumption shows relatively low significance for the lagged coefficients when $\mathrm{p}=2$ (SIC selection) compared to $\mathrm{p}=5$ (AIC selection), the use of 5 lags leads to a conclusion that there is no unit root. This is in contrast to the PP testing which concludes that there is a unit root. Furthermore, the Ljung-Box Q-statistics suggest that $\mathrm{p}=2$ generates a residual series that is closer to white noise than $\mathrm{p}=5$. Thus I assume that household consumption is I(1).

\subsubsection{Cointegration}

The above results give one $\mathrm{I}(0)$ series and six $\mathrm{I}(1)$ series. This raises the issue of how to adequately deal with variables of mixed degrees of integration. In order for classical regression to be applicable, the I(1) series must be cointegrated so that their combination is stationary. With six I(1) series, there is a large number of potential cointegrating relationships. For example, there could be three different cointegrating relationships between two variables each, two relationships betwen three variables each or two relationships between two and four variables. This makes the EngleGranger approach of testing specific combinations impractical.

The Johansen method gives an alternative to the Engle-Granger method for identifying the number of cointegrating relationships. The Johansen method estimates the rank of the estimated matrix (П) to test the null hypothesis that the number of distinct cointegrating vectors is less than or equal to a given value, $r$. It should be noted that the Johansen method is also dependent upon the assumption of whether an intercept or trend is present in the data. While it would appear that there are trends in the log level data, the cointegration test uses differenced data and thus as Enders notes a trend should only be incorporated in the cointegration test when 
there is a clear economic rationale for its inclusion.

The above univariate ADF tests suggest that LWGDP is I(0) and need not be differenced. That said, given that LWGDP is likely to be exogenous with regard to the New Zealand data, using a standard VAR where the coefficients of the LWGDP equation with respect to the New Zealand data would not be assumed to be zero may result in estimated non-zero coefficients where none should exist. Although EViews can incorporate exogenous variables, their treatment is analagous to dummy variables, where they appear only as current explanatory variables in the form of:

$$
y_{t}=A_{1} y_{t-1}+A_{2} y_{t-2}+\cdots+A_{p} y_{t-p}+B x_{t}+e_{t}
$$

where $B$ is the matrix of coefficients for the exogenous variables, $x_{t}$. Thus it does not allow for past values of the exogenous variable to influence current endogenous variables.

As a result, using the standard Johansen methodology to test for cointegration in the presence of an exogenous lagged variable is somewhat problematic. One alternative is to apply a Johansen test to the domestic variables only with the international variables (LWGDP_HP and LTOT_HP) and their lags appearing as exogenous series, noting that this then removes the possibility of a relationship between the international variables. ${ }^{1}$ This issue would also occur when specifying a VECM given the related need to set both the long-run and short-run relationships so that the exogenous variable has zero coefficients with regard to the New Zealand data and also appears with a lag in the equations for the New Zealand variables.

Given the above issues with using a VECM with levels data, detrending and using a VAR approach obviates the need to apply non-standard processes such as Boswijk and Doornik (2005). Brady and Stimel (2011) note the difficulties associated with non-stationarity and cointegration and the use of VECMs and opt for use of loglevel data. Given this lack of clarity in the literature as to which is the appropriate method, the detrended model estimated in Section 4.8 was also run using log-level data and no material differences in the results were found.

\footnotetext{
${ }^{1}$ Adopting this approach, EViews suggests that there are four cointegrating relations.
} 


\subsection{Lag length selection}

Estimation of a VAR is based on an assumed number of lags. In order to ascertain the appropriate number of lags the AIC, SIC, and likelihood (LR) tests are employed. The two criteria choose very different lag lengths with the SIC selecting 1 lag only and the AIC selecting 6 (the maximum number of lags tested). The LR test consecutively tests the null hypothesis that the lag length is $p$ against the alternate that $p$ is of a larger specified value. The results of the lag length tests are shown in Table 4.3. The null is repeatedly rejected until testing $H_{0}: p=1$ verus $H_{1}: p=2$, implying that the lag length should be set to 2 .

The SIC is known to perform better with small samples (see Ivanov and Kilian, 2005) . However, when the actual lag length exceeds the maximum number of lags examined, the AIC is known to pick a better approximatation of the true data generating process. Given that the LR testing process also picks a relatively low number of lags, it seems more probable that the appropriate lag length for the model is relatively low. Thus I set the lag length to 2. Rerunning the model with 4 lags (not reported) does not result in significantly different results.

Lag selection criteria values

\begin{tabular}{rlllll}
\hline Criteria & $p=1$ & $p=2$ & $p=3$ & $p=4$ & $p=6$ \\
\hline AIC & -4500 & -4533 & -4516 & -4509 & $-4589^{*}$ \\
SIC & $-4383^{*}$ & -4316 & -4199 & -4092 & -3972 \\
\hline * Indicates selected lag length
\end{tabular}

Likelihood Ratio test

\begin{tabular}{rrrrr} 
& $H_{0}: p=1$ & $H_{0}: p=2$ & $H_{0}: p=3$ & $H_{0}: p=4$ \\
$H_{1}: p=2$ & $H_{1}: p=3$ & $H_{1}: p=4$ & $H_{1}: p=6$ \\
$\chi^{2}$ & 80.94 & 41.08 & 39.87 & 78.81 \\
Significance & 0.0048 & 0.8381 & 0.8701 & 0.9571 \\
\hline
\end{tabular}

Table 4.3: Lag length selection criteria and LR test

\subsection{Identification}

It is likely that at least some of the variables are affected contemporaneously by other variables. Hence, the underlying relationships are of the form:

$$
\beta x_{t}=\Gamma_{0}+\Gamma_{1} x_{t-1}+\Gamma_{2} x_{t-2}+\cdots+\Gamma_{p} x_{t-p}+\varepsilon_{t}
$$


Premultiplying by $\beta^{-1}$

$$
x_{t}=\beta^{-1} \Gamma_{0}+\beta^{-1} \Gamma_{1} x_{t-1}+\beta^{-1} \Gamma_{2} x_{t-2}+\cdots+\beta^{-1} \Gamma_{p} x_{t-p}+\beta^{-1} \varepsilon_{t}
$$

which is equivalent to the standard form VAR

$$
x_{t}=A_{0}+A_{1} x_{t-1}+\cdots+A_{p} x_{t-p}+e_{t}
$$

In order to achieve identification $\left(n^{2}-n\right) / 2$ restrictions must be imposed. I use a standard Choleski factorisation of $\beta$ to allow for exact identification, where

$$
\beta=\left(\begin{array}{ccccc}
1 & 0 & 0 & \ldots & 0 \\
\beta_{21} & 1 & 0 & \ldots & 0 \\
\beta_{31} & \beta_{32} & 1 & \ldots & 0 \\
\vdots & & & & \\
\beta_{71} & \beta_{72} & \beta_{73} & \ldots & 1
\end{array}\right)
$$

SVARs typically involve forms of restrictions other than a Choleski factorisation, including coefficinet restictions, variance restrictions and symmetry restrictions. As the SVAR used here is not intended to be a representation of a theoretical model, I have not attempted to use specific restrictions on individual elements of $\beta$. It should also be noted that additional restrictions may also have a cost in terms of the degrees of freedom which given the relatively short time series available may lead to a loss in efficiency.

\section{7 $\quad$ Ordering}

The Choleski factorisation lends itself well to the fact that LWGDP _HP is exogenous, as the imposed zeroes are equivalent to saying that LWGDP _HP is unaffected by contemporaneous values of all other variables. The ordering of variables in a Choleski factorisation is important given that it determines the extent to which the estimated error terms are affected by the underlying shocks and thence the variancecovariance matrix. As noted, it is reasonable to order LWGDP _HP first. Given the extent to which the prices of New Zealand's tradable goods are driven by offshore events, it is also reasonable to put the terms of trade variable second (and thus unaffected by New Zealand domestic events). There are three non-housing domes- 
tic activity variables: GDP, household consumption and government expenditure. Arguably, current government spending is not determined by the current level of activity or private sector spending. Thus LGOV_HP appears ahead of the other two in the ordering. Buckle et al. order domestic demand ahead of GDP. While there is no particularly strong reason for doing this, I similarly order the demand variable (household consumption) ahead of output (GDP). Reversing this to put GDP ahead of household consumption does not change the model output in any significant manner. The housing market variables are next with the financial accelerator implying that the spread should follow house prices (as the driver of net worth).

Thus the ordering is as follows: LWGDP_HP, LTOT_HP, LGOV_HP, LHH_HP, LGDP_HP, LRHPI_HP and SPREAD_HP.

\subsection{Estimation}

As noted above, the inclusion of an exogenous variable with lagged values means that the standard VAR approach to modelling is not applicable. Instead, I use Seemingly Unrelated Regression, a process also used by Buckle et al. (2007). This allows me to specify that the exogenous LWGDP_HP equation is dependent only upon its past history and not on any of the NZ data. It also allows lagged values of LWGDP _HP to appear in the equations for the New Zealand variables. Thus a series of equations are defined with LWGDP _HP depending only on its past history. Other equations include LWGDP _HP and its lags as an explanatory variable. In this regard, the VAR approach used here includes a relatively modest amount of structure over and above the standard VAR methodology. 


\subsection{SVAR equations}

$$
\begin{aligned}
& L W G D P_{-} H P_{t}=A_{01}+\sum_{i=1}^{2} A_{i}^{11} L W G D P_{-} H P_{t-i}+e_{1 t} \\
& L T O T \_H P_{t}=A_{02}+\sum_{i=1}^{2} A_{i}^{21} L W G D P_{-} H P_{t-i}+\sum_{i=1}^{2} A_{i}^{22} L T O T \_H P_{t-i}+e_{2 t} \\
& L G O V \_H P_{t}=A_{03}+\sum_{i=1}^{2} A_{i}^{31} L W G D P_{-} H P_{t-i}+\sum_{i=1}^{2} A_{i}^{32} L T O T_{-} H P_{t-i} \\
& +\sum_{i=1}^{2} A_{i}^{33} L G O V_{-} H P_{t-1}+e_{3 t} \\
& L H H_{-} H P_{t}=A_{04}+\sum_{i=1}^{2} A_{i}^{41} L W G D P_{-} H P_{t-i}+\sum_{i=1}^{2} A_{i}^{42} L T O T_{-} H P_{t-i} \\
& +\sum_{i=1}^{2} A_{i}^{43} L G O V \_H P_{t-1}+\sum_{i=1}^{2} A_{i}^{44} L H H_{-} H P_{t-i}+e_{4 t} \\
& L G D P_{-} H P_{t}=A_{05}+\sum_{i=1}^{2} A_{i}^{51} L W G D P_{-} H P_{t-i}+\sum_{i=1}^{2} A_{i}^{52} L T O T_{-} H P_{t-i} \\
& +\sum_{i=1}^{2} A_{i}^{53} L G O V \_H P_{t-1}+\sum_{i=1}^{2} A_{i}^{54} L H H_{-} H P_{t-i}+\sum_{i=1}^{2} A_{i}^{55} L G D P_{-} H P_{t-i}+e_{5 t} \\
& L R H P I_{-} H P_{t}=A_{06}+\sum_{i=1}^{2} A_{i}^{61} L W G D P_{-} H P_{t-i}+\sum_{i=1}^{2} A_{i}^{62} L T O T P_{-} H P_{t-i} \\
& +\sum_{i=1}^{2} A_{i}^{63} L G O V_{-} H P_{t-1}+\sum_{i=1}^{2} A_{i}^{64} L H H_{-} H P_{t-i}+\sum_{i=1}^{2} A_{i}^{65} L G D P_{-} H P_{t-i} \\
& +\sum_{i=1}^{2} A_{i}^{66} L R H P I_{-} H P_{t-i}+e_{6 t} \\
& S P R E A D \_H P_{t}=A_{07}+\sum_{i=1}^{2} A_{i}^{71} L W G D P_{-} H P_{t-i}+\sum_{i=1}^{2} A_{i}^{72} L T O T \_H P_{t-i} \\
& +\sum_{i=1}^{2} A_{i}^{73} L G O V_{-} H P_{t-1}+\sum_{i=1}^{2} A_{i}^{74} L H H_{-} H P_{t-i}+\sum_{i=1}^{2} A_{i}^{75} L G D P_{-} H P_{t-i} \\
& +\sum_{i=1}^{2} A_{i}^{76} L R H P I \_H P_{t-i}+\sum_{i=1}^{2} A_{i}^{77} S P R E A D \_H P_{t-i}+e_{7 t}
\end{aligned}
$$


where $A_{i}^{k l}$ represents the element at the row $k$ column $l$ of matrix $A_{i}$ consistent with Equation (4.6.3).

The resulting equations are grouped and OLS used to estimate the variance-covariance matrix of the residuals. Combined with the restrictions above, the remaining elements of $\beta$ can be identified using maximum likelihood (by way of the CVMODEL command in RATS). Unfortunately, this means that standard errors for the impulse responses cannot be directly calculated. The standard errors to the impulse response functions are created by bootstrapping. The observed residuals to the SVAR are randomly shuffled and $\beta$ is re-estimated and then in turn a new impulse response function for each variable is also created. This is repeated 1000 times and from this the standard deviation of the impulse response functions is calculated.

\subsection{Impulse response functions}

Figures (4.5a) and (4.5b) contain the impulse response functions for positive one standard deviation shocks to the spread and real house prices, respectively.

Contrary to the financial accelerator theory, a positive shock to house prices does not reduce the spread. The theory of the financial accelerator says that a positive shock to the ratio of net worth to housing value should reduce the riskiness of mortgage debt and thus reduce the spread between mortgage interest rates and the benchmark risk-free rate. However, the initial response of the spread is an unambiguous increase. The spread declines and by the fourth period after the shock is not significantly different from zero.

I note that the way in which the financial accelerator is modelled in Chapters 2 and 3 concentrates on the ratio of net worth (in essence the equity of houseowners) to the value of the housing stock. This is not identical to house prices. However, net worth and house prices are very closely correlated (the cross-correlation of house prices with net worth is around 0.93, see also Figure 4.1) suggesting that the housing stock and debt change relatively slowly compared to prices. In turn, this implies that house prices are the primary driver of net worth. In order to check this, the model was rerun with the net worth ratio instead of real house prices (results available on request) and the impulse responses to a shock to the net worth ratio was 
similar to the response to a real house price shock. 
Figure 4.5: Impulse response functions

(a) Spread shock impulse response function
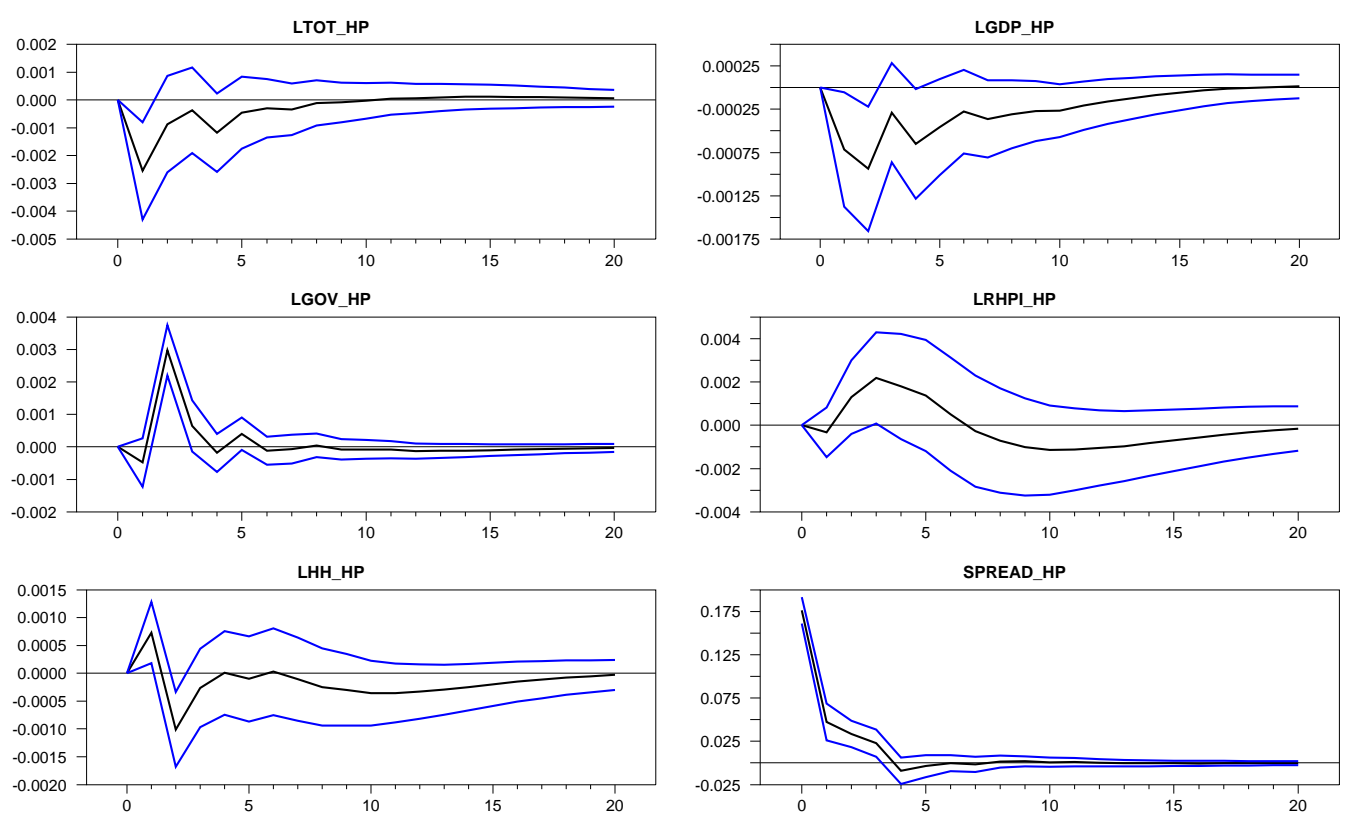

Responses to SPREAD_HP

(b) Real house price shock impulse response function
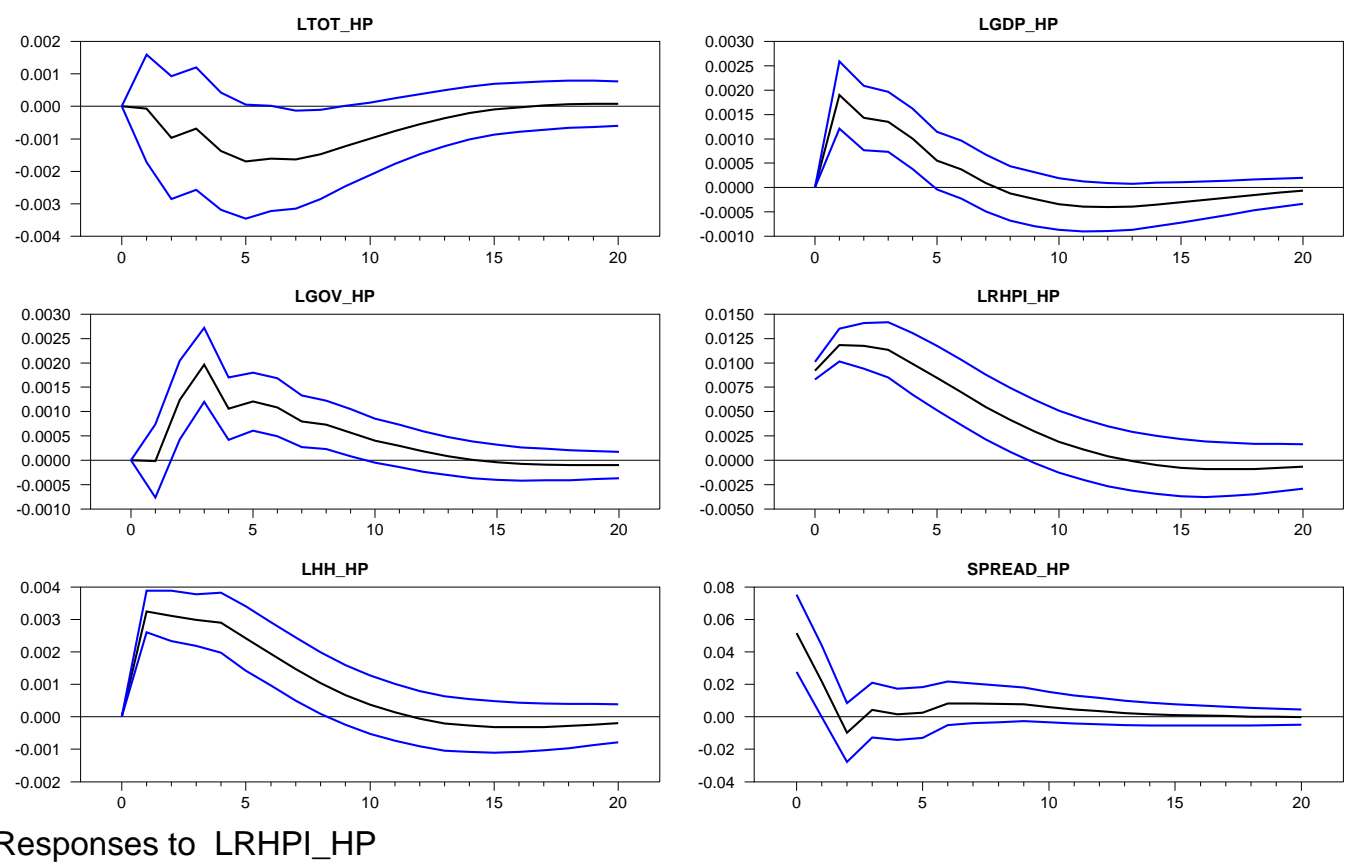

Responses to LRHPI_HP 
Figure 4.5: Impulse response functions (continued)

(c) Government spending shock impulse response function
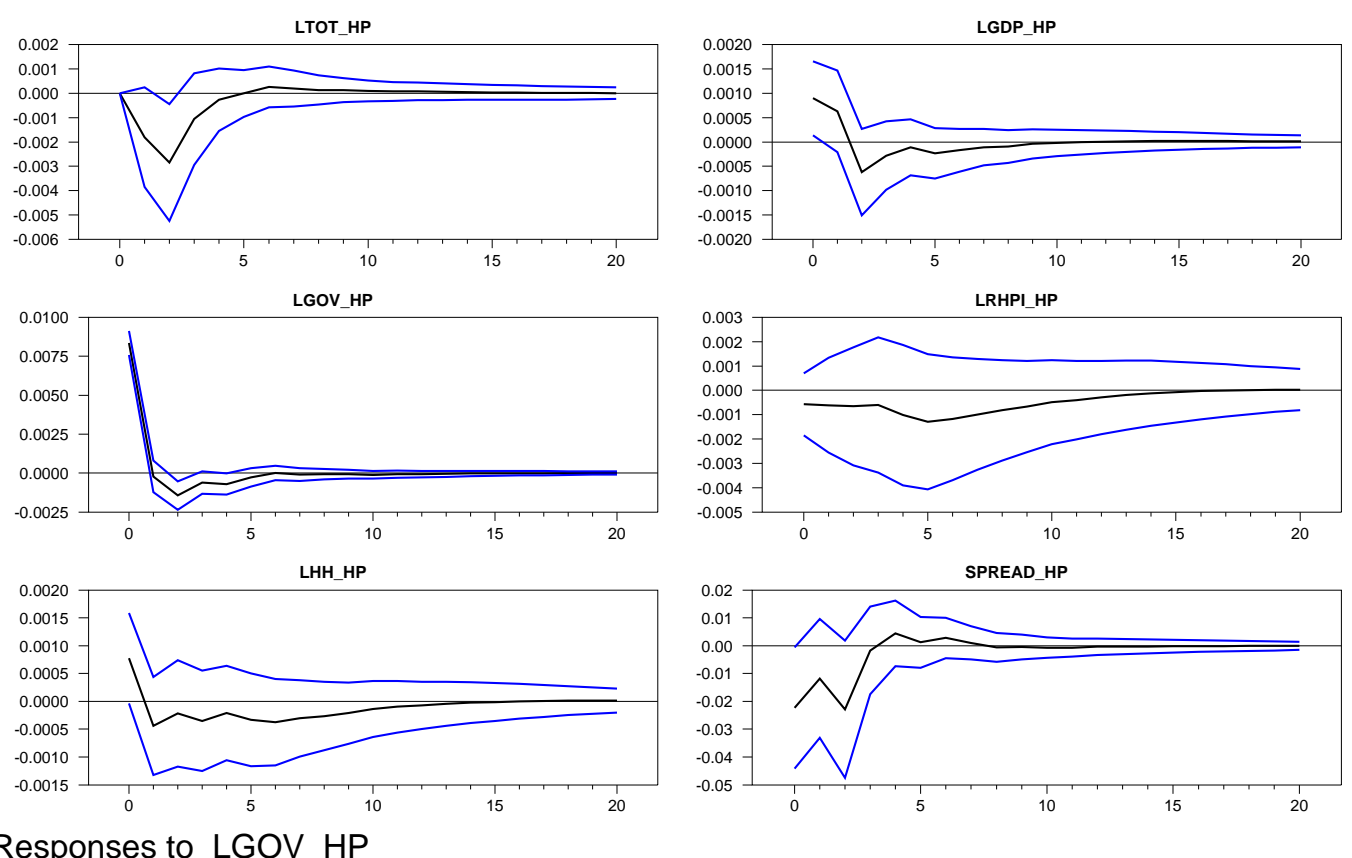

Responses to LGOV_HP

One possible explanation is that the source of the house price shock is important in determining the spread response. The models set out in Chapters 2 and 3 do not incorporate speculative bubbles, with house prices determined by a Tobin's $q$-type relationship. However, an increase in net worth generated by a speculative bubble in house prices may not be viewed as sustainable and therefore not decreasing the credit risk associated with mortgage lending.

Alternatively, the nature in which mortgages are funded may have a significant impact on their pricing. Given the large proportion of bank funding in New Zealand that originates from overseas rather than domestic savings, the spread may be determined more by long-term swap rates rather than considerations of credit risk. Indeed, the volatility of New Zealand Dollar swap rates, through which offshore funding is priced, is considerably higher than that of the IMF's New Zealand Dollar bank prime rate. The small and open (especially with regard to capital flows) nature of the New Zealand economy means that there is both a relatively small domestic pool of funds available for mortgage lending and a rapid pass-through from the internationalised swap markets to domestic mortgage rates. 
At the same time, the positive house price shock is associated with a positive household consumption response. Household expenditure is unambiguously positive in its response to a positive house price shock and the remains clearly so for two years. At first blush this would appear to support the general concept of a wealth effect, although as noted in Chapter 1, the exact theoretical underpinning is less convincing. Indeed, this positive consumption response does not rule out the possibility that a "common cause" is at work, serving to stimulate both house prices and household consumption at the same time. It should be noted that the IRFs do not in themselves say that households do not respond to the spread but that rather if the spread does have an effect on household spending, there appears to be another more significant mechanism that works in the same direction as the house price shock.

An interesting result is the response of government spending to the (positive) house price shock. This may reflect a strengthening of government revenues concurrent with (but not necessarily linked to) a rising housing market, allowing for an expansion of government spending.

The impulse responses to a spread shock provides only weak support for the view that there is a financial accelerator effect. In the period immediately following the positive shock the response by household consumption is unambiguously positive. This clearly contradicts the theory behind the accelerator as a wider spread should result in a decline in consumption. However, the initial positive household consumption response is reversed immediately and the median response is almost entirely negative thereafter. The error bands suggest that from the third quarter onwards, any impact on household consumption is not significant.

A shock to government spending has practically no significant impact on the housing market variables (see Figure 4.5c). Both the house price and spread error bands are mostly centred around the zero line. The spread does appear to have an initially negative reaction. The median responses for both these variables are initially negative with the spread moving into mildly positive territory over roughly the second year but this ebbs away while the house price response converges to zero from below. Although not significant, this tendency for a negative reaction is consistent with the model presented in Chapter 3 where government spending had a negative impact on the housing market. 


\subsection{Variance decomposition}

The variance decompostions for household consumption are given in Table 4.4a. The most striking feature here is that aside from its own innovations, variability in household consumption is attributable more to house price shocks rather than shocks to the broad activity measure of GDP. After two quarters (the first in which household consumption may respond to house prices by design) shocks to house prices account for 21 percent of household consumption movement. This is in sharp contrast to the 2 percent attributable to GDP shocks. By the fifth quarter, house price shocks explains over twice as much of the variability in consumption as for GDP. As with the IRFs, while this underscores the correlation between household consumption and house prices, it does not automatically follow that there is a causal relationship. Given that the linkage with general activity - as measured by GDP is of a lesser magnitude, one might argue that this does not support the "common cause" view of the house price-consumption relationship, particularly if one believes that expectations are strongly influenced by recent experience. That said, where a common cause is not tied to aggregate activity, the common cause view may still be valid.

Little of the movement in household consumption can be attributed to shocks to the spread. Less than 2 percent of the variation in household consumption may be explained by changes to the spread. By the second year following the shock, the spread contributes less than government spending shocks. A shock to the spread would likely have a small effect on spending given that when translated into dollars, a 50 basis point change to the mortgage interest rate would be relatively small in comparison to changes in other factors that impact on consumption (such as consumer prices). The small influence of government spending shocks is consistent with the view that households take into account the implied future tax implications.

The variance decomposition of the spread variable (Table 4.4c) suggests that house price shocks have at least as much effect on the spread as consumption and GDP individually. While this points to house prices being relatively important in terms of their contribution to spread variability, the magnitude is modest, beginning at 7 percent and falling to 5 percent. As noted above, if the spread is more influenced by funding costs than the net worth of households then the persistently high weight on its own innovations and the significant influence of shocks from the external econ- 
omy (particularly world GDP) are unsurprising.

House price variability (Table 4.4b) stems mainly from a combination of its own shocks, world GDP, household consumption and New Zealand GDP. Government spending shocks have an even smaller contribution to house price variability than they do to consumption which suggests that stimulatory fiscal policy is not a source of house price growth. This underscores the insignificant response of house prices to a positive government spending shock.

\begin{tabular}{rrrrrrrrr}
\hline Step & Std Error & LWGDP_HP & LTOT_HP & LGOV_HP & LHH_HP & LGDP_HP & LRHPI_HP & SPREAD_HP \\
\hline 1 & 0.006446 & 0.985 & 3.463 & 2.382 & 93.170 & 0.000 & 0.000 & 0.000 \\
2 & 0.008380 & 1.284 & 2.275 & 1.631 & 71.244 & 1.550 & 20.942 & 1.074 \\
3 & 0.009996 & 1.564 & 1.976 & 1.195 & 57.119 & 5.798 & 30.492 & 1.856 \\
4 & 0.011476 & 1.233 & 1.822 & 1.025 & 48.471 & 10.992 & 34.981 & 1.475 \\
5 & 0.012844 & 1.697 & 1.648 & 0.861 & 41.810 & 15.516 & 37.290 & 1.178 \\
6 & 0.014057 & 4.044 & 1.496 & 0.796 & 37.479 & 18.113 & 37.087 & 0.984 \\
7 & 0.015196 & 8.046 & 1.415 & 0.784 & 34.185 & 19.310 & 35.411 & 0.849 \\
8 & 0.016211 & 12.577 & 1.394 & 0.765 & 31.517 & 19.706 & 33.295 & 0.746 \\
12 & 0.018326 & 22.426 & 1.841 & 0.729 & 26.560 & 19.832 & 27.873 & 0.738 \\
16 & 0.018655 & 23.416 & 2.384 & 0.721 & 25.703 & 19.844 & 26.983 & 0.949 \\
20 & 0.018737 & 23.254 & 2.523 & 0.715 & 25.641 & 19.699 & 27.140 & 1.027 \\
\hline
\end{tabular}

(a) Variance decomposition for LHH_HP

\begin{tabular}{rrrrrrrrr}
\hline Step & Std Error & LWGDP_HP & LTOT_HP & LGOV_HP & LHH_HP & LGDP_HP & LRHPI_HP & SPREAD_HP \\
\hline 1 & 0.012623 & 11.127 & 0.741 & 0.233 & 11.352 & 4.027 & 72.521 & 0.000 \\
2 & 0.021518 & 11.923 & 0.387 & 0.200 & 9.102 & 6.526 & 71.833 & 0.030 \\
3 & 0.028697 & 8.473 & 0.766 & 0.207 & 10.388 & 11.480 & 68.343 & 0.343 \\
4 & 0.034817 & 5.862 & 1.027 & 0.186 & 12.117 & 15.029 & 64.860 & 0.919 \\
5 & 0.040206 & 6.760 & 1.031 & 0.228 & 13.853 & 16.789 & 60.201 & 1.139 \\
6 & 0.045215 & 10.462 & 0.872 & 0.296 & 15.017 & 17.445 & 54.737 & 1.172 \\
7 & 0.049695 & 15.108 & 0.722 & 0.340 & 15.437 & 17.646 & 49.692 & 1.055 \\
8 & 0.053414 & 19.229 & 0.653 & 0.369 & 15.454 & 17.762 & 45.614 & 0.919 \\
12 & 0.060889 & 26.734 & 1.106 & 0.406 & 14.553 & 18.578 & 37.792 & 0.832 \\
16 & 0.062282 & 27.744 & 1.699 & 0.414 & 14.069 & 18.848 & 36.211 & 1.014 \\
20 & 0.062543 & 27.612 & 1.893 & 0.412 & 14.051 & 18.732 & 36.192 & 1.107 \\
\hline
\end{tabular}

(b) Variance decomposition for LRHPI_HP

\begin{tabular}{rrrrrrrrr}
\hline Step & Std Error & LWGDP_HP & LTOT_HP & LGOV_HP & LHH_HP & LGDP_HP & LRHPI_HP & SPREAD_HP \\
\hline 1 & 0.228966 & 7.925 & 1.195 & 1.380 & 0.139 & 1.019 & 7.085 & 81.257 \\
2 & 0.257993 & 12.286 & 5.208 & 1.528 & 0.303 & 3.036 & 6.895 & 70.743 \\
3 & 0.276242 & 10.824 & 7.199 & 2.510 & 3.577 & 5.437 & 6.031 & 64.422 \\
4 & 0.283758 & 10.959 & 7.995 & 2.436 & 4.500 & 5.876 & 5.766 & 62.468 \\
5 & 0.291234 & 14.215 & 8.249 & 2.328 & 4.581 & 5.812 & 5.478 & 59.337 \\
6 & 0.299935 & 18.712 & 7.937 & 2.203 & 4.523 & 5.500 & 5.167 & 55.958 \\
7 & 0.305763 & 21.609 & 7.658 & 2.146 & 4.394 & 5.303 & 5.042 & 53.846 \\
8 & 0.308620 & 22.889 & 7.519 & 2.114 & 4.339 & 5.233 & 5.041 & 52.865 \\
12 & 0.311110 & 23.314 & 7.402 & 2.086 & 4.432 & 5.358 & 5.379 & 52.030 \\
16 & 0.313204 & 23.939 & 7.312 & 2.063 & 4.472 & 5.442 & 5.436 & 51.338 \\
20 & 0.313518 & 23.997 & 7.314 & 2.060 & 4.476 & 5.480 & 5.434 & 51.240 \\
\hline
\end{tabular}

(c) Variance decomposition for SPREAD_HP

Table 4.4: Variance decomposition 


\subsection{Concluding comments}

Overall, there is little evidence from the empirical data that there is a financial accelerator effect in New Zealand. It is possible that a financial accelerator effect exists in that, all other things constant, a change in the net worth of households would influence the spread but if there are other influences on the mortgage rate (such as funding costs) that have a bigger impact, the linkage from house prices (via the net worth ratio) to the spread may well be swamped. In addition, the data does not clearly support a linkage from the spread to consumption. That said, the impulse responses and variance decomposition results point to a significant correlation between house prices and spending. In other words, despite the apparent lack of a financial accelerator there remains evidence of a high level "wealth effect".

The inclusion of government spending allows for examination in part of whether fiscal policy has an influence on house prices. The median IRFs suggest that government spending has a negative impact on both the housing market and consumption but as with the financial accelerator, the impact is not significant. 


\section{Chapter 5}

\section{Conclusions and potential future research}

\subsection{The DSGE models}

The financial accelerator has been posited as a mechanism through which the value of housing might influence consumption expenditure. This thesis incorporates a financial accelerator into a DSGE model with an explicit housing sector. It builds on work by Bernanke, Gertler and Gilchrist (1999) and Aoki, Proudman and Vlieghe (2002). The model extends the preceding work by opening the economy to international trade in goods and capital. For a small open economy like New Zealand's, incorporating such elements is essential in order to capture key economic drivers and their impact on the housing market.

The exchange rate and international trade and capital flows are key adjustment mechanisms that impact on the housing market and the manner in which it adjusts. In comparison to the closed economy models of BGG and APV, the incorporation of the exchange rate moderates the response to a nominal interest rate shock, resulting in smaller and shorter responses by both the housing market and non-housing market variables.

In contrast to the earlier literature, I find that the financial accelerator, while amplifying the effect of a nominal interest rate shock on the housing market, dampens the response of non-housing market variables. Following an unexpected reduction in the nominal interest rate, the model with the financial accelerator switched on 
displays a smaller decline in the real interest rate compared to the model without the financial accelerator. Thus the stimulatory effect is moderated. A similar result occurs when comparing the responses of the basic model and the model with the financial accelerator switched off, to technology, real foreign interest rate, and foreign demand shocks.

I extend the basic open economy model further by including an explicit fiscal sector. Government spending is financed by a combination of lump-sum taxes and government debt. The split between these two is determined by the fiscal rule. The fiscal authority faces a budget constraint that equates spending (on goods and debt repayment including interest) with income (taxes and the funds from new debt issuance).

I find that government spending has a modestly positive impact on aggregate consumption in the baseline model but this impact varies depending on the proportion of ROT consumers assumed. For example, even when PIH consumers make up only 31 percent of consumers, household consumption reacts positively to government spending shocks but when this is increased to 99 percent the reaction is negative. In contrast, the impact of a government spending shock on the housing market is negative regardless of the proportion of consumers that are PIH, with a negative reaction across house prices, housing capital, investment, the dividend and the relative price of rent. The size of the fiscal model responses to government spending shocks suggests that were the model to be subjected to a variety of shocks over time, the impact of the government spending shocks would be hard to discern.

\subsection{The SVAR}

In Chapter 4 I examine the New Zealand data using a Structural Vector Auto Regression (SVAR) model. I find that data provides no support for the contention that there is a financial accelerator. Indeed, the impulse responses of the spread between the mortgage rate and the benchmark (risk-free) interest rate react in the opposite manner to that suggested by the DSGE models of Chapter 2 and 3. Similarly, the variance decomposition of movement in the spread attributes only a small proportion to house price shocks. It is possible that in reality the mortgage rate is 
determined by a number of other factors, including funding costs, and the linkage between house prices and the spread is too weak to be apparent. This suggests that including other variables that capture these funding costs may be necessary in order to estimate the impact of house prices or net worth on the spread.

The spread may have a small effect on household spending. Whereas the DSGE model suggests that a positive shock to the spread should dampen consumption, the IRFs from a shock to the spread initially indicate a rise in consumption. This is quickly reversed and, subject to the fairly wide standard error bands, consumption is slightly below the trend over the remainder of the five-year horizon used. Thus although the response of consumption over time appears to be consistent with the models of the earlier chapters, it is not significant enough for one to conclude that empirically the spread does impact on consumption. Combined with the variance decomposition data, which also show that little of the movement in consumption can be atributed to shocks to the spread, the SVAR provides only weak evidence for the existence of a financial accelerator effect.

Consistent with the results from the DSGE models, the SVAR suggests that government spending does not have a significant sustained effect on the housing market or even household consumption. The IRF's of house prices and consumption do not deviate significantly from zero in terms of their response to a government spending shock and little of their movement is attributed to government spending shocks. I note that apart from an initially positive response of household consumption to a government spending shock, the median responses of both house prices and household consumption are negative, albeit not significantly so. The negative responses are also consistent with the responses of the DSGE model in Chapter 4.

The econometric data does confirm the widely observed correlation between house prices and consumption. This thesis has shown that a DSGE model of the New Zealand economy exhibits the correlation of consumption with house prices despite the absence of a direct wealth effect. Moreover, this result is still present in the absence of a financial accelerator. Although this does not disprove that a wealth effect exists, the models in Chapters 2 and 3, supported by the evidence of Chapter 4, are consistent with a "common cause" view of the housing-consumption relationship. 


\subsection{Future research}

There are a number of avenues for further work, six of which I suggest below.

The widespread empirical relationship between house prices and consumption has been used by proponents of the wealth effect as the reason for positing a direct relationship between the two. This is embodied in this thesis by way of the dividend from homeowners to consumers. However, the behavioural equations behind this should be based more firmly on microeconomic theory. One way of doing this, as noted by Buiter (2008) is to introduce into the DSGE models a "bubble" element in house prices that reflects a degree of myopia.

Second, in Chapters 2 and 3 the behaviour of the homeowner component of the household is based on equilibrium relations rather than an explicit maximisation problem. This does not quantify the impact of rental income on homeowners, which may be useful given that PIH households are not just owner-occupiers but also landlords (to the ROT renters). Thus there is scope to expand the model to explicitly describe the behaviour of the homeowners and the associated budget constraint incorporating rental income from ROT consumers.

Third, Stillman and Maré (2008) find that immigration, particularly that due to returning New Zealanders, has a significant impact on house prices. The DSGE model in this thesis is framed in terms of representative agents and thus abstracts from demographic factors (e.g. population growth, migration). Thus the housing capital variable is equivalent to the housing stock per capita. One possible way to represent population shocks is to examine the impact of a negative shock to the housing stock.

Fourth, the models set out in Chapters 2 and 3 do not explicitly model the behaviour of financial intermediaries or their funding costs. The addition of an explicit financial intermediary sector (see, for example, Claus, 2005) would allow for a more rigorous treatment of funding costs. While this is captured to some extent by the De Paoli (2009) approach to setting the domestic interest rate as a function of foreign debt, a more developed treatment of financial intermediaries may further strengthen the effect of foreign interest rates on the domestic housing market. 
Fifth, government spending reflects, in part, the fiscal stance of the Government. The model presented in Chapter 3 is relatively simple with taxation set on a lumpsum basis. This approach is consistent with DSGE models developed by a number of central banks (see, for example, Dib et al., 2008,). However, there is scope for further development of the fiscal sector. Possible avenues for extension include labour and consumption taxes, transfers and automatic stabilizers (e.g. Zubairy, 2010). Such extensions would partly endogenise tax rates and spending, and potentially result in a richer dynamic response to the various shocks.

Finally, in Chapter 4 the terms of trade has been assumed to be dependent on the domestic economy on a lagged basis but dependent only on world GDP on a contemporary basis. Evans and Wells (1982) suggest that exogeneity is more justifiable when the terms of trade is calculated on a foreign currency basis. As the Statistics New Zealand series is calculated on a New Zealand dollar basis, there is likely to be a degree of endogeneity. One possible approach would be to replace the current terms of trade series with a foreign currency terms of trade series and a separate exchange rate variable although the addition of another variable to the SVAR may also lead to insufficient observations.

While the literature on financial accelerators, and particularly their relevance to the housing market, has developed in recent years, the empirical evidence is not strongly supportive at least in the context of the New Zealand data. Given the increasing focus on housing as a transmission mechanism of monetary policy and other shocks, further research in this area is necessary in order to determine the extent to which the housing market does indeed amplify or instead simply reflect macroeconomic shocks. 


\section{Bibliography}

[1] Ahmad, Y., M.C. Lo and O. Mykhaylova (2011), Volatility, persistence and nonlinearity of simulated DSGE real exchange rates, University of Wisconsin Whitewater Department of Economics Working Paper 11-01.

[2] Aoki, K., J. Proudman and G. Vlieghe (2002), 'House prices, consumption, and monetary policy: a financial accelerator approach', Bank of England Working Paper 169.

[3] Aoki, K., J. Proudman and G. Vlieghe (2002a), 'Houses as collateral: Has the link between house prices and consumption in the U.K. changed?', FRBNY Economic Policy Review 8.

[4] Aoki, K., J. Proudman and G. Vlieghe (2004), 'House prices, consumption, and monetary policy: a financial accelerator approach', Journal of Financial Intermediation 14, 414-435.

[5] Aron, J., J.V. Duca, J. Muellbauer, K. Murata and A. Murphy (2010), 'Credit, housing collateral and consumption: Evidence from the U.K., Japan and the U.S.', Centre for Economic Policy Research Discussion Paper No. 7876.

[6] Attanasio, O., A. Leicester and M. Wakefield (2011), 'Do house prices drive consumption growth? The coincident cycles of house prices and consumption in the U.K.', Journal of the European Economic Association 9, 399-437.

[7] Beneš, J., A. Binning, M. Fukač, K. Lees and T. Matheson (2009), 'K.I.T.T.: Kiwi Inflation Targeting Technology', Reserve Bank of New Zealand.

[8] Bernanke, B., M. Gertler, and S. Gilchrist (1999), The financial accelerator in a quantitative business cycle framework, in J.B. Taylor and M. Woodford, eds, 'Handbook of Macroeconomics', Vol.1 C, Chapter 21, North Holland. 
[9] Bjørnland, H.C. and D.H. Jacobsen (2008), 'The role of house prices in the monetary policy transmission mechanism in the U.S.', Norges Bank Working Paper 2008/24.

[10] Bjørnland, H.C. and D.H. Jacobsen (2010), 'The role of house prices in the monetary policy transmission mechanism in small open economies', Journal of Financial Stability 6, 218-219.

[11] Black, R., V. Cassino, A. Drew, E. Hansen, B. Hunt, D. Rose and A. Scott (1997), 'The Forecasting and Policy System: the core model,' Reserve Bank of New Zealand Research Paper 43.

[12] Blanchard, O. and R. Perotti (2002), 'An empirical characterization of the dynamic effects of changes in government spending and taxes on output', The Quarterly Journal of Economics 117, 1329-1368.

[13] Boswijk, H.P. and J.A. Doornik (2005), 'Distribution approximations for cointegration tests with stationary exogenous egressors', Journal of Applied Econometrics 20, 797810 .

[14] Brady, R.R. and D.S. Stimel (2011), 'How the housing and financial wealth effects have changed over time', The B.E. Journal of Macroeconomics 11.

[15] Brook, A. (2011), 'Making fiscal policy more stabilising in the next upturn: Challenges and policy options', Paper presented at the June 2011 forum: New Zealand's Macroeconomic Imbalances - Causes and Remedies.

[16] Buckle, R.A., K. Kim, H. Kirkham, N. McLellan and J. Sharma (2007), 'A structural VAR business cycle model for a volatile small open economy', Economic Modelling 24, 990-1017.

[17] Buiter, W.H. (2008), 'Lessons from the North Atlantic financial crisis', Paper prepared for presentation at the conference The Role of Money Markets" jointly organised by Columbia Business School and the Federal Reserve Bank of New York on May 29-30.

[18] Buiter W.H.(2010), 'Housing wealth isn't wealth', Economics: The OpenAccess, Open-Assessment E-Journal Vol. 4, 2010-22. 
[19] Campbell, J.Y. and N.G. Mankiw (1989), 'Consumption, income and interest rates: Reinterpreting the time series evidence', NBER Macroeconomics Annual 1989, Vol. 4, 185-246.

[20] Case, K.E., J. M. Quigley and R. J. Shiller (2001), 'Comparing wealth effects: The stock market versus the housing market', The B.E. Journal of Macroeconomics: Advances in Macroeconomics, 5(1), 1-32.

[21] Claus, I. (2005), 'Financial intermediation and the cost of capital in an open economy', CAMA Working Paper 18/2005.

[22] Cogley, T.F. and J.M. Nason (1995), 'Effects of the Hodrick-Prescott filter on trend and difference stationary time series: Implications for business cycles research', Journal of Economic Dynamics and Control 19, 253-278..

[23] De Paoli, B. (2009), 'Monetary policy under alternative asset market structures: The case of a small open economy', Journal of Money, Credit and Banking 41.

[24] De Veirman E.D. and A. Dunstan (2008), 'How do housing wealth, financial wealth and consumption interact? Evidence from New Zealand', RBNZ Discussion Paper 2008/05.

[25] Dib, A., C. Mendicino and Y.H. Zhang (2008), 'Price level targeting in a small open economy with financial frictions: welfare analysis', Bank of Canada Working Paper 2008-40.

[26] Dolado, J.J., Jenkinson, T., and Sosvilla-Rivero, S. (1990), 'Cointegration and unit roots', Journal of Economic Surveys 4, 249-273.

[27] Elbourne, A. (2007), 'The UK housing market and the monetary policy transmission mechanism: An SVAR approach', Journal of Housing Economics 17, $65-87$.

[28] Enders, W. (2004), Applied Econometric Time Series, Wiley.

[29] Evans, L.T. and G.M. Wells (1982), 'Granger causality and econometric exogeneity: An application with implications for New Zealand macroeconometric models', New Zealand Economic Papers 16, 157-173.

[30] Fisher L.A., G. Otto and G.M. Voss (2010), 'The response of Australian consumption to housing wealth', Journal of Macroeconomics 32, 284299. 
[31] Galí, J., J. Vallés and J.D. López-Salido (2004), 'Rule-of-Thumb Consumers and the Design of Interest Rate Rules', Journal of Money, Credit and Banking 36, 739-763.

[32] Galí, J., J. Vallés and J.D. López-Salido (2007), 'Understanding the effects of government spending on consumption', Journal of the European Economic Association 5, 227-270.

[33] Grimes A., and A. Aitken (2006),'Housing supply and price adjustment', Motu Working Paper 06-01.

[34] Iacoviello, M. and R. Minetti (2008), 'The credit channel of monetary policy: Evidence from the housing market', Journal of Macroeconomics 30, 69-96.

[35] Iacoviello, M. and S. Neri (2010), 'Housing market spillovers: Evidence from and estimated DSGE model', American Economic Journal: Macroeconomics 2, 125-164.

[36] Ivanov, V and L. Kilian (2005), 'A practitioners guide to lag order selection for VAR impulse response analysis', Studies in Nonlinear Dynamics \& Econometrics 1, 4-37.

[37] Liu, P. (2006), 'A small New Keynesian model of the New Zealand economy', RBNZ Discussion Paper 2006/03.

[38] Liu, Z., P. Wang and T. Zha (2010), 'Do credit constraints amplify macroeconomic fluctuations?' Federal Reserve Bank of Atlanta Working Paper 2010-1.

[39] Lütkepohl, H. (2005), New Introduction to Multiple Time Series Analysis, Berlin, Springer-Verlag.

[40] Mankiw, N.G. (2000), 'The savers-spenders theory of fiscal policy', American Economic Review 90, Papers and proceedings of the 112th Annual Meeting of the AEA, 120-125.

[41] McCallum, B. T. and Nelson, E. (1999), 'Nominal income targeting in an openeconomy optimizing model', Journal of Monetary Economics 43, 553578.

[42] Obstfeld, M. and Rogoff, K. (1996), Foundations of international macroeconomics, The MIT Press, Chapter 10. 
[43] Shifer, E., and R.H. Thaler (2006), 'Invest now, drink later, spend never: On the mental accounting of delayed consumption', Journal of Economic Psychology 27, 694-712.

[44] Smith, M. (2010), 'Evaluating household expenditures and their relationship with house prices at the microeconomic level', RBNZ Discussion Paper 2010/01.

[45] Stillman, S. and D.C. Maré (2008), 'Housing markets and migration: Evidence from New Zealand', Motu Working Paper 08-06.

[46] Sutton, G. (2002), 'Explaining changes in house prices', BIS Quaterly Review September.

[47] Szeto, K.L. (2002), 'A dynamic computable general equilibrium (CGE) model of the New Zealand economy', Treasury Working Paper 02/07.

[48] Thoenissen, C. (2004), 'Real exchange rates, current accounts and the net foreign asset position', Money Macro and Finance (MMF) Research Group Conference 200471.

[49] Uhlig, H. (1995), 'A toolkit for analyzing nonlinear dynamic stochastic models easily', Tilburg University Center for Economic Research Discussion Paper 1995-97.

[50] Zubairy, S. (2010), 'On fiscal multipliers: Estimates from a medium scale DSGE model', Bank of Canada Working Paper 2010-30. 
Appendices 


\section{Appendix A}

Comparison of basic model with and without financial accelerator to other shocks 
Figure A.1: Response to a $1 \%$ technology shock, basic model with and without the financial accelerator
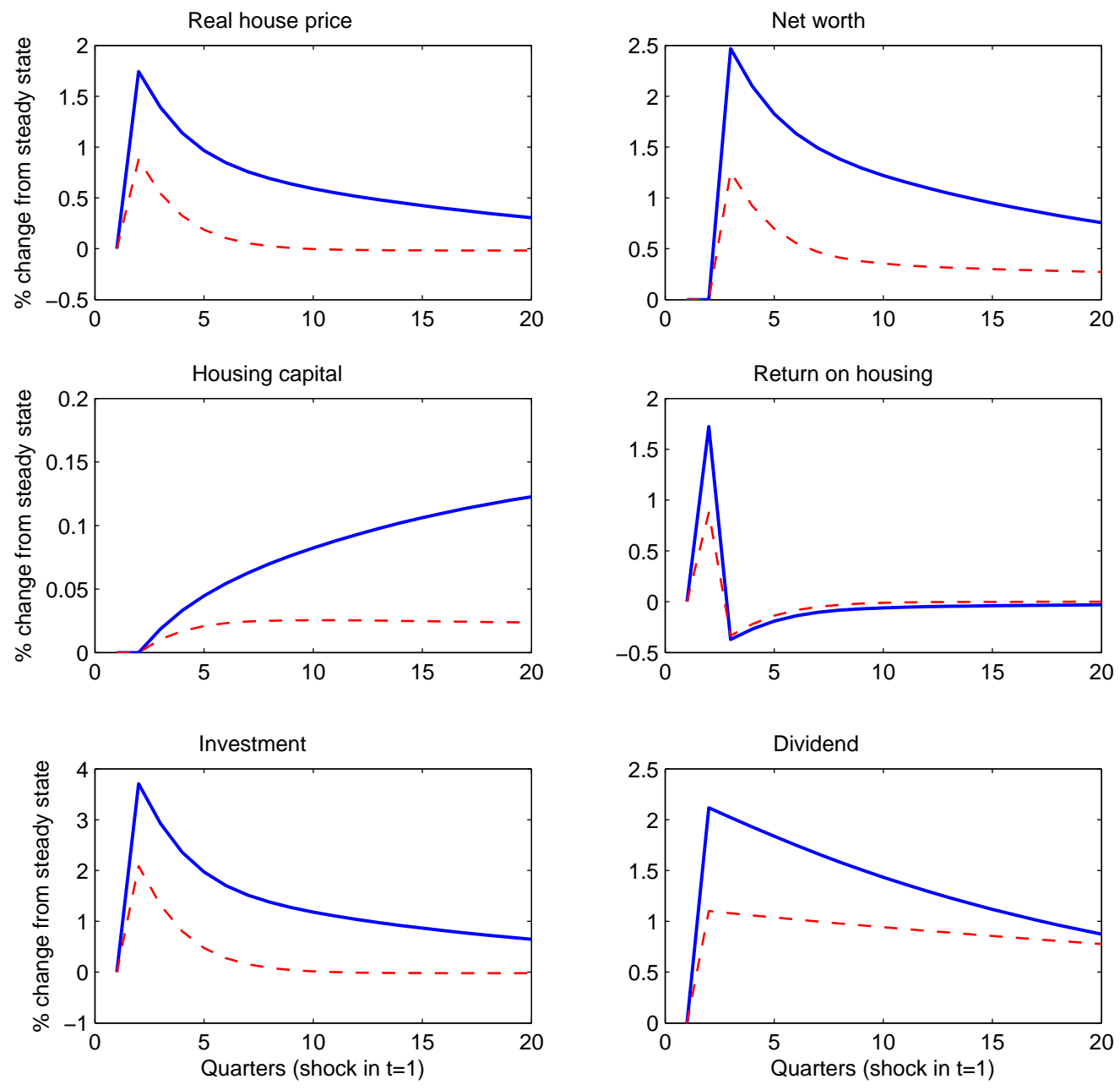

Basic model --- No accelerator 
Figure A.1: Response to a $1 \%$ technology shock, basic model with and without the financial accelerator (continued)
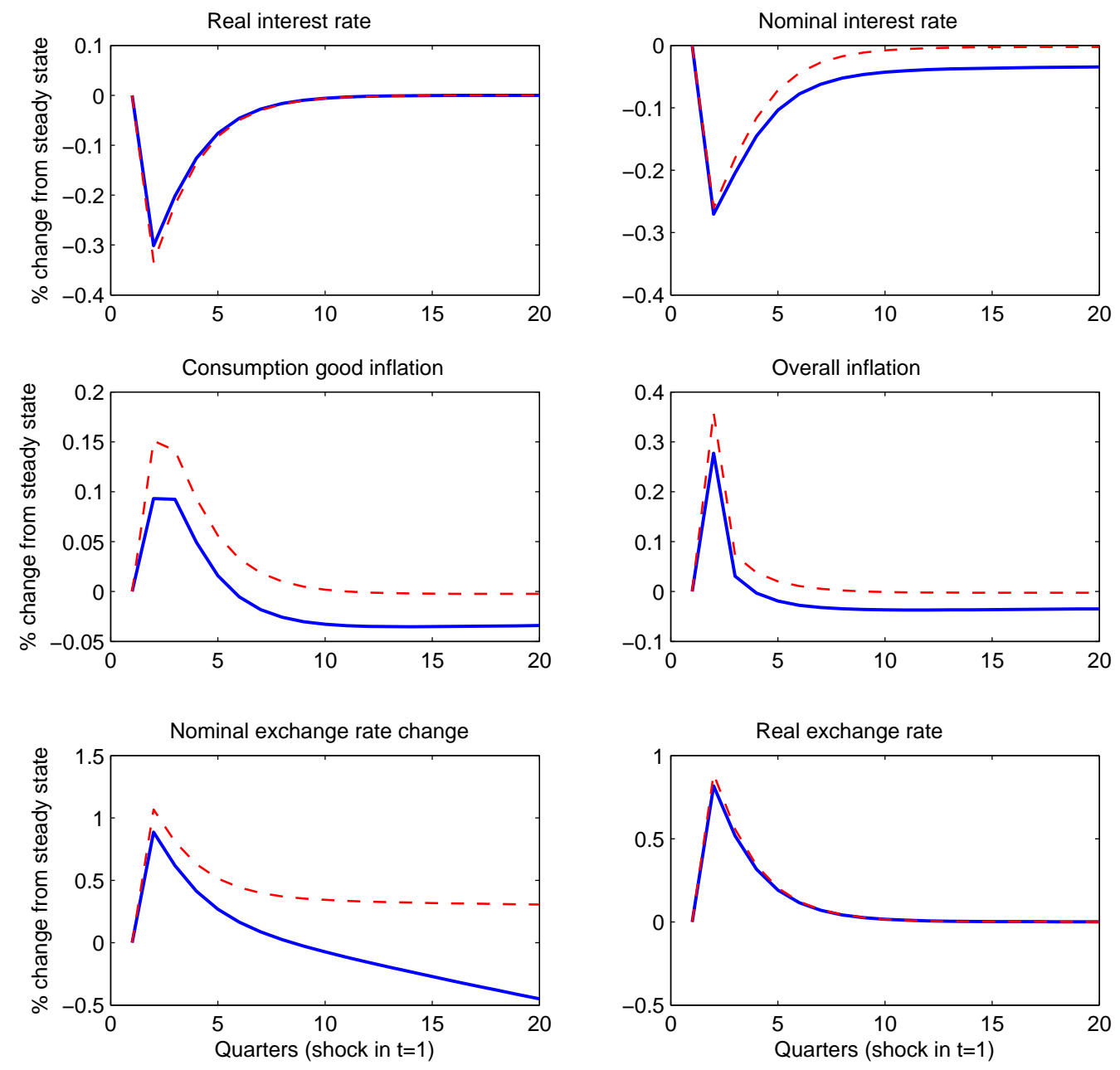

Basic model --- No accelerator 
Figure A.1: Response to a 1\% technology shock, basic model with and without the financial accelerator (continued)
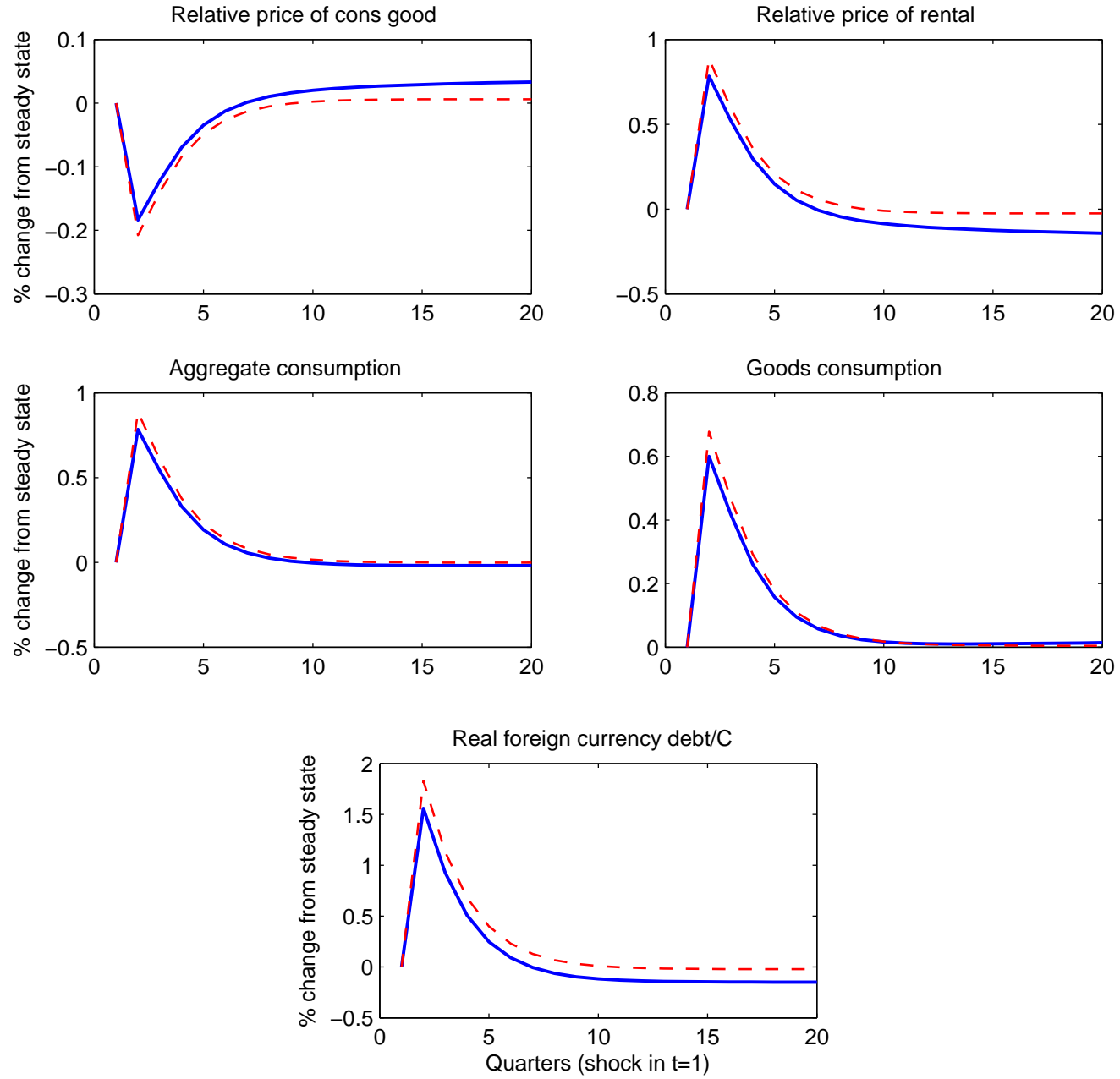

- Basic model - - - No accelerator 
Figure A.1: Response to a 1\% technology shock, basic model with and without the financial accelerator (continued)
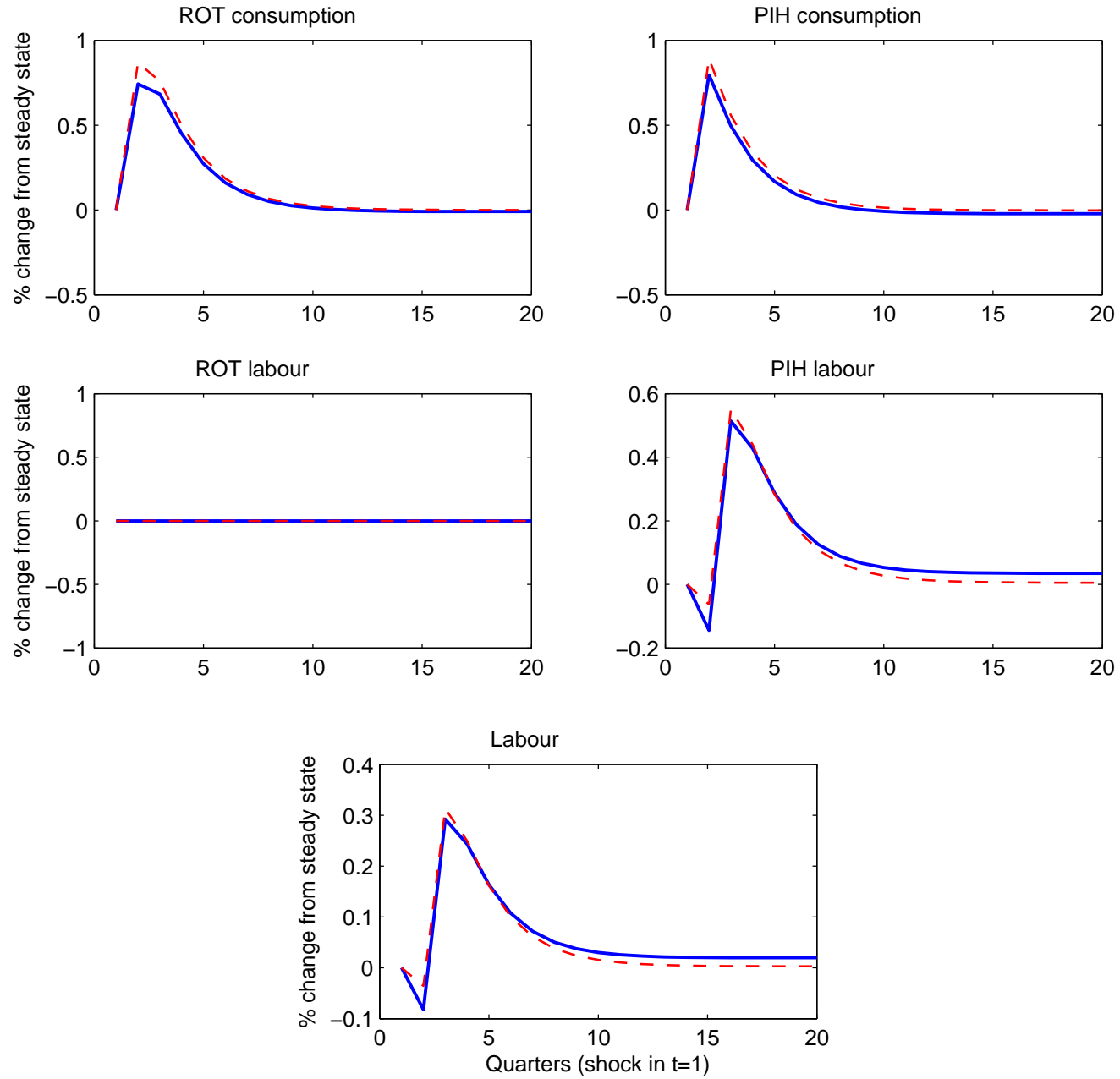

- Basic model - - - No accelerator 
Figure A.1: Response to a 1\% technology shock, basic model with and without the financial accelerator (continued)
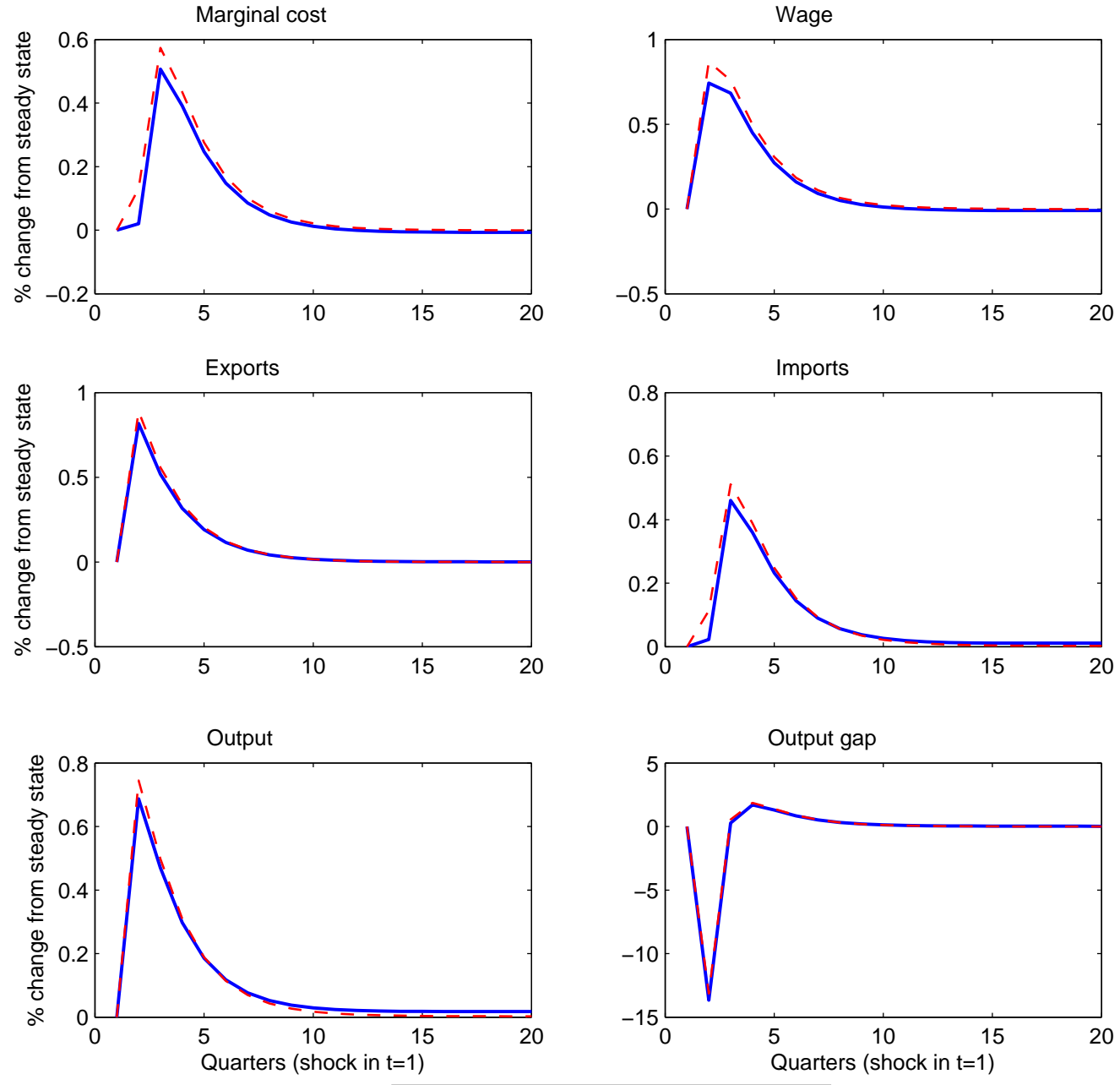

Basic model --- No accelerator 
Figure A.2: Response to a 25 basis point foreign real interest rate shock, basic model with and without the financial accelerator
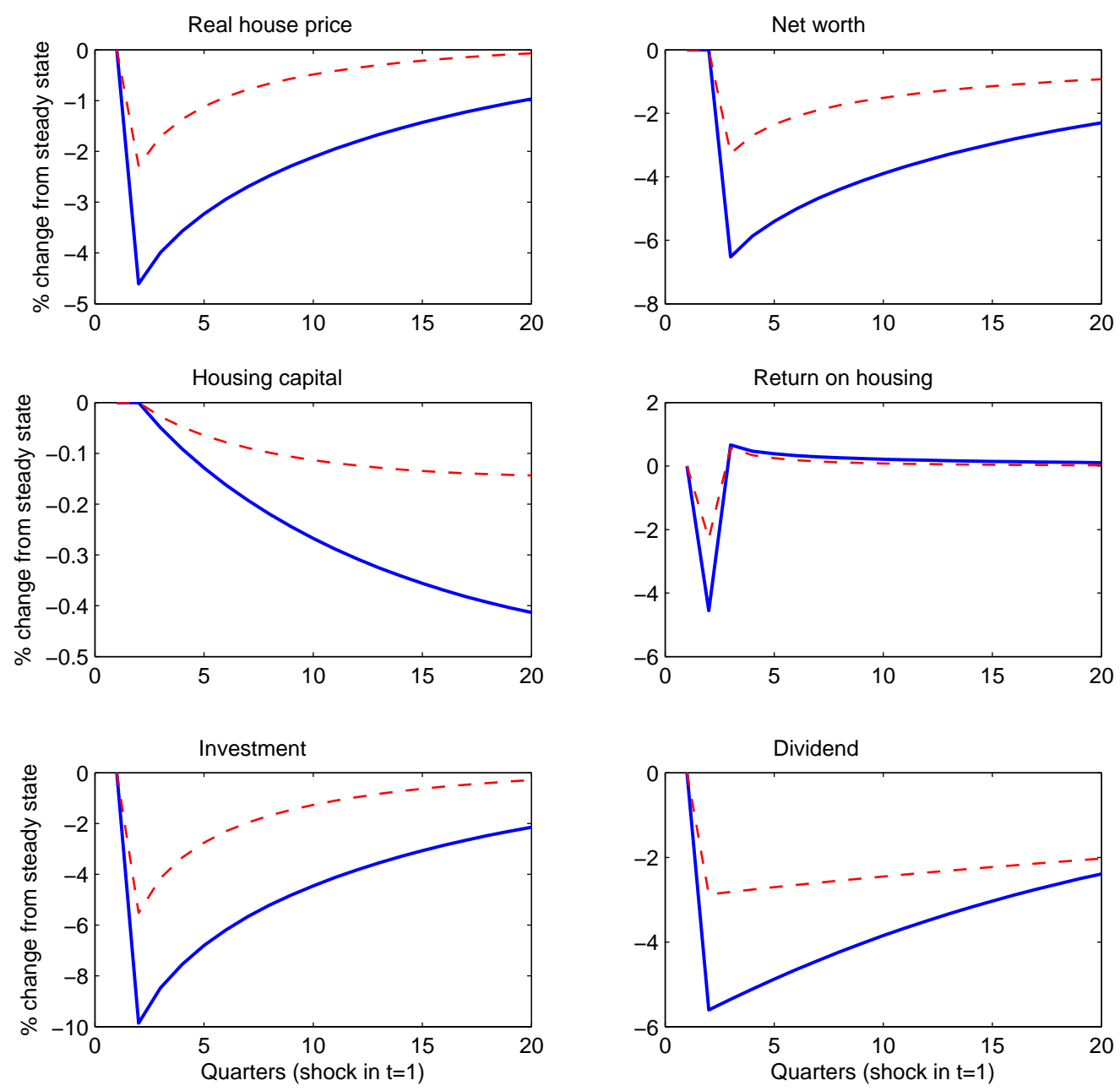

- Basic model - - - No accelerator 
Figure A.2: Response to a 25 basis point foreign real interest rate shock, basic model with and without the financial accelerator (continued)
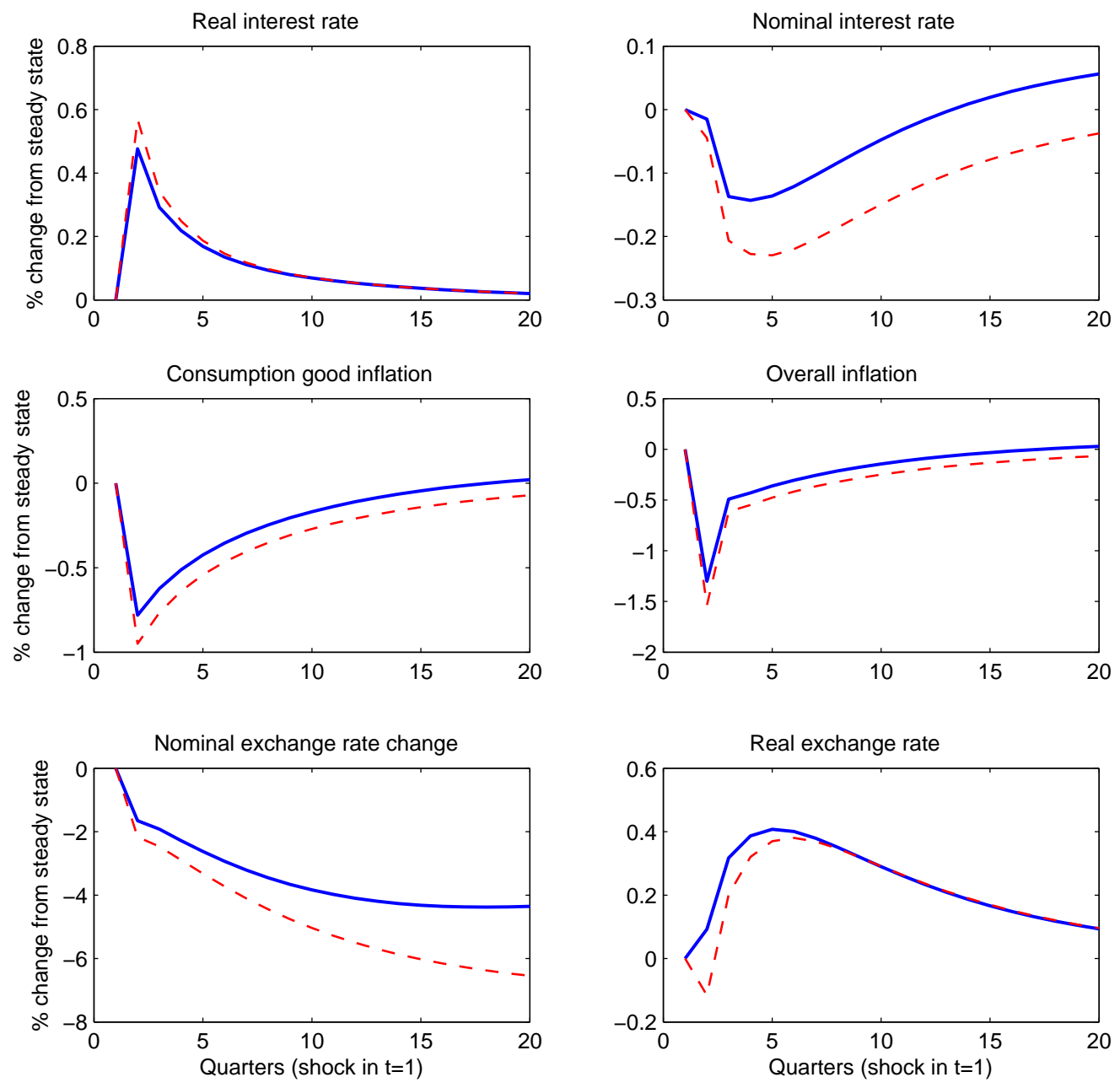

Basic model --- No accelerator 
Figure A.2: Response to a 25 basis point foreign real interest rate shock, basic model with and without the financial accelerator (continued)
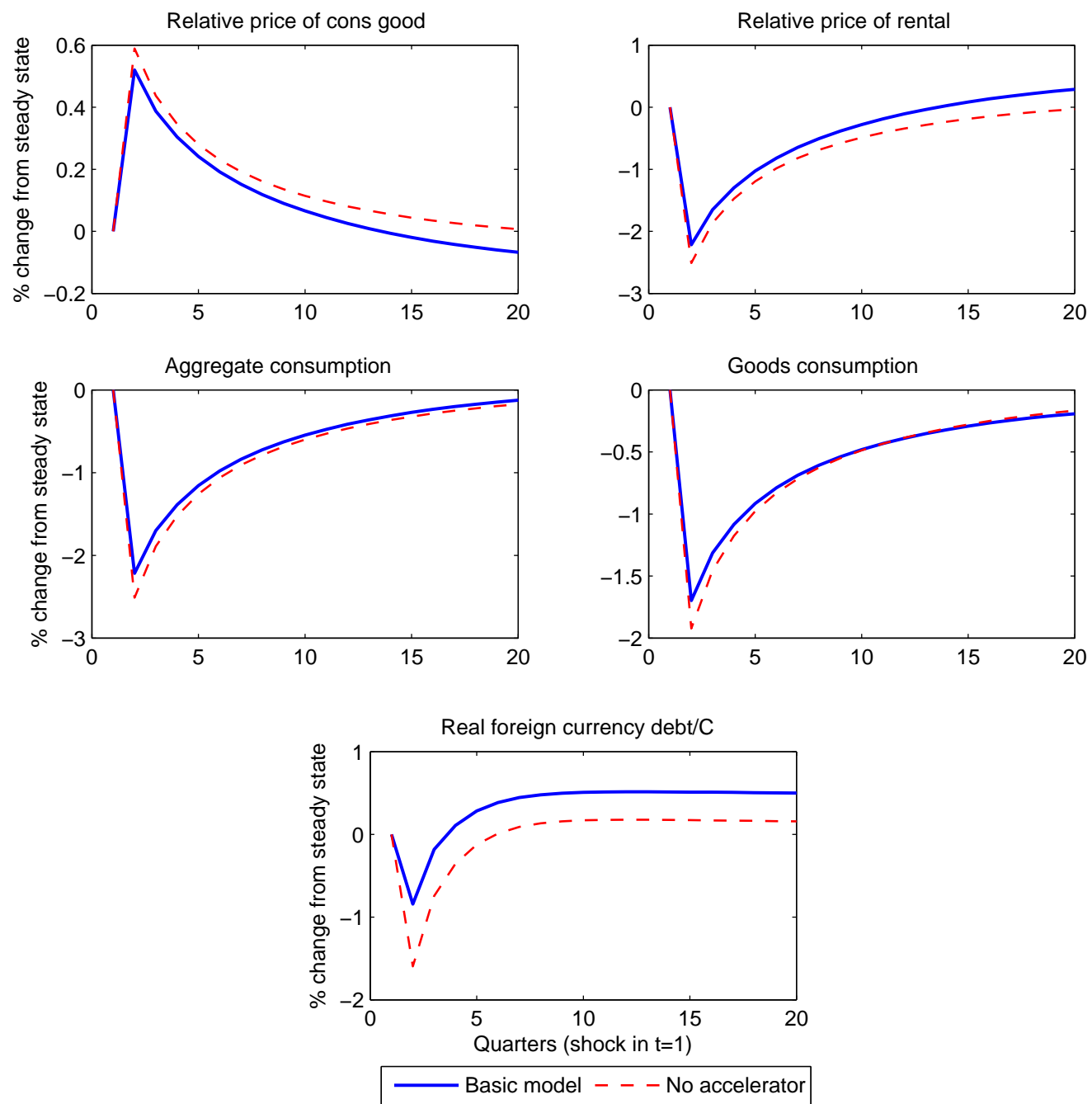
Figure A.2: Response to a 25 basis point foreign real interest rate shock, basic model with and without the financial accelerator (continued)
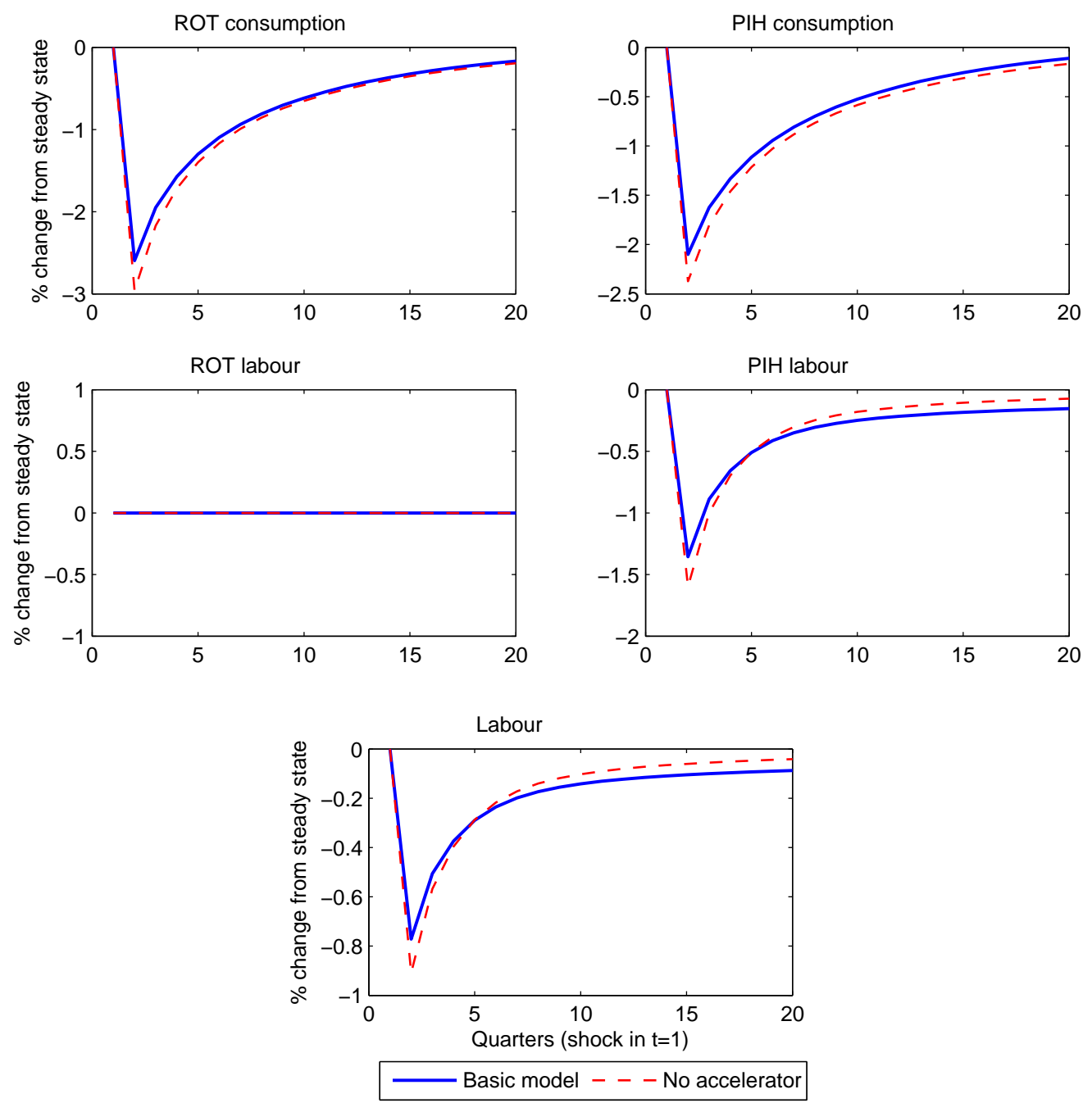
Figure A.2: Response to a 25 basis point foreign real interest rate shock, basic model with and without the financial accelerator (continued)
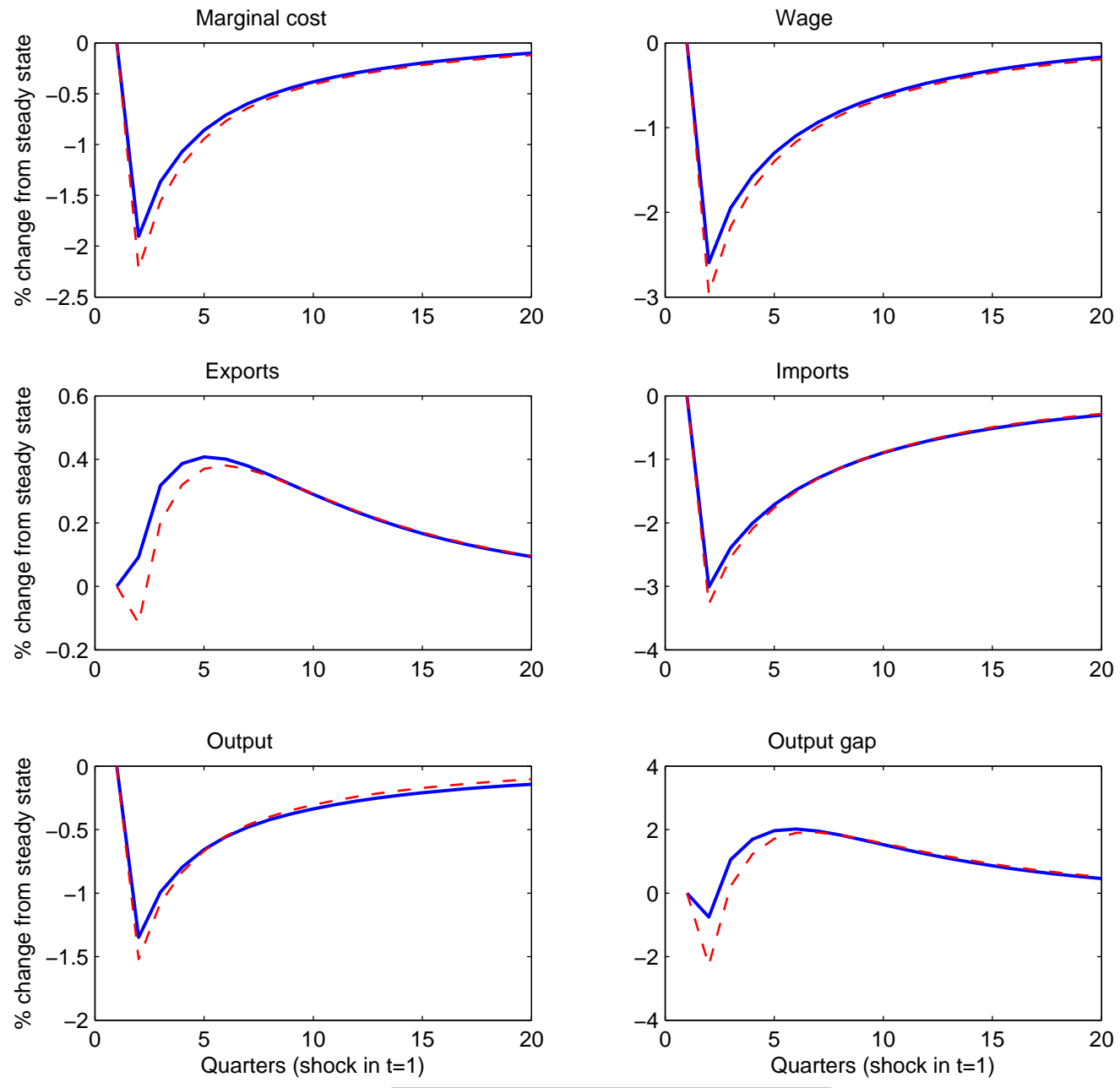

Basic model --- No accelerator 
Figure A.3: Response to a $1 \%$ foreign demand shock, basic model with and without the financial accelerator
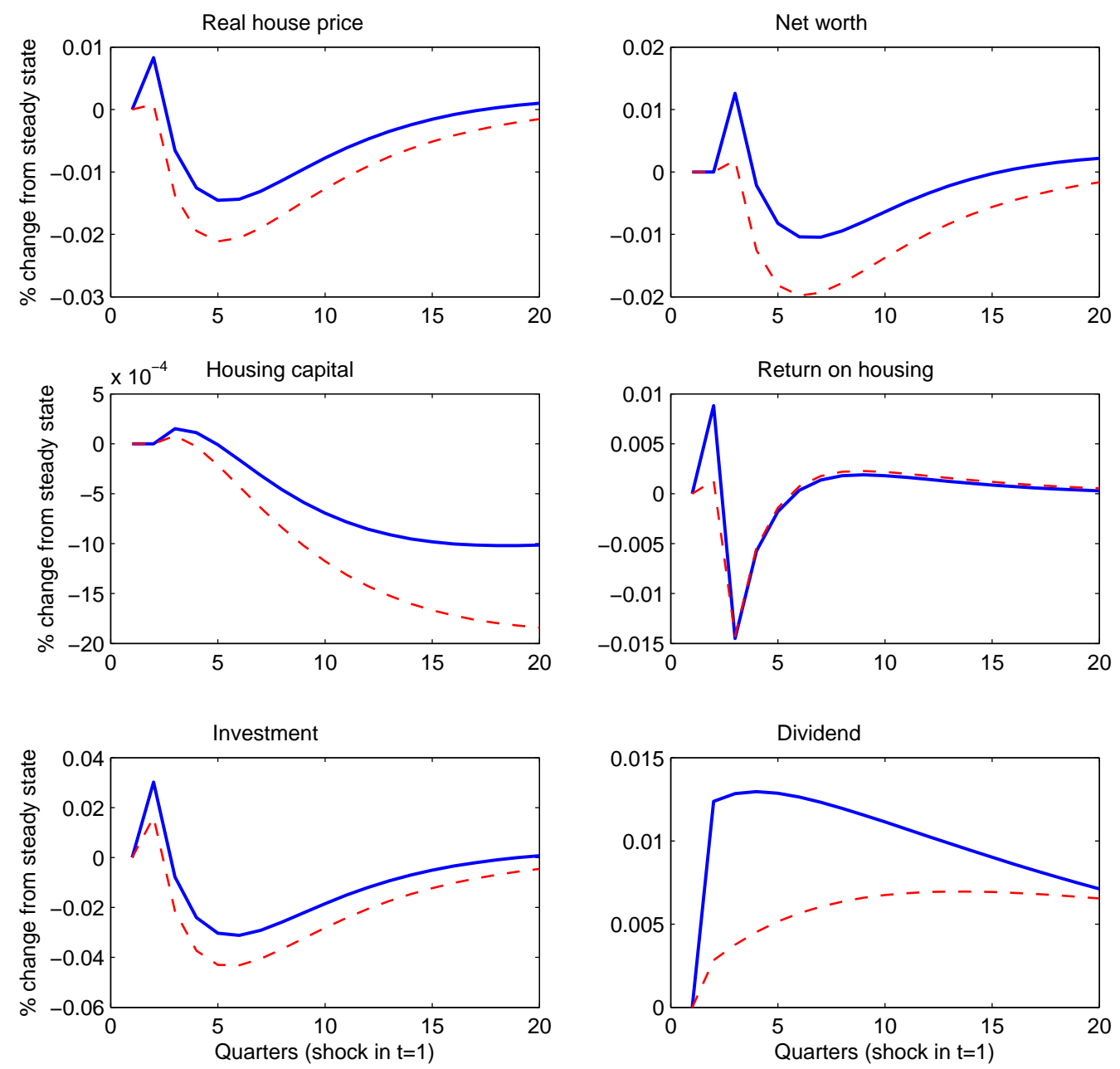

Basic model --- No accelerator 
Figure A.3: Response to a $1 \%$ foreign demand shock, basic model with and without the financial accelerator (continued)
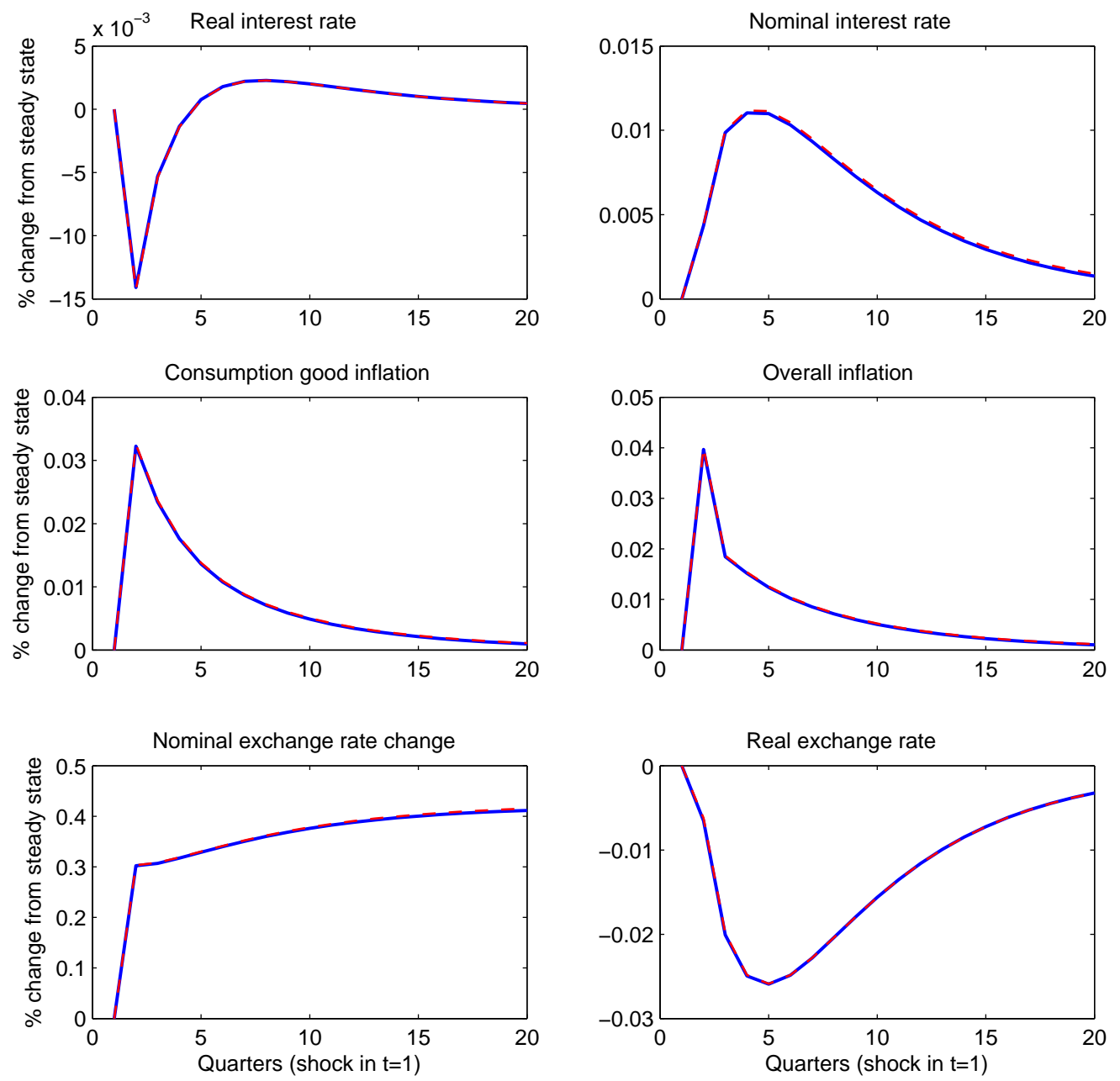

- Basic model - - - No accelerator 
Figure A.3: Response to a $1 \%$ foreign demand shock, basic model with and without the financial accelerator (continued)
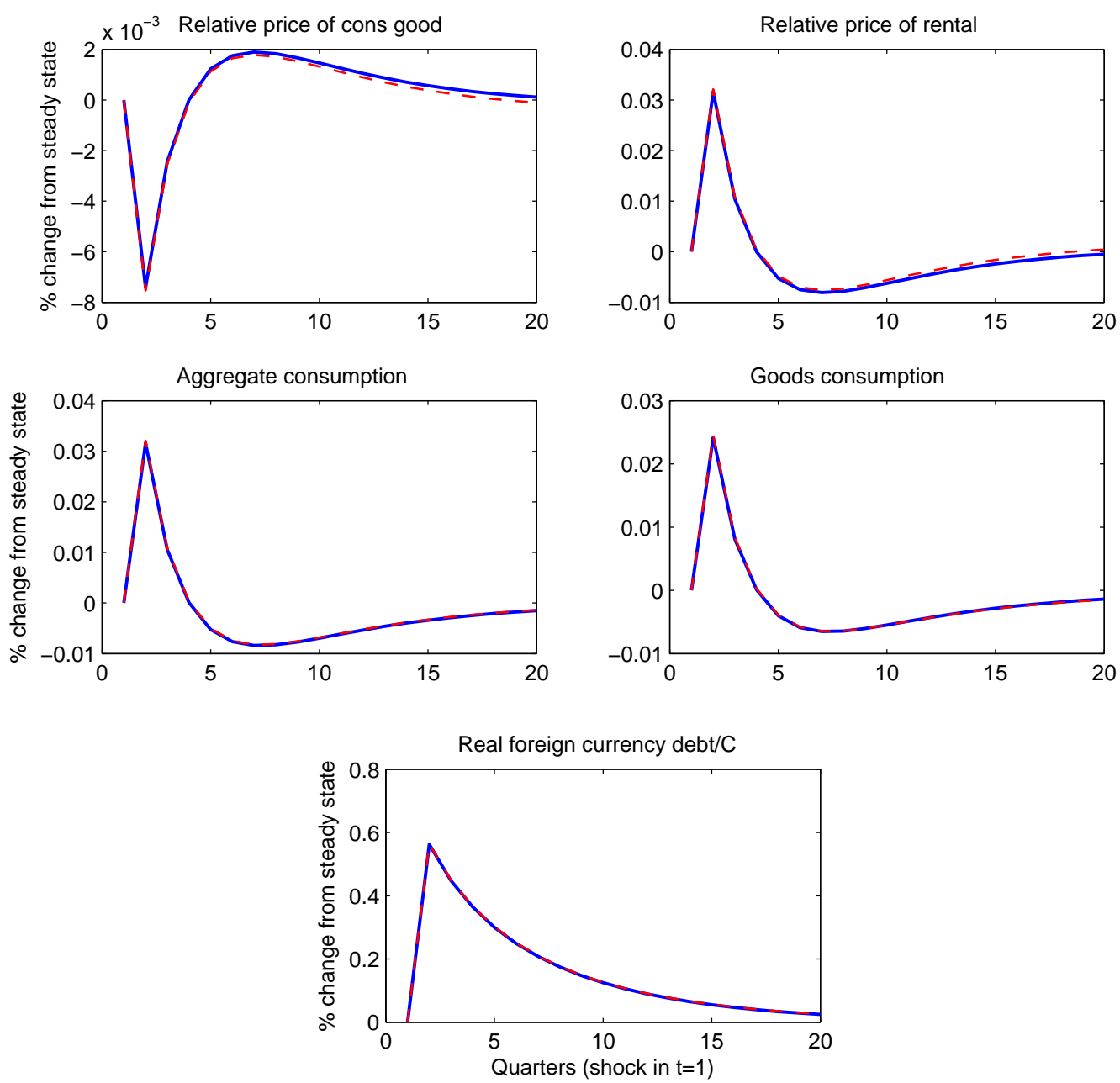

- Basic model - - - No accelerator 
Figure A.3: Response to a $1 \%$ foreign demand shock, basic model with and without the financial accelerator (continued)
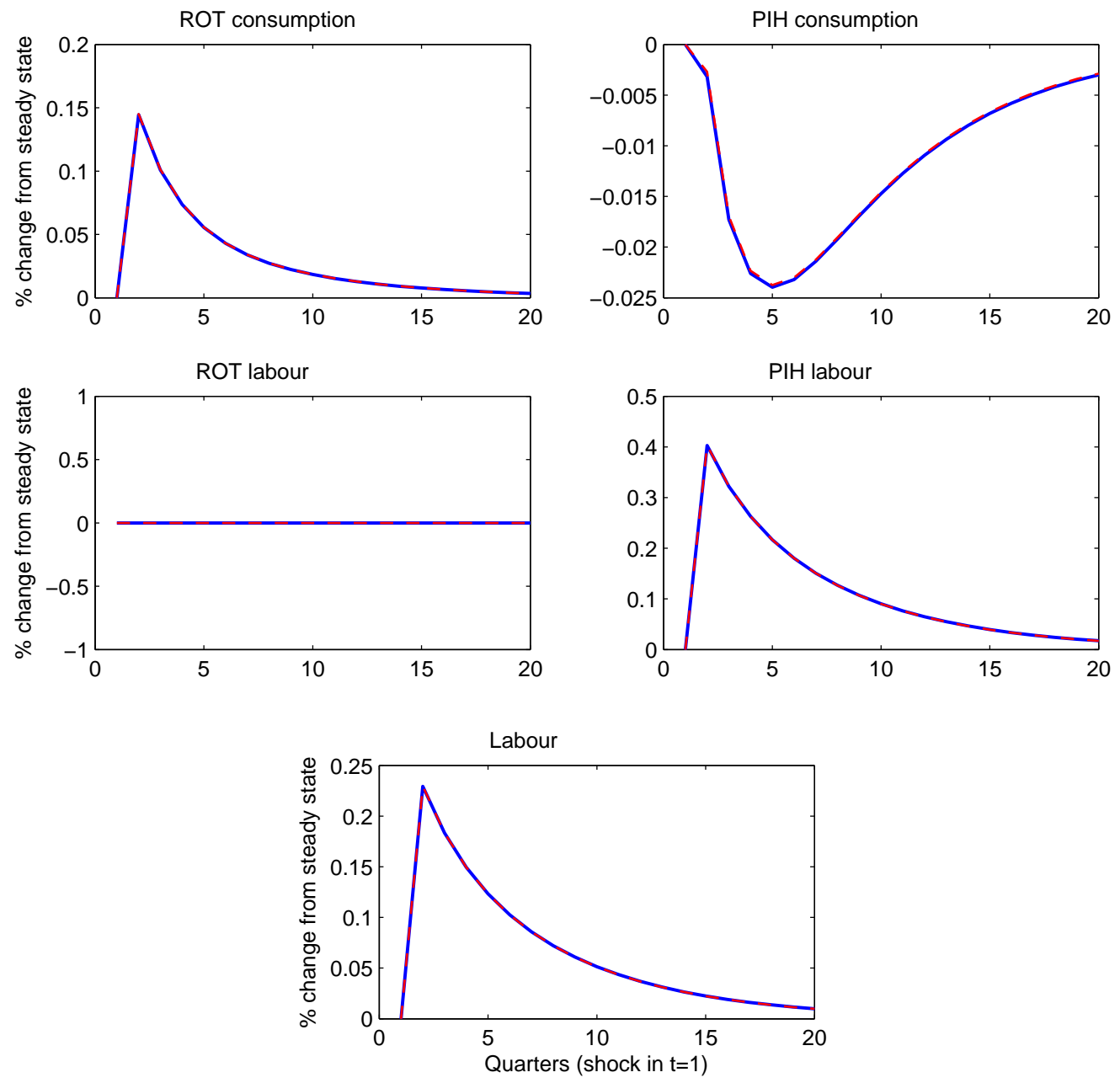

- Basic model - - - No accelerator 
Figure A.3: Response to a $1 \%$ foreign demand shock, basic model with and without the financial accelerator (continued)
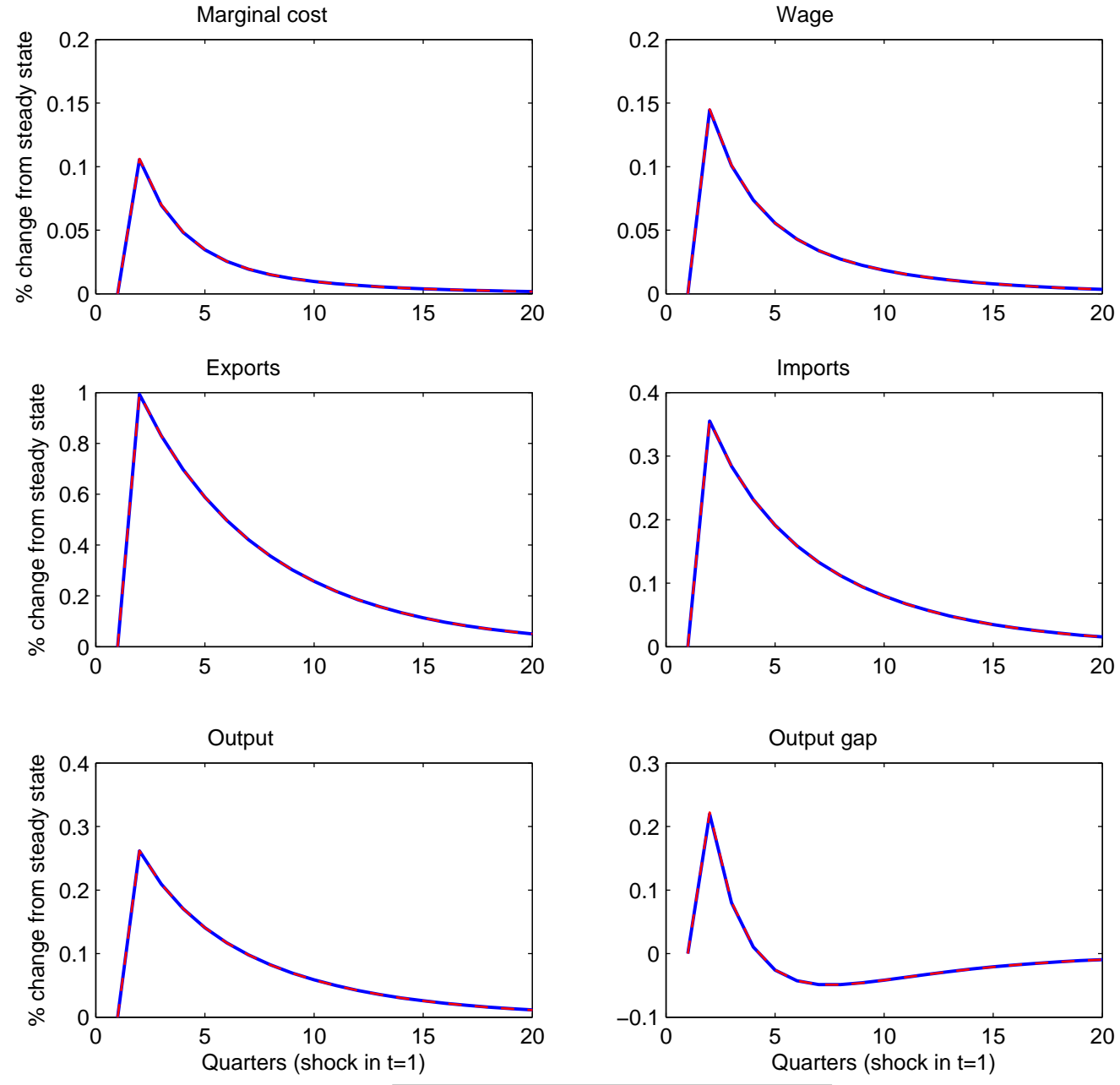

Basic model --- No accelerator 


\section{Appendix B}

\section{Data description}

The data used in this thesis are quarterly observations, that being the frequency of most macroeconomic data series published by Statistics New Zealand. The interest rate series are generated by averaging monthly data. Where possible, the data covers the period from 1988Q1 to 2008Q3. The net worth ratio is calculated using the RBNZ's 'Total Household Claims' data and thus starts in 1990Q4.

The moments used to calibrate the fiscal model of Chapter 3 (Table 3.3) are derived from HP-filtered data. House prices are from the All Residential HPI published by the RBNZ. This series is based primarily on QVNZ data with earlier observations estimated by the RBNZ. It is deflated by the CPI to obtain a real house price series. Net worth is derived from the RBNZ's aggregate private sector dwellings values less total household credit and deflated by the CPI. Consumption, output and residential investment are from data from the RBNZ (derived from Statistics New Zealand data). The real exchange rate data is the RBNZ's real Trade Weighted Index.

The data used in the SVAR of Chapter 4 are seasonally adjusted unless otherwise specified before logging. The world GDP series was obtained directly from the Reserve Bank of New Zealand (RBNZ) and represents aggregate growth for New Zealand's trading partners. There is no discernible seasonality in the raw data and thus it was not seasonally adjusted. The terms of trade data is repesented by seasonally unadjusted Statistics New Zealand's Terms of Trade Index (Table Reference: OTP019AA), expressed in logs. New Zealand GDP and household consumption data were obtained from the RBNZ due to the relatively short history of the official Statistics New Zealand data. The RBNZ series are based on Statistics New Zealand's 
chain-linked constant price expenditure-based measures. Government expenditure is represented by Statistics New Zealand's chain-linked constant price expenditurebased measure (Table reference: SNC062AA). Real house prices were obtained by deflating the RBNZ/Quotable Value nominal house price index by Statistic New Zealand's Consumer Price Index. The spread between the mortgage rate and the risk-free interest rate is calculated as the difference between the RBNZ's Variable First Home Mortgage rate and the IMF's New Zealand 90-day Treasury Bill rate, both on an annual basis and seasonally unadjusted. Net worth is represented by the difference between the RBNZ/Quotable Value Aggregate Private Sector Dwelling Value and the RBNZ's Total Household Claims. The data used in the SVAR is available on request. 


\section{Appendix C}

\section{Derivation of log-linear equations: Basic model}

In the the following description and derivation of the various model equations, a hat indicates percentage change. As the linearisation is around the steady state the hat variables are equivalent to percentage deviations from the steady state.

\section{C.1 Firms}

Consumer goods producing firms are monopolistically competitive and use a combination of labour and imported intermediate goods as inputs by way of a CES production function:

$$
y_{t}(z)=\left[\alpha I M_{t}(z)^{\gamma}+(1-\alpha)\left(A_{t} L_{t}(z)\right)^{\gamma}\right]^{\frac{1}{\gamma}}
$$

where $I M_{t}(z)$ is the quantity of intermediate imports used by firm $z, L_{t}(z)$ is similarly labour demand, $A_{t}$ is economywide labour-augmenting technology and $\frac{1}{1-\gamma}$ is the elasticity of substitution between labour and imports.

Log linearising and aggregating across all firms

$$
\begin{aligned}
\log Y_{t} & =\log \left[\alpha I M_{t}^{\gamma}+(1-\alpha)\left(A_{t} L_{t}\right)^{\gamma}\right]^{\frac{1}{\gamma}} \\
\hat{Y}_{t} & =\frac{1}{Y_{t}} \frac{1}{\gamma} Y_{t}^{1-\gamma}\left[\alpha I M_{t}^{\gamma} I \hat{M}_{t}+(1-\alpha)\left(A_{t} L_{t}\right)^{\gamma}\left(\hat{A}_{t}-\hat{L}_{t}\right)\right]
\end{aligned}
$$


which around the steady state reduces to

$$
\hat{Y}_{t}=\varphi I \hat{M}_{t}+(1-\varphi)\left(\hat{A}_{t}-\hat{L}_{t}\right)
$$

where

$$
\varphi=\frac{\alpha I M^{\gamma}}{\alpha I M^{\gamma}+(1-\alpha)(A L)^{\gamma}}
$$

\section{C.2 Input demand determination}

The cost minimisation problem for the firm may be written as:

$$
\mathcal{L}=W_{t} L_{t}+\left(S_{t} P_{t}^{f}\right) I M_{t}+\lambda_{t}\left(y_{t}-\left[\alpha I M_{t}^{\gamma}+(1-\alpha)\left(A_{t} L_{t}\right)^{\gamma}\right]^{\frac{1}{\gamma}}\right)
$$

Differentiating this with respect to $L_{t}$ and $I M_{t}$ yields:

$$
\begin{aligned}
\frac{d \mathcal{L}}{d L_{t}} & =W_{t}-\lambda_{t} \frac{1}{\gamma}\left[\alpha I M_{t}^{\gamma}+(1-\alpha)\left(A_{t} L_{t}\right)^{\gamma}\right]^{\frac{1}{\gamma}-1}(1-\alpha) \gamma\left(A_{t} L_{t}\right)^{\gamma-1} A_{t} \\
& =W_{t}-\lambda_{t} y_{t}^{1-\gamma}(1-\alpha)\left(A_{t} L_{t}\right)^{\gamma-1} A_{t} \\
& =W_{t}-\lambda_{t}(1-\alpha) A_{t}\left\{\frac{y_{t}}{\left(A_{t} L_{t}\right)}\right\}^{1-\gamma} \\
\lambda_{t} & =\frac{W_{t}}{(1-\alpha) A_{t}^{\gamma}\left\{\frac{y_{t}}{L_{t}}\right\}^{1-\gamma}}
\end{aligned}
$$

and

$$
\begin{aligned}
\frac{d \mathcal{L}}{d I M_{t}} & =\left(S_{t} P_{t}^{f}\right)-\lambda_{t} \frac{1}{\gamma}\left[\alpha I M_{t}^{\gamma}+(1-\alpha)\left(A_{t} L_{t}\right)^{\gamma}\right]^{\frac{1}{\gamma}-1} \alpha \gamma I M_{t}^{\gamma-1} \\
& =\left(S_{t} P_{t}^{f}\right)-\lambda_{t} \alpha\left\{\frac{y_{t}}{I M_{t}}\right\}^{1-\gamma} \\
\lambda_{t} & =\frac{S_{t} P_{t}^{f}}{\alpha\left\{\frac{y_{t}}{I M_{t}}\right\}^{1-\gamma}}
\end{aligned}
$$


Hence

$$
\begin{aligned}
\frac{W_{t}}{(1-\alpha) A_{t}^{\gamma}\left\{\frac{y_{t}}{L_{t}}\right\}^{1-\gamma}} & =\frac{\left(S_{t} P_{t}^{f}\right)}{\alpha\left\{\frac{y_{t}}{I M_{t}}\right\}^{1-\gamma}} \\
\frac{w_{t}}{R S_{t}} & =\frac{(1-\alpha) A_{t}^{\gamma}\left\{\frac{y_{t}}{L_{t}}\right\}^{1-\gamma}}{\alpha\left\{\frac{y_{t}}{I M_{t}}\right\}^{1-\gamma}}
\end{aligned}
$$

The $y_{t}$ 's also cancel and this may be expressed as:

$$
\left(\frac{I M_{t}}{L_{t}}\right)^{1-\gamma} A_{t}^{\gamma}=\frac{\alpha}{1-\alpha} \frac{w_{t}}{R S_{t}}
$$

Log-linearising

$$
\begin{aligned}
(1-\gamma)\left(\log I M_{t}-\log L_{t}\right)+\gamma \log A_{t} & =\log \alpha-\log (1-\alpha)+\log w_{t}-\log R S_{t} \\
(1-\gamma)\left(\frac{d I M_{t}}{I M_{t}}-\frac{d L_{t}}{L_{t}}\right)+\gamma \frac{d A_{t}}{A_{t}} & =\frac{d w_{t}}{w_{t}}-\frac{d R S_{t}}{R S_{t}} \\
(1-\gamma)\left(I \hat{M}_{t}-\hat{L}_{t}\right)+\gamma \hat{A}_{t} & =\hat{w}_{t}-\hat{R S_{t}} \\
I \hat{M}_{t} & =\left(\frac{1}{1-\gamma}\right)\left(\hat{w}_{t}-\hat{R S_{t}}-\gamma \hat{A}_{t}\right)+\hat{L}_{t}
\end{aligned}
$$

\section{C.3 Marginal cost}

From the production function, note that

$$
\begin{aligned}
\left(\frac{y_{t}}{L_{t}}\right)^{\gamma} & =\frac{\alpha I M_{t}^{\gamma}+(1-\alpha)\left(A_{t} L_{t}\right)^{\gamma}}{L_{t}^{\gamma}} \\
& =\alpha\left(\frac{I M_{t}}{L_{t}}\right)^{\gamma}+(1-\alpha) A_{t}^{\gamma} \\
\frac{y_{t}}{L_{t}} & =\left[\alpha\left(\frac{I M_{t}}{L_{t}}\right)^{\gamma}+(1-\alpha) A_{t}^{\gamma}\right]^{\frac{1}{\gamma}}
\end{aligned}
$$


Log linearising the marginal cost Equation (C.2.2)

$$
\begin{aligned}
\lambda_{t} & =\frac{W_{t}}{(1-\alpha) A_{t}^{\gamma}\left\{\frac{y_{t}}{L_{t}}\right\}^{1-\gamma}} \\
\log \frac{\lambda_{t}}{P_{c, t}} & =\log \frac{W_{t}}{P_{c, t}}-\log (1-\alpha)-\gamma \log A_{t}-(1-\gamma) \log \frac{y_{t}}{L_{t}} \\
\log m c_{t} & =\log w_{t}-\log (1-\alpha)-\gamma \log A_{t}-\frac{1-\gamma}{\gamma} \log \left(\alpha\left(\frac{I M_{t}}{L_{t}}\right)^{\gamma}+(1-\alpha) A_{t}^{\gamma}\right)
\end{aligned}
$$

Differentiating the last element of Equation(C.3.1)

$$
\begin{aligned}
d\left[\alpha\left(\frac{I M_{t}}{L_{t}}\right)^{\gamma}+(1-\alpha) A_{t}^{\gamma}\right] & =\alpha \gamma\left(\frac{I M_{t}}{L_{t}}\right)^{\gamma-1}\left(\frac{L_{t} d I M_{t}-I M_{t} d L_{t}}{L_{t}^{2}}\right)+(1-\alpha) \gamma A_{t}^{\gamma-1} d A_{t} \\
& =\alpha \gamma\left(\frac{I M_{t}}{L_{t}}\right)^{\gamma}\left(\frac{d I M_{t} L_{t}}{I M_{t} L_{t}}-\frac{I M_{t}}{L_{t}} \frac{L_{t}}{I M_{t}} \frac{d L_{t}}{L_{t}}\right)+(1-\alpha) \gamma A_{t} \gamma \frac{d A_{t}}{A_{t}} \\
& =\alpha \gamma\left(\frac{I M_{t}}{L_{t}}\right)^{\gamma}\left(I \hat{M}_{t}-\hat{L}_{t}\right)+(1-\alpha) \gamma A_{t}^{\gamma} \hat{A}_{t}
\end{aligned}
$$

Notice we can re-express $\varphi$ as

$$
\varphi=\frac{\alpha\left(\frac{I M}{L}\right)^{\gamma}}{\alpha\left(\frac{I M}{L}\right)^{\gamma}+(1-\alpha) A^{\gamma}}
$$

Then

$$
d \log \left(\alpha\left(\frac{I M_{t}}{L_{t}}\right)^{\gamma}+(1-\alpha) A_{t}^{\gamma}\right)=\varphi\left(I \hat{M}_{t}-\hat{L}_{t}\right)+(1-\varphi) \hat{A}_{t}
$$

and

$$
\begin{aligned}
\hat{m} c_{t} & =\hat{w}_{t}-\gamma \hat{A}_{t}-(1-\gamma)\left[\varphi\left(I \hat{M}_{t}-\hat{L}_{t}\right)+(1-\varphi) \hat{A}_{t}\right] \\
& =\hat{w}_{t}-(1-\gamma) \varphi\left(I \hat{M}_{t}-\hat{L}_{t}\right)-[(1-\gamma)(1-\varphi)+\gamma] \hat{A}_{t}
\end{aligned}
$$




\section{C.4 Resource constraint}

Output from firms is consumed by domestic consumers, foreign consumers or utilised in the production of housing:

$$
\begin{aligned}
Y_{t} & =c_{t}+I_{t}+E X_{t} \\
\frac{d Y_{t}}{Y_{t}} & =\frac{c_{t}}{Y_{t}} \frac{d c_{t}}{c_{t}}+\frac{I_{t}}{Y_{t}} \frac{d I_{t}}{I_{t}}+\frac{E X_{t}}{Y_{t}} \frac{d E X_{t}}{E X_{t}} \\
\hat{Y}_{t} & =\frac{c_{t}}{Y_{t}} \hat{c}_{t}+\frac{I_{t}}{Y_{t}} \hat{I}_{t}+\frac{E X_{t}}{Y_{t}} \hat{E X_{t}}
\end{aligned}
$$

Dropping the time subscripts for the levels variables because of the steady state

$$
\hat{Y}_{t}=\frac{c}{Y} \hat{c}_{t}+\frac{I}{Y} \hat{I}_{t}+\frac{E X}{Y} \hat{E X}
$$

where $c_{t}$ is domestic consumption of consumption goods, $I_{t}$ is investment in housing and $E X_{t}$ is consumption goods exported to foreign consumers.

\section{C.5 Export demand}

Foreign demand for firm $z$ 's output is given by

$$
\begin{aligned}
E X_{t}(z) & =\left(\frac{S_{t}^{-1} P_{t}(z)}{S_{t}^{-1} P_{c, t}}\right)^{-\epsilon} E X_{t} \\
& =\left(\frac{P_{t}(z)}{P_{c, t}}\right)^{-\epsilon} E X_{t}
\end{aligned}
$$

As per McCallum and Nelson (1999), I assume that aggregate export demand is given by

$$
\begin{gathered}
E X_{t}=\left(\frac{S_{t} P_{t}^{f}}{P_{t}}\right)^{\vartheta}\left(Y_{t}^{f}\right)^{\zeta} \\
\hat{E X_{t}}=\vartheta \hat{R S_{t}}+\zeta \hat{Y}_{t}^{f}
\end{gathered}
$$




\section{C.6 Prices}

The composite price index combines the prices of consumption goods and rental in the following manner:

$$
P_{t}=\left[\nu P_{c, t}^{1-\eta}+(1-\nu) P_{h, t}^{1-\eta}\right]^{\frac{1}{1-\eta}}
$$

Taking differences

$$
\begin{aligned}
0 & =\nu(1-\eta) X_{c, t}^{-\eta} d X_{c, t}+(1-\nu)(1-\eta) X_{h, t}^{-\eta} d X_{h, t} \\
& =\frac{d X_{c, t}}{X_{c, t}} \nu(1-\eta) X_{c, t}^{1-\eta}+(1-\nu)(1-\eta) \frac{d X_{h, t}}{X_{h, t}} X_{h, t}^{1-\eta} \\
& =\hat{X}_{c, t}+\left(\frac{1-\nu}{\nu}\right)\left(\frac{X_{h}}{X_{c}}\right)^{1-\eta} \hat{X}_{h, t}
\end{aligned}
$$

\section{C.7 Households}

PIH consumers maximise their utility over time with the intra-period utility given by

$$
\log C_{t}^{P}+\xi \log \left(1-L_{t}^{P}\right)
$$

where $C_{t}^{P}$ represents PIH consumers cobined consumption of goods and housing services and $L_{t}^{P}$ represents the labour supplied by PIH consumers.

Standard Dixit-Stiglitz assumptions on utility and demand lead to consumer $j$ 's demand for aggregated consumption goods in the form

$$
c_{t}^{j}=\left[\int_{0}^{1} c_{t}^{j}(z)^{\frac{\epsilon-1}{\epsilon}} d z\right]^{\frac{\epsilon}{\epsilon-1}}
$$

where

$$
c_{t}^{j}(z)=\left(\frac{p_{t}(z)}{P_{c, t}}\right)^{-\epsilon} c_{t}^{j}
$$


and aggregating across all consumers leads to

$$
\begin{aligned}
c_{t} & =v\left(\frac{P_{c, t}}{P_{t}}\right)^{-\eta} C_{t} \\
& =v X_{c, t}^{-\eta} C_{t} \\
\log c_{t} & =\log v-\eta \log X_{c, t}+\log C_{t} \\
\hat{c}_{t} & =\hat{C}_{t}-\eta \hat{X}_{c, t}
\end{aligned}
$$

and

$$
\begin{aligned}
h_{t} & =(1-v)\left(\frac{P_{h, t}}{P_{t}}\right)^{-\eta} C_{t} \\
& =(1-v) X_{h, t}^{-\eta} C_{t} \\
\log h_{t} & =\log (1-v)-\eta \log X_{h, t}+\log C_{t} \\
\hat{h}_{t} & =\hat{C}_{t}-\eta \hat{X}_{h, t}
\end{aligned}
$$

\section{C.7.1 PIH consumers' first order conditions}

Each period consumers face a budget constraint. Each period consumers may purchase or sell financial assets either domestically or abroad. Following De Paoli (2009) (but expressed in real terms) the budget constraint is:

$$
C_{t}^{P}+B_{H, t-1}+R S_{t} B_{F, t-1}=\frac{B_{H, t}}{\left(R_{t+1}\right)}+\frac{R S_{t} B_{F, t}}{\left(R_{t+1}^{f}\right) \psi\left(R S_{t} B_{F, t}\right)}+\frac{W_{t}}{P_{t}} L_{t}^{p}+D_{t}
$$

where $B_{H, t-1}$ is the amount of real domestic currency bonds purchased $\left(B_{H, t-1}<0\right)$ or issued $\left(B_{H, t-1}>0\right)$ at time $t-1$ with maturity $t, B_{F, t-1}$ is similarly real foreign currency denominated bonds, $R S_{t}$ is the real exchange rate, $R_{t+1}$ the real domestic interest rate from period $t$ to $t+1, R_{t+1}^{f}$ is similarly the foreign interest rate, and $D_{t}$ is the dividend paid by homeowners to consumers. 
The maximisation problem is:

$$
\begin{aligned}
\mathcal{L}=\sum_{s=t}^{\infty} \beta^{s-t} E_{t}\{ & \log C_{s}^{P}+\xi \log \left(1-L_{s}^{P}\right) \\
& +\lambda_{s}\left[C_{s}^{P}+B_{H, s-1}+R S_{s} B_{F, s-1}\right. \\
& \left.\left.-\frac{B_{H, s}}{R_{s+1}}-\frac{R S_{s} B_{F, s}}{\left(R_{s}^{f}\right) \psi\left(R S_{s} B_{F, t}\right)}-\frac{W_{s}}{P_{c, s}} L_{s}-D_{s}\right]\right\}
\end{aligned}
$$

Hence maximising with respect to $C_{s}^{P}$ :

$$
\frac{\partial \mathcal{L}}{\partial C_{s}^{P}}=\beta^{s-t}\left(\frac{1}{C_{s}^{P}}+\lambda_{s}\right)
$$

Setting to zero,

$$
\begin{aligned}
\beta^{s-t}\left(\frac{1}{C_{s}^{P}}+\lambda_{s}\right) & =0 \\
\Rightarrow \lambda_{t} & =-\frac{1}{C_{t}^{P}}
\end{aligned}
$$

Maximising with respect to $B_{H, s}$ :

$$
\frac{\partial \mathcal{L}}{\partial B_{H, s}}=-\beta^{s-t} \lambda_{s} \frac{1}{R_{s+1}}+\beta^{s-t+1} E_{t} \lambda_{s+1}
$$

Setting to zero,

$$
\begin{aligned}
\beta^{s-t} \lambda_{s} \frac{1}{R_{s+1}}-\beta^{s-t+1} E_{t} \lambda_{s+1} & =0 \\
\Rightarrow \lambda_{t} & =R_{t+1} \beta E_{t} \lambda_{t+1}
\end{aligned}
$$

Substituting (C.7.4) into this yields:

$$
\frac{1}{C_{t}^{P}}=\beta R_{t+1} E_{t} \frac{1}{C_{t+1}^{P}}
$$


Log-linearising

$$
\begin{aligned}
\log \frac{1}{C_{t}^{P}} & =\log \beta+\log R_{t+1}+\log E_{t} \frac{1}{C_{t+1}^{P}} \\
-\log C_{t}^{P} & =\log \beta+\log R_{t+1}-\log E_{t} C_{t+1}^{P} \\
\frac{d C_{t}^{P}}{C_{t}^{P}} & =E_{t} \frac{d C_{t+1}^{P}}{C_{t+1}^{P}}-\frac{d R_{t+1}}{R_{t+1}} \\
\hat{C}_{t}^{P} & =E_{t} \hat{C}_{t+1}^{P}-\hat{R}_{t+1}
\end{aligned}
$$

Maximising with respect to $B_{F, s}$ :

$$
\frac{\partial \mathcal{L}}{\partial B_{F, s}}=-\beta^{s-t} \lambda_{s} \frac{R S_{s}}{\left(R_{s+1}^{f}\right) \psi\left(R S_{s} B_{F, s}\right)}+\beta^{s-t+1} E_{s} \lambda_{s+1} R S_{s+1}
$$

Setting to zero,

$$
\frac{\lambda_{s} R S_{s}}{R_{s+1}^{f} \psi\left(R S_{s} B_{F, s}\right)}=\beta E_{t}\left(\lambda_{s+1} R S_{s+1}\right)
$$

Substituting (C.7.4) into this yields:

$$
\frac{1}{C_{t}^{P}}=R_{t+1}^{f} \psi\left(R S_{t} B_{F, t}\right) \beta E_{t}\left(\frac{1}{C_{t+1}^{P}} \frac{R S_{t+1}}{R S_{t}}\right)
$$

Substituting (C.7.5) into this yields:

$$
\begin{aligned}
\beta R_{t+1} E_{t} \frac{1}{C_{t+1}^{P}} & =R_{t+1}^{f} \psi\left(R S_{t} B_{F, t}\right) E_{t}\left[\frac{1}{C_{t+1}^{P}} \frac{R S_{t+1}}{R S_{t}}\right] \\
\Rightarrow \beta R_{t+1} & =R_{t+1}^{f} \psi\left(R S_{t} B_{F, t}\right) E_{t} \frac{R S_{t+1}}{R S_{t}} \\
\hat{R}_{t+1} & =\hat{R}_{t+1}^{f}-\delta_{b} \hat{b}_{t}+E_{t}\left(\hat{R S_{t+1}}-\hat{R S_{t}}\right)
\end{aligned}
$$

where

$$
\begin{gathered}
\hat{b}_{t}=\left(\frac{S_{t} P_{t}^{f} B_{F, t}}{P_{t}}-b\right) \frac{1}{C} \\
\delta_{b}=-\psi^{\prime} C
\end{gathered}
$$

$b=$ steady state level of foreign currency debt. 


\section{C.7.2 Wage determination}

Maximising (C.7.3) wrt labour

$$
\frac{\partial \mathcal{L}}{\partial L_{s}^{P}}=\beta^{s-t}\left[\frac{\xi}{1-L_{s}^{P}}(-1)-\lambda_{s} \frac{W_{s}}{P_{c, s}}\right]=0
$$

Substituting in (C.7.4)

$$
\begin{aligned}
\frac{1}{C_{t}^{P}} & =\frac{\xi}{w_{t}\left(1-L_{t}^{P}\right)} \\
\xi C_{t}^{P}=w_{t}\left(1-L_{t}^{P}\right) & \\
\log \xi+\log C_{t}^{P} & =\log w_{t}+\log \left(1-L_{t}^{P}\right) \\
\frac{d C_{t}^{P}}{C_{t}^{P}} & =\frac{d w_{t}}{w_{t}}-\frac{L_{t}^{P}}{1-L_{t}^{P}} \frac{d L_{t}^{P}}{L_{t}^{P}} \\
\hat{C}_{t}^{P} & =\hat{w}_{t}-\frac{L^{P}}{1-L^{P}} \hat{L}_{t}^{P}
\end{aligned}
$$

where $w_{t}$ is the real wage.

\section{C.7.3 Rule of thumb first order conditions}

Rule of thumb consumers maximise utility of

$$
\log C_{t}^{r}+\xi \log \left(1-L_{t}^{r}\right)
$$

subject to

$$
w_{t} L_{t}^{r}=C_{t}^{r}
$$


Thus combining the first order conditions with respect to consumption and labour for ROT consumers gives

$$
\begin{aligned}
w_{t} L_{t}^{r} & =\frac{w_{t}}{\xi}\left(1-L_{t}^{r}\right) \\
\Rightarrow L_{t}^{r} & =\frac{1}{\xi}-\frac{L_{t}^{r}}{\xi} \\
\Rightarrow L_{t}^{r}\left(\frac{1+\xi}{\xi}\right) & =\frac{1}{\xi} \\
\Rightarrow L_{t}^{r} & =\frac{1}{1+\xi} \\
\Rightarrow \hat{L}_{t}^{r} & =0
\end{aligned}
$$

In other words, labour supply by ROT consumers is fixed and thus $\hat{L}_{t}^{r}$ can be dropped from the log-linear model. Consequently, changes to the aggregate labour supply are driven only by changes in PIH labour supply.

$$
\begin{aligned}
L_{t} & =n L_{t}^{p}+(1-n) L_{t}^{r} \\
d L_{t} & =n d L_{t}^{p}+(1-n) d L_{t}^{r} \\
\frac{d L_{t}}{L} & =\frac{n L^{p}}{L} \frac{d L_{t}^{p}}{L^{p}}+(1-n) \frac{n L^{r}}{L} \frac{d L_{t}^{r}}{L^{r}} \\
\hat{L}_{t} & =n_{L} \hat{L}_{t}^{p}+(1-n) \hat{L}_{t}^{r} \\
\hat{L}_{t} & =n_{L} \hat{L}_{t}^{p}
\end{aligned}
$$

where $n_{L}=\frac{n L^{p}}{L}$.

As a result, ROT consumption is derived as follows:

$$
\begin{aligned}
C_{t}^{r} & =w_{t} L_{t}^{r} \\
d C_{t}^{r} & =w_{t} d L_{t}^{r}+L_{t} d w_{t} \\
\hat{C}_{t}^{r} & =\frac{w L^{r}}{C^{r}} \hat{w}_{t}
\end{aligned}
$$




\section{C.8 Aggregate consumption definition}

Aggregate consumption is the weighted consumption of PIH and ROT consumers

$$
\begin{aligned}
C_{t} & =n C_{t}^{P}+(n-1) C_{t}^{r} \\
d C_{t} & =n d C_{t}^{P}+(n-1) d C_{t}^{r} \\
\frac{d C_{t}}{C_{t}} & =\frac{n C_{t}^{P}}{C_{t}} \frac{d C_{t}^{P}}{C_{t}^{P}}+\frac{(1-n) C_{t}^{r}}{C_{t}} \frac{d C_{t}^{r}}{C_{t}^{r}}
\end{aligned}
$$

Re-expressing the second element of the RHS of the above equation

$$
\begin{aligned}
& =\frac{n C_{t}^{P}}{C_{t}} \frac{d C_{t}^{P}}{C_{t}^{P}}+\frac{(1-n)}{(1-n)} \frac{C_{t}-n C_{t}^{P}}{C_{t}} \frac{d C_{t}^{r}}{C_{t}^{r}} \\
\hat{C}_{t} & =n_{p} \hat{C}_{t}^{P}+\frac{C-n C^{P}}{C} \hat{C}_{t}^{r} \\
& =n_{C} \hat{C}_{t}^{P}+\left(1-n_{C}\right) \hat{C}_{t}^{r}
\end{aligned}
$$

where $n_{C}=n \frac{C^{P}}{C}$

\section{C.9 The mortgage - risk-free interest rate relation}

In keeping with BGG, the cost of borrowing for the purchase of housing capital is at a premium to the risk-free interest rate, this premium varying inversely with the extent that the borrower has net positive wealth. Because of the agency problem outlined in BBG, mortgage lenders will only lend to homeowners at a premium to the risk-free rate. Homeowners will stand to make again (or loss) on their caiptal as well as the rental from consumers. They will borrow up to the point that the cost of borrowing is just equal to their expected return from the housing asset. Thus,

$$
E_{t} R_{h, t+1}=f\left(\frac{N_{t+1}}{q_{t} h_{t+1}}\right) R_{t+1}
$$

where $E_{t} R_{h, t+1}$ is the rate of return on owning housing from period $t$ to $t+1, N_{t+1}$ is the net worth of the household determined at the end of period $t$ and thus carried over into period $t+1, q_{t}$ is the real price of housing in period $t, f^{\prime}<0$ and and $h_{t+1}$ is the stock of housing determined at the end of period $t$ and carried over into period $t+1$. 
Log-linearising

$$
\begin{aligned}
\log E_{t} R_{h, t+1} & =\log f\left(\frac{N_{t+1}}{q_{t} h_{t+1}}\right)+\log R_{t+1} \\
E_{t} \frac{d R_{h, t+1}}{R_{h, t+1}} & =\frac{f^{\prime}(.)}{f(.)} \frac{N_{t+1}}{q_{t} h_{t+1}}\left(\frac{d N_{t+1}}{N_{t+1}}-\frac{d q_{t}}{q_{t}}-\frac{d h_{t+1}}{h_{t+1}}\right)+\frac{d R_{t+1}}{R_{t+1}} \\
E_{t} \hat{R}_{h, t+1} & =\Omega\left(\hat{N}_{t+1}-\hat{q}_{t}-\hat{h}_{t+1}\right)+\hat{R}_{t+1}
\end{aligned}
$$

where $\phi$ is the steady state net worth ratio, $\frac{N}{q h}$, and $\Omega=\frac{f^{\prime}(\phi)}{f(\phi)} \phi$.

\section{C.10 Ex-post gross return on housing}

Homeowners will have a retun on the housing asset. Housing stock bought in period $t$ is rented to consumers in period $t+1$. In addition, the price of the housing stock may change thus providing a capital gain or loss. Finally, depreciation is assumed to erode some of the value of the exisitng housing stock.

$$
E_{t} R_{h, t+1}=E_{t}\left(\frac{X_{h, t+1}+(1-\delta) q_{t+1}}{q_{t}}\right)
$$

where $q_{t}$ is the real house price.

Ex-post this becomes

$$
\begin{aligned}
\log R_{h, t} & =\log \left(X_{h, t}+(1-\delta) q_{t}\right)-\log q_{t-1} \\
d \log R_{h, t} & =\frac{1}{X_{h, t}+(1-\delta) q_{t}}\left(d X_{h, t}+(1-\delta) d q_{t}\right)-d \log q_{t-1}
\end{aligned}
$$

Defining $\mu=\frac{(1-\delta) q}{X_{h}+(1-\delta) q}$

$$
\hat{R}_{h, t}=(1-\mu) \hat{X}_{h, t}+\mu \hat{q}_{t}-\hat{q}_{t-1}
$$




\section{C.11 Net worth accumulation}

At the end of each period, the value of homeowners is given by

$$
V_{t}=R_{h, t} q_{t-1} h_{t}-f\left(\frac{N_{t}}{q_{t-1} h_{t}}\right) R_{t} b_{t}
$$

where $b_{t}$ the borrowing undertaken to finance the purchase of the housing stock is equal to $q_{t} h_{t+1}-N_{t+1}$. After paying the dividend $\left(D_{t}\right)$ to consumers, the net worth of homeowners is given by

$$
\begin{aligned}
N_{t+1} & =V_{t}-D_{t} \\
\log N_{t+1} & =\log V_{t}-D_{t} \\
d \log N_{t+1} & =\frac{1}{V_{t}-D_{t}}\left(V_{t} \frac{d V_{t}}{V_{t}}-D_{t} \frac{d D_{t}}{D_{t}}\right) \\
\frac{d N_{t+1}}{N_{t+1}} & =\frac{1}{N_{t+1}}\left(V_{t} \frac{d V_{t}}{V_{t}}-D_{t} \frac{d D_{t}}{D_{t}}\right)
\end{aligned}
$$

Note that C.11.1 can be simplified:

$$
\begin{aligned}
V_{t} & =R_{h, t} q_{t-1} h_{t}-f\left(\frac{N_{t}}{q_{t-1} h_{t}}\right) R_{t} b_{t} \\
& =R_{h, t} q_{t-1} h_{t}-f\left(\phi_{t-1}\right) R_{t}\left(q_{t-1} h_{t}-N_{t}\right) \\
& \left.=R_{h, t} q_{t-1} h_{t}-f\left(\phi_{t-1}\right) R_{t} q_{t-1} h_{t}+f\left(\phi_{t-1}\right) R_{t} N_{t}\right) \\
& =R_{h, t} q_{t-1} h_{t}-R_{h, t} q_{t-1} h_{t}+R_{h, t} N_{t}-N_{t+1} \\
& =R_{h, t} N_{t}
\end{aligned}
$$

Hence,

$$
\begin{aligned}
\frac{d N_{t+1}}{N_{t+1}} & =\frac{1}{N_{t+1}}\left[R_{h, t} N_{t} \hat{V}_{t}-\left(R_{h, t} N_{t}-N_{t+1}\right) \hat{D}_{t}\right] \\
& =\frac{R_{h, t} N_{t}}{N_{t+1}} \hat{V}_{t}-\frac{R_{h, t} N_{t}-N_{t+1}}{N_{t+1}} \hat{D}_{t}
\end{aligned}
$$

and noting that in the steady state $N_{t+1}=N_{t}=N$

$$
\hat{N}_{t+1}=R_{h} \hat{V}_{t}-\left(R_{h}-1\right) \hat{D}_{t}
$$


Starting from the expanded definition of $V_{t}$

$$
\begin{aligned}
V_{t} & \left.=R_{h, t} q_{t-1} h_{t}-f\left(\phi_{t-1}\right) R_{t} q_{t-1} h_{t}+f\left(\phi_{t-1}\right) R_{t} N_{t}\right) \\
d\left(R_{h, t} q_{t-1} h_{t}\right) & =R_{h} q h\left(\hat{R}_{h, t}+\hat{q}_{t-1}+\hat{h}_{t}\right) \\
d\left(f\left(\phi_{t-1}\right) R_{t} q_{t-1} h_{t}\right) & =R q h f^{\prime}(\phi) \phi\left(\hat{N}_{t}-\hat{q}_{t-1}-\hat{h}_{t}\right)+f(\phi) R q h\left(\hat{R}_{t}+\hat{q}_{t-1}+\hat{h}_{t}\right) \\
d\left(f\left(\phi_{t-1}\right) R_{t} N_{t}\right) & =R N f^{\prime}(\phi) \phi\left(\hat{N}_{t}-\hat{q}_{t-1}-\hat{h}_{t}\right)+f(\phi) R N\left(\hat{N}_{t}+\hat{R}_{t}\right)
\end{aligned}
$$

Hence

$$
\begin{aligned}
\frac{d V_{t}}{V}=\frac{d V_{t}}{R_{h} N}= & \frac{q h}{N}\left(\hat{R}_{h, t}+\hat{q}_{t-1}+\hat{h}_{t}\right) \\
& -\frac{q h}{N} \frac{f^{\prime}(\phi)}{f(\phi)} \phi\left(\hat{N}_{t}-\hat{q}_{t-1}-\hat{h}_{t}\right)-\frac{q h}{N}\left(\hat{R}_{t}+\hat{q}_{t-1}+\hat{h}_{t}\right) \\
& +\frac{f^{\prime}(\phi)}{f(\phi)} \phi\left(\hat{N}_{t}-\hat{q}_{t-1}-\hat{h}_{t}\right)+\hat{N}_{t}+\hat{R}_{t} \\
= & (1+b n) \hat{R}_{h, t}-b n \hat{R}_{t}+(1-b n \Omega) \hat{N}_{t}+b n \Omega\left(\hat{q}_{t-1}+\hat{h}_{t}\right)
\end{aligned}
$$

where $\Omega=\frac{f^{\prime}(\phi)}{f(\phi)} \phi$ and $b n=\frac{1}{\phi}-1$.

$$
\Rightarrow \hat{N}_{t+1}=R_{h}\left[(1+b n) \hat{R}_{h, t}-b n \hat{R}_{t}+(1-b n \Omega) \hat{N}_{t}+b n \Omega\left(\hat{q}_{t-1}+\hat{h}_{t}\right)\right]-\left(R_{h}-1\right) \hat{D}_{t}
$$

\section{C.12 Housing equity withdrawal}

Homeowners pay a dividend to consumers each period, the size of which is determined by the homeowner's net worth.

$$
\begin{aligned}
D_{t} & =\chi\left(\frac{N_{t+1}}{q_{t} h_{t+1}}\right) \\
d D_{t} & =\chi^{\prime}(.)\left(\frac{N_{t+1}}{q_{t} h_{t+1}}\right)\left[\hat{N}_{t+1}-\hat{q}_{t}-\hat{h}_{t+1}\right] \\
\hat{D}_{t} & =\frac{\chi^{\prime}(\phi)}{\chi(\phi)} \phi\left[\hat{N}_{t+1}-\hat{q}_{t}-\hat{h}_{t+1}\right]
\end{aligned}
$$




\section{C.13 Housing capital accumulation}

Given the investment above the housing stock evolves

$$
\begin{aligned}
h_{t+1} & =h_{t}+I_{t}-\delta h_{t} \\
d h_{t+1} & =(1-\delta) d h_{t}+d I_{t} \\
\frac{d h_{t+1}}{h_{t+1}} & =(1-\delta) \frac{h_{t}}{h_{t+1}} \frac{d h_{t}}{h_{t}}+\frac{I_{t}}{h_{t+1}} \frac{d I_{t}}{I_{t}}
\end{aligned}
$$

Note in the steady state $h_{t+1}=h_{t}=h$ and $I_{t} / h_{t+1}=I / h=\delta$. Thus

$$
\hat{h}_{t+1}=(1-\delta) \hat{h}_{t}+\delta \hat{I}_{t}
$$

\section{C.14 House prices and investment}

In keeping with APV, investment and house prices are linked by a q-theory. House producers purchase $I_{t}$ of the consumption goods and use this to produce $h_{t+1}$ units of housing:

$$
h_{t+1}=\Phi\left(\frac{I_{t}}{h_{t}}\right) h_{t}
$$

where $\Phi($.$) is concave, giving rise to the equilibrium condition of$

$$
\frac{q_{t}}{X_{c, t}}=\Phi^{\prime}\left(\frac{I_{t}}{h_{t}}\right)
$$

Log-linearising

$$
\begin{aligned}
\log q_{t}-\log X_{c, t} & =\log \Phi^{\prime}\left(\frac{I_{t}}{h_{t}}\right) \\
d \log q_{t}-d \log X_{c, t} & =\frac{1}{\Phi^{\prime}(.)} \Phi^{\prime \prime}\left[\frac{h_{t} d I_{t}-I_{t} d h_{t}}{h_{t}^{2}}\right] \\
& =\frac{\Phi^{\prime \prime}(.)}{\Phi^{\prime}(.)}\left[\frac{I_{t}}{h_{t}}\left(\hat{I}_{t}-\hat{h}_{t}\right)\right] \\
\hat{q}_{t} & =\Gamma_{d}\left(\hat{I}_{t}-\hat{h}_{t}\right)+\hat{X}_{c, t}
\end{aligned}
$$

where $\Gamma_{d}=\frac{\Phi^{\prime \prime}(.)}{\Phi^{\prime}(.)}\left(\frac{I}{h}\right)$ 


\section{C.15 Current account}

Following De Paoli (2009) by assuming that foreign households trade only foreign currency denominated debt, then as noted in Section 2.7, the current account reduces to

$$
\frac{S_{t} P_{t}^{f} B_{F, t-1}}{P_{t}}=\frac{S_{t} P_{t}^{f} B_{F, t}}{P_{t} R_{t+1}^{f} \psi(.)}+E X_{t}-\frac{S_{t} P_{t}^{f}}{P_{t}} I M_{t}
$$

$$
\begin{aligned}
d\left(\frac{S_{t} P_{t}^{f} B_{F, t}}{P_{t} R_{t+1}^{f} \psi\left(\frac{S_{t} P_{t}^{f} B_{F, t}}{P_{t}}\right)}\right)= & \frac{1}{R^{f} \psi\left(\frac{S P^{f} B_{F}}{P}\right)} d\left(\frac{S_{t} P_{t}^{f} B_{F, t}}{P_{t}}\right) \\
& +\frac{S P^{f} B_{F}}{P} \frac{1}{R^{f}}\left[-\psi\left(\frac{S P^{f} B_{F}}{P}\right)^{-2} \psi^{\prime}\left(\frac{S P^{f} B_{F}}{P}\right) d\left(\frac{S_{t} P_{t}^{f} B_{F, t}}{P_{t}}\right)\right] \\
& +\frac{S P^{f} B_{F}}{P} \frac{1}{\psi\left(\frac{S P^{f} B_{F}}{P}\right)}\left[-\left(R^{f}\right)^{-2} d R_{t}^{f}\right] \\
= & \beta d\left(\frac{S_{t} P_{t}^{f} B_{F, t}}{P_{t}}\right) \\
& -\beta \frac{S P^{f} B_{F}}{P} \frac{\psi^{\prime}\left(\frac{S P^{f} B_{F}}{P}\right)}{\psi\left(\frac{S P^{f} B_{F}}{P}\right)} d\left(\frac{S_{t} P_{t}^{f} B_{F, t}}{P_{t}}\right) \\
& -\beta \frac{S P^{f} B_{F}}{P} \frac{d R_{t+1}^{f}}{R_{t+1}^{f}}
\end{aligned}
$$

Using the assumption that in the steady state the premium factor is equal to 1.

$$
=\beta\left[d\left(\frac{S_{t} P_{t}^{f} B_{F, t}}{P_{t}}\right)\left[1-\frac{S P^{f} B_{F}}{P} \psi^{\prime}\left(\frac{S P^{f} B_{F}}{P}\right)\right]-\frac{S P^{f} B_{F}}{P} \frac{d R_{t+1}^{f}}{R_{t+1}^{f}}\right]
$$


Defining $b_{t}=\frac{\left(\frac{S_{t} P_{t}^{f} B_{F, t}}{P_{t}}-b\right)}{C}, \quad a=\frac{b}{C}, \quad \delta_{b}=-\psi^{\prime}(b) C \Rightarrow a \delta=-\psi^{\prime}(b) b .^{1}$

$$
\begin{aligned}
& d\left(\frac{S_{t} P_{t}^{f} B_{F, t}}{P_{t} R_{t+1}^{f} \psi\left(\frac{S_{t} P_{t}^{f} B_{F, t}}{P_{t}}\right)}\right)=\beta\left[b_{t} C\left(1+a \delta_{b}\right)-b \hat{R}_{t+1}^{f}\right] \\
& =\beta\left[b_{t} C\left(1+a \delta_{b}\right)-a C \hat{R}_{t+1}^{f}\right] \\
& =\beta C\left[b_{t}\left(1+a \delta_{b}\right)-a \hat{R}_{t+1}^{f}\right] \\
& \frac{S_{t} P_{t}^{f} B_{F, t-1}}{P_{t}}=\frac{S_{t-1} P_{t-1}^{f} B_{F, t-1}}{P_{t-1}} \frac{S_{t}}{S_{t-1}} \frac{P_{t}^{f}}{P_{t-1}^{f}} \frac{P_{t-1}}{P_{t}} \\
& d\left(\frac{S_{t} P_{t}^{f} B_{F, t-1}}{P_{t}}\right)=d\left(\frac{S_{t-1} P_{t-1}^{f} B_{F, t-1}}{P_{t-1}}\right)+\frac{S P^{f} B_{F}}{P}\left[d\left(\frac{S_{t}}{S_{t-1}}\right)+d\left(\frac{P_{t}^{f}}{P_{t-1}^{f}}\right)+d\left(\frac{P_{t-1}}{P_{t}}\right)\right] \\
& =b_{t-1} C+b\left[\Delta \hat{S}_{t}+\hat{\pi}_{t}^{f}-\hat{\pi}_{t}\right] \\
& d\left(E X_{t}\right)=\left(\frac{S P^{f}}{P}\right)^{\vartheta} \zeta\left(Y^{f}\right)^{\zeta-1} d Y_{t}^{f}+\left(Y^{f}\right)^{\zeta} \vartheta\left(\frac{S P^{f}}{P}\right)^{\vartheta-1} d\left(\frac{S_{t} P_{t}^{f}}{P_{t}}\right) \\
& =E X\left[\zeta \frac{d Y_{t}^{f}}{Y^{f}}+\vartheta \frac{d\left(\frac{S_{t} P_{t}^{f}}{P_{t}}\right)}{\frac{S P^{f}}{P}}\right] \\
& =E X\left[\zeta \hat{Y}_{t}^{f}+\vartheta \hat{R S_{t}}\right] \\
& d\left(I M_{t} \frac{S_{t} P_{t}^{f}}{P_{t}}\right)=\frac{S P^{f}}{P} d I M_{t}+I M d\left(\frac{S_{t} P_{t}^{f}}{P_{t}}\right) \\
& =\frac{S P^{f}}{P} I M\left[\frac{d I M_{t}}{I M}+\frac{d\left(\frac{S_{t} P_{t}^{f}}{P_{t}}\right)}{\frac{S P^{f}}{P}}\right] \\
& =\frac{S P^{f}}{P} I M\left[I \hat{M}_{t}+\hat{R S} S_{t}\right]
\end{aligned}
$$

${ }^{1} \delta_{b}$ here is the cost of intermediation in the foreign bond market as discusseed in Thoenissen
$(2004)$. 
Hence

$$
\begin{aligned}
\beta C\left[b_{t}(1+a \delta)-a \hat{R}_{t+1}^{f}\right]= & b_{t-1} C+b\left[\Delta \hat{S}_{t}+\hat{\pi}_{t}^{f}-\hat{\pi}_{t}\right] \\
& -E X\left[\zeta \hat{Y}_{t}^{f}+\vartheta \hat{R S_{t}}\right]+\frac{S P^{f}}{P} I M\left[I \hat{M}_{t}+\hat{R S_{t}}\right]
\end{aligned}
$$

\section{C.16 Phillips curve}

Prices are sticky in that firms get to reset their prices each period with a probability $1-\theta$. For simplicity, I assume that no indexing takes place. Hence firm $z$ that is able to reset its price in period $t$ will seek to optimise

$$
\begin{aligned}
\mathcal{L} & =E_{t} \sum_{k=0}^{\infty}(\theta \beta)^{k} \lambda_{k}\left[p_{t}^{*}(z) y_{t+k}(z)-T C_{t+k}\left(y_{t+k}(z)\right)\right] \\
& =E_{t} \sum_{k=0}^{\infty}(\theta \beta)^{k} \lambda_{k}\left[p_{t}^{*}(z)\left(\frac{p_{t}^{*}(z)}{P_{c, t+k}}\right)^{-\epsilon} Y_{t+k}-T C_{t+k}\left(\left(\frac{p_{t}^{*}(z)}{P_{c, t+k}}\right)^{-\epsilon} Y_{t+k}\right)\right] \\
& =E_{t} \sum_{k=0}^{\infty}(\theta \beta)^{k} \lambda_{k}\left[p_{t}^{*}(z)^{1-\epsilon}\left(\frac{1}{P_{c, t+k}}\right)^{-\epsilon} Y_{t+k}-T C_{t+k}\left(\left(\frac{p_{t}^{*}(z)}{P_{c, t+k}}\right)^{-\epsilon} Y_{t+k}\right)\right]
\end{aligned}
$$

$$
\begin{aligned}
\frac{\partial \mathcal{L}}{\partial p_{t}^{*} z}=E_{t} \sum_{k=0}^{\infty}(\theta \beta)^{k} \lambda_{k}\left[(1-\epsilon) p_{t}^{*}(z)^{1-\epsilon}\left(\frac{1}{P_{c, t+k}}\right)^{-\epsilon} Y_{t+k}\right. \\
\left.\quad-M C_{t+k}(.)(-\epsilon) p_{t}^{*}(z)^{-\epsilon-1}\left(\frac{1}{P_{c, t+k}}\right)^{-\epsilon} Y_{t+k}\right] \\
=E_{t} \sum_{k=0}^{\infty}(\theta \beta)^{k} \lambda_{k}\left[(1-\epsilon)\left(\frac{p_{t}^{*}(z)}{P_{c, t+k}}\right)^{-\epsilon} Y_{t+k}+M C_{t+k}(.) \frac{\epsilon}{p_{t}^{*}(z)}\left(\frac{p_{t}^{*}(z)}{P_{c, t+k}}\right)^{-\epsilon} Y_{t+k}\right]
\end{aligned}
$$

Setting to zero

$$
\begin{aligned}
0= & E_{t} \sum_{k=0}^{\infty}(\theta \beta)^{k} \frac{1-\epsilon}{p_{t}^{*}(z)} \lambda_{k} y_{t+k}(z)\left[p_{t}^{*}(z)-\frac{\epsilon}{\epsilon-1} M C_{t+k}(.)\right] \\
& p_{t}^{*}(z) E_{t} \sum_{k=0}^{\infty}(\theta \beta)^{k} \lambda_{k} y_{t+k}(z)=\frac{\epsilon}{\epsilon-1} E_{t} \sum_{k=o}^{\infty}(\theta \beta)^{k} \lambda_{k} y_{t+k}(z) M C_{t+k}(z)
\end{aligned}
$$


Aggregating and differentiating with respect to $P_{c, t}^{*}$ and $\lambda_{t+k} Y_{t+k}$

$$
\begin{aligned}
& d P_{c, t}^{*} \lambda Y \sum_{k=0}^{\infty}(\theta \beta)^{k}+P_{c} E_{t} \sum_{k=0}^{\infty}(\theta \beta)^{k} d\left(\lambda_{t+k} Y_{t+k}\right)=\frac{\epsilon}{\epsilon-1} M C E_{t} \sum_{k=0}^{\infty}(\theta \beta)^{k} d\left(\lambda_{t+k} Y_{t+k}\right) \\
& +\frac{\epsilon}{\epsilon-1} \lambda Y E_{t} \sum_{k=0}^{\infty}(\theta \beta)^{k} d M C_{t+k}
\end{aligned}
$$

Dividing through by $\lambda Y \sum_{k=0}^{\infty}(\theta \beta)^{k}$

$$
\begin{aligned}
d P_{c, t}^{*}+P_{c} \frac{E_{t} \sum_{k=0}^{\infty}(\theta \beta)^{k} d\left(\lambda_{t+k} Y_{t+k}\right)}{\lambda Y \sum_{k=0}^{\infty}(\theta \beta)^{k}}= & \frac{\epsilon}{\epsilon-1} M C \frac{E_{t} \sum_{k=0}^{\infty}(\theta \beta)^{k} d\left(\lambda_{t+k} Y_{t+k}\right)}{\lambda Y \sum_{k=0}^{\infty}(\theta \beta)^{k}} \\
& +\frac{\epsilon}{\epsilon-1} \frac{E_{t} \sum_{k=0}^{\infty}(\theta \beta)^{k} d M C_{t+k}}{\sum_{k=0}^{\infty}(\theta \beta)^{k}}
\end{aligned}
$$

Dividng through by $P_{c}=\frac{\epsilon}{\epsilon-1} M C$

$$
\begin{aligned}
& \hat{P}_{c, t}^{*}+\frac{E_{t} \sum_{k=0}^{\infty}(\theta \beta)^{k} d\left(\lambda_{t+k} Y_{t+k}\right)}{\lambda Y \sum_{k=0}^{\infty}(\theta \beta)^{k}}= \frac{E_{t} \sum_{k=0}^{\infty}(\theta \beta)^{k} d\left(\lambda_{t+k} Y_{t+k}\right)}{\lambda Y \sum_{k=0}^{\infty}(\theta \beta)^{k}} \\
&+\frac{E_{t} \sum_{k=0}^{\infty}(\theta \beta)^{k} d M C_{t+k}}{\sum_{k=0}^{\infty}(\theta \beta)^{k} M C} \\
& \hat{P}_{c, t}^{*}=(1-\theta \beta) E_{t} \sum_{k=0}^{\infty}(\theta \beta)^{k} M C_{t+k}
\end{aligned}
$$

Expanding (C.16.4)

$$
\begin{aligned}
\hat{P}_{c, t}^{*} & =(1-\theta \beta) E_{t}\left[\hat{M} C_{t}+(\theta \beta) \hat{M} C_{t+1}+(\theta \beta)^{2} \hat{M} C_{t+2}+\cdots\right] \\
& =(1-\theta \beta) \hat{M} C_{t}+(1-\theta \beta)(\theta \beta) E_{t} \sum_{k=0}^{\infty}(\theta \beta)^{k} \hat{M} C_{t+k+1} \\
& =(1-\theta \beta) \hat{M} C_{t}+(\theta \beta) E_{t} \hat{P}_{c, t+1}^{*}
\end{aligned}
$$

Subtracting $\hat{P}_{c, t}$ from both sides

$$
\hat{P}_{c, t}^{*}-\hat{P}_{c, t}=(1-\theta \beta)\left(\hat{M} C_{t}-\hat{P}_{c, t}\right)+\theta \beta\left[E_{t} \hat{P}_{c, t+1}^{*}-\hat{P}_{c, t}\right]
$$


Define the fraction of firms whose price was set $j$ periods ago as $\omega_{j}$ such that

$$
\omega_{j}=(1-\theta) \theta^{j}
$$

Thus the current aggregate price may be written as

$$
P_{c, t}=\left[\sum_{j=0}^{\infty} \omega_{j} p_{t-j}^{*}(z)^{1-\epsilon}\right]^{\frac{1}{1-\epsilon}}
$$

where $p_{t-j}^{*}(z)$ is effectively the common price set by firms $j$ periods ago.

Hence

$$
\begin{aligned}
P_{c, t}^{1-\epsilon} & =\sum_{j=0}^{\infty} \omega_{j} p_{t-j}^{*}(z)^{1-\epsilon} \\
& =(1-\theta) p_{t}^{*}(z)^{1-\epsilon}+(1-\theta) \theta p_{t-1}^{*}(z)^{1-\epsilon}+(1-\theta) \theta^{2} p_{t-2}^{*}(z)^{1-\epsilon}+\cdots
\end{aligned}
$$

Thus

$$
\begin{aligned}
P_{c, t-1}^{1-\epsilon} & =(1-\theta) p_{t-1}^{*}(z)^{1-\epsilon}+(1-\theta) \theta p_{t-2}^{*}(z)^{1-\epsilon}+(1-\theta) \theta^{2} p_{t-3}^{*}(z)^{1-\epsilon}+\cdots \\
P_{c, t}^{1-\epsilon} & =(1-\theta) p_{t}^{*}(z)^{1-\epsilon}+\theta P_{c, t-1}^{1-\epsilon} \\
P_{c, t} & =\left[(1-\theta) p_{t}^{*}(z)^{1-\epsilon}+\theta P_{c, t-1}^{1-\epsilon}\right]^{\frac{1}{1-\epsilon}} \\
\log P_{c, t} & =\frac{1}{1-\epsilon} \log \left[(1-\theta) p_{t}^{*}(z)^{1-\epsilon}+\theta P_{c, t-1}^{1-\epsilon}\right] \\
\frac{d P_{c, t}}{P_{c, t}} & =\frac{1}{1-\epsilon} \frac{1}{P_{c, t}^{1-\epsilon}}\left\{(1-\theta)(1-\epsilon) p_{t}^{*}(z)^{1-\epsilon} \frac{d p_{t}^{*}(z)}{p_{t}^{*}(z)}+\theta(1-\epsilon) P_{c, t-1}^{1-\epsilon} \frac{d P_{c, t-1}}{P_{c, t-1}}\right\}
\end{aligned}
$$

Noting that in the steady state $P_{c}=p^{*}(z)$ and that $p_{t}^{*}(z)$ is equivalent to the aggregate $P_{c, t}^{*}$

$$
\begin{aligned}
\hat{P}_{c, t} & =(1-\theta) \hat{P}_{c, t}^{*}+\theta \hat{P}_{c, t-1} \\
\Rightarrow \hat{P}_{c, t}^{*} & =\frac{\hat{P}_{c, t}}{1-\theta}-\frac{\theta}{1-\theta} \hat{P}_{c, t-1}
\end{aligned}
$$


Subtracting $\hat{P}_{c, t}$ from (C.16.6)

$$
\hat{P}_{c, t}^{*}-\hat{P}_{c, t}=\frac{1}{1-\theta} \hat{P}_{c, t}-\frac{\theta}{1-\theta} \hat{P}_{c, t-1}-\hat{P}_{c, t}
$$

Which is also equal to (C.16.5)

$$
\begin{aligned}
\frac{1}{1-\theta} \hat{P}_{c, t}-\frac{\theta}{1-\theta} \hat{P}_{c, t-1}-\hat{P}_{c, t} & =(1-\theta \beta)\left(M C_{t}-\hat{P}_{c, t}\right)+\theta \beta\left[E_{t} \hat{P}_{c, t+1}^{*}-\hat{P}_{c, t}\right] \\
& =(1-\theta \beta)\left(\hat{M} C_{t}-\hat{P}_{c, t}\right)+\theta \beta\left[E_{t} \frac{1}{1-\theta} \hat{P}_{c, t+1}-\frac{\theta}{1-\theta} \hat{P}_{c, t}-\hat{P}_{c, t}\right] \\
\frac{1-1+\theta}{1-\theta} \hat{P}_{c, t}-\frac{\theta}{1-\theta} \hat{P}_{c, t-1} & =(1-\theta \beta)\left(\hat{M} C_{t}-\hat{P}_{c, t}\right)+\frac{\theta \beta}{1-\theta}\left[E_{t} \hat{P}_{c, t+1}-\theta \hat{P}_{c, t}-(1-\theta) \hat{P}_{c, t}\right] \\
\frac{\theta}{1-\theta}\left(\hat{P}_{c, t}-\hat{P}_{c, t-1}\right) & =(1-\theta \beta)\left(M C_{t}-\hat{P}_{c, t}\right)+\frac{\theta \beta}{1-\theta}\left[E_{t} \hat{P}_{c, t+1}-\hat{P}_{c, t}\right] \\
\hat{P}_{c, t}-\hat{P}_{c, t-1} & =\frac{(1-\theta)(1-\theta \beta)}{\theta}\left(\hat{M} C_{t}-\hat{P}_{c, t}\right)+\beta\left[E_{t} \hat{P}_{c, t+1}-\hat{P}_{c, t}\right] \\
\hat{\pi}_{c, t} & =\frac{(1-\theta)(1-\theta \beta)}{\theta}\left(\hat{M} C_{t}-\hat{P}_{c, t}\right)+\beta E_{t} \hat{\pi}_{c, t+1}
\end{aligned}
$$

Note here that $\hat{M} C_{t}$ is nominal marginal cost and thus $\hat{m} c_{t}=\hat{M} C_{t}-\hat{P}_{c, t}$.

\section{C.16.1 Flexible price output}

$$
\hat{Y}_{t}^{f l e x}=\frac{-\alpha\left(\frac{I M}{Y}\right)^{\gamma}}{(1-\gamma)\left[(1-\alpha)\left(\frac{A L}{Y}\right)^{\gamma}-\left(\frac{1-\gamma}{1-\gamma+\tau}\right)\right]} \hat{R S}+\frac{(1-\alpha)\left(\frac{1+\tau}{1-\gamma+\tau}\right)\left(\frac{A L}{Y}\right)^{\gamma}}{(1-\alpha)\left(\frac{A L}{Y}\right)^{\gamma}-\frac{1-\gamma}{1-\gamma+\tau}} \hat{A}_{t}
$$

It should be noted that the design of the denominator in the coefficient on the technology shock is not unambiguously positive. Given assumed values for $L$ of 0.33 and $\alpha$ of 0.2 , I found that a $\gamma$ value of -0.2 ensures the coefficient is positive while a $\gamma$ value of -0.3 results in a negative coefficient. 


\section{C.17 Real exchange rate identity}

$$
\begin{aligned}
R S_{t} & =\frac{S_{t} P_{t}^{f}}{P_{t}} \\
\frac{E_{t} R S_{t+1}}{R S_{t}} & =\frac{E_{t}\left(\frac{S_{t+1} P_{t+1}^{f}}{P_{t+1}}\right)}{\frac{S_{t} P_{t}^{f}}{P_{t}}} \\
& =E_{t} \frac{\frac{S_{t+1}}{S_{t}} \pi_{t+1}^{f}}{\pi_{t+1}} \\
E_{t} \hat{R} S_{t+1}-\hat{R S} S_{t} & =E_{t} \hat{S}_{t+1}-\hat{S}_{t}+E_{t} \hat{\pi}_{t+1}^{f}-E_{t} \hat{\pi}_{t+1} \\
& =E_{t} \hat{S}_{t+1}-\hat{S}_{t}+E_{t} \hat{\pi}_{t+1}^{f}-E_{t} \hat{\pi}_{c, t+1}+\left(E_{t} \hat{X}_{c, t+1}-\hat{X}_{c, t}\right)
\end{aligned}
$$

\section{C.18 Nominal interest rate identity}

$$
R_{t+1}^{n}=R_{t+1} \frac{E_{t} P_{t+1}}{P_{t}}
$$

Define

$$
\pi_{t}=P_{t} / P_{t-1}
$$

Hence,

$$
\begin{gathered}
\pi_{t} \times \frac{P_{c, t-1}}{P_{c, t}}=\frac{X_{c, t-1}}{X_{c, t}} \\
\frac{\pi_{t}}{\pi_{c, t}}=\frac{X_{c, t-1}}{X_{c, t}} \\
\hat{\pi}_{t}-\hat{\pi}_{c, t}=\hat{X}_{c, t-1}-\hat{X}_{c, t} \\
\log R_{t+1}^{n}=\log R_{t+1}+\log E_{t} \pi_{t+1} \\
\hat{R}_{t+1}^{n}=\hat{R}_{t+1}+E_{t} \hat{\pi}_{c, t+1}-\left(E_{t} \hat{X}_{c, t+1}-\hat{X}_{c, t}\right)
\end{gathered}
$$




\section{Appendix D}

\section{Derivation of log-linear equations: Fiscal model}

\section{D.1 Rule of thumb consumption}

Rule of thumb consumers do not income smooth and consume all their income each period.

$$
\begin{aligned}
C_{t}^{r} & =w_{t} L_{t}^{r}-(1-n) T_{t} \\
d C_{t}^{r} & =w_{t} d L_{t}^{r}+L_{t} d w_{t}-(1-n) d T_{t} \\
\hat{C}_{t}^{r} & =\frac{w L^{r}}{C^{r}}\left[\hat{L}_{t}^{r}+\hat{w}_{t}\right]-\frac{(1-n) T}{C^{r}} \hat{T}_{t}
\end{aligned}
$$

Combining the definition of ROT consumption with the first order conditions for consumption and labour supply yields

$$
\begin{aligned}
w_{t} L_{t}^{r}-(1-n) T_{t} & =\frac{w_{t}\left(1-L_{t}^{r}\right)}{\xi} \\
\Rightarrow w_{t} L_{t}^{r}\left(1+\frac{1}{\xi}\right) & =\frac{w_{t}}{\xi}+(1-n) T_{t} \\
\Rightarrow L_{t}^{r} & =\frac{1}{1+\xi}+\frac{\xi}{w_{t}}(1-n) T_{t}
\end{aligned}
$$

\section{D.2 Government}

For simplicity government expenditure does not impact households directly (typically done in the form of a transfer) but is rather a source of demand for producers 
(and thence labour demand). Following Galí, Vallés and López-Salido (2007), fiscal policy is modelled as the combination of (all in real terms) exogenous government spending $\left(G_{t}\right)$, government debt $\left(B_{t}^{G}\right)$ and lump-sum taxes $\left(T_{t}\right)$.

$R_{t+1}^{-1} B_{t+1}^{G}$ represents the quantum of funds borrowed in period $t$ with $B_{t+1}^{G}$ repaid in period $t+1$. Hence the government budget constraint can be written:

$$
\begin{array}{r}
T_{t}+R_{t+1}^{-1} B_{t+1}^{G}=B_{t}^{G}+G_{t} \\
d T_{t}+\frac{R d B_{t+1}^{G}-B^{G} d R_{t+1}}{R^{2}}=d G_{t}+d B^{G}
\end{array}
$$

Given that in the steady state $T+B=B+G \Leftrightarrow T=G$ and in addition assuming a steady state of $B^{G}=0$

$$
\begin{aligned}
\frac{G}{Y} \frac{d T_{t}}{T}+\frac{1}{R}\left(\frac{d B_{t+1}^{G}}{Y}-\frac{B^{G}}{Y} \frac{d R_{t+1}}{R}\right) & =\frac{d B_{t}^{G}}{Y}+\frac{G}{Y} \frac{d G_{t}}{G} \\
\frac{d B_{t+1}^{G}}{Y} & =R\left[\frac{d B_{t}^{G}}{Y}+\frac{G}{Y}\left(\hat{G}_{t}-\hat{T}_{t}\right)\right]
\end{aligned}
$$

The fiscal rule determines how expenditure is funded, initially as a rule for lump-sum taxes and consequently how much new debt is issued.

$$
\begin{aligned}
\frac{T_{t}-T}{T} \frac{T}{Y} & =\phi_{B} \frac{B_{t}^{G}}{Y}+\phi_{G} \frac{G_{t}-G}{G} \frac{G}{Y} \\
\hat{T}_{t} & =\left(\frac{G}{Y}\right)^{-1} \phi_{B} \frac{B_{t}^{G}}{Y}+\phi_{G} \hat{G}_{t}
\end{aligned}
$$

Government expenditure on good $z$ is given by

$$
G_{t}(z)=\left(\frac{p_{t}(z)}{P_{c, t}}\right)^{-\epsilon} G_{t}
$$

\section{D.3 Resource constraint}

Output from firms is consumed by domestic consumers, government and foreign consumers or utilised in the production of housing:

$$
\begin{aligned}
& Y_{t}=c_{t}+I_{t}+G_{t}+E X_{t} \\
& \hat{Y}_{t}=\frac{c}{Y} \hat{c}_{t}+\frac{I}{Y} \hat{I}_{t}+\frac{G}{Y} \hat{G}_{t}+\frac{E X}{Y} \hat{E X_{t}}
\end{aligned}
$$


where $c_{t}$ is domestic consumption of consumption goods, $I_{t}$ is investment in housing, $G_{t}$ is government purchases of conumption goods and $E X_{t}$ is consumption goods exported to foreign consumers.

\section{D.4 Current account}

Assuming that domestic debt issued by PIH consumers and government debt are perfect subsititutes and are in net zero supply means that the inclusion of governemnt debt in the fiscal model leaves the log-linearised current account equation the same as the basic model, i.e.

$$
\begin{aligned}
\beta C\left[b_{t}(1+a \delta)-a \hat{R}_{t+1}^{f}\right]= & b_{t-1} C+b\left[\Delta \hat{S}_{t}+\hat{\pi}_{t}^{f}-\hat{\pi}_{t}\right] \\
& -E X\left[\zeta \hat{Y}_{t}^{f}+\vartheta \hat{R S_{t}}\right]+\frac{S P^{f}}{P} I M\left[I \hat{M}_{t}+\hat{R S_{t}}\right]
\end{aligned}
$$




\section{Appendix E}

\section{Derivation of the steady state equations}

E.1 Ex-ante return on housing

$$
\begin{aligned}
E_{t} R_{h, t+1} & =f\left(\frac{N_{t+1}}{q_{t} h_{t+1}}\right) R_{t+1} \\
\Rightarrow R_{h} & =f\left(\frac{N}{q h}\right) R
\end{aligned}
$$

E.2 Relative price of rental

$$
\begin{aligned}
E_{t} R_{h, t+1} & =E_{t}\left(\frac{X_{h, t+1}+(1-\delta) q_{t+1}}{q_{t}}\right) \\
\Rightarrow R_{h} & =\left(\frac{X_{h}}{q}\right)+(1-\delta) \\
\Rightarrow X_{h} & =\left[R_{h}-(1-\delta)\right] q
\end{aligned}
$$


E.3 Relative price of consumption goods

$$
\begin{aligned}
P_{t} & =\left[v P_{c, t}^{1-\eta}+(1-v) P_{h, t}^{1-\eta}\right]^{\frac{1}{1-\eta}} \\
1 & =\left[v X_{c, t}^{1-\eta}+(1-v) X_{h, t}^{1-\eta}\right]^{\frac{1}{1-\eta}} \\
1 & =\left[v X_{c}^{1-\eta}+(1-v) X_{h}^{1-\eta}\right]^{\frac{1}{1-\eta}}
\end{aligned}
$$

\section{E.4 Dividend}

$$
\begin{aligned}
N_{t+1} & =V_{t}-D_{t} \\
& =R_{h, t} q_{t-1} h_{t}-f\left(\frac{N_{t}}{q_{t-1} h_{t}}\right) R_{t} b_{t}-D_{t} \\
\Rightarrow N & =R_{h} q h-f\left(\frac{N}{q h}\right) R(q h-N)-D \\
& =R_{h} N-D \\
N\left(1-R_{h}\right) & =-D \\
D & =N\left(R_{h}-1\right)
\end{aligned}
$$

\section{E.5 Aggregate consumption}

$$
\begin{aligned}
h_{t} & =(1-v)\left(\frac{P_{h, t}}{P_{t}}\right)^{-\eta} C_{t} \\
& =(1-v) X_{h}^{-\eta} C \\
\Rightarrow C & =\frac{h}{(1-v) X_{h}^{-\eta}}
\end{aligned}
$$




\section{E.6 Household consumption of goods}

$$
\begin{aligned}
c_{t} & =v\left(\frac{P_{c, t}}{P_{t}}\right)^{-\eta} C_{t} \\
\Rightarrow c & =v X_{c}^{-\eta} C
\end{aligned}
$$

\section{E.7 Investment}

$$
\begin{aligned}
& h_{t+1}=h_{t}+I_{t}-\delta h_{t} \\
& \Rightarrow I=\delta h
\end{aligned}
$$

E.8 Resource constraint

$$
\begin{gathered}
Y_{t}=c_{t}+I_{t}+E X_{t} \\
\Rightarrow Y=c+I+\frac{E X}{Y} Y \\
Y\left(1-\frac{E X}{Y}\right)=c+I \\
Y=\frac{c+I}{1-\frac{E X}{Y}}
\end{gathered}
$$

E.9 Aggregate labour

$$
\begin{aligned}
Y_{t}(z) & =\left[\alpha I M_{t}(z)^{\gamma}+(1-\alpha)\left(A_{t} L_{t}(z)\right)^{\gamma}\right]^{\frac{1}{\gamma}} \\
\Rightarrow L & =\left(\frac{Y^{\gamma}-I M^{\gamma}}{1-\alpha}\right)^{\frac{1}{\gamma}}
\end{aligned}
$$


E.10 Goods producers first order conditions

$$
\begin{aligned}
\left(\frac{I M_{t}}{L_{t}}\right)^{1-\gamma} & =\frac{\alpha}{1-\alpha} \frac{w_{t}}{R S_{t}} \\
\Rightarrow\left(\frac{I M}{L}\right)^{1-\gamma} & =\frac{\alpha}{1-\alpha} \frac{w}{R S}
\end{aligned}
$$

E.11 Wage rate

$$
\begin{aligned}
\frac{1}{C_{t}} & =\frac{\xi}{w_{t}\left(1-L_{t}\right)} \\
& \Rightarrow w=\frac{C \xi}{(1-L)}
\end{aligned}
$$

E.12 Rule of thumb labour supply

$$
\begin{aligned}
w L^{r} & =\frac{w}{\xi}\left(1-L^{r}\right) \\
\Rightarrow L^{r} & =\frac{1}{\xi}-\frac{L^{r}}{\xi} \\
\Rightarrow L^{r}\left(\frac{1+\xi}{\xi}\right) & =\frac{1}{\xi} \\
\Rightarrow L^{r} & =\frac{1}{1+\xi}
\end{aligned}
$$

E.13 Permanent income hypothesis labour supply

$$
\begin{aligned}
L_{t} & =n L_{t}^{p}+(1-n) L_{t}^{r} \\
\Rightarrow L^{p} & =\frac{L-(1-n) L^{r}}{n}
\end{aligned}
$$


E.14 Rule of thumb consumption

$$
\begin{aligned}
C_{t}^{r} & =w_{t} L_{t}^{r} \\
\rightarrow C^{r} & =w L^{r}
\end{aligned}
$$

E.15 Permanent income hypothesis consumption

$$
\begin{aligned}
C_{t} & =n C_{t}^{p}+(1-n) C_{t}^{r} \\
\Rightarrow C^{p} & =\frac{C-(1-n) C^{r}}{n}
\end{aligned}
$$




\section{Appendix F}

\section{Derivation of the steady state equations: fiscal model}

F.1 Resource constraint

$$
\begin{gathered}
Y_{t}=c_{t}+I_{t}+G_{t}+E X_{t} \\
\Rightarrow Y=c+I+\frac{G}{Y} Y+\frac{E X}{Y} Y \\
Y\left(1-\frac{G}{Y}-\frac{E X}{Y}\right)=c+I \\
Y=\frac{c+I}{1-\frac{G}{Y}-\frac{E X}{Y}}
\end{gathered}
$$

F.2 Rule of thumb labour supply

From equation (D.1.2) it follows that

$$
L^{r}=\frac{1}{1+\xi}+\frac{\xi}{w}(1-n) T
$$

